\title{
Molecular mechanisms of germ cell specification and migration in Xenopus laevis
}

in partial fulfillment of the requirements for the degree Doctor rerum

naturalium (Dr. rer. nat.) in the Molecular Biology Program in the Faculty of Biology at the Georg-August University, Göttingen.

submitted by

Tarbashevich Katsiaryna

born in

Volkovysk, Belarus

December, 2007 


\begin{abstract}
Affidavit
Herewith I declare, that I prepared the $\mathrm{PhD}$ thesis "Molecular mechanisms of germ cell specification and migration in Xenopus laevis" on my own and with no other sources and aids than quoted.
\end{abstract}

21.12.2007

Submission date

Katsiaryna Tarbashevich 


\section{List of Publications:}

1. Golovatii A. S., Kononko O. N., Torbashevich E. S., Lapko, A.G. TSH isoforms as markers of ecology induced diseases. Bulletin of experimental biology and medicine., 2001, 5: $574-81$

2. Torbashevich E. S., Lapko A. G. Change of Glycosilation Level of IgG in Heart Pathology. Bulletin of experimental biology and medicine (submitted)

3. Torbashevich E. S., Krasniy S. A., Feschenko S. P. Use of ARMAS-PCR and SSCPanalysis for revealing gene p53 mutations in samples of cancer tissues of patients with breast or bladder cancer. Medicinskii Vestnik, 2003 Sep 9:215-222

4. Bogdanova N. V., Torbashevich E. S., Krasniy S. A., Feschenko S. P. Molecular methods of evaluation of genetic risk and monitoring of somatic mutations for families received additional ionizing radiation. Modern Methods of Diagnostics, Cure and Prophylactics of Diseases, 2004, reg. N 168-1203

5. Tarbashevich K., Koebernick K., Pieler T. XGRIP2.1 is encoded by a vegetally localizing, maternal mRNA and functions in germ cell development and anteroposterior PGC positioning in Xenopus laevis. Dev Biol., 2007 Nov 15; 311(2): 554-65. 


\section{Table of Contents}

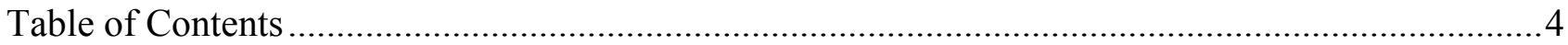

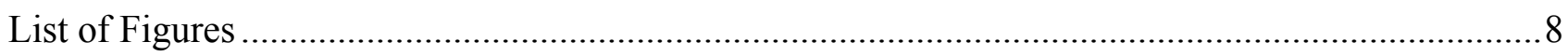

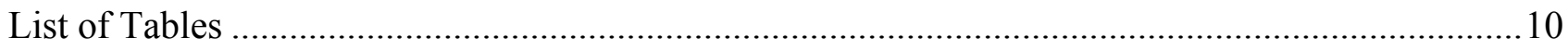

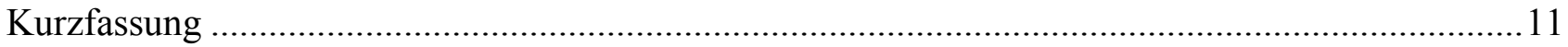

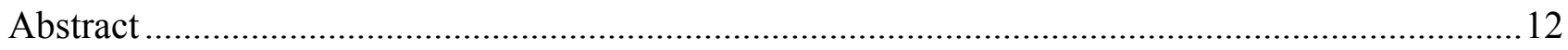

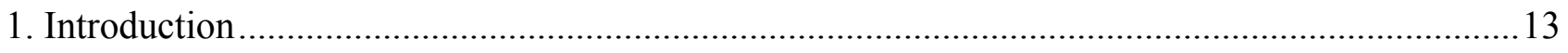

1.1 Vegetal mRNA localization in Xenopus oocytes ........................................................... 13

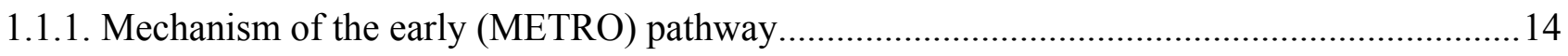

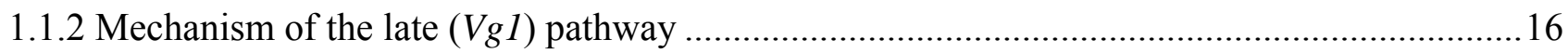

1.1.3 Cis-acting mRNA elements mediating vegetal localization of a transcript ...........................19

1.1.4 Trans-acting factors involved in vegetal localization of mRNAs.....................................20

1.2 Formation and development of germ plasm and primordial germ cells in Xenopus ..................21

1.3 Molecular mechanisms of germ cells development and migration in other organisms..............25

1.3.1 Molecular mechanism of germ cells development and migration in Zebrafish......................25

1.3.2 Molecular mechanism of germ cell development and migration in Drosophila ....................27

1.3.3. Molecular mechanism of germ cell development and migration in the mouse ......................30

1.3.4 Germ cells development and migration in the chicken.................................................3

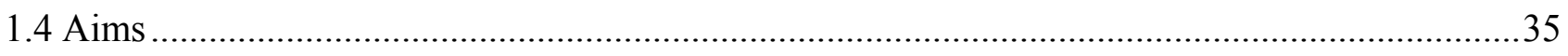

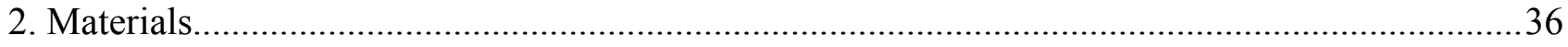

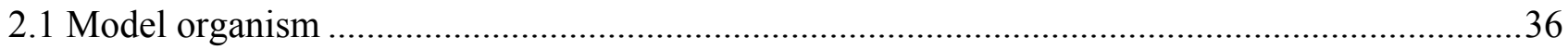

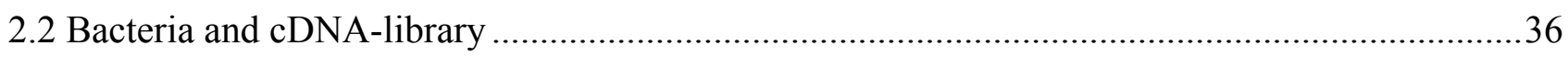

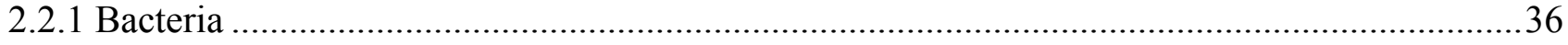

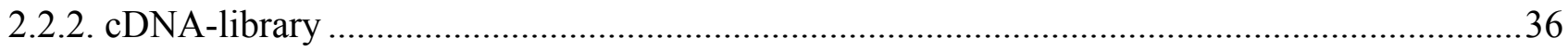

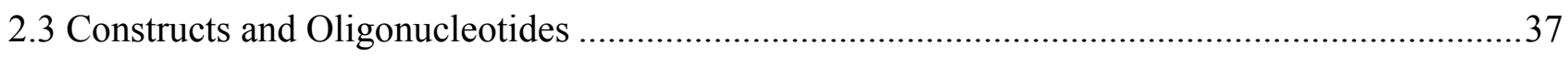

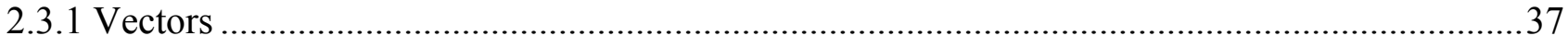

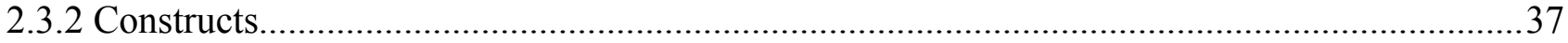

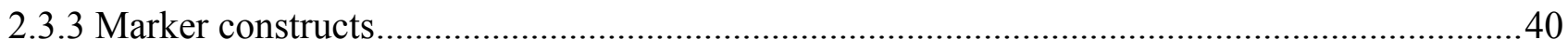

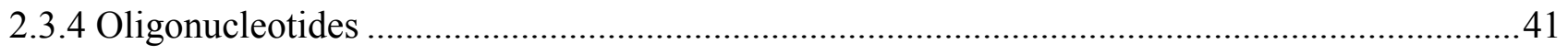

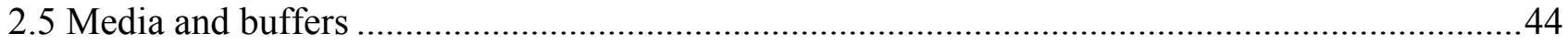

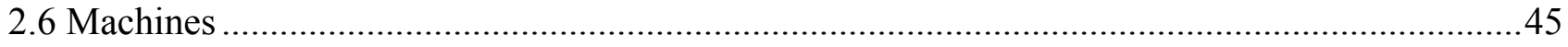




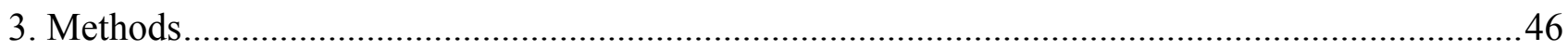

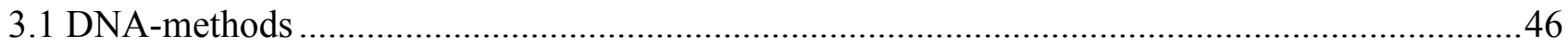

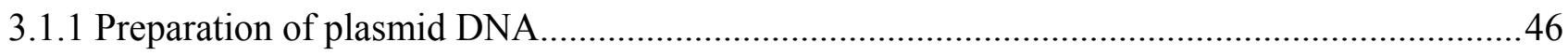

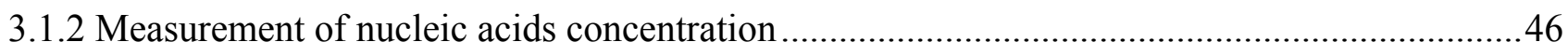

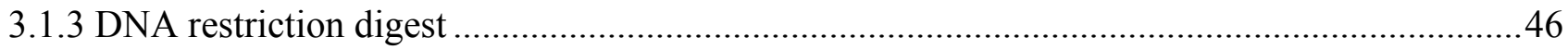

3.1.4 Agarose-gel electrophoresis (Sharp et al., 1973) ……..........................................................47

3.1.5 Polymerase chain reaction (PCR) (Mullis et al., 1986) ..........................................................

3.1.6 DNA-sequencing and sequence analysis .............................................................................. 48

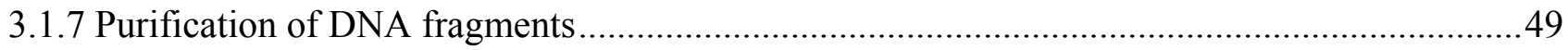

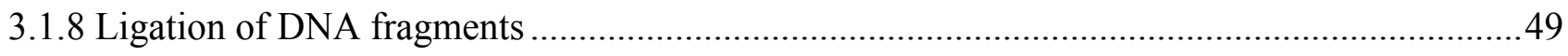

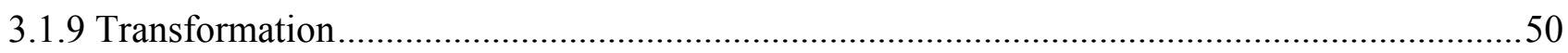

3.1.10 Verification of the integration of a DNA fragment of interest ...........................................50

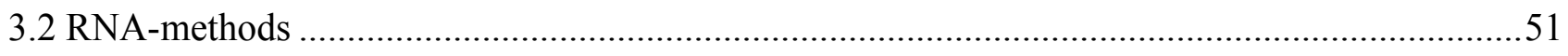

3.2.1 Isolation of total RNA (modified from Sambrook et al., 1989).................................................51

3.2.2 Semiquntitative Reverse-Transcription PCR (RT-PCR) (essentially as described by Sambrook

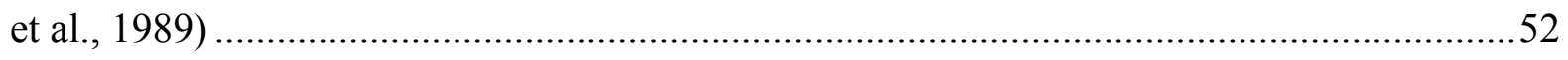

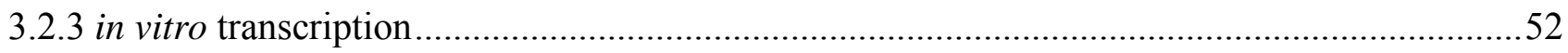

3.2.4 Co-immunoprecipitation (J. Loeber, $\mathrm{PhD}$ thesis in preparation) ..............................................54

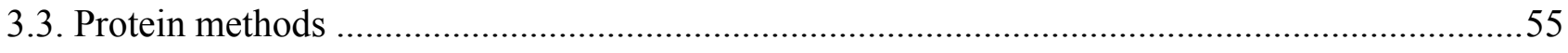

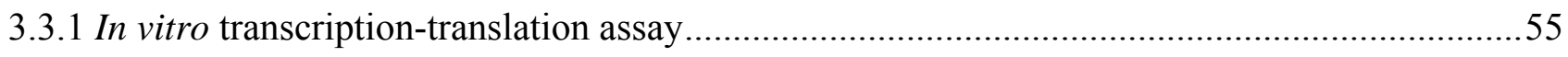

3.3.2 Preparation of total protein extracts (modified from Sottong et al., 1976) ………………….....56

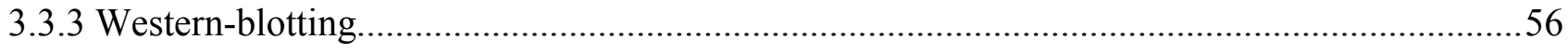

3.3.4 UV-crosslinking (essentially as described by Mowry, 1996) ..................................................57

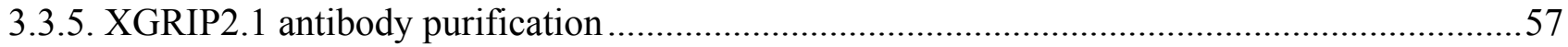

3.4 Preparation and manipulation of Xenopus laevis embryos and oocytes (Richardson et al., 1995;

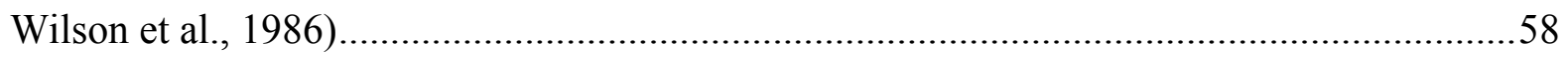

3.4.1 Preparation of Xenopus leavis testis.................................................................................5

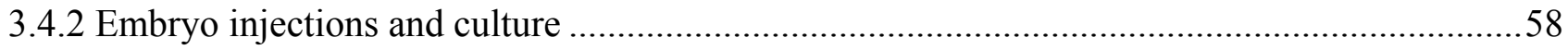

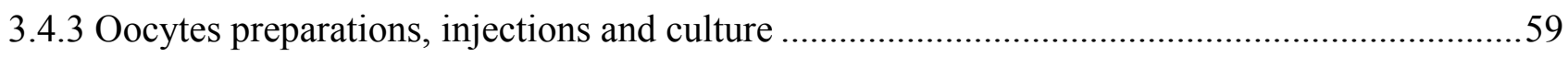

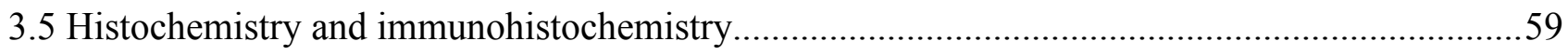

3.5.1 Whole - mount in situ hybridization (Harland, 1991; Hollemann et al., 1999) ..........................59

3.5.2 In situ hybridization on paraffin sections (Collombat et al., 2003) ...........................................63 
3.5.3 TUNEL-staining. .65

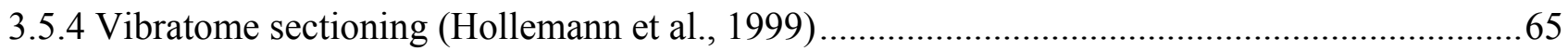

3.5.5 Immunohistochemistry (modified from Hollemann et al., 1999; Collombat et al., 2003) .......66

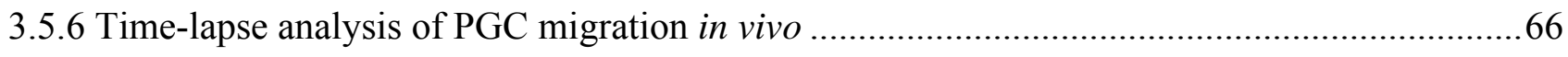

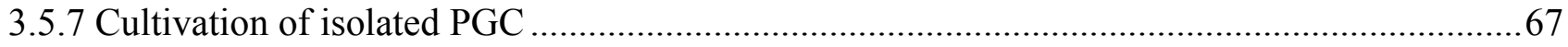

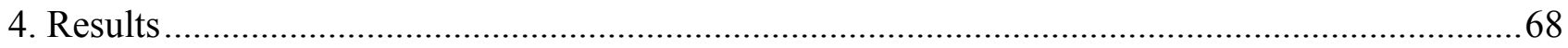

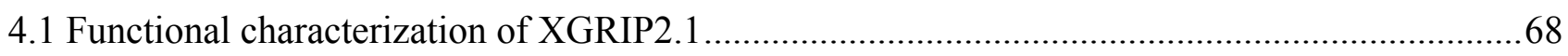

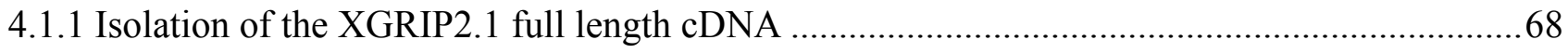

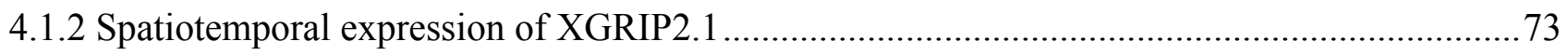

4.1.3 XGRIP2.1 protein expression and subcellular localization ..................................................75

4.1.4 XGRIP2.1 gain-of-function results in a decrease of average PGC numbers .........................77

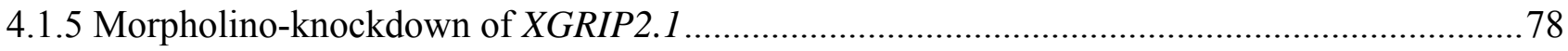

4.1.6 Normal positioning of PGCs along the anteroposterior axis in Xenopus tailbud stage embryos

4.1.7 The XGRIP2.1 dominant-negative PDZ 23 interferes with the survival and anteroposterior

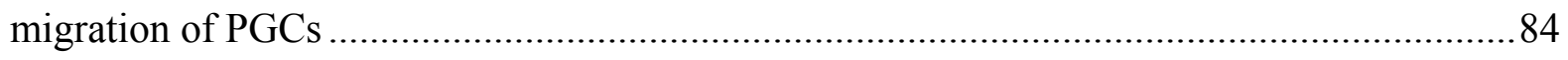

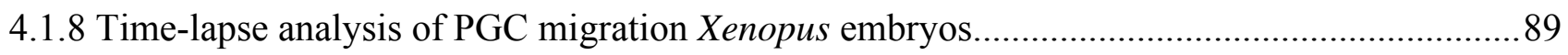

4.2 Characterization of the XGRIP2.1 mRNA localization element necessary and sufficient for its

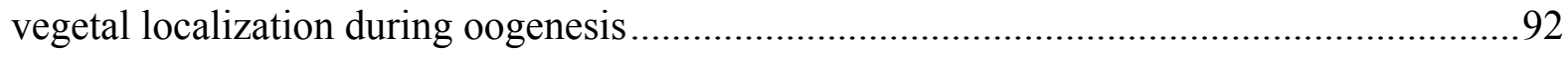

4.2.1 A 210 nucleotide element within the XGRIP2.1 3'UTR is necessary and sufficient for vegetal

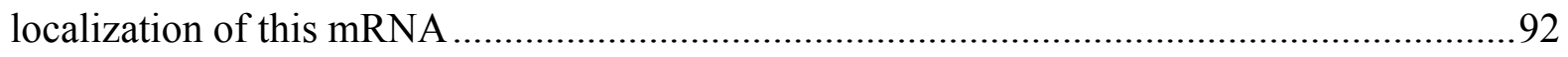

4.2.2 Six LE-binding proteins are shared by XGRIP2.1 and two other germ cell specific mRNAs,

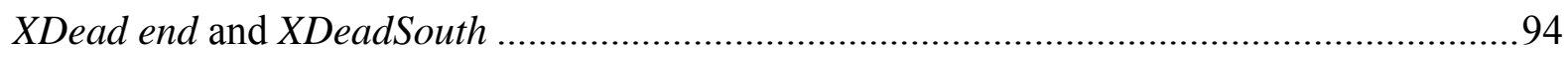

4.2.3 Verification of Vg1RBP, ElrA, ElrB and FRGYs binding to the XGRIP2.1 LE by co-

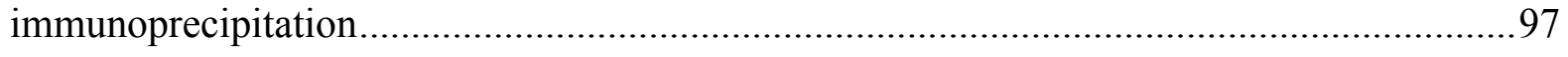

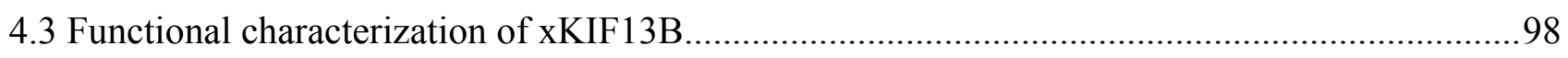

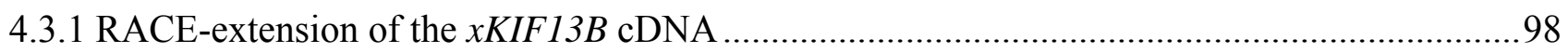

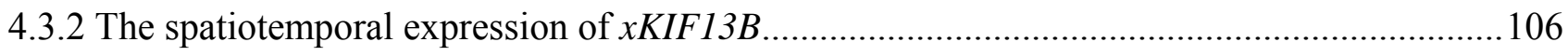

4.3.3 Morpholino-mediated knockdown of xKIF13B reduces the average PGC numbers and results

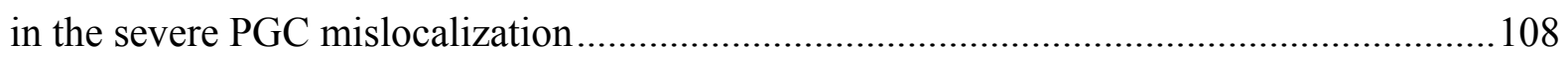

4.3.4 Overexpression of putative dominant negative fragments of xKIF13B reduces average PGC numbers but has no significant effect on the PGC migration. 


\section{Table of Contents}

4.4 Comparative analysis of impacts of PIP3- and SDF1- signalling pathways on the development and migration of Xenopus PGCs

4.4.1 Interference with the PIP3-signalling cascade results in a dramatic decrease of average PGC numbers and PGC mislocalization

4.4.2 Mis/overexpression of xSDF1 did not affect PGC migration in Xenopus until tailbud stage 32

4.4.3 PGC-specific overexpression of $\mathrm{xN}$-Wasp has no significant effect on average PGC numbers and migration.....

4.5 Time-lapse analysis of the migratory behaviour of isolated Xenopus PGCs in different culturing conditions.

5. Discussion

5.1 XGRIP2.1 is encoded by a vegetally localizing, maternal mRNA and functions in germ cell development and anteroposterior positioning in Xenopus laevis

5.2 xKIF13B is encoded by a novel vegetally localizing mRNA and plays an important role in primordial germ cells migration in Xenopus laevis...... .126

5.3 Comparative analysis of the involvement of PIP3- and SDF1-signalling pathways in development and directional migration of Xenopus PGCs

5.3.1 Interference with PIP3-signalling cascade results in a dramatic decrease of average PGC numbers and PGC mislocalization

5.3.2 Misexpression of the XSDF1 does not significantly affect PGC migration in Xenopus until late tailbud stages

5.3.3 Interference with Xenopus N-Wasp does not significantly impair development and migration of primordial germ cells

5.4 Investigation of the migratory behaviour of Xenopus PGCs in different culturing conditions .. 131

6. Conclusions.

7. Bibliography......

8. Appendix

9. Acknowledgements.

10. Curriculum Vitae. 


\section{List of Figures}

Fig. 1.1 The two major pathways driving vegetal mRNA localization during Xenopus oogenesis.

Fig. 1.2 Germ plasm/ PGC development in Xenopus...................................................22

Fig. 1.3 Six steps of early PGC migration in Zebrafish. ................................................26

Fig. 1.4 PGC miration in Drosophila: stages and genes involved. .....................................30

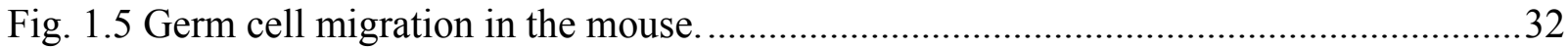

Fig. 4.1. Nucleotide and predicted amino acid sequence of the isolated full-length XGRIP2.1.

Fig. 4.2. Schematic illustration of the XGRIP2.1 cDNA structure and SWISS-plot alignment of the predicted protein sequence.

Fig. 4.3. Analysis of XGRIP2.1 expression by whole mount in situ hybridization and RT-PCR.

Fig. 4.4. Analysis of the XGRIP2.1 protein expression and subcellular localization .76

Fig. 4.5. Overexpression of XGRIP2.1 results in a very mild reduction in the average PGC number......

Fig. 4.6. XGRIP2.1 morpholino oligonucleotides inhibit translation of XGRIP2.1 in vitro and in vivo. .78

Fig. 4.7. XGRIP2.1 knockdown results in reduced average PGC numbers. .81

Fig 4.8. Positioning of PGCs along the A/P axis in control and XGRIP2.1 morphant embryos.

Fig. 4.9. Misexpression of the putative dominant negative XGRIP2.1 fragment PDZ 23 impairs normal PGC development and migration. .85

Fig. 4.10. Dominant negative activity of XGRIP2.1 PRZ 23 requires structural integrity of the predicted cargo binding domain.

Fig. 4.11. PDZ domains 2 and 3 are necessary for the normal functioning of XGRIP.2.1 .......88

Fig. 4.12. Time-lapse analysis of PGC migration and average PGC velocities during embryionic stages 26-42.

Fig. 4.13. Time-lapse analysis of PGC migration in control and PDZ 23 injected Xenopus embryos stage $32-33$ 
Fig. 4.14. The 3'UTR of XGRIP2.1 contains a $210 \mathrm{nt}$ localization element.

Fig. 4.15. UV-cross-linking analysis of XGRIP2.1 LE binding proteins with S100 oocyte extract.

Fig. 4.16. UV-cross-linking analysis of XGRIP2.1 LE binding proteins with RNP-enriched protein fractions.

Fig. 4.17. Co-immunoprecipitations of Alexa-UTP-labelled XGRIP2.1 LE RNA with myctagged putative binding proteins.

Fig. 4.18. Nucleotide and amino acid sequence of xKIF13B

Fig. 4.19. The schematic illustration of the xKIF13B protein structure and SWISS plot alignment with homologues from other orgamisms

Fig. 4.20. Spaciotemporal analysis of $x K I F 13 B$ expression by whole mount in situ hybridization and RT-PCR

Fig. 4.21. $\mathrm{xKIF13B} \mathrm{MO1} \mathrm{and} \mathrm{MO2} \mathrm{inhibit} \mathrm{translation} \mathrm{of} \mathrm{xKIF} 13 \mathrm{~B}$ in vitro and in vivo

Fig. 4.22. xKIF13B knockdown results in reduced average PGC numbers and severe PGC mislocalization.

Fig. 4.23. Overexpreiion of putative dominant negative xKIF13B fragments leads to the moderate reduction of average PGC numbers.

Fig. 4.24. Inhibition of PI3K impairs germ cell development and migration in Xenopus.

Fig. 4.25. Overexpression of xPTEN significantly impairs PGC development and migration in Xenopus.

Fig. 4.26. Overexpression and misexpression of $\mathrm{xSDF} 1$ does not influence PGC migration in Xenopus. 


\section{List of Tables}

Table 1.1 mRNAs vegetally localized during Xenopus oogenesis ...................................... 18

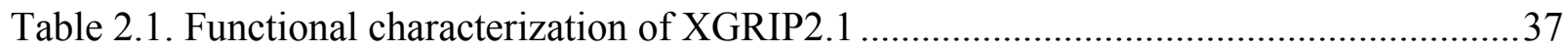

Table 2.2. Mapping of the XGRIP2.1 localization element ...............................................39

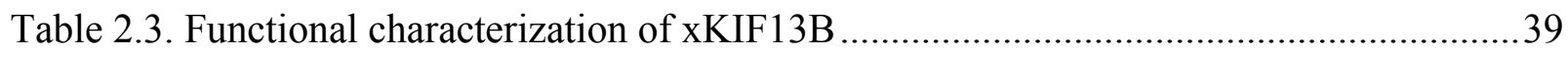

Table 2.4. Molecular mechanism of PGC migration....................................................... 40

Table 2.5. Mapping of the XGRIP2.1 localization element ................................................. 41

Table 2.6. XGRIP2.1 functional characterization .............................................................. 41

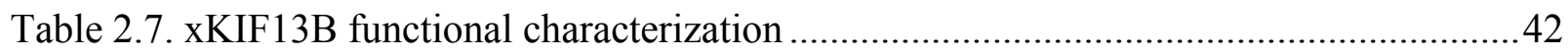

Table 2.8. Primers used for successful RACE-extensions of xKIF13B ..............................42

Table 2.9. Other oligonucleotides .........................................................................43

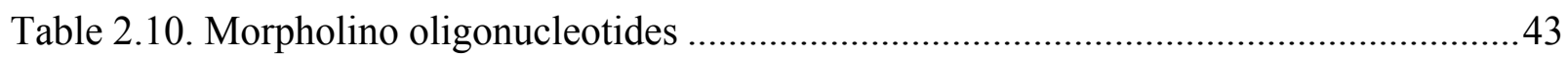




\section{Kurzfassung}

Die vegetative Lokalisation von mRNA während der Xenopus Oogenese ist entscheidend für die spätere Keimblattbildung, frühembryonale Musterbildung und die Entwicklung der Keimbahn. Im Frosch wurde eine Reihe Keimzell-spezifischer Transkripte identifiziert, aber die funktionelle Bedeutung der Mehrzahl dieser mRNAs ist noch unbekannt.

In dieser Arbeit sollten die zwei neuen vegetativ lokalisierten und Keimbahn-spezifischen Transkripte XGRIP2.1 und XKIF13B isoliert und funktionell charakterisiert werden. Die Ergebnisse unserer Experimente weisen auf eine wichtige Rolle von XGRIP2.1 in der Positionierung der primordialen Keimzellen entlang der anterior-posterioren Achse des Xenopus Embryos hin. Außerdem scheint XKIF13B an der Ausbildung der Keimzell-Polarität und der gerichteten Migration der Keimzellen beteiligt zu sein.

Im Rahmen des XGRIP2.1-Projektes wurde ein minimales Lokalisationselement identifiziert, welches sowohl notwendig als auch ausreichend für die Lokalisierung der XGRIP2.1 mRNA ist. Eine Analyse des Proteinbindungsprofiles ergab auffällige Ähnlichkeiten zur Proteinbindung zweier anderer Keimplasma-spezifischer mRNAs.

Ein weiterer Teil der Arbeit widmete sich der Etablierung eines in-vivo-Imaging-Systems für die Beobachtung der Keimzellmigration im lebenden Embryo und in Kultur. Außerdem wurde erstmals die genaue Positionierung der primordialen Keimzellen entlang der anteriorposterioren Achse während der Schwanzknospenstadien der Embryonalentwicklung beschrieben. 


\section{Abstract}

Vegetal localization of mRNA during Xenopus oogenesis is critical for future germ layers formation, embryonic patterning and germ line development. In frogs, a number of germ cells specific transcripts were identified, but functional role of majority of these mRNAs remains unknown. In this work, we aimed in isolation and functional characterization of two novel vegetally localizing and germ line specific transcripts XGRIP2.1 and xKIF13B. Our gain- and loss-of-function data suggest an important role for XGRIP2.1 is PGC positioning along the anteroposterior axis of Xenopus embryos, whereas XKIF13B is involved in the establishing of germ cell polarity and proper directional migration of PGCs.

In scopes of the XGRIP2.1 part of the project, we identified a minimal localization element necessary and sufficient for XGRIP2.1 mRNA translocation to the vegetal pole of an oocyte. Analysis of the protein binding profile of this fragment revealed striking similarities with two other germ plasm/germ cell specific mRNAs.

Another part of the work was devoted to establishing the in vivo imaging of germ cell migration in the context of the entire embryo and in culture as well as to the assignment of the proper positioning of PGCs along the anteroposterior axis of tailbud stage embryos, which was not described earlier. 


\section{Introduction}

\subsection{Vegetal mRNA localization in Xenopus oocytes}

Restriction of the messenger RNA distribution to a certain region of a cell enables spatial regulation of protein expression. Localization of mRNAs is involved in four main developmental processes: formation of protein gradients, asymmetric distribution of cell fate determinants, local assembly of protein complexes and protein sorting to organelles (Du et al., 2007).

Establishment of morphogen gradients facilitates patterning of germ layers and embryonic axis formation by regulating expression of target-genes responsive to different morphogen concentrations along the gradient. In Drosophila, localization of Bicoid mRNA results in the specification of the anterior parts of an embryo, when localization of the Oskar mRNA to the opposite (posterior) end leads to the proper formation of the pole plasm essential for the development of the future germ line (Ephrussi et al., 1991; Ephrussi and St Johnston, 2004). In Xenopus, vegetal localization of $\mathrm{Vg} 1$ and $\mathrm{VegT}$ messages in the oocytes is crucial for germ layer formation, mesoderm induction and anterior-posterior patterning of an embryo (Melton, 1987; Zhang and King, 1996).

Proper localization of mRNA can not only generate intracellular protein gradients but also modulate extracellular signalling. Mislocalization of Drosophila Wingless mRNA to the basal instead of to the apical cell membrane phenocopies its loss-of-function, suggesting necessity of correct mRNA targeting for the proper secretion of the protein (Simmonds et al., 2001).

Determination of cell fate by asymmetric cell division is known in variety of cell types. It implies differential inheritance of asymmetrically distributed cell fate determinants during mitosis. The classical example providing a link between mRNA distribution and cell fate determination is localization of ASH1 mRNA to the tip of a daughter cell, which regulates the mating-type switch in yeast (Cosma, 2004).

Unequal distribution of mRNAs within a cell is as well an important mechanism of maintaining cell polarity. One of the best studied examples for that is the localization of $\beta$-actin mRNA to the leading edge of a fibroblast, which results in the local transcription of $\beta$-actin facilitating lamellaepodia formation and cell migration (Condeelis and Singer, 2005). 
Recently, a novel role for localized transcripts in protein sorting to ER, mitochondria and nuclei was described. For example, ATP2 mRNA in yeast coding for mitochondrial ATP synthase was found in the vicinity of these organelles. Mislocalization of the transcript resulted in the severe respiratory deficiency, coupling proper mRNA localization to the protein sorting and functioning within a cell (Du et al., 2007).

Thus, the importance of the mRNA localization could be defined in many organisms and developmental processes, which makes an understanding of the mechanisms driving this process a key issue in developmental biology. In Xenopus oocytes, two major pathways of mRNA localization were characterized: early microtubule-independent or METRO and late microtubuledependent or Vg1 pathway (Fig. 1.1) (King et al., 2005; Kloc and Etkin, 2005).

\subsubsection{Mechanism of the early (METRO) pathway}

At stage I of oogenesis mRNAs localized via the early pathway (Table 1.1) are enriched in a special transporting organelle termed mitochondrial cloud (MC) or Balbiany body (Fig. 1.1). This structure is developed from the so called fusome, composed of endoplasmic reticulum (ER), mitochondria and Golgi, which depict vegetal pole by favouring one side of the nucleus in the primary oogonium (Kloc et al., 2004b). Mature MC is a polarized structure containing a centrosome, ER, about half a million mitochondria, and hundreds of germinal granules with early localizing mRNAs concentrated in the most vegetal part of the cloud (so called messenger transport organizer or METRO) (Kloc et al., 2002a). A 3D-analysis of the MC structure revealed Xcat2, Xpat and XDEADSouth mRNA being associated with germinal granules, when Xlsirts and Xdazl were found in the matrix surrounding those (Kloc et al., 2002a). 
A

\section{Early (METRO) pathway}

1

2 3

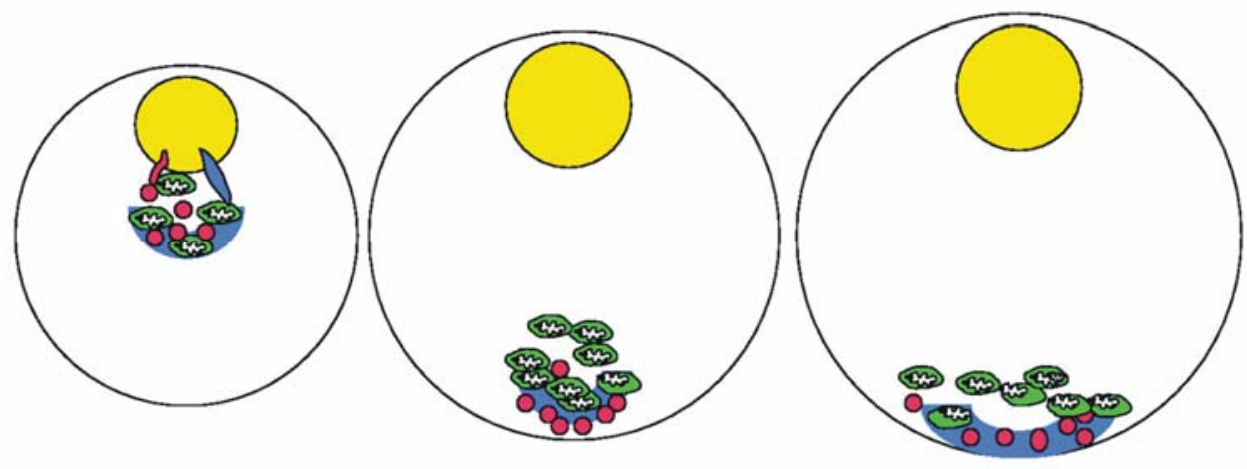

B

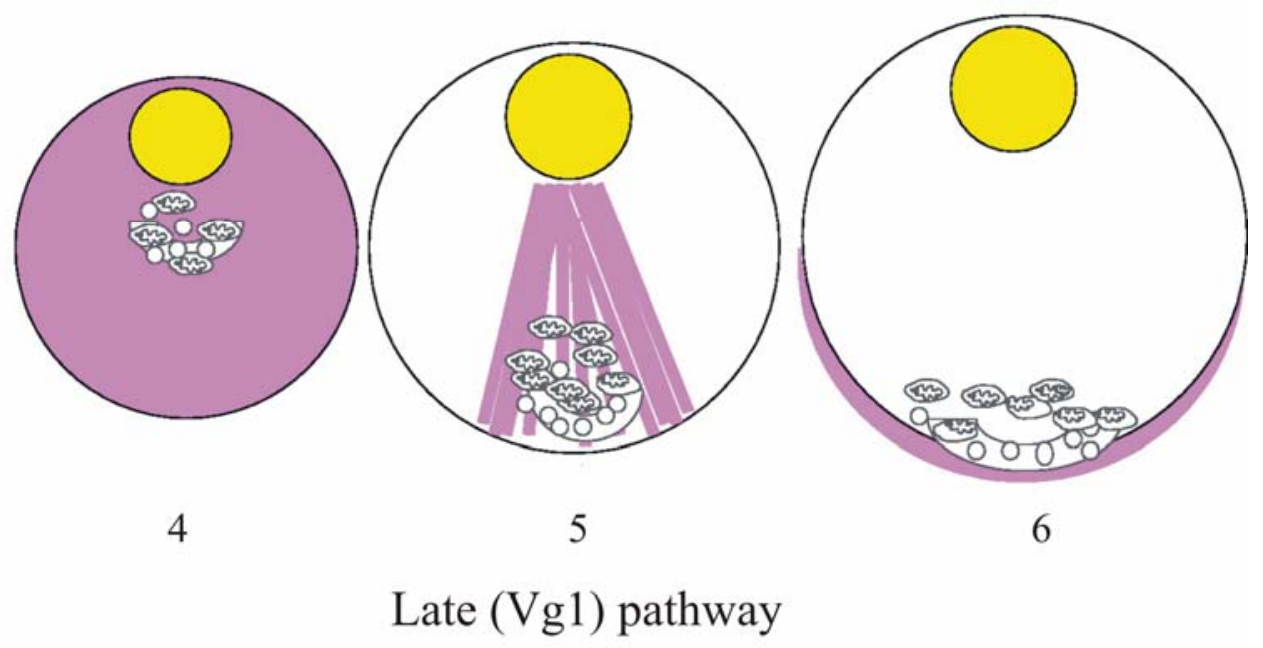

Fig. 1.1 The two major pathways driving vegetal mRNA localization during Xenopus oogenesis. (A) At stage I of oogenesis (1) RNAs localized via the early (METRO) pathway are exported from the nucleus (yellow circle) and enriched in the mitochondrial cloud (MC, mitochondria are depicted in green). Such RNAs like Xcat2 (red spheres) locate to the germinal granules, when transcripts like Xlsirts (blue) are localized to the organizer region of the MC. By stage II (2), the MC translocates to the vegetal pole and starts to disintegrate. In oocytes of stage III (3), the MC is dispersed and mRNAs are anchored to the tip of the vegetal cortex. (B) RNAs localized via late (Vg1) pathway (purple) are excluded from the MC and uniformly distributed in the ooplasm at stage I (4). In late stage II oocytes (5), these mRNAs accumulate in a wedge-shaped region between the nucleus and vegetal pole around moving MC. The transcripts associate with the ER and are translocated to the vegetal pole in the microtubule-dependent manner. By stage III-IV these mRNA are anchored to the vortex of the entire vegetal hemisphere (from Kloc and Etkin, 2005). 
How do mRNAs get enriched in the METRO region of the MC? Strong evidence for a diffusion/ entrapment mechanism was reported by Chang et al. (2004). Combination of timelapse confocal microscopy and FRAP allowed detection of Xcat2 and Xdazl injected mRNAs, which were first passively diffusing in the ooplasm and then got immobilized in the MC region (Chang et al., 2004). It is believed, that entrapment of mRNAs is facilitated by aggregation of smooth ER, mitochondria, Xlsirts and spectrin, which provide a matrix or scaffold for RNA enrichment. Alternatively, some early localizing mRNAs could encode for proteins with RNA as well as cytoskeleton binding activity [like Germes containing RNA binding motif and EF-domain (Berekelya et al., 2003)], which could additionally assist in bringing RNAs to the MC (King et al., 2005; Kloc et al., 2004a; Kloc and Etkin, 2005).

In addition, Bilinski et al. reported on a novel splicing-independent role for Sm-proteins. The Vasa-like DEAD-box helicase together with components of the splicing machinery were found in the nuage of Xenopus oocytes, and Sm-proteins bound to mRNAs were proposed to shuttle between the nucleus and MC assisting in the assembly of germ plasm particles (Bilinski et al., 2004).

By stage II of oogenesis, MC translocates to the vegetal pole by unknown but microtubule-independent mechanism [most probably, by the cytoplasmic streaming (Kloc et al., 2004b)], where it breaks apart and mRNAs become enriched at the tip of the vegetal cortex.

\subsubsection{Mechanism of the late (Vg1) pathway}

In Xenopus, a number of mRNAs are localized late during mid and late oogenesis (stages III-IV) via the late microtubule-dependent or Vg1-pathway (Fig. 1.1). These transcripts (Table 1.1) are excluded from the MC during early oogenesis and are evenly distributed in the ooplasm until stage III, when they accumulate in the microtubule and ER-enriched "wedge"-shaped region between the nucleus and the vegetal pole of an oocyte. Then mRNAs are "streamed" to the vegetal pole in the microtubule-dependent manner and are anchored to the broad region of the vegetal hemisphere. It is not clear so far, whether transcripts associate with ER-vesicles via linker proteins and are trafficked along microtubules, or ER is triggering cytoskeletal rearrangements necessary for mRNA localization (Deshler et al., 1997; Kloc and Etkin, 1998). 
Intriguingly, vegetal localization of $\mathrm{Vg} 1 \mathrm{mRNA}$ was reported to require plus-end directed motor protein kinesin II and, probably, kinesin I (Betley et al., 2004; Yoon and Mowry, 2004). In contradiction with that, the arrangement of microtubules in an oocyte differs from the one in other eukaryotic cells and implies the minus-end of microtubules to be directed to the cortex and the plus-end to the nucleus (Pfeiffer and Gard, 1999). Therefore, vegetal RNA localization is more expected to be driven by minus-end motors and not plus-end kinesins as it was reported. These contradictory findings could be explained by a shift in microtubule polarity during oogenesis or by existence of an RNA-binding protein, which could control directionality of RNA transport. For example, the Halo-like protein can influence the affinity of the cargo bearing motor protein to the microtubule and switch the direction of transport (Cohen, 2003).

The anchoring of the late-localized mRNAs to the vegetal cortex depends on the microfilaments, especially on the cytokeratin and actin (Kloc and Etkin, 1995). In addition, two localized RNAs Xlsirts and VegT were also found involved in that process (Kloc and Etkin, 1994).

Except for early and late localization pathways described above, a few mRNAs (Table 1.1) make use of the so called intermediate pathway. These transcripts are enriched in MC at stages I-II and use microtubule-dependent trafficking during later stages (King et al., 2005). The majority of the early localizing mRNAs is later involved in the germ line development, while several of the late localizing transcripts function in germ layers establishment. The protein encoded by mRNAs localizing via intermediate pathway are proposed to play as well dual functional roles later during embryogenesis. For example, fatvg was found in developing fat bodies and in germ plasm (Chan et al., 2001). Interestingly, synthetic early localizing mRNAs (Xcat2, XNIF) upon injection into nuclei of stage III-IV oocytes are localized via late pathway in a microtubule-dependent manner (Claussen et al., 2004; Claussen and Pieler, 2004; Zhou and King, 1996). In addition, XNIF and Vg1 mRNAs have overlapping protein binding patterns (Claussen et al., 2004). These data argue for a cross-talk between both localization machineries, albeit the exact mechanism of mRNA sorting into distinct transporting pathways remains to be characterized. 
Table 1.1 mRNAs vegetally localized during Xenopus oogenesis

\begin{tabular}{|c|c|c|c|}
\hline mRNA & Pathway & Function/ structure & Reference \\
\hline Xlsirts & Early & Non-coding RNA & $\begin{array}{l}\text { (Kloc et al., 1993; Zearfoss et al., } \\
\text { 2003) }\end{array}$ \\
\hline XWnt 11 & Early & Wnt-family member & $\begin{array}{l}\text { (Kloc et al., 1998; Ku and Melton, } \\
\text { 1993) }\end{array}$ \\
\hline Xcat2 & Early & $\begin{array}{l}\text { Nanos- related, } \mathrm{Zn} \text {-finger } \\
\text { protein }\end{array}$ & $\begin{array}{l}\text { (Forristall et al., 1995; Kloc and } \\
\text { Etkin, 2005; Mosquera et al., } \\
\text { 1993) }\end{array}$ \\
\hline XFACS & Early & $\begin{array}{l}\text { Fatty Acyl CoA } \\
\text { synthetase (FACS) }\end{array}$ & (King, 1995; Kloc et al., 2002b) \\
\hline Fingers & Early & Zn-finger protein & (King, 1995; Kloc et al., 2002b) \\
\hline Xlerk & Early & Eph-family ligand & $\begin{array}{l}\text { (Betley et al., 2002; Jones et al., } \\
\text { 1997) }\end{array}$ \\
\hline Xdazl & Early & $\begin{array}{l}\text { DAZ-related, RNA } \\
\text { binding protein }\end{array}$ & (Houston et al., 1998) \\
\hline Xpat & Early & $\begin{array}{l}\text { Structuring of germ } \\
\text { plasm }\end{array}$ & $\begin{array}{l}\text { (Hudson and Woodland, 1998; } \\
\text { Machado et al., 2005) }\end{array}$ \\
\hline DEADSouth & Early & RNA-helicase & (MacArthur et al., 2000) \\
\hline Germes & Early & $\begin{array}{l}\text { EF-hand, Leucine zipper } \\
\text { motif }\end{array}$ & $\begin{array}{l}\text { (Berekelya et al., 2003; Berekelya, } \\
\text { 2005) }\end{array}$ \\
\hline XNIF & Early & NIF-domain protein & (Claussen et al., 2004) \\
\hline XPACE4 & Early & $\begin{array}{l}\text { Mesoderm induction, } \\
\text { protease }\end{array}$ & (Birsoy et al., 2005) \\
\hline XDead end & Early & $\begin{array}{l}\text { DEAD-box helicase, } \\
\text { Germ cell survival }\end{array}$ & (Horvay et al., 2006) \\
\hline XGRIP2.1 & Early & $\begin{array}{l}7 \text { PDZ-domains, } \\
\text { PGC migration }\end{array}$ & (Tarbashevich et al., 2007) \\
\hline Fatvg & Intermediate & $\begin{array}{l}\text { Adipophilin/ADRP- } \\
\text { related, PGC survival }\end{array}$ & $\begin{array}{l}\text { (Chan et al., 2001; Chan et al., } \\
\text { 1999) }\end{array}$ \\
\hline Xotx 1 & Intermediate & $\begin{array}{l}\text { Orthodenticle-related, } \\
\text { transcription factor }\end{array}$ & (Pannese et al., 2000) \\
\hline Hermes & Intermediate & RNA-binding protein & (Zearfoss et al., 2004) \\
\hline XGRIP2 & Intermediate & $\begin{array}{l}7 \text { PDZ-domains } \\
\text { PGC migration }\end{array}$ & (Kirilenko et al., 2007) \\
\hline Vg1 & Late & TGF- $\beta$-family member & $\begin{array}{l}\text { (Rebagliati et al., 1985; Weeks } \\
\text { and Melton, 1987) }\end{array}$ \\
\hline$\beta-\operatorname{TrCP}-2 / 3$ & Late & $\beta$-transducin & (Hudson et al., 1996) \\
\hline VegT & Late & T-box transcription factor & $\begin{array}{l}\text { (Lustig et al., 1996; Stennard et } \\
\text { al., 1996; Zhang and King, 1996) }\end{array}$ \\
\hline $\mathrm{C} 3 \mathrm{H}-3$ & Late & Zn-finger protein & $\begin{array}{l}\text { (Betley et al., 2002; De et al., } \\
\text { 1999) }\end{array}$ \\
\hline $\mathrm{xBic}-\mathrm{C}$ & Late & $\begin{array}{l}\text { Bicaudal-C homologue, } \\
\text { RBP }\end{array}$ & (Wessely and De Robertis, 2000) \\
\hline $\mathrm{xARH} \alpha$ & Late & ARH-related & $\begin{array}{l}\text { (Zhou et al., 2003; Zhou et al., } \\
\text { 2004) }\end{array}$ \\
\hline
\end{tabular}




\begin{tabular}{|ccll|}
\hline mRNA & Pathway & Function/ structure & Reference \\
\hline Xvelo1 & Late & Novel protein & (Claussen and Pieler, 2004) \\
\hline XGRIP2 & Late & 7 PDZ-domains & (Kaneshiro et al., 2007) \\
\hline
\end{tabular}

\subsubsection{Cis-acting mRNA elements mediating vegetal localization of a transcript}

Recognition by the protein machinery of so called cis-acting mRNA sequences or localization elements (LEs) is one of the first and the most critical steps in the mRNA localization mechanism (King et al., 2005; Kloc et al., 2002b). So far it is not clear how the presence of a cis-acting element is triggering formation of a localizing ribonuclear-protein particle (RNP), because these motifs do not reveal any significant conservation in the primary sequence and their secondary structure is not known. They were found to differ in length and location within the RNA molecules (Kloc et al., 2002b). For example, the LE of Vg1 mRNA is 340-nt long, which is quite large in comparison to the 25-nt of the fatvg LE (Chan et al., 1999; Mowry and Melton, 1992). The vast majority of cis-acting elements characterized until now were mapped in the 3'UTRs, albeit there are some exceptions from this rule, for example, the LE of XNIF residing in the 5'UTR (Claussen et al., 2004).

Presence and clustering of short redundant sequence motifs identified within LEs of a number of mRNAs was proposed to serve as a putative signal for RNP assembly and efficient mRNA localization. In line with that, repetitive VM1 (YYUCU) and E2 (A/C CAC) elements were found to be necessary for $V g 1$ and VegT mRNAs localization (Bubunenko et al., 2002; Deshler et al., 1997; Kwon et al., 2002; Lewis et al., 2004). Several of these and closely related sequences were identified inside and outside LEs mapped in our lab, but no correlation between clustering of these motifs and mRNA localization was observed (Claussen et al., 2004; Claussen and Pieler, 2004; Horvay et al., 2006).

For early localizing mRNAs the best studied examples of cis-acting sequences are those of Xcat2 and Xlsirts (Allen et al., 2003; Chang et al., 2004; Kloc et al., 2000; Zhou and King, 1996).

Within the 3'UTR of Xcat2 a 240-nt sequence necessary and sufficient for the localization of this mRNA to the MC was mapped and termed mitochondrial cloud localization signal (MCLS). The MCLS could be further restricted to a 57-nt LE (termed MCLE) necessary but not sufficient for the MC entrapment of the given mRNA (Chang et al., 2004). Interestingly, MCLS 
supports enrichment of the transcript within the MC, but not further incorporation of the mRNA into germinal granules. The last process is mediated by another 160-nt of the Xcat2 3'UTR beyond the MCLS. This region of the mRNA was termed germinal granules localization element (GGLE) (Kloc et al., 2002a). Moreover, six UGCAC repeats (termed R1 to R6) were found in the Xcat2 3'UTR, but only five of them were important for the entrapment of Xcat2 mRNA to the MC (Chang et al., 2004). Mutation of UGCAC to UUCAC (E2-motif) did not abolish localization of the transcript to the MC, and vice-a-versa substitution of E2-fragments in the Vg1 LE by UGCAC-repeats did not change the mode of this mRNA localization (Chang et al., 2004).

Presence of UGCAC repeats were reported as well for another early localizing mRNA Xpat (Hudson and Woodland, 1998), albeit here clustering of these motifs did not correlate with the localization of mRNA.

Xlsirts is the only one mRNA known so far, where small size of the LE (135 nt) allowed to perform the computer modelling of its secondary structure (Allen et al., 2003). Disruption of the predicted mRNA folding abolished localization of the transcript. In addition, a tandem of unique short-sequence repeats were mapped within the region of the LE, but the functional significance of these motifs in mRNA localization is not clear till now (Allen et al., 2003).

So far the only common feature of localized mRNAs are numerous CAC-bearing repeats (Allen et al., 2003), but a consensus sequence or structure of a cis-acting element is yet to be identified.

\subsubsection{Trans-acting factors involved in vegetal localization of mRNAs}

The presence of the cis-acting RNA signal is not sufficient for the vegetal trafficking and anchoring of a transcript. mRNA localization is a complicated process, which implies formation of a large RNA-protein (RNP) complex involving LEs and trans-acting protein factors. The assembly and rearrangement of this RNP is best studied in the context of late localizing transcripts, and can be illustrated on the example of the Vg1 RNP (Czaplinski and Singer, 2006; King et al., 2005). RNP assembly starts in the nucleus (Kress et al., 2004), where Vg1 RNA binding protein (Vg1RBP also known as Vera or xVICKZ3) binds to E2-motifs, and heterogeneous nuclear ribonuclear protein I (hnRNP I or Vg1RBP60) interacts with VM1sequences (Cote et al., 1999; Deshler et al., 1998; Havin et al., 1998; Yisraeli, 2005). Binding of 
these two proteins triggers recognition of this RNP by another trans-acting factor 40LoVe (Czaplinski et al., 2005). Intriguingly, Vg1RPB/Vera can associate with ER and link localizing RNPs with this organelle facilitating the trafficking (Deshler et al., 1997). In general, Vg1RPB belongs to the family of VICKZ-proteins (Vg1RPB/Vera, Imp-1,2,3, CRD-BP, KOC, ZBP-1) involved in numerous developmental processes like proliferation, cell polarity and migration (Oberman et al., 2007; Yisraeli, 2005). Vg1RBP60/hnRNP I is a Xenopus homologue of human PTB (polypyrimidine tract-binding protein) and its splice-version hnRBP I, which can function in post-transcriptional RNA modification (Cote et al., 1999).

The RNA and these three proteins is translocated into the cytoplasm of an oocyte, where it is joined by at least three other proteins: Vg1RBP71 (Kroll et al., 2002), xStau (Yoon and Mowry, 2004) and Prrp (Zhao et al., 2001). Vg1RBP71 is believed to regulate translational derepression of the mRNA (Kroll et al., 2002). xStau is the Xenopus homologue of Drosophila Staufen (St Johnston et al., 1991) and is involved in linking of an RNP to motor proteins (kinesin II and kinesin I) (Betley et al., 2004; Yoon and Mowry, 2004). Prrp is a proline-rich domain containing protein interacting with profilin, and was proposed to mediate anchoring of the RNP to the vegetal cortex (Zhao et al., 2001).

The composition of the early localizing RNPs is very poorly characterized till nowadays. Xcat2 mRNA can bind Vg1RBP and Vg1RBP60, but the necessity of this interaction in the context of this mRNA localization is not clear so far (Chang et al., 2004).

Series of cross-linking experiments preformed in our lab with a number of vegetally localizing transcripts resulted in the visualization of several novel RNA-binding proteins, identities of those are yet to be defined (Claussen et al., 2004; Claussen and Pieler, 2004; Horvay et al., 2006).

\subsection{Formation and development of germ plasm and primordial germ cells in Xenopus}

Segregation of the germ line from somatic tissues may occur in two main modes. In a number of organisms like amphibians, Drosophila and nematodes, the segregation of the germ line starts already at early cleavage stages by asymmetric distribution of cytoplasmic determinants present in so called "germ"- or "pole"- plasm. In amniotes these early determinants 
have not been identified, which resulted in the hypothesis of "epigenetic" germ line development (Braat et al., 1999a). However, in the majority of organisms primordial germ cells originate at relatively distant locations in respect to future gonads and have to make their way through different embryonic tissues. Intriguingly, the mode of migration and guidance cues orienting germ cells on their way to the target region might be strikingly similar between species (Molyneaux and Wylie, 2004).

Development of the germ plasm in Xenopus starts already during early oogenesis, at the stage of a primary oogonium, when a structure termed fusome is formed. This organelle contains mitochondria, Golgi apparatus and ER, and is a precursor of the mitochondrial cement developing by the stage of the secondary oogonium. Mitochondrial cement is regarded as a future scaffold or organizing centre for the early localizing mRNAs (Heasman et al., 1984). The derivative from the mitochondrial cement termed granulofibrillar material (GFM) already contains future germ plasm specific mRNAs like Xcat2 and Xpat (Kloc et al., 2002b) and it is a precursor of the mitochondrial cloud (MC), developing by stage I of oogenesis. Mature MC contains a centrosome, mitochondria, ER, electron-dense material and mRNAs, some of which accumulate in germinal granules and some just associate with them. $\mathrm{MC}$ is a polarised structure, as far as a subset of maternal mRNAs accumulates in a specific subdomain of the MC, referred to as the METRO region (messenger transport organizer). By stage II, MC moves to the vegetal pole, disintegrates and mRNAs are anchored to the restricted apical region of the vegetal cortex (Kloc and Etkin, 1995; Kloc et al., 1996).

Whitington and Dixon performed a detailed investigation of the germ plasm development in Xenopus (Whitington and Dixon, 1975). As they reported, at stage 1 of embryogenesis, germ plasm associates with the plasma membrane and is found in large patches or aggregates at the vegetal pole of an embryo (Fig. 1.2). Aggregation of germ plasm was shown to depend on microtubules and the activity of kinesin-like protein 1 (Xklp-1) (Robb et al., 1996). Contraction waves and cytoplasmic ingression triggered by fertilization facilitate formation of germ plasm islands and its gradual internalisation. During blastula stages germ plasm remains at its perimembrane location and is inherited by one of the daughter cells via asymmetric division of blastomeres. By the onset of gastrulation, germ plasm bearing cells reach the critical germ plasm/ total cell volume ratio and are specified as primordial germ cells (PGCs). At this stage of development germ plasm is relocated to the peri-nuclear region of PGCs and associates with the yolk-free cytoplasm (nuage). By the end of gastrulation new-born PGCs are positioned to the 
posterior endoderm, undergo the first wave of mitotic division, and stay passively involuting with the endoderm until early tailbud stage. At stage 25-26 PGCs start to move laterally and then dorsally. At stage 31-33 the yolk-free cytoplasm disappears and the germ plasm seems to disperse between yolk-granules around the nucleus. Next, actively migrating germ cells undergo two waves of mitotic divisions and end up in the dorsal endodermal crest by stage 40 . After the formation of the dorsal mesentery (stage 43-44), they move along it to the dorsal body wall, then laterally to colonize the region of the future gonads, which are formed by stage 50 (Houston and King, 2000b; Houston et al., 1998; Whitington and Dixon, 1975).

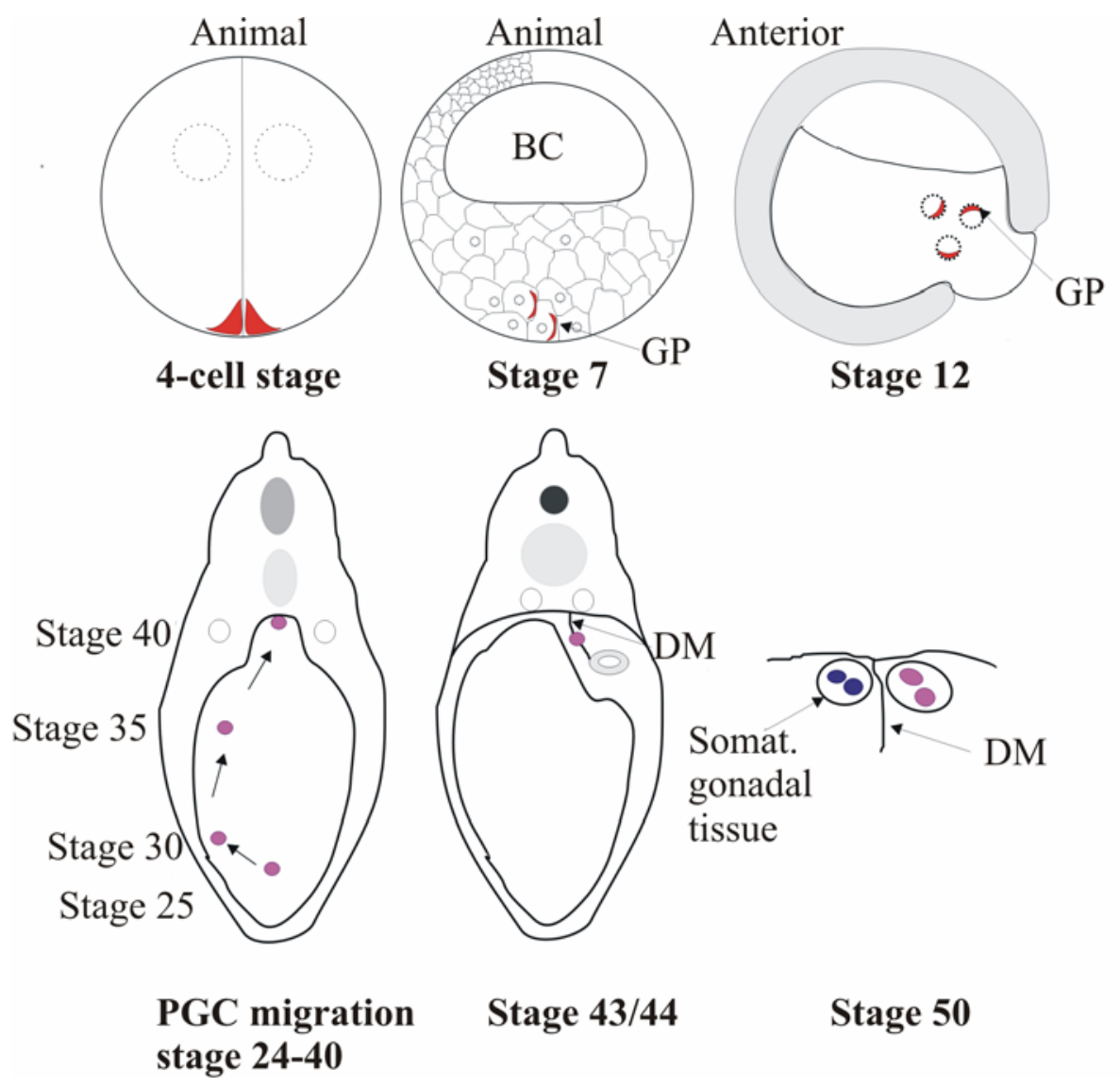

Fig. 1.2 Germ plasm/ PGC development in Xenopus. During early cleavage stages, accompanied by cytoplasmic ingression and contraction waves, germ plasm (red) accumulates in granular germ patches and islands at the tip of the vegetal pole of an embryo. At blastula stages the germ plasm is associated with plasma membranes and inherited by one of daughter cells via asymmetrical cell division. By gastrula stage, germ plasm translocates to the peri-nuclear region of specified germ cells, which are positioned to the posterior endoderm by gastrulation movements and undergo the first wave of mitotic division. By stage 25 PGCs start active migration laterally and then dorsally to reach the dorsal crest. Upon formation of the dorsal mesentery at stage 43-44, PGCs migrate to the dorsal body wall, from where they move laterally, associate with somatic gonadal precursor cells and form the gonads by stage 50 . Abbreviations: GP- germ plasm, BC- blastocoel, DM- dorsal mesentery. (Modified from Houston and King, 2000b). 
Almost all germ plasm/ PGC specific mRNAs are localized via the early pathway [with the exception of late localizing XDead end (Horvay et al., 2006) and fatvg (Chan et al., 1999) using intermediate pathway]. Several vegetally localizing transcripts, such as Xpat, Xcat2 and $D E A D S o u t h$, have been described to remain specifically associated with the germ plasm and PGCs throughout Xenopus embryogenesis (Houston et al., 1998; MacArthur et al., 2000; Mosquera et al., 1993). These germ cell specific mRNAs appear to function in the process of germ cell specification in Xenopus. The early-localizing mRNA Xpat was shown to be important for the organization and positioning of the germ plasm (Machado et al., 2005). Another germ line specific mRNA Germes (Berekelya et al., 2003) was also proposed to be involved in the formation of the germ plasm. The Germes protein contains EF-hand and RNA binding domains and could, therefore, facilitate entrapment of early localizing mRNA to the MC. On the other hand, it was reported to bind dynein light chains and by this means influence aggregation and maturation of germ plasm (Berekelya et al., 2007).

The vegetally localizing mRNAs Xdazl and XDead end both encode RNA binding proteins required for PGC specification in Xenopus (Horvay et al., 2006; Houston and King, 2000a). Interestingly, disrupting the function of either mRNA results in a reduction of PGC number, albeit occurring at different developmental stages, i.e. the late and early tailbud stage, respectively. In addition, depletion of maternal Xdazl mRNA inhibits PGC migration, possibly accounting for the loss of PGCs later in embryogenesis (Houston and King, 2000a).

Another PGC-specific RNA Xdsg (Xenopus laevis nuclear domain-10 protein NDP52) was reported to facilitate differentiation of presumptive PGCs into mature PGCs (Ikenishi et al., 2006; Yamakita et al., 2004). Xenopus homologue of Drosophila vasa (Xenopus vasa-like gene 1) $X V L G 1$ was found expressed in the PGCs of feeding tadpole stage embryos and later in testes and ovaries of adult frogs (Komiya et al., 1994). The protein was proposed to function in late differentiation steps of Xenopus germ cells (Ikenishi and Tanaka, 1997).

In spite of the growing knowledge about the function of germ plasm/PGC associated mRNAs, the molecular mechanism of specification and migration of Xenopus germ cells is still elusive. Apart from fibronectin, which appears to function as a PGC substrate in the dorsal mesentery during the late phase of migration (Heasman and Wylie, 1981), the factors directing PGC migration in Xenopus are largely unknown. 


\subsection{Molecular mechanisms of germ cells development and migration in other organisms}

\subsubsection{Molecular mechanism of germ cells development and migration in Zebrafish}

As briefly mentioned above, the germ line in fish develops in a "preformistic" mode by asymmetric inheritance of specific cytoplasmic determinants, mainly mRNAs and maternally provided proteins in association with mitochondria, ER and electron-dense material (Braat et al., 1999a; Mahowald, 1968). Identification of zebrafish germ plasm markers like vasa (Braat et al., 1999b; Yoon et al., 1997) and Dead end (Weidinger et al., 2003) allowed to follow in more detail development and migration of germ cells in this model organism.

As detected by WMISH, at early cleavage stages germ plasm in zebrafish forms stretches along the first two cleavage planes. At 8-cell stage it aggregates in clusters and ends up in only four germ cells by 32-cell stage. The morphology of the germ cells in fish is very similar to those in other organisms. They are big cells (about $20 \mu \mathrm{m}$ ) with large nuclei surrounded by nuage-like structures. Ultrastructural changes of "nuage" seem to correlate with the maturation stage of germ cells as it was described for frogs (Braat et al., 1999a; Mahowald, 1968).

At the dome stage of development new-born PGCs in zebrafish locate in four clusters forming a "square" in the animal half of the embryo close to the balstoderm margin (Fig. 1.3). Starting from here six steps in PGC migration can be distinguished (Weidinger et al., 1999). First,

PGC clusters converge dorsally together with somatic cells. At $60 \%$ epiboly, they migrate away from the dorsal midline. At 80\% epiboly, dorsal PGC clusters align along the anterior border of the trunk mesoderm, while ventral PGCs align along the lateral border of the mesoderm. At the 2somite stage, anterior germ cells migrate laterally and form two clusters, which start to move posteriorly at the 8 -somite stage. PGCs located ventrally at the 2-somite stage migrate anteriorly. This posterior movement of two lateral PGC clusters and anterior migration of trailing germ cells results in positioning of PGCs between the $8^{\text {th }}$ and $10^{\text {th }}$ somites at $24 \mathrm{hpf}$ (Weidinger et al., 1999).

The six step mode of PGC migration described above is generated by attraction signals from intermediate targets positioned dorsally during gastrulation, then in a border-line between trunk and head mesoderm, later within the lateral plate mesoderm and, finally, in the gonad region (Molyneaux and Wylie, 2004; Weidinger et al., 2002). 
A

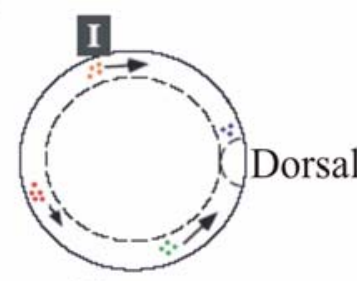

Dome, animal view
B

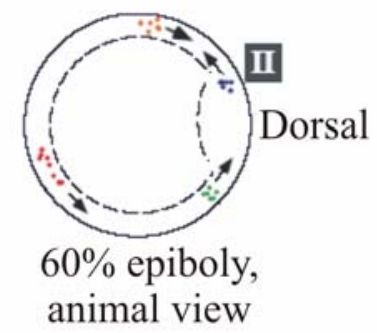

C
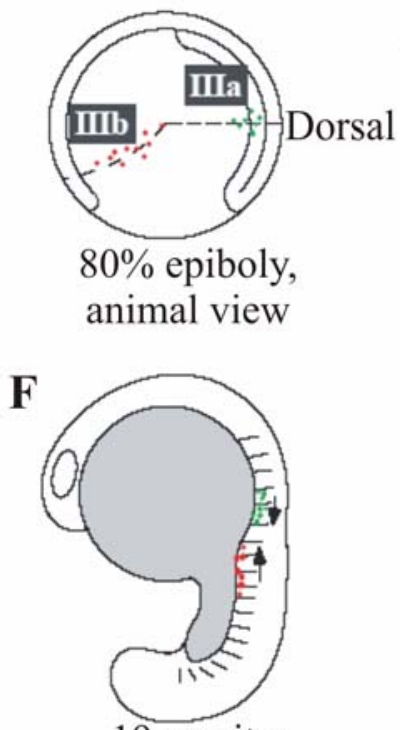

19 somites
G

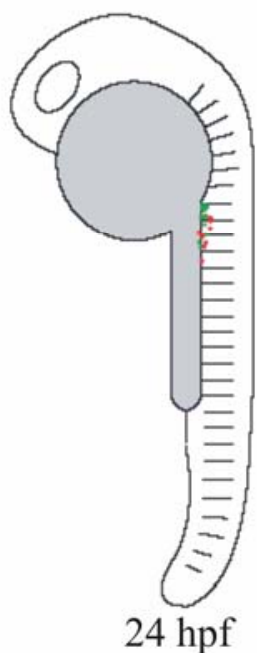

D

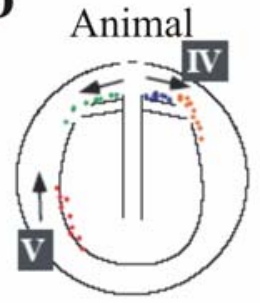

2 somites
E

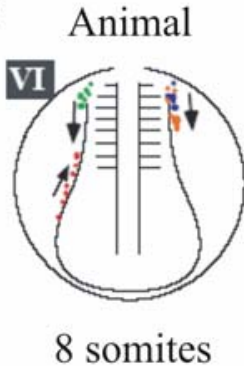

Fig. 1.3 Six steps of early PGC migration in Zebrafish. At the dome stage (A) PGCs locate in four clusters forming a "square" in the animal half of an embryo close to the balstoderm margin. PGC clusters converge dorsally together with somatic cells (step I). At 60\% epiboly (B), they migrate away from the dorsal midline (step II). At 80\% epiboly (C), dorsal PGC clusters align along the anterior border of the trunk mesoderm (step IIIa), when ventral PGCs align along the lateral border of the mesoderm (step IIIb). At the 2-somite stage (D), anterior germ cells migrate laterally and form two lateral clusters (IV), which start to move posteriorly (VI) at 8-somite stage (E). PGCs located ventrally at the 2-somite stage migrate anteriorly $(\mathrm{V})$. This posterior movement of two lateral PGC clusters and anterior migration of trailing germ cells result in positioning of PGC between $8^{\text {th }}$ and $10^{\text {th }}$ somites at $24 \mathrm{hpf}(\mathrm{G})$ (from Weidinger et al., 1999).

The molecular mechanism of PGC migration in Zebrafish was analysed in detail during last five years. During early development zebrafish germ cells undergo three stages of differentiation. Just after specification around $3 \mathrm{hpf}$ cells are simple-shaped and non-motile. Around $3.5 \mathrm{hpf}$ they acquire complicated morphology, express high levels of E-cadherin, but are not polarized and do not respond to the guidance signal. Finally, at $4.5 \mathrm{hpf}$, PGC become competent for directional migration. They are polarized and attracted by a guidance chemokine. This transition to the active migratory phase is accompanied by the start of zygotic transcription in PGCs and down-regulation of E-cadherin levels on the cell surface (Blaser et al., 2005). In addition, this switch from the non-motile behaviour depends on the function of the Dead end protein, found in earlier studies to be crucial for migration and survival of germ cells during later stages of development (Blaser et al., 2005; Weidinger et al., 2003). 
The directional migration of zebrafish PGCs is guided by the chemoattractant signal SDF1a, expressed along the migratory route of germ cells (Doitsidou et al., 2002). SDF-1a binds to the transmembrane receptor CXCR4b (Doitsidou et al., 2002; Knaut et al., 2003), triggering Gprotein- and PI3K-dependent intracellular cascades. G-protein-coupled signalling was found to be essential for the directional migration of PGCs, while the PI3K-cascade modulates cell motility, morphology and stability of filopodia (Dumstrei et al., 2004).

Following the SDF1a guidance cues, zebrafish germ cells switch between apolar "tumbling", when a cell forms protrusion in all direction and is not moving, and "run", when a cell sends protrusions mostly in the direction of migration and is actively moving (ReichmanFried et al., 2004). The molecular mechanism of PGC polarization in response to the guidance signalling was characterized recently by Blaser et al. (2006). The authors propose, that during the tumbling phase a stochastic elevation of calcium levels results in acto-myosin contraction, leading to the local increase in hydrostatic pressure and detachment of the membrane from the cell cortex. The cytoplasmic flow into these regions would cause the formation of a protrusion. The recognition of the guidance signal on one side of the cell would favour stabilization of a protrusion in the direction of migration by local amplification of the $\mathrm{Ca}^{2+}$-influx in this territory. The enhanced calcium signalling at the leading edge of PGCs is maintained during "run" phase by a positive feed-back loop driven by the activation of the CXCR4-receptor (Blaser et al., 2006).

In spite of tight guidance regulation, some PGCs still fail to reach the gonads and can be found in a variety of ectopic positions (Ikenishi et al., 2007). In mouse and Drosophila these cells are eliminated by apoptosis (Boldajipour and Raz, 2007), which is most probably, also true in Xenopus and Zebrafish as well, but the exact mechanism and regulation of this process remains elusive.

\subsubsection{Molecular mechanism of germ cell development and migration in Drosophila}

Germ cells in Drosophila are the first cells to form in the syncytium of an early embryo. Their formation depends on presence and correct localization of specific maternally provided determinants stored in the germ- or pole- plasm, which accumulates at the posterior pole of an oocyte during Drosophila oogenesis (Mahowald et al., 1962). Maternal germ plasm enriched 
components are responsible for localization, protection and translation of maternal mRNAs, the PGC-specific mode of cellularization and germ cell migration (Santos and Lehmann, 2004).

PGCs in Drosophila are formed by budding of a cell membrane around nuclei at the posterior end of an embryo, when they reach the germ plasm region. In contrast to that, somatic cells are formed by the ingrowth of a polarized membrane. Another significant difference between PGCs and somatic cells is transcriptional silencing. Germ cells in the fly lack active RNA polymerase II and methylation of histones, which correlates with transcriptionally active chromatin (Santos and Lehmann, 2004). In addition, three localized mRNAs germ cell-less (gcl), nanos (nos) and polar granule component (pgc) were reported to regulate specification of and transcriptional repression in germ cells (Jongens et al., 1994; Martinho et al., 2004; Wang and Lehmann, 1991).

Specification of germ cells from the somatic cell mass is finished by $2,5 \mathrm{~h}$ after egg laying (AEL). At stage 8 (3.5h AEL) PGCs are found to be adhered to the midgut region (Fig. 1.4). During these developmental stages germ cells to not exhibit significant migratory activity. However, transplantation experiments or interference with the Jak/Stat pathway revealed that these cells are potentially motile (Jaglarz and Howard, 1994; Li et al., 2003).

At stage 9 PGCs start the active migratory phase by transepithelial migration through the midgut. The function of serpent (srp), huckebein (hkb) and trapped-in-endoderm-1 (tre-1) was reported to be crucial for this step. Srp and $k h b$ are involved in dissociation of apical junctions in the epithelium of the posterior midgut. The exact role of the G-protein coupled receptor Tre-1 is not clear so far (Santos and Lehmann, 2004).

After 5h AEL PGCs have passed the midgut epithelium and continue to migrate dorsally. This dorsal direction of cell migration is controlled by chemorepellent Wunen and its homologue Wunen-2, expressed in the ventral- most regions of the posterior midgut (Starz-Gaiano et al., 2001; Zhang et al., 1997). Drosophila Wunens are homologues of mammalian lipid phosphate phosphatase (LPP), which is a transmembrane exoenzyme, hydrolysing phospholipid substrates on the cell surface. The activity of Wunens as chemorepellents can be explained in two ways. On one hand, Wunen-expressing cells can produce germ cell repellent, on the other hand, phosphatase activity of Wunen may deplete the lipid germ cell factor, important for their migration and survival (Renault et al., 2004; Santos and Lehmann, 2004).

During stages 11 and 12 of embryonic development Drosophila germ cells are provided with the guidance signal by 3-Hydroxy-3-Methylglutaryl Coenzyme A (HMGCoAR/Hmgcr) and 
migrate towards the gonadal mesoderm (Van Doren et al., 1998). Mammalian HMGCoAR is an enzyme involved in the synthesis of cholesterol and isoprenoids, suggesting that a germ cell attractant is lipid-modified. In consistency with this hypothesis, mutations in FarnesylDiphosphate Synthase (fpps), Geranylgeranyl-Diphosphate Synthase (quemao) and Geranylgeranyl Transferase type I (GGT1) result in migration defects at these stages of development. One possible candidate signalling molecule with critical lipid modification is Hedgehog, which is activated by the transfer of the cholesterol group. However, PGC migration was not affected by the Smoothened loss-of-function (Santos and Lehmann, 2004). Therefore, the identity of the molecule attracting germ cells to their target regions is yet to be determined.

By stage 12 germ cell associate with clusters of somatic gonadal precursors at the level of parasegments 10 to 12 . PGCs first arrive at the most posterior cluster and then move anteriorly during germ band retraction. Eventually, three clusters of somatic gonadal precursors and germ cells merge and compact into gonads (Santos and Lehmann, 2004). Two genes were reported to have an impact on those morphogenic movements. Fear-of-intimacy (foi) encodes for a transmembrane zink transporter, which might regulate expression of cell adhesion molecules and modulate cell shape changes (Van Doren et al., 2003). Shotgun (stg), which is a fly homologue of E-cadherin, regulates adhesive properties of somatic gonadal precursors (Jenkins et al., 2003).

Recently, Megosh et al. proposed that specification of the Drosophila germ line might be miRNA-dependent (Megosh et al., 2006). The authors provide evidence for PIWI-mediated regulation of Oskar (osk) and Vasa (vas) mRNA localization to the germ plasm, which plays a critical role for the future formation of Drosophila germ cells (Megosh et al., 2006; Williamson and Lehmann, 1996). PIWI is a member of conserved PIWI/Argonaute (AGO) family containing PAZ and PIWI domains as well as bearing RNA-binding activity. PIWI and Aubergine (AUB) were reported to maintain genome stability in the Drosophila germ line (Vagin et al., 2006). However, the direct molecular mechanism linking the PIWI-mediated miRNA pathway and RNA localization is still unknown. 


\section{Stage}

Stage 5
$2.5 \mathrm{~h}$ AEL

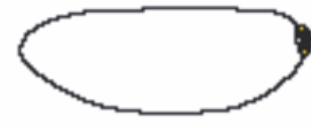

Stage 8

3.5h AEL

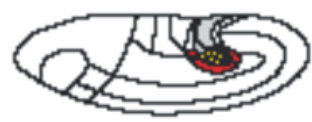

Stage 9

4.5h AEL

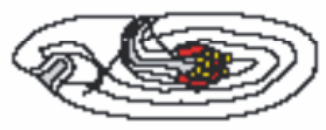

Stage 10

$5 \mathrm{~h}$ AEL

Stage 11

7h AEL
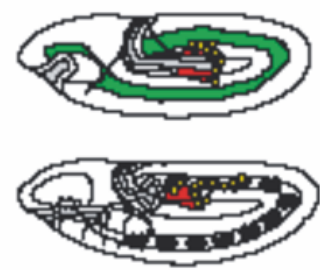

Stage 12

9h AEL

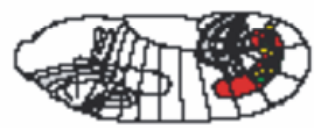

Stage 13

$10.5 \mathrm{~h}$

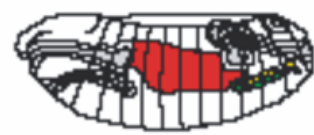

Stage 14

$11.5 \mathrm{~h}$

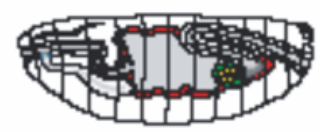

Step

Formation and transcriptional

silencing

Adhesion to

midgut

Transgut

migration

Movement on

midgut

Migration to

mesoderm

Association with gonadal mesoderm

Germ line-soma

alignment

Gonad

coalescence

\section{Genes}

osk, vas, aug, tub, mtlr RNA, gcl, nos, pum, pgc

tre-l, srp, $h k b$

Wun and wun-2

Hmgcr, fpps, quemao, GTTi, tin, zfhl, bryn, slam

Fig. 1.4 PGC migrations in Drosophila: stages and genes involved. Embryos on schematic drawing are positioned with the anterior to the left and dorsal on top. Yellow circles represent germ cells; red - midgut; green - all mesoderm at stage 10 and somatic gonadal precursors from stage 11 onward; blue - male specific gonadal precursors (from Santos and Lehmann, 2004).

\subsubsection{Molecular mechanism of germ cell development and migration in the mouse}

In mice, primordial germ cells are specified between E6.5 and E7.5 from pluripotent precursors of the proximal epiblast (Lawson and Hage, 1994). Grafting experiments suggest that the formation of the germ line in this organism depends on cell signalling during gastrulation and not on the existence of localized maternal determinants.

In search for signals responsible for the induction of PGCs, Lawson et al. (1999) and Ying et al. (2000) identified BMP4 and BMP8b as being crucial for that process. Inactivation of any of 
these genes abolished germ cell formation (Lawson et al., 1999; Ying et al., 2000). In addition, the number of specified PGCs is regulated by BMP2 activity in the visceral ectoderm. Double knock-outs demonstrated, that BMP2 and BMP4 act complementary, when BMP8b does not cooperate with any of them (Ying and Zhao, 2001). What remains unknown until now is the intracellular molecular mechanism inducing PGC specification. According to expression patterns, the most probable candidates for the signal transducers are the Smads 1 and 5, but the receptor complex that could act in the epiblast at these developmental stages was not identified yet (Berekelya, 2005).

Origin and behaviour of PGCs in the mouse was studied by labelling germ cells with a number of molecular markers like SSE1, EpCAM (cell surface molecules) and alkaline phosphatase, as well as by using the transgenic line (Oct-4 $P$ PE:GFP+), where GFP is expressed specifically in PGCs under the control of the truncated Oct-4 promoter (Wylie, 2000). By this means it was defined, that PGCs in mice arise from a common precursor in the posterior primitive streak on the $7^{\text {th }}$ day of development. From there, germ cells migrate ventrally and posteriorly into surrounding tissues (allantois, extraembryonic and embryonic endoderm). After entering the endoderm the germ cells will be incorporated into the hindgut by stage E9.0 and migrate further to gonads, while cell failed to reach the endodermal region by this stage will not contribute to the germ line (Anderson et al., 2000; Lawson and Hage, 1994).

As reviewed by Molyneaux and Wylie, six main stages of PGC behaviour in the mouse can be determined (Fig. 1.5): invasion into the endoderm (described above), migration into the hindgut, migration to the genital ridges, clustering and PGC elimination within the midline structures (Molyneaux and Wylie, 2004).

It is not clear so far, whether the PGC incorporation into the hindgut is an active or a passive process. On one hand, PGCs were found to move around hindgut epithelial cell (stage E9.0), but at stage E8.5 they are round and non-motile, suggesting passive incorporation into the hindgut and re-initiation of motility later on. The morphogenic movements at stages E7.5-8.5 did not allow to directly monitor cell behaviour during this time of development (Molyneaux et al., 2001). 


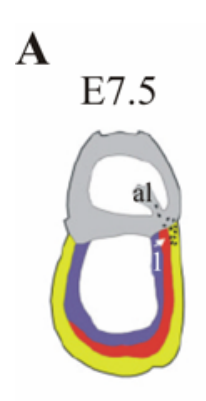

B

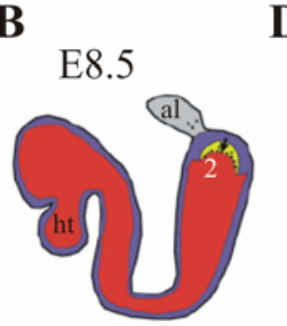

C

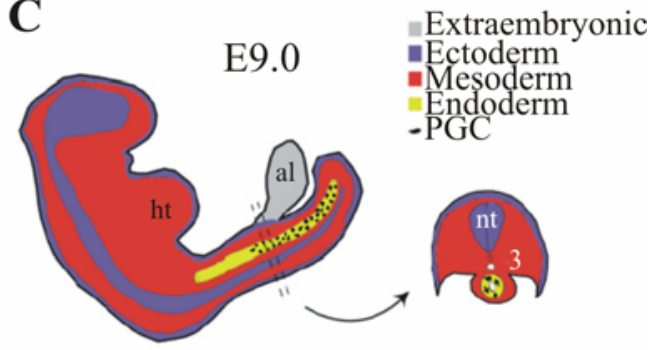

D

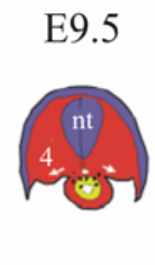

$\mathbf{E}$

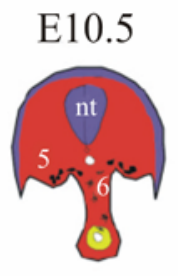

Fig. 1.5 Germ cell migration in the mouse. (A) PGCs are formed in the proximal epiblast. During gastrulation, they migrate through the primitive streak and invade the endoderm and allantois (step 1). (B) PGCs in the definitive endoderm are incorporated into the hindgut pocket (step 2). Some PGCs remain in the allantois. (C) At E9.0, PGCs are confined to the hindgut, but move freely around the cells of the hindgut epithelium (step 3). PGC motility appears random with respect to the body axes at this stage. (D) Between stages E9.0 and E9.5, PGCs exit the dorsal side of the hindgut and migrate towards the developing genital ridges (step 4). (E) At stage E10.5, PGCs begin to cluster by forming a network of migrating cells (step 5). PGCs left in midline structures are eliminated by apoptosis (step 6). By E11.5 most PGCs have colonized the genital ridge. Abbreviations: al- allantois; ht- heart; nt- neural tube. Arrows indicate the net direction of PGC movements (from Molyneaux and Wylie, 2004).

Migration of germ cells within the gut was described as random. Nonetheless, two molecules were found to be involved in the regulation of PGC behaviour and survival during this period. E-cadherin is expressed by the epithelial cells of the hindgut. PGCs do not express this molecule during the migration within the gut. However, elevated levels of E-cadherin on the cell surface later on might facilitate their exit from the gut (Bendel-Stenzel et al., 2000). In addition, interaction of the Steel Factor ligand expressed by gut cells and tyrosin-kinase receptor c-kit on PGCs was found crucial for germ cell colonization, migration and survival in the gut (Molyneaux and Wylie, 2004).

During E9.0-E9.5 of development, mouse PGCs exit the gut, separate into two streams and migrate towards the genital ridges. Based on time-lapse analysis of PGC movement in cultured tissue slices, this step of migration was described as unidirectional (Molyneaux et al., 2001), albeit TGF $\beta$-signalling was shown to stimulate PGC attraction in vitro in serum-free medium. Interaction of stromal-derived factor 1 (SDF1) and CXCR4-receptor on germ cells was shown to be involved in PGC guidance similar to what is described for Zebrafish and chicken 
(Ara et al., 2003; Dumstrei et al., 2004; Molyneaux et al., 2003). Mutations of either SDF1 or CXCR4-receptor reduced the amount of PGCs reaching the gonads. On the other hand, broad expression of SDF1 at these embryonic stages does not explain how exactly it could provide a guidance cue for migrating germ cells. According to one hypothesis, directional migration of PGCs to the gonads and prevention of their attraction by SDF1 to other regions may be regulated by the extracellular matrix (ECM). In line with this, PGCs lacking $\beta 1$-integrin failed to colonize the gonads; however, ectopic wild-type germ cells were still able to find their way to the genital ridges (Anderson et al., 1999; Molyneaux et al., 2004). An additional role of SDF1/CXCR4 interaction was described by Holt et al. (2006), who suggested that SDF1/CXCR4 are necessary to maintain the size and longevity of the primordial follicle pool (Holt et al., 2006).

Interestingly, after exiting the gut, PGCs in the mouse migrate not as single cells, but as a cell-network, where PGCs are connected via long thin protrusions. This networking facilitates formations of PGC clusters at the end of the migratory phase and could be abolished by blocking the activity of E-cadherin (Bendel-Stenzel et al., 2000; Molyneaux and Wylie, 2004). A similar type of migratory behaviour was observed for neural crest cells. In this system the gap-junction protein $\mathrm{Cx} 43$ was vital for cell-to-cell communication and interfered with cell migration (Xu et al., 2001). Mouse $C x 43$ is expressed in germ cells of migratory stages and was found to be downregulated after colonizing the gonads, which could suggest a conserved role for this protein in cell behaviour (Molyneaux et al., 2004).

Another important aspect of proper PGC positioning is elimination of mismigrated germ cells. It was proposed that lagging or mispositioned germ cells in the mouse undergo apoptosis. In line with that, loss of a pro-apoptotic Bgl-2-family member Bax could rescue ectopic PGCs in the hindgut mesentery and midline of the body wall (Molyneaux et al., 2001; Stallock et al., 2003). Application of leukaemia inhibiting factor (LIF), FGF2 and Steel can support PGC survival in culture. In vivo the role of LIF in the context of PGC survival and migration was not characterized so far. Steel-kit interaction is crucial for PGC survival and migration in vitro and in vivo (as discussed above) (De Felici, 2000). Two types of FGF receptors (FGFR-IIIb and FGFRIIIC) were found to be expressed in PGCs at stage E10.5. In vivo functional studies confirmed the importance of FGF2 activity (the ligand for FGFR-IIIc) for PGC motility and FGF7-signalling (the ligand for FGFR-IIIb) for germ cell maintenance (Takeuchi et al., 2005).

Taken together, proper positioning of germ cells might include not only directional guidance but also selective survival of correctly migrating cells and elimination of mispositioned 
ones. This could be controlled by localization of survival factors along the migratory route and their exclusion from other regions. A similar mechanism was suggested for germ cell positioning in Drosophila and might, therefore, be evolutionary conserved (Boldajipour and Raz, 2007).

\subsubsection{Germ cells development and migration in the chicken}

Studies of avian germ cell development and migration are mainly performed in chicken embryos, where PGCs originate from the central zone of area pellucida of the epiblast. Subsequently, PGCs translocate to the extra-embryonic region referred as germinal crescent (Swift, 1914). The migration of germ cells to the gonadal region occurs in two steps. First, PGCs are incorporated into the vascular network (Hamburger and Hamilton (1951) stage 8) and circulate in the blood stream (HH 11) (Hamburger, 1951). As a second step, germ cells leave the vascular system and actively migrate into the gonadal anlage (HH 15-29) (Nieuwkoop and Sutasurya, 1976; Petitte et al., 1997).

The mechanism of PGC migration during the first migratory phase (before HH 11) has not been revealed so far. Grafting experiments, with quail genital ridges transplanted into chicken embryos behind the optic vesicle, revealed that chicken germ cells are able to colonize these ectopic gonads. This suggests existence of an unknown attractant guiding PGC migration already at the early developmental stages.

Directional PGC migration to the gonads after extravasation was reported to be regulated by SDF-1 $\alpha /$ CXCR12-signalling (Stebler et al., 2004). Nevertheless, early germ cells (before stage $\mathrm{HH}$ 11) were not responsive to SDF1-attraction. Therefore, a signalling molecule, responsible for the early steps of PGC migration as well as for the ectopic PGC positioning in the head (Nakamura et al., 1988), still needs to be identified. Taking into account similar observations in mice, where PGCs were attracted by SDF-signalling also only at later stages of migration (Molyneaux et al., 2003; Stebler et al., 2004), it would be interesting to find out whether a common mechanism exists as well for the early phases of PGC positioning in these two organisms. 


\subsection{Aims}

Vegetal localization of mRNA in the Xenopus oocytes is important for future embryonic patterning and formation of the germ line. In our lab, the microarray-based screening for novel vegetally localized transcripts was performed, and 55 novel mRNAs were identified (Horvay et al., 2006). Further investigation of two of these transcripts ( $x G R I P 2.1$ and $x K I F 13 B$ ) was the topic of this work.

mRNA localization is a complex multistep process exact mechanism of which is poorly understood. Majority of studies on vegetal localization in Xenopus broaden our knowledge about the localization machinery operating at later stages of oogenesis. For the early mRNA localization (during stages I to II of oogenesis) the diffusion-entrapment model was suggested (Chang et al., 2004), but the precise mRNA sequences and protein complexes responsible for the enrichment of these mRNAs in the proper region of the cell are largely unknown. Studying vegetal localization of individual mRNAs would, on one hand, widen our knowledge about the function of the given transcripts; on the other hand, systematic analysis of the data obtained from the representative set of individual mRNAs would promote general understanding of this process. Therefore, in the first part of the work, we aimed to find out the minimal sequence necessary and sufficient for the localization of XGRIP2.1 mRNA and assign its protein binding pattern.

The early localization of the given mRNAs during oogenesis and specific expression in germ plasm/ germ cells later throughout embryogenesis argued for their possible involvement in the germ line development. Thus, functional characterization of both transcripts in scopes of PGC specification and migration was the central goal of the thesis.

The molecular mechanism of germ cells migration in Xenopus is studied over 30 years but is far from complete insight. The large part of the work was devoted for the establishment of the conditions for the in vivo imaging of PGC migration in the context of the whole embryo and in culture. 


\section{Materials}

\subsection{Model organism}

In vivo experiments of the given work were done in oocytes and embryos of African clawed frogs Xenopus leavis (Pipidae, Anura). Pigmented and albino animals were ordered from Dipl.-Ing. Hoest Kähler (Hamburg), Xenopus I (Ann Arbor, USA) and Nasco (Ft. Atkinson, USA).

\subsection{Bacteria and cDNA-library}

\subsubsection{Bacteria}

The following genotypes of E. coli were used:

XL1-Blue: RecA1, endA1, gyrA96, thi-1, hsdR17, supE44, relA1, lac[F'proAB, $\left.\operatorname{lacI}^{\mathrm{q}} \mathrm{Z} \Delta \mathrm{M} 15, \operatorname{Tn} 10\left(\operatorname{Tet}^{\mathrm{r}}\right)\right]^{\mathrm{c}}$. (Stratagene);

BL21(DE3): E.coli B F', dcm, ompT, hsdS(r $\left.\mathrm{r}_{\mathrm{B}^{-}} \mathrm{m}_{\mathrm{B}^{-}}\right)$, gal $\mathbf{k}(\mathrm{DE} 3)$ (Staratagene)

\subsection{2. cDNA-library}

The cDNA library enriched in vegetally localizing sequences (Horvay et al., 2006) was used to amplify the full-length XGRIP2.1 and partial XKIF13B cDNAs. 


\subsection{Constructs and Oligonucleotides}

\subsubsection{Vectors}

1. pGEM-T / pGEM-T easy (Promega) - subcloning vectors;

2. pBKCMV lacZ (Claussen et al., 2004) - the expression vector, contains the LacZ-tag, used for LE mapping experiments;

2. pCS2+ (Rupp et al., 1994) - the expression vector, contains SV40 viral polyadenylation signal;

3. pCS2+DELE - the expression vector based on pCS2+ with the XDead end localization element cDNA (Horvay et al., 2006) cloned into XhoI/ SnaBI sites;

4. mycGFPpCS2+ (Klisch et al., 2006) - the expression vector with a myc-tag cloned $\mathrm{N}$ terminally in frame with the GFP ORF;

5. mycGFPpCS2+polyA (Koch, unpublished) - the expression vector with a myc-tag cloned N-terminally in frame with the GFP ORF and poly A stretch in stead of original SV40 polyadenylation signal;

6. EGFP pCS2+DELE - the expression vector containing the EGFP ORF and the XDead end localization element cDNA (Horvay et al., 2006) cloned into XhoI/ SnaBI sites;

7. fEGFP pCS2+DELE - the expression vector containing the farnesylated EGFP ORF and the XDead end localization element cDNA (Horvay et al., 2006) cloned into XhoI/ SnaBI sites;

8. fpd2EGFP pCS2+DELE - the expression vector containing the farnesylated ORF of the short-leaving GFP-version and the XDead end localization element cDNA (Horvay et al., 2006) cloned into XhoI/ SnaBI sites.

\subsubsection{Constructs}

Table 2.1. Functional characterization of XGRIP2.1

\begin{tabular}{|c|c|c|c|c|c|c|}
\hline \multirow{2}{*}{ Construct name } & \multirow{2}{*}{ Insert } & \multirow{2}{*}{ Vector } & \multirow{2}{*}{$\begin{array}{l}\text { Cloning } \\
\text { sites }\end{array}$} & \multicolumn{3}{|c|}{ Transcription } \\
\hline & & & & CUT & POLY & DIRECTION \\
\hline $\begin{array}{l}\text { XGRIP2.1 3'UTR } \\
\text { +ORF pCS2+FLAG }\end{array}$ & XGRIP2.1 ORF+3'UTR & $\mathrm{pCS} 2+\mathrm{FLAG}$ & $\begin{array}{l}\text { SalI/ } \\
\text { XbaI }\end{array}$ & $\begin{array}{l}\text { NotI } \\
\text { SalI }\end{array}$ & $\begin{array}{l}\text { Sp6 } \\
\text { T7 }\end{array}$ & $\begin{array}{l}\text { sense } \\
\text { antisense }\end{array}$ \\
\hline XGRIP2.1 ORF $\Delta$ Stop & $\begin{array}{l}\text { XGRIP2.1 ORF } \Delta \text { Stop } \\
\text { codon }\end{array}$ & $\mathrm{pCS} 2+$ & $\begin{array}{l}\text { SalI/ } \\
\text { XhoI }\end{array}$ & $\begin{array}{l}\text { NotI } \\
\text { SalI }\end{array}$ & $\begin{array}{l}\text { Sp6 } \\
\text { T7 }\end{array}$ & $\begin{array}{c}\text { sense } \\
\text { antisense }\end{array}$ \\
\hline XGRIP2.1 ORF & XGRIP2.1 ORF & pGEM-T & & NotI & $\mathrm{T} 7$ & sense \\
\hline
\end{tabular}




\begin{tabular}{|c|c|c|c|c|c|c|}
\hline \multirow{2}{*}{ Construct name } & \multirow{2}{*}{ Insert } & \multirow{2}{*}{ Vector } & \multirow{2}{*}{$\begin{array}{l}\text { Cloning } \\
\text { sites }\end{array}$} & \multicolumn{3}{|c|}{ Transcription } \\
\hline & & & & CUT & POLY & DIRECTION \\
\hline pGEM-T & & & & SphI & Sp6 & antisense \\
\hline $\begin{array}{l}\text { XGRIP2.1 ORF } \\
\text { pCS2+DELE }\end{array}$ & XGRIP2.1 ORF & $\mathrm{pCS} 2+\mathrm{DELE}$ & $\begin{array}{l}\text { SalI/ } \\
\text { XhoI }\end{array}$ & $\begin{array}{l}\text { NotI } \\
\text { HindIII }\end{array}$ & $\begin{array}{c}\text { Sp6 } \\
\text { T3 }\end{array}$ & $\begin{array}{c}\text { sense } \\
\text { antisense }\end{array}$ \\
\hline $\begin{array}{l}\text { mycGFPXGRIP2.1ORF } \\
\text { pCS2+polyA }\end{array}$ & mycGFPXGRIP2.1ORF & pCS2+polyA & $\begin{array}{l}\text { EcoRI/ } \\
\text { NotI }\end{array}$ & $\begin{array}{l}\text { NotI } \\
\text { ClaI }\end{array}$ & $\begin{array}{l}\text { Sp6 } \\
\text { T3 }\end{array}$ & $\begin{array}{c}\text { sense } \\
\text { antisense }\end{array}$ \\
\hline $\begin{array}{l}\text { mycGFPXGRIP2.1ORF } \\
\text { pCS2+DELE }\end{array}$ & mycGFPXGRIP2.1ORF & pCS2+DELE & $\begin{array}{l}\text { HindIII/ } \\
\text { XhoI }\end{array}$ & $\begin{array}{l}\text { NotI } \\
\text { HindIII } \\
\end{array}$ & $\begin{array}{c}\text { Sp6 } \\
\text { T3 } \\
\end{array}$ & $\begin{array}{c}\text { sense } \\
\text { antisense } \\
\end{array}$ \\
\hline $\begin{array}{l}\text { XGRIP2.1 ORF } \\
\text { pMal-c2x }\end{array}$ & XGRIP2.1 ORF & pMal-c $2 x$ & $\begin{array}{l}\text { SalI/ } \\
\text { XhoI }\end{array}$ & & & \\
\hline $\begin{array}{l}\text { XGRIP2.1 DN PDZ123 } \\
\text { pCS2+DELE }\end{array}$ & XGRIP2.1 PDZ123 & pCS2+DELE & $\begin{array}{l}\text { StuI/ } \\
\text { XhoI }\end{array}$ & $\begin{array}{l}\text { NotI } \\
\text { StuI }\end{array}$ & $\begin{array}{l}\text { Sp6 } \\
\text { T3 }\end{array}$ & $\begin{array}{c}\text { sense } \\
\text { antisense }\end{array}$ \\
\hline $\begin{array}{l}\text { XGRIP2.1 DN PDZ234 } \\
\text { pCS2+DELE }\end{array}$ & XGRIP2.1 PDZ234 & $\mathrm{pCS} 2+\mathrm{DELE}$ & $\begin{array}{l}\text { StuI/ } \\
\text { XhoI }\end{array}$ & $\begin{array}{l}\text { NotI } \\
\text { StuI }\end{array}$ & $\begin{array}{l}\text { Sp6 } \\
\text { T3 }\end{array}$ & $\begin{array}{c}\text { sense } \\
\text { antisense }\end{array}$ \\
\hline $\begin{array}{l}\text { XGRIP2.1 DN PDZ345 } \\
\text { pCS2+DELE }\end{array}$ & XGRIP2.1 PDZ345 & $\mathrm{pCS} 2+\mathrm{DELE}$ & $\begin{array}{l}\text { StuI/ } \\
\text { XhoI }\end{array}$ & $\begin{array}{l}\text { NotI } \\
\text { StuI }\end{array}$ & $\begin{array}{l}\text { Sp6 } \\
\text { T3 }\end{array}$ & $\begin{array}{c}\text { sense } \\
\text { antisense }\end{array}$ \\
\hline $\begin{array}{l}\text { XGRIP2.1 DN PDZ456 } \\
\text { pCS2+DELE }\end{array}$ & XGRIP2.1 PDZ456 & $\mathrm{pCS} 2+\mathrm{DELE}$ & $\begin{array}{l}\text { ClaI/ } \\
\text { XhoI }\end{array}$ & $\begin{array}{l}\text { NotI } \\
\text { ClaI }\end{array}$ & $\begin{array}{l}\text { Sp6 } \\
\text { T3 }\end{array}$ & $\begin{array}{c}\text { sense } \\
\text { antisense }\end{array}$ \\
\hline $\begin{array}{l}\text { XGRIP2.1 DN PDZ567 } \\
\text { pCS2+DELE }\end{array}$ & XGRIP2.1 PDZ567 & pCS2+DELE & $\begin{array}{l}\text { ClaI/ } \\
\text { XhoI }\end{array}$ & $\begin{array}{l}\text { NotI } \\
\text { ClaI }\end{array}$ & $\begin{array}{l}\text { Sp6 } \\
\text { T3 }\end{array}$ & $\begin{array}{c}\text { sense } \\
\text { antisense }\end{array}$ \\
\hline $\begin{array}{l}\text { XGRIP2.1 DN PDZ12 } \\
\text { pCS2+DELE }\end{array}$ & XGRIP2.1 PDZ12 & $\mathrm{pCS} 2+\mathrm{DELE}$ & $\begin{array}{l}\text { ClaI/ } \\
\text { XhoI }\end{array}$ & $\begin{array}{l}\text { NotI } \\
\text { ClaI }\end{array}$ & $\begin{array}{l}\text { Sp6 } \\
\text { T3 }\end{array}$ & $\begin{array}{c}\text { sense } \\
\text { antisense }\end{array}$ \\
\hline $\begin{array}{l}\text { XGRIP2.1 DN PDZ23 } \\
\text { pCS2+DELE }\end{array}$ & XGRIP2.1 PDZ23 & $\mathrm{pCS} 2+\mathrm{DELE}$ & $\begin{array}{l}\text { StuI/ } \\
\text { XhoI }\end{array}$ & $\begin{array}{l}\text { NotI } \\
\text { StuI }\end{array}$ & $\begin{array}{l}\text { Sp6 } \\
\text { T3 }\end{array}$ & $\begin{array}{c}\text { sense } \\
\text { antisense }\end{array}$ \\
\hline $\begin{array}{l}\text { XGRIP2.1 DN PDZ34 } \\
\text { pCS2+DELE }\end{array}$ & XGRIP2.1 PDZ34 & $\mathrm{pCS} 2+\mathrm{DELE}$ & $\begin{array}{l}\text { StuI/ } \\
\text { XhoI }\end{array}$ & $\begin{array}{l}\text { NotI } \\
\text { StuI }\end{array}$ & $\begin{array}{l}\text { Sp6 } \\
\text { T3 }\end{array}$ & $\begin{array}{c}\text { sense } \\
\text { antisense }\end{array}$ \\
\hline $\begin{array}{l}\text { XGRIP2.1 DN PDZ45 } \\
\text { pCS2+DELE }\end{array}$ & XGRIP2.1 PDZ45 & $\mathrm{pCS} 2+\mathrm{DELE}$ & $\begin{array}{l}\text { ClaI/ } \\
\text { XhoI }\end{array}$ & $\begin{array}{l}\text { NotI } \\
\text { ClaI } \\
\end{array}$ & $\begin{array}{l}\text { Sp6 } \\
\text { T3 }\end{array}$ & $\begin{array}{c}\text { sense } \\
\text { antisense }\end{array}$ \\
\hline $\begin{array}{l}\text { XGRIP2.1 DN PDZ56 } \\
\text { pCS2+DELE }\end{array}$ & XGRIP2.1 PDZ56 & $\mathrm{pCS} 2+\mathrm{DELE}$ & $\begin{array}{l}\text { ClaI/ } \\
\text { XhoI }\end{array}$ & $\begin{array}{l}\text { NotI } \\
\text { ClaI }\end{array}$ & $\begin{array}{l}\text { Sp6 } \\
\text { T3 }\end{array}$ & $\begin{array}{c}\text { sense } \\
\text { antisense }\end{array}$ \\
\hline $\begin{array}{l}\text { XGRIP2.1 DN PDZ67 } \\
\text { pCS2+DELE }\end{array}$ & XGRIP2.1 PDZ67 & $\mathrm{pCS} 2+\mathrm{DELE}$ & $\begin{array}{l}\text { ClaI/ } \\
\text { XhoI }\end{array}$ & $\begin{array}{l}\text { NotI } \\
\text { ClaI } \\
\end{array}$ & $\begin{array}{l}\text { Sp6 } \\
\text { T3 }\end{array}$ & $\begin{array}{c}\text { sense } \\
\text { antisense } \\
\end{array}$ \\
\hline $\begin{array}{l}\text { XGRIP2.1ORFSRSmut } \\
\text { pCS2+DELE }\end{array}$ & XGRIP2.1ORFSRSmut & $\mathrm{pCS} 2+\mathrm{DELE}$ & $\begin{array}{l}\text { SalI/ } \\
\text { XhoI }\end{array}$ & $\begin{array}{l}\text { NotI } \\
\text { HindIII }\end{array}$ & $\begin{array}{c}\text { Sp6 } \\
\text { T3 } \\
\end{array}$ & $\begin{array}{c}\text { sense } \\
\text { antisense }\end{array}$ \\
\hline $\begin{array}{l}\text { XGRIP2.1ORF } \triangle \mathrm{PDZ} 2 \\
\text { pCS2+DELE }\end{array}$ & XGRIP2.1ORFAPDZ2 & pCS2+DELE & $\begin{array}{l}\text { SalI/ } \\
\text { XhoI }\end{array}$ & $\begin{array}{l}\text { NotI } \\
\text { HindIII }\end{array}$ & $\begin{array}{c}\text { Sp6 } \\
\text { T3 } \\
\end{array}$ & $\begin{array}{c}\text { sense } \\
\text { antisense }\end{array}$ \\
\hline $\begin{array}{l}\text { XGRIP2.1ORF } \triangle \mathrm{PDZ} 3 \\
\text { pCS2+DELE }\end{array}$ & XGRIP2.1ORF $\triangle \mathrm{PDZ} 3$ & pCS2+DELE & $\begin{array}{l}\text { SalI/ } \\
\text { XhoI }\end{array}$ & $\begin{array}{l}\text { NotI } \\
\text { HindIII } \\
\end{array}$ & $\begin{array}{c}\text { Sp6 } \\
\text { T3 } \\
\end{array}$ & $\begin{array}{c}\text { sense } \\
\text { antisense }\end{array}$ \\
\hline $\begin{array}{l}\text { XGRIP2.1ORF } \triangle \text { PDZ23 } \\
\text { pCS2+DELE }\end{array}$ & XGRIP2.1ORFAPDZ23 & $\mathrm{pCS} 2+\mathrm{DELE}$ & $\begin{array}{l}\text { SalI/ } \\
\text { XhoI }\end{array}$ & $\begin{array}{l}\text { NotI } \\
\text { HindIII }\end{array}$ & $\begin{array}{c}\text { Sp6 } \\
\text { T3 }\end{array}$ & $\begin{array}{c}\text { sense } \\
\text { antisense }\end{array}$ \\
\hline $\begin{array}{l}\text { XGRIP2.1 DN PDZ23 } \\
\text { SRSmut pCS2+DELE }\end{array}$ & $\begin{array}{l}\text { XGRIP2.1 DN PDZ23 } \\
\text { SRSmut }\end{array}$ & $\mathrm{pCS} 2+\mathrm{DELE}$ & $\begin{array}{l}\text { StuI/ } \\
\text { XhoI }\end{array}$ & $\begin{array}{l}\text { NotI } \\
\text { StuI }\end{array}$ & $\begin{array}{l}\text { Sp6 } \\
\text { T3 }\end{array}$ & $\begin{array}{c}\text { sense } \\
\text { antisense }\end{array}$ \\
\hline $\begin{array}{l}\text { XGRIP2.1 DN PDZ23 } \\
\text { Del pCS2+DELE }\end{array}$ & $\begin{array}{l}\text { XGRIP2.1 DN PDZ23 } \\
\text { Del }\end{array}$ & $\mathrm{pCS} 2+\mathrm{DELE}$ & $\begin{array}{l}\text { StuI/ } \\
\text { XhoI }\end{array}$ & $\begin{array}{l}\text { NotI } \\
\text { StuI } \\
\end{array}$ & $\begin{array}{l}\text { Sp6 } \\
\text { T3 }\end{array}$ & $\begin{array}{c}\text { sense } \\
\text { antisense } \\
\end{array}$ \\
\hline $\begin{array}{l}\text { XGRIP2.1 5'UTR } \\
\text { mycGFPpCS2+ }\end{array}$ & XGRIP2.1 5'UTR & mycGFPpCS2+ & BamHI & $\begin{array}{l}\text { NotI } \\
\text { HindIII }\end{array}$ & $\begin{array}{c}\text { Sp6 } \\
\text { T3 } \\
\end{array}$ & $\begin{array}{c}\text { sense } \\
\text { antisense } \\
\end{array}$ \\
\hline $\begin{array}{l}\text { XGRIP2.1 5'UTRmut1 } \\
\text { mycGFPpCS2+ }\end{array}$ & XGRIP2.1 5'UTRmut1 & mycGFPpCS2+ & BamHI & $\begin{array}{l}\text { NotI } \\
\text { HindIII }\end{array}$ & $\begin{array}{c}\text { Sp6 } \\
\text { T3 } \\
\end{array}$ & $\begin{array}{c}\text { sense } \\
\text { antisense }\end{array}$ \\
\hline $\begin{array}{l}\text { XGRIP2.1 5'UTRmut2 } \\
\text { mycGFPpCS2+ }\end{array}$ & XGRIP2.1 5'UTRmut2 & mycGFPpCS2+ & BamHI & $\begin{array}{l}\text { NotI } \\
\text { HindIII }\end{array}$ & $\begin{array}{c}\text { Sp6 } \\
\text { T3 } \\
\end{array}$ & $\begin{array}{c}\text { sense } \\
\text { antisense }\end{array}$ \\
\hline
\end{tabular}


Table 2.2. Mapping of the XGRIP2.1 localization element

\begin{tabular}{|c|c|c|c|c|c|c|}
\hline \multirow{2}{*}{ Construct name } & \multirow{2}{*}{ Insert } & \multirow{2}{*}{ Vector } & \multirow{2}{*}{$\begin{array}{l}\text { Cloning } \\
\text { sites }\end{array}$} & \multicolumn{3}{|c|}{ Transcription } \\
\hline & & & & CUT & POLY & DIRECTION \\
\hline $\begin{array}{l}\text { XGRIP2.13'UTR pBK- } \\
\text { CMV LacZ }\end{array}$ & XGRIP2.1 3'UTR & $\begin{array}{l}\text { pBK- } \\
\text { CMV LacZ }\end{array}$ & $\begin{array}{l}\text { SmaI/ } \\
\text { NotI }\end{array}$ & $\begin{array}{l}\text { KpnI } \\
\text { SacI }\end{array}$ & $\begin{array}{l}\text { T3 } \\
\text { T7 }\end{array}$ & $\begin{array}{l}\text { sense } \\
\text { antisense }\end{array}$ \\
\hline $\begin{array}{l}\text { XGRIP2.1 3'UTR } \\
\text { pGEM-T }\end{array}$ & XGRIP2.1 3'UTR & pGEM-T & & $\begin{array}{l}\text { ApaI } \\
\text { NotI }\end{array}$ & $\begin{array}{l}\text { Sp6 } \\
\text { T7 }\end{array}$ & $\begin{array}{c}\text { sense } \\
\text { antisense }\end{array}$ \\
\hline $\begin{array}{l}\text { XGRIP2.1 5'UTR+ORF } \\
\text { pBK-CMV_LacZ }\end{array}$ & $\begin{array}{l}\text { XGRIP2.1 5'UTR+ } \\
\text { ORF }\end{array}$ & $\begin{array}{l}\text { pBK- } \\
\text { CMV_LacZ }\end{array}$ & $\begin{array}{c}\text { ApaI/ } \\
\text { NotI }\end{array}$ & $\begin{array}{l}\text { KpnI } \\
\text { SacI }\end{array}$ & $\begin{array}{l}\text { T3 } \\
\text { T7 }\end{array}$ & $\begin{array}{c}\text { sense } \\
\text { antisense }\end{array}$ \\
\hline $\begin{array}{l}\text { XGRIP2.13'UTR_A } \\
\text { pBK-CMV_LacZ }\end{array}$ & $\begin{array}{l}\text { XGRIP2.1 3'UTR_A } \\
\text { (nt 4374-4994) }\end{array}$ & $\begin{array}{l}\text { pBK- } \\
\text { CMV_LacZ }\end{array}$ & $\begin{array}{l}\text { EcoRI/ } \\
\text { NotI }\end{array}$ & $\begin{array}{l}\text { KpnI } \\
\text { SacI }\end{array}$ & $\begin{array}{l}\text { T3 } \\
\text { T7 }\end{array}$ & $\begin{array}{c}\text { sense } \\
\text { antisense }\end{array}$ \\
\hline $\begin{array}{l}\text { XGRIP2.1 3'UTR_A } \\
\text { pGEM-T }\end{array}$ & $\begin{array}{l}\text { XGRIP2.1 3'UTR_A } \\
\text { (nt 4374-4994) }\end{array}$ & pGEM-T & & $\begin{array}{l}\text { ApaI } \\
\text { NotI }\end{array}$ & $\begin{array}{l}\text { Sp6 } \\
\text { T7 }\end{array}$ & $\begin{array}{c}\text { sense } \\
\text { antisense }\end{array}$ \\
\hline $\begin{array}{l}\text { XGRIP2.1 3'UTR_B } \\
\text { pBK-CMV_LacZ }\end{array}$ & $\begin{array}{l}\text { XGRIP2.1 3'UTR_B } \\
\text { (nt 3376-4376) }\end{array}$ & $\begin{array}{l}\mathrm{pBK}- \\
\mathrm{CMV} \text { LacZ }\end{array}$ & $\begin{array}{l}\text { EcoRI/ } \\
\text { NotI }\end{array}$ & $\begin{array}{l}\text { KpnI } \\
\text { SacI }\end{array}$ & $\begin{array}{l}\text { T3 } \\
\text { T7 }\end{array}$ & $\begin{array}{c}\text { sense } \\
\text { antisense }\end{array}$ \\
\hline $\begin{array}{l}\text { XGRIP2.1 3'UTR_B } \\
\text { pGEM-T }\end{array}$ & $\begin{array}{l}\text { XGRIP2.1 3'UTR_B } \\
\text { (nt 3376-4376) }\end{array}$ & pGEM-T & & $\begin{array}{l}\text { NotI } \\
\text { ApaI }\end{array}$ & $\begin{array}{l}\text { T7 } \\
\text { Sp6 }\end{array}$ & $\begin{array}{l}\text { sense } \\
\text { antisense }\end{array}$ \\
\hline $\begin{array}{l}\text { XGRIP2.1 3'UTR_B1 } \\
\text { pGEM-T }\end{array}$ & $\begin{array}{l}\text { XGRIP2.1 3’UTR_B1 } \\
\text { (nt 3376-3840) }\end{array}$ & pGEM-T & & $\begin{array}{l}\text { NotI } \\
\text { ApaI }\end{array}$ & $\begin{array}{l}\text { T7 } \\
\text { Sp6 }\end{array}$ & $\begin{array}{l}\text { sense } \\
\text { antisense }\end{array}$ \\
\hline $\begin{array}{l}\text { XGRIP2.1 3'UTR_B2 } \\
\text { pGEM-T }\end{array}$ & $\begin{array}{l}\text { XGRIP2.1 3’UTR_B2 } \\
\text { (nt 3734-4169) }\end{array}$ & pGEM-T & & $\begin{array}{l}\text { NotI } \\
\text { ApaI }\end{array}$ & $\begin{array}{l}\text { T7 } \\
\text { Sp6 }\end{array}$ & $\begin{array}{l}\text { sense } \\
\text { antisense }\end{array}$ \\
\hline $\begin{array}{l}\text { XGRIP2.1 3'UTR_B3 } \\
\text { pGEM-T }\end{array}$ & $\begin{array}{l}\text { XGRIP2.1 3'UTR_B3 } \\
\text { (nt 4033-4376) }\end{array}$ & pGEM-T & & $\begin{array}{l}\text { NotI } \\
\text { ApaI }\end{array}$ & $\begin{array}{l}\text { T7 } \\
\text { Sp6 }\end{array}$ & $\begin{array}{l}\text { sense } \\
\text { antisense }\end{array}$ \\
\hline $\begin{array}{l}\text { XGRIP2.1 3'UTR_B2_1 } \\
\text { pGEM-T }\end{array}$ & $\begin{array}{l}\text { XGRIP2.1 } \\
\text { 3'UTR_B2_1 (nt 3730- } \\
\text { 3880) }\end{array}$ & pGEM-T & & $\begin{array}{l}\text { NotI } \\
\text { ApaI }\end{array}$ & $\begin{array}{l}\text { T7 } \\
\text { Sp6 }\end{array}$ & $\begin{array}{l}\text { sense } \\
\text { antisense }\end{array}$ \\
\hline $\begin{array}{l}\text { XGRIP2.13'UTR_B2_2 } \\
\text { (LE) pGEM-T }\end{array}$ & $\begin{array}{l}\text { XGRIP2.1 } \\
\text { 3'UTR_B2 2 } \\
\text { (LE) (nt 3875-4084) }\end{array}$ & pGEM-T & & $\begin{array}{l}\text { NotI } \\
\text { ApaI }\end{array}$ & $\begin{array}{l}\text { T7 } \\
\text { Sp6 }\end{array}$ & $\begin{array}{l}\text { sense } \\
\text { antisense }\end{array}$ \\
\hline $\begin{array}{l}\text { XGRIP2.13'UTR_B2_3 } \\
\text { pGEM-T }\end{array}$ & $\begin{array}{l}\text { XGRIP2.1 } \\
\text { 3’UTR_B2_3 } \\
\text { (nt 4067-4164) } \\
\end{array}$ & pGEM-T & & $\begin{array}{l}\text { AatII } \\
\text { NotI }\end{array}$ & $\begin{array}{l}\text { Sp6 } \\
\text { T7 }\end{array}$ & $\begin{array}{l}\text { sense } \\
\text { antisense }\end{array}$ \\
\hline $\begin{array}{l}\text { XGRIP2.13'UTRALE } \\
\text { pBK_CMV_LacZ }\end{array}$ & $\begin{array}{l}\text { XGRIP2.1 3'UTRALE } \\
\text { (3'UTR del nt 4033- } \\
\text { 4084) }\end{array}$ & $\begin{array}{l}\text { pBK- } \\
\text { CMV_LacZ }\end{array}$ & $\begin{array}{l}\text { SmaI/ } \\
\text { EcoRI }\end{array}$ & $\begin{array}{l}\text { KpnI } \\
\text { SacI }\end{array}$ & $\begin{array}{l}\text { T3 } \\
\text { T7 }\end{array}$ & $\begin{array}{l}\text { sense } \\
\text { antisense }\end{array}$ \\
\hline $\begin{array}{l}\text { XGRIP2.13'UTR_B2_2 } \\
\text { pBK_CMV_LacZ }\end{array}$ & $\begin{array}{l}\text { XGRIP2.1 } \\
\text { 3'UTR_B2 } 2 \\
\text { (LE) (nt 3875-4084) }\end{array}$ & $\begin{array}{l}\text { pBK- } \\
\text { CMV_LacZ }\end{array}$ & $\begin{array}{l}\text { ApaI/ } \\
\text { NotI }\end{array}$ & $\begin{array}{l}\text { KpnI } \\
\text { SacI }\end{array}$ & $\begin{array}{l}\mathrm{T} 3 \\
\mathrm{~T} 7\end{array}$ & $\begin{array}{l}\text { antisense } \\
\text { sense }\end{array}$ \\
\hline
\end{tabular}

Table 2.3. Functional characterization of xKIF13B

\begin{tabular}{|c|c|c|c|c|c|c|}
\hline \multirow{2}{*}{ Construct name } & \multirow{2}{*}{ Insert } & \multirow{2}{*}{ Vector } & \multirow{2}{*}{ Cloning sites } & \multicolumn{3}{|c|}{ Transcription } \\
\hline & & & & CUT & POLY & DIRECTION \\
\hline $\begin{array}{l}\text { xKIF13B } 500 \text { bp ORF } \\
\text { pGEM-T }\end{array}$ & $\begin{array}{l}\text { xKIF13B } 500 \\
\text { bp ORF }\end{array}$ & pGEM-T & & $\begin{array}{l}\text { AatII } \\
\text { NotI }\end{array}$ & $\begin{array}{c}\text { Sp6 } \\
\text { T7 }\end{array}$ & $\begin{array}{c}\text { sense } \\
\text { antisense }\end{array}$ \\
\hline $\begin{array}{l}\text { xKIF13B 5'UTR } \\
\text { mycGFPpCS2+ }\end{array}$ & $\begin{array}{l}\mathrm{xKIF} 13 \mathrm{~B} \\
5, \mathrm{UTR} \\
\end{array}$ & mycGFPpCS2+ & BamHI & $\begin{array}{l}\text { NotI } \\
\text { HindIII } \\
\end{array}$ & $\begin{array}{l}\text { Sp6 } \\
\text { T3 }\end{array}$ & $\begin{array}{c}\text { sense } \\
\text { antisense }\end{array}$ \\
\hline $\begin{array}{l}\text { xKIF13B 5'UTRmut } \\
\text { mycGFPpCS2+ }\end{array}$ & $\begin{array}{l}\text { xKIF13B } \\
\text { 5'UTRmut }\end{array}$ & mycGFPpCS2+ & BamHI & $\begin{array}{l}\text { NotI } \\
\text { HindIII }\end{array}$ & $\begin{array}{l}\text { Sp6 } \\
\text { T3 }\end{array}$ & $\begin{array}{c}\text { sense } \\
\text { antisense }\end{array}$ \\
\hline $\begin{array}{l}\text { xKIF13B MD } \\
\text { pCS2+DELE }\end{array}$ & xKIF13B MD & $\mathrm{pCS} 2+\mathrm{DELE}$ & ClaI/ XhoI & $\begin{array}{l}\text { NotI } \\
\text { ClaI }\end{array}$ & $\begin{array}{l}\text { Sp6 } \\
\text { T3 }\end{array}$ & $\begin{array}{c}\text { sense } \\
\text { antisense }\end{array}$ \\
\hline $\begin{array}{l}\text { xKIF13B MBS } \\
\text { pCS2+DELE }\end{array}$ & xKIF13B MBS & $\mathrm{pCS} 2+\mathrm{DELE}$ & ClaI/ XhoI & $\begin{array}{l}\text { NotI } \\
\text { ClaI }\end{array}$ & $\begin{array}{l}\text { Sp6 } \\
\text { T3 }\end{array}$ & $\begin{array}{c}\text { sense } \\
\text { antisense }\end{array}$ \\
\hline $\begin{array}{l}\text { xKIF13B CBS } \\
\text { pCS2+DELE }\end{array}$ & xKIF13B CBS & $\mathrm{pCS} 2+\mathrm{DELE}$ & ClaI/ XhoI & $\begin{array}{l}\text { NotI } \\
\text { ClaI }\end{array}$ & $\begin{array}{l}\text { Sp6 } \\
\text { T3 }\end{array}$ & $\begin{array}{c}\text { sense } \\
\text { antisense }\end{array}$ \\
\hline $\begin{array}{l}\text { xKIF13B Stalk } \\
\text { pCS2+DELE }\end{array}$ & xKIF13B Stalk & pCS2+DELE & ClaI/ XhoI & $\begin{array}{l}\text { NotI } \\
\text { ClaI }\end{array}$ & $\begin{array}{l}\text { Sp6 } \\
\text { T3 }\end{array}$ & $\begin{array}{c}\text { sense } \\
\text { antisense }\end{array}$ \\
\hline
\end{tabular}




\begin{tabular}{|c|c|c|c|c|c|c|}
\hline \multirow{2}{*}{ Construct name } & \multirow{2}{*}{ Insert } & \multirow{2}{*}{ Vector } & \multirow{2}{*}{ Cloning sites } & \multicolumn{3}{|c|}{ Transcription } \\
\hline & & & & CUT & POLY & DIRECTION \\
\hline $\begin{array}{l}\text { xKIF13B MD_MBS } \\
\text { pCS2+DELE }\end{array}$ & $\begin{array}{l}\text { xKIF13B } \\
\text { MD MBS }\end{array}$ & $\mathrm{pCS} 2+\mathrm{DELE}$ & ClaI/ XhoI & $\begin{array}{l}\text { NotI } \\
\text { ClaI }\end{array}$ & $\begin{array}{l}\text { Sp6 } \\
\text { T3 }\end{array}$ & $\begin{array}{l}\text { sense } \\
\text { antisense }\end{array}$ \\
\hline $\begin{array}{l}\text { xKIF13B MBS_CBS } \\
\text { pCS2+DELE }\end{array}$ & $\begin{array}{l}\text { xKIF13B } \\
\text { MBS_CBS }\end{array}$ & $\mathrm{pCS} 2+\mathrm{DELE}$ & ClaI/ XhoI & $\begin{array}{l}\text { NotI } \\
\text { ClaI }\end{array}$ & $\begin{array}{l}\text { Sp6 } \\
\text { T3 }\end{array}$ & $\begin{array}{c}\text { sense } \\
\text { antisense }\end{array}$ \\
\hline $\begin{array}{l}\text { xKIF13B MBS_Stalk } \\
\text { pCS2+DELE }\end{array}$ & $\begin{array}{l}\text { xKIF13B } \\
\text { MBS Stalk }\end{array}$ & pCS2+DELE & ClaI/ XhoI & $\begin{array}{l}\text { NotI } \\
\text { ClaI }\end{array}$ & $\begin{array}{l}\text { Sp6 } \\
\text { T3 }\end{array}$ & $\begin{array}{c}\text { sense } \\
\text { antisense }\end{array}$ \\
\hline $\begin{array}{l}\text { xKIF13B CBS_Stalk } \\
\text { pCS2+DELE }\end{array}$ & $\begin{array}{l}\text { xKIF13B } \\
\text { CBS Stalk }\end{array}$ & pCS2+DELE & ClaI/ XhoI & $\begin{array}{l}\text { NotI } \\
\text { ClaI }\end{array}$ & $\begin{array}{l}\text { Sp6 } \\
\text { T3 }\end{array}$ & $\begin{array}{c}\text { sense } \\
\text { antisense }\end{array}$ \\
\hline
\end{tabular}

Table 2.4. Molecular mechanism of PGC migration

\begin{tabular}{|c|c|c|c|c|c|c|}
\hline \multirow{2}{*}{ Construct name } & \multirow{2}{*}{ Insert } & \multirow{2}{*}{ Vector } & \multirow{2}{*}{$\begin{array}{l}\text { Cloning } \\
\text { sites }\end{array}$} & \multicolumn{3}{|c|}{ Transcription } \\
\hline & & & & CUT & POLY & DIRECTION \\
\hline xPTEN pCS2+DELE & xPTEN ORF & pCS2+DELE & $\begin{array}{l}\text { StuI/ } \\
\text { XhoI }\end{array}$ & $\begin{array}{l}\text { NotI } \\
\text { StuI }\end{array}$ & $\begin{array}{l}\text { Sp6 } \\
\text { T3 }\end{array}$ & $\begin{array}{c}\text { sense } \\
\text { antisense }\end{array}$ \\
\hline PI3Kdn pCS2+DELE & $\begin{array}{l}\text { PI3Kdn (ORF with } \\
\text { mutated } \\
\text { phosphorylation } \\
\text { domain) }\end{array}$ & $\mathrm{pCS} 2+\mathrm{DELE}$ & $\begin{array}{l}\text { ClaI/ } \\
\text { StuI }\end{array}$ & $\begin{array}{l}\text { NotI } \\
\text { ClaI }\end{array}$ & $\begin{array}{l}\text { Sp6 } \\
\text { T3 }\end{array}$ & $\begin{array}{c}\text { sense } \\
\text { antisense }\end{array}$ \\
\hline $\begin{array}{l}\text { xSDF1 (s) pSP64T3 (a } \\
\text { gift from B. Moepps) }\end{array}$ & $\begin{array}{l}\text { xSDF1 ORF (sense } \\
\text { orientation) }\end{array}$ & pSP64T3 & & SacI & Sp6 & sense \\
\hline $\begin{array}{l}\text { xSDF1 (as) pSP64T3 (a } \\
\text { gift from B. Moepps) }\end{array}$ & $\begin{array}{l}\text { xSDF1 (antisense } \\
\text { orientation) }\end{array}$ & pSP64T3 & & SacI & Sp6 & antisense \\
\hline
\end{tabular}

\subsubsection{Marker constructs}

1. The $\mathbf{M y o D}$ antisense RNA probe was generated by BamHI digestion of the plasmid pSP73XMyoD (Hopwood et al., 1989) and Sp6 transcription;

2. The Xpat antisense RNA probe was generated by EcoRI digestion of the pBKXpat plasmid (Hudson and Woodland, 1998) and T7 transcription;

3. The $x$ DeadSouth antisense RNA probe was generated by NcoI digestion of the MC138b plasmid (Claussen, PhD thesis, University Göttingen) and T3 transcription;

4. The $x$ Dazl antisense RNA probe was generated by EcoRI digestion of the xDazl TripleEx plasmid (Claussen, $\mathrm{PhD}$ thesis, University Göttingen) and $\mathrm{T} 7$ transcription;

5. The XGRIP2.1 antisense RNA probe was generated by SphI digestion of the pGEM-T XGRIP2.1.1 ORF plasmid (see Constructs) and Sp6 transcription 


\subsubsection{Oligonucleotides}

All primers were ordered from Sigma-Aldrich Chemie (Deisenhofen, Germany).

Table 2.5. Mapping of the XGRIP2.1 localization element

\begin{tabular}{lll}
\hline Construct & Primer name & Primer sequence 5'-3' \\
\hline 5'UTR_ORF & XGRIP2.1_5'UTR_F5 & TACTGGACCGCGGCGAATCT \\
& XGRIP2.1_ORF_XhoIR & TTAATTCTCGAGTCAGAGAGTCTTTGTGCTTGTCTG \\
ORF_3'UTR & XGRIP2.1_ORF_Star__F & CCCCTCGAGATGCATTTTTCCAGACCATTC \\
& XGRIP2.1_3'UTR4 & GGCAGCTCGCCGCAGCATCCAGCAGCTTT \\
3'UTR & XGRIP2.1_3'UTR1 & GGCAGCTCGCCTTCCATTGGCTTGCTCCA \\
& XGRIP2.1_3'UTR4 & GGCAGCTCGCCGCAGCATCCAGCAGCTTT \\
nt 3376-4376 & XGRIP2.1_3'UTR1 & GGCAGCTCGCCTTCCATTGGCTTGCTCCA \\
& XGRIP2.1_3'UTR3 & GGCAGCTCGCCTTCCATTGGCTTGCTCCA \\
nt 4374-4994 & XGRIP2.1_'UTR2 & GGAATTCCCTTCAGACAATGTTCAATTGT \\
& XGRIP2.1_3'UTR4 & GGCAGCTCGCCGCAGCATCCAGCAGCTTT \\
nt 3376-3840 & XGRIP2.1_3'UTR1 & GGCAGCTCGCCTTCCATTGGCTTGCTCCA \\
& XGRIP2.1_3'UTR_B1_R & ACTGGTTGGCAGAGGAGCCTTGGAA \\
nt 3734-4169 & XGRIP2.1_3'UTR_B2_F & GCTTTTTCACCCCACGGAAACACAC \\
& XGRIP2.1_3'UTR_B2_R & CTGGTACGATGGCTGTGCATTCCTA \\
nt 4033-4376 & XGRIP2.1_3'UTR_B3_F & GGGATGTCTCTCACCCATTGAGAAC \\
& XGRIP2.1_3'UTR3 & GGCAGCTCGCCTTCCATTGGCTTGCTCCA \\
nt 3730-3880 & XGRIP2.1_3'UTR_B2_F & GCTTTTTCACCCCACGGAAACACAC \\
& XGRIP2.1_3'UTR_B2_1_R & CAACTGCCTCTGATGCTATG \\
nt 3875-4084 & XGRIP2.1_3'UTR_B2_2_F & GCATCAGAGGCAGTTGTATC \\
& XGRIP2.1_'UTR_B2_2_R & GCAGAGGTTGTGTTGGAGTT \\
nt 4067-4164 & XGRIP2.1_3'UTR_B2_3_F & AACCTCTGCTCACTGCATCA \\
& XGRIP2.1_3'UTR_B2_R & CTGGTACGATGGCTGTGCATTCCTA \\
3'UTR del nt & XGRIP2.1_3'UTR_B2_1_R & CAACTGCCTCTGATGCTATG \\
4033-4084 & XGRIP2.1_3'UTR_B2_3_F & AACCTCTGCTCACTGCATCA \\
\hline & &
\end{tabular}

Table 2.6. XGRIP2.1 functional characterization

\begin{tabular}{ll}
\hline Primer name & \multicolumn{1}{c}{ Sequence 5'-3' } \\
\hline XGRIP2.1_DN_PDZ_1F_ClaI & ATCGATATGGAGGAGTTTCGGGGGGTAAC \\
XGRIP2.1_DN_PDZ_1R_XhoI & CTCGAGTTACTCATACTCCACTTCTAGGACCACTCGCTCGCCCAGTT \\
XGRIP2.1_DN_PDZ_2F_ClaI & ATCGATATGGAAATCACCTTGTGCAAAGAGGGCAACAG \\
XGRIP2.1_DN_PDZ_2R_XhoI & CTCGAGTTAATCATATTCTATCTGGAAGACACCCTCTTG \\
XGRIP2.1_DN_PDZ_3F_ClaI & ATCGATATGCTAGTGGAAATCGCCAAGACCCCAGGA \\
XGRIP2.1_DN_PDZ_3R_XhoI & CTCGAGTTAATGGGCTGGGAGAATTTCCAG \\
XGRIP2.1_DN_PDZ_4R_XhoI & CCCTCGAGTTAACCACAGACTCTGCCACATC \\
XGRIP2.1_DN_PDZ_4F_ClaI & CCCATCGATATGCAGATAATACACACGGAGAG \\
XGRIP2.1_DN_PDZ_5F_ClaI & CCCATCGATATGCACGTCAAACTGCCGAAAAG \\
XGRIP2.1_DN_PDZ_5R_XhoI & CCCCTCGAGTTATGAATTATCCTCATCTTTAC \\
XGRIP2.1_DN_PDZ_6F_ClaI & CCCATCGATATGTACACCGTTGAGCTCAAGAG \\
XGRIP2.1_DN_PDZ_6R_XhoI & GCGCTCGAGTTACTGTTTCTTTATCTTGAGGG \\
XGRIP2.1_DN_PDZ_7F_ClaI & ATCGATATGAAGGTAACTGTACAGAAAGAT \\
XGRIP2.1_DN_PDZ_7R_XhoI & CTCGAGTTACAAACCGCGACTAATCACCAG \\
XGRIP2.1_1_1F & ACCACTAAGTGAAGCCATCCACCTTCT \\
XGRIP2.1_1_3R & CCTTTCTCCAGGAGACCATCTGACACG \\
XGRIP2.1_3'UTR4 & GGCAGCTCGCCGCAGCATCCAGCAGCTTT \\
XGRIP2.1_5'UTR_F5 & TACTGGACCGCGGCGAATCT
\end{tabular}




\begin{tabular}{ll}
\hline Primer name & \multicolumn{1}{c}{ Sequence 5'-3' } \\
\hline XGRIP2.1_5'UTR_F53 & CCCGAATTCCTCTGTCCCTGTCTGAAAAG \\
XGRIP2.1_ORF_XhoIR & TTAATTCTCGAGTCAGAGAGTCTTTGTGCTTGTCTG \\
XGRIP2.1_5'UTR_BamHI_F & CACGGATCCCTCTGTCCCTGTCTGAAAAGTCAA \\
XGRIP2.1_5'UTR_BamHI_R & CACGGATCCTGCATTTAGAGGTTCTTCATTG \\
XGRIP2.1_ORF_SalF & AAGAACGTCGACATGCATTTTTTCCAGACCATTCTT \\
XGRIP2.1 PDZ23 del_F & AATATAACCCATACTGATGCT \\
XGRIP2.1 PDZ23 del_F & CTTATGCCAGTCCTCATGTGC \\
XGRIP2.1 SRSmut_F & AGGGCAACAGCTCTCGCTCTGTAATGAGAG \\
XGRIP2.1 SRSmut_R & CTCTCATTACAGAGCGAGAGCTGTTGCCCT \\
XGRIP2.1 $\Delta$ PDZ2_F & ATCATCCCAAAGACTGTTGCTCTCATGGACACTGTGACCAAT \\
XGRIP2.1 $\Delta$ PDZ2_R & GTCCATGAGAGCAACGATAGTCTTTGGGATGATGGCTGAG \\
XGRIP2.1 $\Delta$ PDZ3_F & TCCGGACCTCTGCTAGCCCATCACAACAGACTCCCTCTG \\
XGRIP2.1 $\Delta$ PDZ3_R & TCTGTTGTGATGGGCTAGCAGAGGTCCGGATGCATTGG \\
XGRIP2.1 $\Delta$ PDZ23_F & ATCATCCCAAAGACTGCCCATCACAACAGACTCCCTCTG \\
XGRIP2.1 $\Delta$ PDZ23_R & TCTGTTGTGATGGGCGATAGTCTTTGGGATGATGGCTGAG
\end{tabular}

Table 2.7. xKIF13B functional characterization

\begin{tabular}{ll}
\hline Primer name & Sequence 5'-3' \\
\hline xKIF13B ORF 500 bp_F & CCATGAACCGAAGAGAACAG \\
xKIF13B ORF 500 bp_R & CCTTGTAACTGGCGACAGCTTGCTT \\
xKIF13B 5'UTR Motest_F & CGCGGATCCAGTGGTATCAACGCAGAGTA \\
xKIF13B 5'UTR Motes_R & CGCGGATCCTCCTGTTCTCTTCGGTTCAT \\
xKIF13B MD_F & CCATCGATATGAGCGACTCCAATGTAAAGGT \\
xKIF13B MD_R & CCCCTCGAGCTACTCATTGACAACAGCATGGT \\
xKIF13B CBS_F & CCCATCGATATGAAGGCCCCAGAGTTAAA \\
xKIF13B CBS_R & CCGCTCGAGCTAGGGGAAAGTCTGCGGCGCAAC \\
xKIF13B MBS_F & CCATCGATATGCAGTCCATCCTACAGAG \\
xKIF13B MBS_R & CCGCTCGAGCTATCCTGCAACCTCCCCTTTCT \\
xKIF13B STALK_F & CCATCGATATGATTAAAGTGCTCCAGGCCACAGGT \\
xKIF13B STALK_R & CCGCTCGAGCTAGCGTCAGTCTCATTTCTAAC \\
xKIF13B START_F & CCCGGGATGAGCGACTCCAATGTAAA \\
xKIF13B RT_F & AGAGGAGATGTCCGACTCTG \\
xKIF13B RT_R & CCACCAACTGAGCCGTCATT \\
\hline
\end{tabular}

Table 2.8. Primers used for successful RACE-extensions of xKIF13B

\begin{tabular}{ll}
\hline Primer name & Sequence 5'-3' \\
\hline RACE1 & GCAAGCTGTCGCCAGTTACAAGGACATTGA \\
RACE2 & TCAATGTCCTTGTAACTGGCGACAGCTTGC \\
RACE3 & GCAAGCTGTCGCCAGTTACAAGGACATTGA \\
RACE4 & CATTGGAGTCGCTCATCTTGCACAG \\
RACE5 & CCTTGTAACTGGCGACAGCTTGCTT \\
RACE6 & TTCTCTTCGGTTCATGGCGTCGGAT \\
RACE7 & ATGGACCAGAAGCAGTGATCGTAGG \\
RACE8 & TGCGTCAATGTCTACAGCCGACAGG \\
RACE9 & CGTCTCCGTCAGGAAGTGGCGGTAA \\
RACE10 & CAGTCTCTGGCGCTCAAGAGCGGAT \\
RACE11 & TCCGCATCAGTGGTGACATCGGAGA \\
RACE12 & TCTCGTACAGTGGCGGCAACCAACA \\
\hline
\end{tabular}


Table 2.9. Other oligonucleotides

\begin{tabular}{ll}
\hline Primer name & Sequence 5'-3' \\
\hline XPTEN_StuI_F & AAGGCCTTATGACCGCCATCATCAAGGAGT \\
XPTEN_XhoI_R & CCGCCGCTCGAGCGGTCAGACTTTTGTAATTGTGATCT \\
fEGFP_BamHI_F & CGCGGATCCATGGTGAGCAAGGGCGAGGAG \\
fEGFP_XhoI_R & CCGCTCGAGCGGGGAGAGCACACACTTGCAGCTCAT \\
fpd2EGFP_BamHI_F & CGCGGATCCGCGATGGTGAGCAAGGGCGAG \\
fpd2EGFP_farnesyl_F & GCTTCTGCTAGGATCAATGTGAAGCTGAACCCTCCTGATGAG \\
fpd2EGFP_farnesyl_R & CTCATCAGGAGGGTTCAGCTTCACATTGATCCTAGCAG \\
H4_F & CGGGATAACATTCAGGGTATCACT \\
H4_R & ATCCATGGCGGTAACTGTCTTCCT \\
Sp6 & TTAGGTGACACTATAGAATAC \\
T7 & GTAATACGACTCACTATAGGGC \\
T3 & AATTAACCCTCACTAAAGGG \\
\hline
\end{tabular}

Table 2.10. Morpholino oligonucleotides

\begin{tabular}{ll}
\hline Morpholino name & Sequence 5'-3' \\
\hline XGRIP 2.1 MO1 & TGCATTTAGAGGTTCTTCATTGGCT \\
XGRIP 2.1 MO2 & GGATCAATACCCCTCTTCTCACGTT \\
xKIF13B MO1 & TAACCTCCCCGCGTACTCTGCGTTG \\
xKIF13B MO2 & ACCTTTACATTGGAGTCGCTCATCT \\
CO MO & CCTCTTACCTCAGTTACAATTTAT A \\
\hline
\end{tabular}

\subsection{Enzymes:}

Alkaline phosphatase $(1 \mathrm{U} / \mu \mathrm{l})$

Restriction endonucleases

RNAseout (40 U/ $\mu \mathrm{l})$

RNase A

RNse T1

Proteinase K

Lysozyme

Sp6 RNA polymerase $(50 \mathrm{U} / \mu \mathrm{l})$

T7 RNA polymerase $(50 \mathrm{U} / \mu \mathrm{l})$

T3 RNA polymerase $(50 \mathrm{U} / \mu \mathrm{l})$

Taq DNA polymerase $(5 \mathrm{U} / \mu \mathrm{l})$

Pfu DNA polymerase $(2,5 \mathrm{U} / \mu \mathrm{l})$

T4 DNA ligase $(1 \mathrm{U} / \mu \mathrm{l})$
Boehringer, Mannheim;

New England Biolabs GmbH, Schwalbach;

Fermentas GmbH; St. Leon-Rot;

Promega, Mannheim;

Sigma-Aldrich Chemie GmbH, Deisenhofen;

Sigma-Aldrich Chemie GmbH, Deisenhofen;

Merck KgaA, Darmstadt;

Biomol GmbH, Hamburg;

Stratagene GmbH, Heidelberg;

Stratagene GmbH, Heidelberg;

Stratagene GmbH, Heidelberg;

Perkin-Elmer, Weiterstadt;

Stratagene GmbH, Heidelberg;

New England Biolabs GmbH, Schwalbach; 


\subsection{Media and buffers}

All solutions were prepared with bidestilled water and autoclaved $20 \mathrm{~min}$ at $121^{\circ} \mathrm{C}$. Termolabile buffers sterilized with membrane filters $(0.2 \mu \mathrm{m}$ pore size, Sartorius $)$

Luria-Bertani (LB)-Medium: 1\% (w/v) Bacto-Trypton (DIFCO), $0.5 \%$ (w/v) yeast extract (DIFCO), 1\% (w/v) NaCl, $\mathrm{pH} 7,5$;

Tris-HCl (pH 6.8, 7.5, 8.2, 8.8, or 9.5): $1 \mathrm{M}$ Tris- $\mathrm{HCl}$, adjust $\mathrm{pH}$ with $37 \% \mathrm{HCl}$;

TBE (10x): 0.9 M Tris, 0.9 M Boric acid, 0.02 M EDTA;

PBS (10x): 8\% (w/v) NaCl, 2\% (w/v) KCl, $65 \mathrm{mM} \mathrm{Na}_{2} \mathrm{HPO}_{4} * 12 \mathrm{H}_{2} \mathrm{O}, 18 \mathrm{mM} \mathrm{KH}_{2} \mathrm{PO}_{4}$, pH 7.2

SSC (20x): $3 \mathrm{M} \mathrm{NaCl}, 0.3 \mathrm{M}$ Na-citrate, $\mathrm{pH}$ 7.2;

SSPE (20x): $3 \mathrm{M} \mathrm{NaCl}, 0.2 \mathrm{M} \mathrm{Na}_{2} \mathrm{HPO}_{4} * 2 \mathrm{H} 2 \mathrm{O}, 20$ mM EDTA, pH 7.4;

$\mathbf{M g C l}_{2}: 1 \mathrm{M} \mathrm{MgCl}_{2} * 6 \mathrm{H}_{2} \mathrm{O}$;

$\mathrm{MgSO}_{4}: 1 \mathrm{M} \mathrm{MgSO}_{4} * 7 \mathrm{H}_{2} \mathrm{O}$;

NaCl: $5 \mathrm{M} \mathrm{NaCl}$;

KCI: $1 \mathrm{M} \mathrm{KCl}$;

Sodium-acetate: $3 \mathrm{M} \mathrm{NaCH}_{3} \mathrm{COO}$;

$\mathbf{N a H}_{2} \mathbf{P O}_{4}: 1 \mathrm{M} \mathrm{NaH}_{2} \mathrm{PO}_{4} * 1 \mathrm{H}_{2} \mathrm{O}$;

$\mathrm{Na}_{2} \mathrm{HPO}_{4}: 1 \mathrm{M} \mathrm{Na}_{2} \mathrm{HPO}_{4} * 2 \mathrm{H}_{2} \mathrm{O}$;

Ethidium bromide: $10 \mathrm{mg} / \mathrm{ml}$ ethidium bromide;

Ficoll: 10\% (w/v) Ficoll, filtered;

SDS: $10 \%(\mathrm{w} / \mathrm{v})$ SDS (not autoclaved);

Tween-20: 25\% (w/v) Tween-20,

DEPC-H2O: $1 \mathrm{ml}$ DEPC per $1 \mathrm{~L} \mathrm{H} 2 \mathrm{O}$, dissolve with mixing ON, autoclave 


\subsection{Machines}

\section{Microinjection}

Microinjector 5242

Eppendorf, Hamburg;

Needle puller

Leitz, Wetzlar;

PCR

UNOII Thermoblock

Biometra, Göttingen;

TRIO Thermoblock

Biometra, Göttingen;

\section{Optics}

Stereomicroscope (Camera U-PMVC)

STX12, Olympus

Fluorescence microscope I (Camera AxioCamRHc)

Axioplan 2, Zeiss;

Fluorescence microscope II (Camera U-TV1x-2)

STX12, Olympus

Fluorescence microscope III (Camera AxioCamRHc)

Lumar.V12, Zeiss;

\section{Histology}

Vibratome Type 1000, Pelco International, Redding, California, USA;

Microtome Leica Instruments GmbH, Nussloch;

Phosphoimag

Molecular Dynamics

\section{Software:}

Microsoft ofiice 2000,

Vector NTI (Invitrogen),

SeqMan (DNASTAR Inc., Madison, USA),

BLAST online system (Altschul et al., 1990),

Adobe Photoshop 7 (Adobe systems Europe Ltd., Edinburgh, Scotland). 


\section{Methods}

\subsection{DNA-methods}

\subsubsection{Preparation of plasmid DNA}

Isolation of plasmid DNA in preparative amounts (midiprep) was done by QIAprep Spin Midiprep Kit (Qiagen) according to the manufacture's protocol. Isolation of plasmid DNA in analytical amounts (miniprep) was done by QIAprep Spin Miniprep Kit (Qiagen) or Genelute Five-minute Plasmid Miniprep Kit (Sigma) according to the manufactures' protocols.

\subsubsection{Measurement of nucleic acids concentration}

Absorption values at $260 \mathrm{~nm}$ were measured on the Ultraspec 1100 pro spectrofotometer (Amercham Bioscience) against the blank sample (HPLC-water). Concentrations were calculated from $\mathrm{OD}_{260}$ values automatically by the spectrophotometer software using the following principle:

$\mathrm{OD}_{260}=1$ correspond to $50 \mu \mathrm{g}$ of dsDNA;

$\mathrm{OD}_{260}=1$ correspond to $40 \mu \mathrm{g}$ of RNA;

$\mathrm{OD}_{260}=1$ correspond to $33 \mu \mathrm{g}$ of Oligonucteotide;

To estimate the purity of an obtained sample, absorption values at $280 \mathrm{~nm}$ were measured and the ratio $\mathrm{OD}_{260} / \mathrm{OD}_{280}$ was calculated. The DNA or RNA sample preparation was regarded as protein free if the ratio value was 1.8 to 2 .

\subsubsection{DNA restriction digest}

For the analytical or preparative digest $1 \mu \mathrm{g}$ of DNA was incubated with 2-10 $\mathrm{U}$ or an appropriate enzyme in the corresponding enzyme buffer in the $50 \mu \mathrm{l}$ total reaction volume for 224 hours at $37^{\circ} \mathrm{C}$. to prevent the so called "star activity" of an enzyme, its volume was always less then $10 \%$ of the total reaction volume (Sambrook J., 1989). 


\subsubsection{Agarose-gel electrophoresis (Sharp et al., 1973)}

DNA or RNA fragments were size-separated in the horizontal electrical field being embedded into the agarose-matrix. Depending on the expected sizes of DNA/RNA fragments, 0.7 to $2 \%(\mathrm{w} / \mathrm{v})$ agarose gels in TBE buffer were prepared. Gels always contained $0.5 \mu \mathrm{g} / \mathrm{ml}$ ethidium bromine to visualize nucleic acids later on. Before loading into gel slots, nucleic acids were mixed 1/1 (v/v) with the DNA loading dye. The electrophoresis was run in the standard TBE-running buffer at $100-121 \mathrm{~V}$ in the house made horizontal electrophoresis chamber. After the run, DNA/RNA bands were visualized with UV-transilluminator (Herolab) and documented with ChemiDoc video documentation system (EASY view). Sized of experimental bands were determined according to the standard DNA ladder run in parallel (High, Middle or Low Range, Fermentas)

DNA-loading dye (2x): 10 mM Tris- $\mathrm{mCl} \quad(\mathrm{pH}$ 7.5), 1 mM EDTA, $0.025 \%$ bromphenolblue, $0.025 \%$ xylencyanol, $30 \%(\mathrm{v} / \mathrm{v})$ glycerol.

\subsubsection{Polymerase chain reaction (PCR) (Mullis et al., 1986)}

To amplify a wanted DNA fragment a standard PCR reaction was used, containing the following components:

-1x PCR buffer (corresponding to the polymerase used),

- $0.2 \mathrm{mM}$ each dNTPs;

- $0.2 \mathrm{mM}$ each primer;

- 1-100 ng DNA template;

- 0.5-1 U Taq or 2 U Pfu polymerase;

All denaturation steps were performed at $94^{\circ} \mathrm{C}$, all elongation steps - at $72^{\circ} \mathrm{C}$, annealing temperatures depended on the GC-content of the amplifying fragment and primers used in the given reaction. In majority of cases, the $56^{\circ} \mathrm{C}$ annealing temperature was chosen.

To amplify large DNA fragments High Fidelity Amplification Kit (Fermentas) was used according to the manufacture's protocol.

RACE-PCRs were performed using Advantage PCR Kit (Clontech). Primers $\left(\mathrm{Tm}>70^{\circ} \mathrm{C}\right)$ and 5'/3'cDNA were designed and prepared according to the manufacture's protocol of the “tough-down” RACE-PCR. 5'RACE and 3'RACE cDNAs were prepared from the total oocyte 
stages III-VI and stage I embryonic RNAs, respectively, according to the manufacture's protocol.

Quick-Change Site-Directed Mitagenesis Kit (Stratagene) was used according to manufacture's protocol to introduce point mutations into constructs of interest.

\subsubsection{DNA-sequencing and sequence analysis}

The ABI 3100 Automated Capillary DNA Sequencer was used (based on the principle of the sequencing reaction described by Sanger (1977)) (Sanger et al., 1977). The protocol for sequencing with the Big Dye Terminator Kit (Applied Biosystems) is given below.

\section{$\underline{\text { Reaction Mix }}$}

Mix the following components in a thin-walled PCR tube:

Plasmid DNA $200 \mathrm{ng}$

Primer $(10 \mu \mathrm{M}) 1 \mu \mathrm{l}$

BigDyeSeq Buffer $1.5 \mu 1$

Ready Reaction Premix $1.5 \mu 1$

HPLC H20

Total $10 \mu 1$

\section{Cycling parameters}

$96{ }^{\circ} \mathrm{C} 2 \mathrm{~min} ; 26 \mathrm{X}\left(96{ }^{\circ} \mathrm{C} 30 \mathrm{sec}, 50{ }^{\circ} \mathrm{C} 20 \mathrm{sec}, 60{ }^{\circ} \mathrm{C} 4 \mathrm{~min}\right) ; 12{ }^{\circ} \mathrm{C} \bullet$

\section{$\underline{\text { Purification }}$}

Add to a PCR reaction:

$3 \mathrm{M} \mathrm{NaAc}(\mathrm{pH} 5) 1 \mu 1$

$125 \mathrm{mM}$ EDTA $1 \mu 1$

Ethanol $50 \mu 1$

Immediately transfer to a $1.5 \mathrm{ml}$ Eppendorf tube and incubate at room temp for $5 \mathrm{~min}$

- Centrifuge at room temperature for $20 \mathrm{~min}$ at max speed

- Remove supernatant and add $100 \mu 170 \%$ ethanol

- Centrifuge at room temperature for $5 \mathrm{~min}$ at max speed

- Remove supernatant and dry pellet

- Dissolve DNA pellet in $25 \mu 1$ HPLC water 
Sequence reactions were run and documented in the in-house sequencing lab (A. Nolte). The analysis of the received sequence computer files was done by Vector NTI (Invitrogen) and DNASTAR (Inc. Madison, USA) programs.

\subsubsection{Purification of DNA fragments}

To purify preparative PCR-amplified DNA fragments or linearized plasmids the PCR Purification Kit was used according to manufacture's protocol. DNA was eluted with $25 \mu 1$ HPLC-water.

To purify DNA fragments from preparative restriction digests, reaction mixes were separated by gel electrophoresis, and then proper bands were cut out from the agarose gel under UV-light. DNA was extracted using the QIAquick Gel Extraction Kit according to the manufacture's protocol. Elution was performed in $25 \mu 1$ of HPLC-water.

\subsubsection{Ligation of DNA fragments}

\subsubsection{Ligation into a cloning vector}

To ligate into pGEM-T/ pGEM-T easy (Promega) cloning vectors, DNA fragments were PCR-amplified with Taq polymerase to add polyA overhangs, PCR purified and ligated according to the manufacture's protocol. $25 \mathrm{ng}$ of vector DNA was used per $10 \mu$ ligation reaction.

\subsubsection{Ligation into an expression vector}

For the subcloning into an expression vector, the "sticky-ends" ligation was preferred. DNA fragments were amplified with primers containing cutting sites for restriction enzymes chosen from multiple cloning sites of a vector of interest. DNA fragments obtained and a vector were digested with corresponding enzymes over night, PCR-purified and ligated according to the following scheme: T4-Ligase (Gibco) $1 \mathrm{U}, 1 \mathrm{x}$ Ligation buffer (Gibco), insert and vector in 3 to 1 ratio (w/w), water till the final volume of 10 or $20 \mu \mathrm{l}$. As a rule, 25 to $50 \mathrm{ng}$ of vector DNA was used per a ligation (Sambrook J., 1989). 
Alternatively, an insert DNA fragment was cut out from a cloning vector and re-ligated into the expression vector of interest according to the scheme described above.

If the "sticky-end" subcloning was not possible, the "blunt-end" ligation was performed. In this case, "sticky-ends" a vector of interest and of an insert DNA fragment cut out from a different vector or PCR-amplified were filled in by the Klenow fragment (Fermentas) in the following Klenow extension reaction: $1 \mathrm{U}$ Klenow fragment (Fermentas), 1x Klenow Buffer (Fermentas), $0.3 \mathrm{mM}$ dNTPs added to PCR-purified or gel extracted insert and/or vector. The reaction was incubated $15 \mathrm{~min}$ at $\mathrm{RT}$, heat inactivated $20 \mathrm{~min}$ at $75^{\circ} \mathrm{C}$, and then DNA was PCRpurified and ligated as described above (Clark et al., 1987).

\subsubsection{Transformation}

\subsubsection{Chemical transformation}

$100 \mu \mathrm{l}$ of house-made chemically competent cells were tough on ice, mixed with $1-2 \mu 1$ on a ligation mix, incubated for $20 \mathrm{~min}$ on ice, heat-shocked for $90 \mathrm{sec}$ at $42{ }^{\circ} \mathrm{C}$, left for 2 more min on ice, incubated at $37{ }^{\circ} \mathrm{C}$ for 30 min with $700 \mu \mathrm{l}$ of LB-medium and plated on LB-agarplates with the appropriate selectivity antibiotic. Colonies were grown $\mathrm{ON}$ at $37^{\circ} \mathrm{C}$ (Mandel and Higa, 1970).

\subsubsection{Transformation by electroporation}

$40 \mu \mathrm{l}$ of electrocompetent cells were tough on ice, mixed with 1-2 $\mu 1$ on a ligation mix, transferred into an electroporation cuvette and let stand for 10 more min on ice. After application of an electrical pulse of $1.8 \mathrm{kV}$ and $25 \mu \mathrm{F}$, a transformation reaction was mixed by pipeting with $0.5 \mathrm{ml}$ of LB-medium and plated on LB-agar-plates with the appropriate selectivity antibiotic. Colonies were grown $\mathrm{ON}$ at $37^{\circ} \mathrm{C}$ (Dower et al., 1988).

\subsubsection{Verification of the integration of a DNA fragment of interest}

To verify the integration of the insert DNA fragment into a vector of interest a PCR with the colony material as a template was used (colony-PCR). Depending on the availability of 
primers and the expected fragment size, an insert specific pair or a vector specific pair, or a combination of a vector specific and an insert specific primers was selected for the amplification.

Alternatively to the colony-PCR, plasmid isolation in analytical quantities followed by restriction digest with cloning endonucleases was performed (Sambrook J., 1989).

\subsection{RNA-methods}

To inhibit RNases all buffers used for the work with RNA were whether autoclaved or dissolved in DEPC-water (termolabile ones). Instruments and chambers were incubated for minimum 2 hours in $1 \mathrm{M} \mathrm{NaOH}$, washed with ethanol and then with DEPC-water.

3.2.1 Isolation of total RNA (modified from Sambrook et al., 1989)

\subsubsection{1 from oocytes and embryonic stages}

$500 \mu \mathrm{l}$ of Trizol-mix was added to 5-10 Xenopus oocytes/ embryos frozen in liquid nitrogen. After toughing oocytes/ embryos were homogenised with a $1 \mathrm{ml}$ insulin-syringe and let

stand for $5 \mathrm{~min}$ at RT. The homogenate was mixed by shaking with $0.1 \mathrm{ml}$ of chloroform for 15 sec, let stand for 2-3- min at RT and centrifuged for $15 \mathrm{~min}$ at $10000 \mathrm{rpm}, 4 \mathrm{oC}$. The upper phase was transferred into a new eppendorf, mixed with $0.25 \mathrm{ml}$ of isopropanol, incubated for $10 \mathrm{~min}$ at RT and centrifuged for $10 \mathrm{~min}$ at $10000 \mathrm{rpm}, 4^{\circ} \mathrm{C}$. The upper phase was discarded and the pellet washed with 75\% ethanol in DEPC-water. After the centrifugation step (9000 rpm, 5 min, $4^{\circ} \mathrm{C}$ ), ethanol solution was decanted, pellet air dried and subjected for the DNase digest (1 U DNaseI, 1x DNaseI buffer, DEPC-water to the final volume of $10 \mu \mathrm{l}$ ) for minimum 1 hour at $37^{\circ} \mathrm{C}$. The reaction was stopped by adding $1 \mu \mathrm{l}$ of $25 \mathrm{mM}$ EDTA and heat inactivation for $10 \mathrm{~min}$ at $65^{\circ} \mathrm{C}$. to precipitate RNA after the DNA digest $10 \mu 1$ of $10 \mathrm{M}$ ammonium acetate and $250 \mu \mathrm{l}$ of $100 \%$ ethanol in $100 \mu \mathrm{l}$ of DEPC-water were added and incubated $\mathrm{ON}$ at $-20^{\circ} \mathrm{C}$ or for 3 hours at $-80^{\circ} \mathrm{C}$. After the centrifugation step $\left(9000 \mathrm{rpm}, 5 \mathrm{~min}, 4^{\circ} \mathrm{C}\right)$, the supernatant was discarded and the pellet washed twice with $75 \%$ ethanol in DEPC-water, air dried and dissolved in $30 \mu 1$ of DEPL-water.

DNaseI buffer (10x): 400 mM Tris- $\mathrm{HCl}(\mathrm{pH}$ 8), 60 mM MgCl $2,100 \mathrm{mM} \mathrm{NaCl}, 1 \mathrm{mM}$ $\mathrm{CaCl}_{2}$ in DEPC-water. 


\subsubsection{2 from adult frog tissues and organs}

Organs and tissues were extracted from an adult Xenopus male frog immediately after testis preparation, washed twice in 1x MBSH to wash out the blood and frozen in liquid nitrogen. This frozen material was then grinded to powder, transferred into precooled eppendorfs and stored at $-80^{\circ} \mathrm{C}$ till RNA extraction. RNA extraction was performed as described in 3.2.1.1. $100 \mu 1$ of Trizol-mix was used per $10 \mathrm{mg}$ of the material powder.

3.2.2 Semiquntitative Reverse-Transcription PCR (RT-PCR) (essentially as described by Sambrook et al., 1989)

The RT-PCR with RNA extracted from different embryonic stages and tissues was performed using an RT-PCR Kit (Perkin Elmer). For the reverse transcription the following reaction mix was prepared:

$1 \mu \mathrm{l}$ 10x PCR Buffer without $\mathrm{MgCl}_{2}$,

$2 \mu 125 \mathrm{mM} \mathrm{MgCl}_{2}$,

$2 \mu \mathrm{l}$ each $10 \mathrm{mM}$ desoxynucteotide solutions (dATP, dCTP, dGTP, dTTP),

$0.5 \mu 1$ RNaseout,

$0.5 \mu \mathrm{l}$ random hexamers $(50 \mu \mathrm{M})$

$0.2 \mu \mathrm{l}$ reverse transcriptase,

50-100 ng RNA,

DEPC-water to the final volume of $10 \mu \mathrm{l}$

The synthesis of cDNA was performed in three steps: $10 \mathrm{~min} 22^{\circ} \mathrm{C}$ (annealing), $50 \mathrm{~min}$ $42^{\circ} \mathrm{C}$ (reverse transcription) and $5 \mathrm{~min} 99^{\circ} \mathrm{C}$ (heat inactivation of the reverse transriptase).

$5 \mu$ of the obtained cDNA was subjected for the standard Taq-PCR with gene specific primers.

\subsection{3 in vitro transcription}

\subsubsection{1 in vitro transcription of labelled RNA probe for in situ hybridization}

For the synthesis of a digoxigenin-labelled antisense RNA probe for in situ hybridization the following reaction mix was set up: 
$5 \mu l$ of a $5 x$ transcription buffer,

$1 \mu \mathrm{l}$ each $10 \mathrm{mM}$ rATP, rCTP, rGTP

$0.64 \mu 110 \mathrm{mM}$ rUTP,

$0.36 \mu$ l digoxigenin-rUTP (Boehringer),

$1 \mu 10.75$ M DTT,

$0.5 \mu 1$ RNaseout,

200 ng linearized plasmid (the DNA template),

$1 \mu 1$ corresponding polymerase (T3, T7 or Sp6),

DEPC-water to the final volume of $25 \mu \mathrm{l}$

This reaction was incubated minimum 2 hours at $37^{\circ} \mathrm{C}$, and then $0.5 \mu$ of DNaseI was added to destroy the template $\left(15 \mathrm{~min}, 37^{\circ} \mathrm{C}\right)$ followed by the RNA purification (Hollemann et al., 1999).

\subsubsection{2 in vitro transcription of capped-mRNA for microinjections}

The synthesis of sense capped-mRNA for microinjections was done with Sp6, T7 or T3 mMESSAGE mMACHINE Kits (Ambion) according to manufacturer's protocol. For $10 \mu 1$ reaction 200-500 linear template DNA was used.

For the synthesis of Alexa-labelled sense mRNA $1 \mu \mathrm{l}$ of Alexa-546-UTP (Sigma) was added to the standard reaction mix suggested by the manufacturer.

The radioactively labelled mRNAs were synthesised by adding the $\alpha^{32} \mathrm{P}-\mathrm{UTP}$ to the standard in vitro transcription reaction. For each reaction $4 \mu \mathrm{l}$ of $20 \mu \mathrm{Ci} / \mu \mathrm{l} \alpha^{32} \mathrm{P}-\mathrm{UTP}$ (Amersham Biosciences) was used.

Reactions were incubated minimum 2 hours at $37^{\circ} \mathrm{C}$, then $0.5 \mu \mathrm{l}$ of DNaseI was added to destroy the template $\left(15 \mathrm{~min}, 37^{\circ} \mathrm{C}\right)$ followed by the RNA purification.

\subsubsection{Purification of synthetic RNAs}

The purification of in vitro synthesised RNAs was performed with RNeasy Mini Kit for RNA clean up (Qiagen) according to the manufacture's protocol. Elution was done in $30 \mu 1$ of DEPC-water. Purity of the RNA obtained was controlled photometricaly by $\mathrm{OD}_{260} / \mathrm{OD}_{280}$ ratio and on a gel (2\% agarose gel for non-radioactive RNAs (see 3.1.4) and 8\% urea-polyacrylamide gel for radioactive transcripts). 
3.2.3.4 Separation of radioactive RNAs in the urea-polyacrylamide gel (based on the protocol described by Claussen and Pieler, 2004)

Radioactive RNAs were size-separated in the $8 \%$ urea-polyacrylamide gel $(200 * 200 * 0.5)$. RNA samples were mixed $1 / 4(\mathrm{v} / \mathrm{v})$ with RNA-loading dye and loaded on a gel after 10 min of prerun $(200 \mathrm{~V})$. After the run (appr. 2 hours, $300 \mathrm{~V})$, the gel was exposed with a phosphoimager screen (Molecular Dymanics) for 5-10 min, which was then scanned with the phosphoimager (Typhoon image 9400, Amersham Biosciences).

RNA-loading dye: $1 \mathrm{x}$ TBE, $50 \%(\mathrm{v} / \mathrm{v})$ formamide, $0.025 \%$ bromphenolblue, $0.025 \%$ xylencyanol in DEPC-water;

8\% polyacrylamide-urea PAGE stock (1x): $8 \mathrm{M}$ urea, $7.7 \%$ acrylamide, $0.3 \%$ bisacrylamide in $1 \mathrm{x}$ TBE, filtered $(0.45 \mu \mathrm{m})$. Polymerisation was triggered by adding $200 \mu \mathrm{l}$ $10 \%$ APS and $20 \mu 1$ TEMED per $20 \mathrm{ml}$ stock solution.

3.2.4 Co-immunoprecipitation (J. Loeber, $\mathrm{PhD}$ thesis in preparation)

To prove the possible interaction between mRNA and a protein of interest, Alexa-labelled (see 3.2.3.2) mRNA and in vitro synthesised myc-tagged protein (see 3.3.1) were coimmunoprecipitated according to the following protocol:

1. Each co-immunoprecipitation (Co-IP) reaction containing 12,5 $\mu \mathrm{l}$ of TnT, $1 \mu \mathrm{l}$ AlexamRNA, $4 \mu \mathrm{l}$ 5x UV-crosslinking buffer and $4.5 \mu \mathrm{l}$ DEPC-water was incubated for 1 hour at RT for RNA-protein interaction;

2. Myc-tagged proteins were then bound to the $\alpha$-myc sepharose in NET-2 buffer ( $300 \mu 1$ NET-2 buffer, $15 \mu \mathrm{l} \alpha$-myc sepharose per reaction, rotating for 1 hour at $4^{\circ} \mathrm{C}$ );

3. Bound to the $\alpha$-myc sepharose complexes were span down for $1 \mathrm{~min}$ at $2000 \mathrm{rpm}$, supernatant was removed and subjected to RNA extraction to check the quality of the unbound fraction (RNA loading control);

4. Pellet was washed four times with NET-2 buffer, followed by elution of RNA-protein complexes from the sepharose $(200 \mu \mathrm{l}$ NET-2, $20 \mu \mathrm{l} 10 \%$ SDS, $1 \mu \mathrm{l}$ tRNA $(10 \mathrm{mg} / \mathrm{ml})$ per reaction, shaking at $\mathrm{RT}$ for 20-30 $\mathrm{min}$ );

5. Sepharose was then span down, the supernatant was transferred into a new eppendorf and subjected to RNA extraction;

6. For the RNA extraction, $200 \mu \mathrm{l}$ of phenol-chlorophorm mixture was mixed well with the supernatant and centrifuged for $1 \mathrm{~min}$ at $13000 \mathrm{rpm}$. The upper phase was transferred into a 
new eppendorf, mixed with $1 / 10(\mathrm{v} / \mathrm{v}) 10 \mathrm{M}$ ammonium acetate plus 2.5 volumes of $100 \%$ ethanol and put to $-20{ }^{\circ} \mathrm{C}$ minimum for 2 hours and centrifuged for $20 \mathrm{~min}$ at $13000 \mathrm{rpm}\left(4^{\circ} \mathrm{C}\right)$ to precipitate RNA, which was then washed with $80 \%$ ethanol in DEPC-water, air dried and resuspended in the urea-loading buffer $(20 \mu \mathrm{l})$.

Myc-tagged proteins could be precipitated from the lower phenol phase with $1 \mathrm{ml}$ acetone ( 2 hours, $-80^{\circ} \mathrm{C}$ ), washed ones with $70 \%$ ethanol, air dried under the hood and detected by western-blotting;

7. Extracted RNA was run on the $8 \%$ urea-PAGE for $2-3$ hours at $300 \mathrm{~V}$;

8. The gel was scanned with the Typhoon phosphoimager to detect Alexa-labelled RNA (laser: 580 BP 30/ Green $532 \mathrm{~nm}$, normal sensitivity, focal plane $+3 \mathrm{~mm}$ );

5x UV-crosslinking buffer: $25 \mathrm{mg} / \mathrm{ml}$ heparin, 5\% glycerol, $250 \mathrm{mM} \mathrm{KCl,} 50 \mathrm{mM}$ DTT, $26 \mathrm{mM}$ Hepes, $7.5 \mathrm{mM}$ ATP, $5 \mathrm{mM} \mathrm{MgCl}_{2}, 0.5 \mathrm{mM}$ EDTA, $200 \mu \mathrm{g} / \mathrm{ml} \mathrm{tRNA}$;

NET-2 buffer: $50 \mathrm{mM}$ Tris- $\mathrm{HCl}(\mathrm{pH} 7,5), 150 \mathrm{mM} \mathrm{NaCl}, 0.05 \%$ NP40, $1 \mathrm{mM}$ PMSF, 1 protease-inhibitor tablet (Roche) per $50 \mathrm{ml}$ of the buffer;

Preparation of the $\boldsymbol{\alpha}$-myc sepharose: anti-myc-antibody (9E10, Sigma) was incubated with protein $\gamma$-sepharose ( $1 \mu \mathrm{l}$ of antibody per $15 \mu \mathrm{l}$ sepharose) for 1 hour at RT in NET-2 buffer, aliquoted (30 $\mu$ l aliquots) and stored at $-4^{\circ} \mathrm{C}$;

Urea-loading buffer: $7 \mathrm{M}$ urea, $1 \mathrm{x}$ TBE, $0.05 \%$ bromphenolblue, $0.05 \%$ xylencynole;

\subsection{Protein methods}

\subsubsection{In vitro transcription-translation assay}

Coupled in vitro translation was done with the TNT ${ }^{\circledR}$ Coupled Reticulocyte Lysate System (Promega) according to the manufacturer's user manual (12.5 $\mu$ l reactions). Proteins were separated by a standard 12\% SDS-PAGE (Laemmli, 1970). The gel was dried in the vacuum drier for 2 hours at $80^{\circ} \mathrm{C}$, exposed to an autoradiography sensitive phosphoimager screen and scanned the following day with the Typhoon phosphoimager (Amersham Bioscience). 
3.3.2 Preparation of total protein extracts (modified from Sottong et al., 1976)

Grinded adult frog tissues, oocytes or embryos frozen in liquid nitrogen were tough on ice and homogenized in a homogenization buffer $(10 \mu \mathrm{l}$ of a buffer per 1 embryo/oocyte or $1 \mathrm{mg}$ of a tissue) and centrifuged at $13000 \mathrm{rpm}$ for $20 \min \left(4^{\circ} \mathrm{C}\right)$. The clear supernatant was transferred into a new eppendorf and mixed 1/1 (v/v) with 1,1,2-trichlortrifluorethan (Freon) (Merck). This mixture was centrifuged again at $13000 \mathrm{rpm}$ for $20 \mathrm{~min}\left(4^{\circ} \mathrm{C}\right)$ (Sottong et al., 1976). The clear upper phase containing soluble proteins was transferred into a new eppendorf. Protein concentration was determined by Bradford method (Bradford, 1976). Obtained extracts were shock-frozen in liquid nitrogen and stored at $-80^{\circ} \mathrm{C}$.

Homogenization buffer: $50 \mathrm{mM}$ Tris- $\mathrm{HCl}, \mathrm{pH}$ 7.5, $150 \mathrm{mM} \mathrm{NaCl}, 50 \mathrm{mM} \mathrm{NaF}, 15 \%$ glycerol. Before use, 1 tablet complete protease inhibitors (Roche) was added per $50 \mathrm{ml}$ homogenization buffer.

\subsubsection{Western-blotting}

Proteins were separated by $10 \%$ or $12 \%$ SDS-PAGE (Laemmli, 1970) and transferred for 1-2 hours to a nitrocellulose membrane $(0.45 \mu \mathrm{m}$, Schleicher \& Schuell) using the semi-dry blotting method (Sambrook J., 1989).

The membrane was blocked overnight in the blocking buffer in a cold room. After three washes in PTw (at least 10 minutes each), the membrane was incubated with a primary antibody solution for 1 hour, then washed tricefor $10 \mathrm{~min}$ in PTw again and incubated in a secondary antibody solution for 1 hour. After three 10 min washes in PTw, the ECL DirectTm nucleic acid labeling and detection system was used to visualize the proteins (Amersham).

Transfer Buffer: 39 mM glycine, 48 mM Tris-HCl, pH 7.5, 0.04\% SDS, 20\% Methanol;

PTw: 0.1\% Tween 20 in PBS;

Blocking buffer: 5\% (w/v) milk powder in PTw;

Primary antibody solution: $5 \%(\mathrm{w} / \mathrm{v})$ milk powder, 1:2,000 to 1:10,000 dilution of a primary antibody in PTw;

Secondary antibody solution: 5\% (w/v) milk powder, 1:10,000 to 1:20,000 dilution of a secondary antibody in PTw; 
3.3.4 UV-crosslinking (essentially as described by Mowry, 1996)

UV-crosslinking experiments were done for the identification of the protein binding pattern of XGRIP2.1 localization element mRNA. Analysis was done with standard S100 protein extracts from st. V-VI oocytes (described in details by Claussen and Pieler, 2004) and with Xenopus oocytes protein fractions enriched in RNA-binding protein (generously provided by P.K. Arthur, PhD, University Göttingen).

mRNAs were radiolabelled with $\alpha^{32} \mathrm{P}-\mathrm{UTP}$ by in vitro transcription (see 3.2.3.2). The quality of the labeled mRNAs was checked on the 8\% urea-PAGE (see 3.2.3.3). The efficiency of labelling (final amount of radioactivity in the purified mRNA solution) was determined by Bioscan/ QG 2000 (Amercham).

One UV-crosslinking reaction contained: $2,5 \mu \mathrm{l}$ of a protein extract, $200000 \mathrm{cpm}$ of labeled mRNA, $2 \mu$ of 5x UV-crosslinking buffer (see 3.2.4) DEPC-water and/or non-labelled competitive mRNA to the $10 \mu$ final reaction volume. This reaction mix was incubated for 10 min at RT and then UV-irradiated at $254 \mathrm{~nm}$ for $10 \mathrm{~min}$ (Stratalinker 2400, Stratagene). Free mRNAs were then degraded by RNaseI digest (15-30 min, $\left.37^{\circ} \mathrm{C}\right)$. After that samples were mixed with $15 \mu \mathrm{l}$ of protein loading buffer and, boiled for 5 min at $95^{\circ} \mathrm{C}$ and loaded on a $12 \%$ SDSLaemmli gel. Proteins were separated by SDS-PAGE for 2-4 hours at $200 \mathrm{~V}$, then the gel was vacuum dried (2 hours, $80^{\circ} \mathrm{C}$ ) and exposed to an autoradiography sensitive phosphoimager screen (ON or longer) and scanned with the Typhoon phosphoimager (Amersham Bioscience) (Mowry, 1996).

\subsubsection{XGRIP2.1 antibody purification}

The XGRIP2.1 polyclonal rabbit antibody was raised against 19 amino acids peptide (YVPQAVGISLHPHEWRTSR) (BioScience, Göttingen). The antibody was purified from the "3d bleeding" serum via AminoLink columns (Pierce) with the covalently linked synthetic peptide used for rabbits immunization. As an alternative approach, the recombinant XGRIP2.1 protein fused N-terminally in frame to the maltose binding protein was used as an antigen for the antibody purification via the $\mathrm{pMAL}^{\mathrm{TM}}$ protein fusion and purification system (New England BioLabs). Protein expression and purifications were performed according to manufactures' user protocols. 


\subsection{Preparation and manipulation of Xenopus laevis embryos and} oocytes (Richardson et al., 1995; Wilson et al., 1986)

\subsubsection{Preparation of Xenopus leavis testis}

Both testes was taken out from a narcotisized decapitated male frog, washed with and stored in the $1 \mathrm{x}$ MBSH buffer at $4^{\circ} \mathrm{C}$.

5x MBSH: 50 mM HEPES pH 7.4, $440 \mathrm{mM} \mathrm{NaCl}, 10 \mathrm{mM} \mathrm{KCl}, 10 \mathrm{mM} \mathrm{MgSO} 4,25 \mathrm{mM}$ $\mathrm{NaHCO}_{3}, 2.05 \mathrm{mM} \mathrm{CaCl}_{2}, 1.65 \mathrm{mM} \mathrm{Ca}\left(\mathrm{NO}_{3}\right)_{2}$

\subsubsection{Embryo injections and culture}

Embryos were obtained from Xenopus laevis female frogs by HCG induced egg-laying (800 - 1000 U HCG approximately 12 hours before egg-laying). Spawns were in vitro fertilised with minced testis in $0.1 \mathrm{X}$ MBS, dejellied with 1.5-2\% cystein hydrochloride, $\mathrm{pH} 7.5$ and cultured in $0.1 \mathrm{X} \mathrm{MBS}$ at $14^{\circ} \mathrm{C}$. Albino embryos were stained with Nile Blue for $10 \mathrm{~min}$ at RT prior to injections to distinguish better between animal and vegetal poles. Injections were performed in the injection buffer on a cold plate $\left(12.5^{\circ} \mathrm{C}\right)$ vegetally into both blastomeres of the two-cell stage. 1-4 $\mathrm{nl}$ of mRNA or morpholino oligonusletide dilutions per blastomere were injected. Injected embryos were kept for at least 1 hour in the injection buffer at $12.5^{\circ} \mathrm{C}$ ad then transferred into 0.1x MBSH. The staging of embryos was done according to Nieuwkoop and Faber (1994). Grown embryos were fixed in MEMFA at RT for 1 hour and stored in $100 \%$ ethanol at $-20^{\circ} \mathrm{C}$.

Dejelly solution: $1.5-2 \%(\mathrm{w} / \mathrm{v})$ L-cysteine hydrochloride in $0.1 \mathrm{X}$ MBS, $\mathrm{pH} 8.0$;

Injection buffer: $1 \%(\mathrm{w} / \mathrm{v})$ FICOLL in $1 \mathrm{X}$ MBS;

Nile blue staining: $0.01 \%(\mathrm{w} / \mathrm{v})$ Nile Blue chloride, $89.6 \mathrm{mM} \mathrm{Na} 2 \mathrm{HPO}_{4}, 10.4 \mathrm{mM}$ $\mathrm{NaH}_{2} \mathrm{PO}_{4}, \mathrm{pH} \sim 7.8$;

HCG: $2000 \mathrm{U} / \mathrm{mL}$ human chrorionic gonadotropin (HCG) (Sigma);

10x MEM: 1 M MOPS, 20 mM EDTA, $10 \mathrm{mM} \mathrm{MgCl}$;

MEMFA: 1x MEM, 3,7\% formaldehyd 


\subsubsection{Oocytes preparations, injections and culture}

An adult Xenopus laevis female frog was anesthetised in $0.25 \%$ 3aminobenzoateethilester and operated to isolate one ovary. Oocytes of all stages of oogenesis were released from the ovary by the collagenase treatment (1 $\mathrm{mg}$ of the collagenase (Sigma) per $1 \mathrm{ml}$ of the Ca-free collagenase buffer, 1 hour, RT, upon rotation). After this step, oocytes were washed five times with 1xMBSH buffer and stage-separated according to Dumont, 1972. Injections were performed in 1x MBSH into nuclei of stage I-III oocytes. 4-10 $\mathrm{nl}$ of mRNAs per oocyte were injected. After injections, oocytes were cultured for minimum 3 days in vitellogenin-enriched L-15 medium as described before (Claussen et al., 2004). After culturing, oocytes were fixed in MEMFA at RT for $30 \mathrm{~min}$ and stored in $100 \%$ ethanol at $-20^{\circ} \mathrm{C}$.

Collagenase buffer: $82,5 \mathrm{mM} \mathrm{NaCl} ; 2 \mathrm{mM} \mathrm{KCl} ; 1 \mathrm{mM} \mathrm{MgCl}_{2} ; 5 \mathrm{mM}$ HEPES (pH 7,5)

\subsection{Histochemistry and immunohistochemistry}

3.5.1 Whole - mount in situ hybridization (Harland, 1991; Hollemann et al., 1999)

\subsubsection{Rehydration of embryos and oocytes}

Embryos and oocytes of the various stages, prefixed in MEMFA, were rehydrated as shown in the table below (the total volume in each case was $5 \mathrm{ml}$ ):

\begin{tabular}{|l|l|l|l|l|}
\hline & Ethanol (\%) & Buffer (\%) & $\begin{array}{l}\text { Incubation } \\
(\mathrm{min})\end{array}$ & No. of times \\
\hline 1. & Ethanol $100 \%$ & & 5 & $1 \times @$ \\
\hline 2. & Ethanol $75 \%$ & $\mathrm{dH}_{2} \mathrm{O} 25 \%$ & 5 & $1 \times @$ \\
\hline 3. & Ethanol $50 \%$ & $\mathrm{dH}_{2} \mathrm{O} 50 \%$ & 5 & $1 \times @$ \\
\hline 4. & Ethanol $25 \%$ & PTw $75 \%$ & 5 & $1 \times @$ \\
\hline 5. & & PTw $100 \%$ & 5 & $4 \times @$ \\
\hline
\end{tabular}

$@=$ End over end rotaion ; $\mathrm{PTw}=1 \mathrm{xPBS}+0.1 \%$ Tween -20 


\subsubsection{Proteinase-K treatment}

Up to this step, embryos of the same stage were kept together in one tube. Each stage was kept in $1 \mathrm{ml}$ PTw containing 10ug/ml Proteinase K. Embryos of gastrula, neurula and tail bud stages were incubated at room temperature (RT) for 12, 18 and 25 minutes, respectively. Oocytes were incubated at RT for maximum 6 minutes.

\subsubsection{Refixing}

Proteinase $\mathrm{K}$ treatment, though renders oocytes and embryos permeable to antisense RNA probes, makes the embryos fragile and can affect histology negatively. So in the next step, proteinase $\mathrm{K}$ activity is stopped by the treatment with acetanhydride, followed by refixation with PTw and $4 \%$ formaldehyde. The steps are as shown below:

\begin{tabular}{|l|l|l|l|l|}
\hline & Buffer & Other components & $\begin{array}{l}\text { Incubation } \\
(\mathrm{min})\end{array}$ & No. of times \\
\hline 1. & $\begin{array}{l}0.1 \mathrm{M} \text { Triethanolamine } \\
\mathrm{pH} 7.5\end{array}$ & 5 & $2 \mathrm{x} @$ \\
\hline 2. & $0.1 \mathrm{M}$ Triethanolamine & $12.5 \mu \mathrm{l}$ Acetanhydride & 5 & $1 \mathrm{x} @$ \\
\hline 3. & & $12.5 \mu$ l Acetanhydride & 5 & $1 \times 9$ \\
\hline 4. & PTw & & 5 & $2 \times @$ \\
\hline 5. & PTw $+4 \%$ FA & & 20 & $1 \times @$ \\
\hline 6. & PTw & & 5 & $5 \times @$ \\
\hline
\end{tabular}

\subsubsection{Hybridization}

Embryos and oocytes of all the stages were distributed into tubes such that each tube for each of the RNA-probes contained all the stages. Oocytes and embryos were kept in $1 \mathrm{ml}$ PTw to which was added 250ul of Hybridization-Mix, sucked off and 1ml Hybridization-Mix added and incubated at $65^{\circ} \mathrm{C}$ for 10 minutes, this was again sucked off and $1 \mathrm{ml}$ of fresh Hybridization-Mix added and incubated at $60^{\circ} \mathrm{C}$ for 6 hours. The Hybridization -Mix was replaced with $1 \mathrm{ml}$ of new Hybridization buffer to which was added $1 \mu \mathrm{g} / \mathrm{ml}$ of the respective antisense RNA probes and incubated at $60^{\circ} \mathrm{C}$ overnight. 


\subsubsection{Washing}

\begin{tabular}{|c|c|c|c|c|}
\hline & Buffer & Temperature $\left({ }^{\circ} \mathrm{C}\right)$ & Incubation(min) & No. of times \\
\hline 1. & $\begin{array}{l}\text { Hybridization buffer } \\
(500 \mu \mathrm{l})\end{array}$ & 60 & 10 & $1 x$ \\
\hline 2. & $2 \times \mathrm{SSC}$ & 60 & 20 & $3 x$ \\
\hline 3. & $2 \times$ SSC with RNasen* & 37 & 30 & $2 x$ \\
\hline 4. & $2 \times \mathrm{SSC}$ & RT & 10 & $1 x$ \\
\hline 5. & $0.2 \times \mathrm{SSC}$ & 60 & 30 & $2 x$ \\
\hline 6. & MAB & RT & 15 & $2 x$ \\
\hline
\end{tabular}

*RNAse A $20 \mu \mathrm{g} / \mathrm{ml}$ (Sigma R-5000)-dissolved in TE $10 \mathrm{mg} / \mathrm{ml}, 100^{\circ} \mathrm{C} 10 \mathrm{~min}$ ); RNAse $\mathrm{T} 110 \mathrm{U} / \mathrm{ml}$ (Sigma R-8251). Aliquoted and stored at $-20^{\circ} \mathrm{C}$

Steps 3 and 4 were omitted for oocytes.

\subsubsection{Antibody-Incubation}

In this step the oocytes and embryos were incubated with Alkaline Phosphatase(AP)linked anti Dig-antibody or with anti-fluorescing antibody for the FastRed staining (Sigma).

\begin{tabular}{|l|l|l|l|l|}
\hline & Buffer & Temperature $\left({ }^{\circ} \mathrm{C}\right)$ & $\begin{array}{l}\text { Incubation } \\
(\mathrm{min})\end{array}$ & No. of times \\
\hline 1. & MAB $+2 \%$ BMB & RT & 60 & $1 \mathrm{x}-$ \\
\hline 2. & $\begin{array}{l}\text { MAB }+2 \% \text { BMB } \\
20 \% \text { Serum }\end{array}$ & RT & 60 & $1 \mathrm{x}-$ \\
\hline 3. & $\begin{array}{l}\text { MAB }+2 \% \text { BMB } \\
20 \% \quad \text { Serum } \\
\text { Antibody }{ }^{*}(1: 5.000)\end{array}$ & RT & 240 & $1 x-$ \\
\hline 4. & MAB (Washing) & RT & 30 & $2 x-$ \\
\hline 5. & MAB (Washing) & 4 & over night & $1 x-$ \\
\hline
\end{tabular}

*Sheep-Anti-Dig antibody linked to Alkaline Phosphatase or anti-fluorescing antibody for the FastRED staining 


\subsubsection{Colour reaction}

NBT/BCIP is the substrate for Alkaline Phosphatase, which converts it to a coloured product.

\begin{tabular}{|l|l|l|l|l|}
\hline & Buffer & Temperature $\left({ }^{\circ} \mathrm{C}\right)$ & Incubation $(\min )$ & No. of times \\
\hline 1. & MAB & RT & 60 & $1 \mathrm{x}$ \\
\hline 2. & APB & RT & 5 & $2 \mathrm{x}$ \\
\hline 3. & APB $+\mathrm{NBT} / \mathrm{BCIP}^{\star *}$ & RT & $5 \mathrm{~min}-24 \mathrm{~h}$ & $1 \mathrm{x}$ \\
\hline
\end{tabular}

**1.5 $\mu 1 \mathrm{NBT} / \mathrm{ml} \mathrm{APB;} 3.5 \mu 1 \mathrm{BCIP} / \mathrm{ml}$ APB

Double WMISH was performed according to Knecht et al. (1995) (Knecht et al., 1995).

After NBT/BCIP treatment oocytes and embryos were incubated once in MEMFA at room temperature for 15 minutes, followed by an overnight incubation in MEMFA at room temperature and stored in $1 \mathrm{x}$ MEM at $4^{\circ} \mathrm{C}$.

20X SSC: $3 \mathrm{M} \mathrm{NaCl}, 0.3 \mathrm{M} \mathrm{NaCitrat,} \mathrm{pH} 7.2$ - 7.4;

10X PBS: $1.75 \mathrm{M} \mathrm{NaCl}, 1 \mathrm{M} \mathrm{KCl}, 65$ mM Na $2 \mathrm{HPO}_{4}, 18$ mM KH $2 \mathrm{PO}_{4}, \mathrm{pH}$ 7.4;

5X MAB: $500 \mathrm{mM}$ maleic acid, $750 \mathrm{mM} \mathrm{NaCl}, \mathrm{pH}$ 7.5;

Hybridization Mix (Hyb Mix): 50\% Formamid (deionisiert), $1 \mathrm{mg} / \mathrm{ml}$; Torula-RNA, 10 $\mu \mathrm{g} / \mathrm{ml}$ Heparin, $1 X$ Denhardt's, 0.1\% Tween-20, 0.1\% CHAPS, 10 mM EDTA in 5X SSC;

NBT: $100 \mathrm{mg} / \mathrm{mL}$ in $70 \%$ Dimethylformamide; stored at $-20^{\circ} \mathrm{C}$;

BCIP: $50 \mathrm{mg} / \mathrm{mL}$ in $100 \%$ Dimethylformamide; stored at $-20^{\circ} \mathrm{C}$;

EtOH series: $100 \%, 75 \%, 50 \%$ ethanol in $\mathrm{H}_{2} \mathrm{O}$, respectively, $25 \%$ ethanol inPTw;

MeOH series: $100 \%, 75 \%, 50 \%, 25 \%$ methanol in $\mathrm{H}_{2} \mathrm{O}$, respectively;

PTw: $0.1 \%$ Tween-20 in $1 \mathrm{X}$ PBS;

Proteinase K: $5 \mu \mathrm{g} / \mathrm{ml}$ Proteinase $\mathrm{K}$ in $0.1 \mathrm{X}$ PBS;

PTw/MEMFA: 4\% (v/v) formaldehyde in PTw;

MAB/BMB: $2 \%$ BMB in $1 \mathrm{X}$ MAB;

MAB/BMB/HS: $2 \%$ BMB, $20 \%$ heat treated horse serum in $1 \mathrm{X}$ MAB;

Antibody solution: 2\% BMB, 20\% heat treated horse serum, 1:5000 dilution of an antibody in $1 \mathrm{X}$ MAB;

APB: 100 mM Tris-HCl, pH 9.0, 50 mM MgCl2, 100 mM NaCl, 0.1\% TWEEN-20 
3.5.2 In situ hybridization on paraffin sections (Collombat et al., 2003)

\subsubsection{Sample preparation}

Embryos were fixed for 1 hour in MEMFA and transferred into 100\% ethanol for storage. For paraffin embedding, embryos were incubated in Xylene (2x 20 minutes), followed by incubation in molten paraffin $\left(2 \times 1\right.$ hour at $\left.60^{\circ} \mathrm{C}\right)$ and then embedded in paraffin. A microtome was used to prepare $5 \mu \mathrm{m}$ tissue sections and fixed onto precoated glass slides.

\subsubsection{Dewaxing and rehydration}

Sectioned material was dewaxed in Xylene ( $2 \mathrm{x} 10$ minutes) and rehydrated in a decreasing series of ethanol $(100 \%, 95 \%, 80 \%, 70 \%$ and $40 \%$ ethanol, respectively). Dehydrated tissue sections were then refixed for 20 minutes using 4\% Formaldehyde in 1x PBS, pH 8.0.

\subsubsection{Prehybridisation treatments}

Rehydrated samples were prepared for hybridisation as follows:

1 Rinse slide in 2x SSPE;

2 Incubate slides in Proteinase $\mathrm{K}$ solution at $37^{\circ} \mathrm{C}$ for 30 minutes $(3 \mu \mathrm{g} / \mathrm{ml}$ Prot.K in o.1M Tris $\mathrm{pH} 7.5,10 \mathrm{mM}$ EDTA);

3 Rinse slides in 2x SSPE;

4 Incubate slides in $0.2 \mathrm{M} \mathrm{HCl}$ for 15 minutes at RT;

5 Rinse slides in 2x SSPE;

6 Transfer slides to $0.1 \mathrm{M}$ triethanolamine, $\mathrm{pH} 8.0$, add $0.25 \%$ acetic anhydride while agitating slides; repeat after 5 minutes;

7 Rinse slides in 2x SSPE;

8 Put $300 \mu 1$ hybridisation buffer on each slide. Incubate in a humid chamber for approximately 2 hours. 


\subsubsection{Hybridisation}

1 Heat probes for 5 minutes at $70^{\circ} \mathrm{C}$;

2 Drain off excess hybridisation buffer. Add $1 \mu \mathrm{g} / \mathrm{ml}$ probe solution and return slides to the humid chamber and incubate overnight.

\subsubsection{Post Hybridisation}

1 Rinse slides in $2 x \operatorname{SSPE}\left(65^{\circ} \mathrm{C}\right)$;

2 Add $300 \mu 1$ hybridisation buffer to each slide. Incubate at $65^{\circ} \mathrm{C}$ for 10 minutes;

3 Drain slides and add $300 \mu 150 \%$ hybridisation buffer; 50\% 2x SSPE $+0.3 \%$ CHAPS. Incubate at $65^{\circ} \mathrm{C}$ for 10 minutes;

4 Add $500 \mu 12 x$ SSPE + 0.3\% CHAPS. Incubate at RT for 30 minutes;

5 Rinse slides in 2x SSPE for 30 minutes;

6 Incubate slides in $0.02 \mu \mathrm{g} / \mathrm{ml}$ Rnase $\mathrm{A}$ in $4 \mathrm{x}$ SSPE at $37^{\circ} \mathrm{C}$ for 30 minutes;

7 Wash slides with $50 \%$ formamide in $2 \mathrm{x}$ SSPE at $65^{\circ} \mathrm{C}$ for 45 minutes;

8 Drain slides and add $500 \mu \mathrm{l}$ of $2 \mathrm{x}$ SSPE $+0.3 \%$ CHAPS. Incubate at RT for 10 minutes;

9 Rinse slides 3x, 10 minutes each in buffer1 (100mM Tris-HCl pH 7.5, $150 \mathrm{mM} \mathrm{NaCl})$;

10 Add $500 \mu 1$ 1\% BMB/20\% serum in buffer1 to each slide. Incubate at RT for 2 hours;

11 Drain slides and add $200 \mu 1$ 1/1000 anti-Dig-AP or anti-Flu-AP fragments in buffer 1. Incubate at RT for 1 hour;

12 Rinse slides 3x 10 minutes in buffer 1;

13 Rinse slides for 10 minutes in APB;

14 Add $1 \mathrm{ml}$ colour development solution to each slide. Develop in dark at RT;

15 Rinse in water to stop reaction, rinse quickly in methanol;

16 Fix in MEMFA for 40 minutes. Rinse in 1x PBS/Tween for 3x 7 minutes each before mounting in PBS glycerol $(1: 10)$

For double in situ hybridisation on sections, the second staining was performed by starting from step 9.

20x SSPE: $3.6 \mathrm{M} \mathrm{NaCl}, 0.2 \mathrm{M} \mathrm{NaH}_{2} \mathrm{PO}_{4} * 1 \mathrm{H}_{2} \mathrm{O}, 20 \mathrm{mM}$ EDTA, pH 7.4;

Buffer 1: $100 \mathrm{mM}$ Tris - $\mathrm{HCl} \mathrm{pH} 7.5,150 \mathrm{mM} \mathrm{NaCl}$;

Buffer 3: $100 \mathrm{mM}$ Tris - $\mathrm{HCl} \mathrm{pH}$ 9.5, $100 \mathrm{mM} \mathrm{NaCl}, 50 \mathrm{mM} \mathrm{MgCl} 2,0.1 \%$ Tween-20. 


\subsubsection{TUNEL-staining}

The TdT-mediated dUTP digoxygenin nick end-labeling (TUNEL) staining technique was modified from Hensey and Gautier (1997) (Hensey and Gautier, 1997). Embryos were rehydrated with the $\mathrm{MeOH}$ series to PBS. After one wash in PBS for $10 \mathrm{~min}$, the solution was exchanged twice with PTw, 15 min each. Embryos were washed twice in PBS for 20 min before they were incubated for 1 hour in TdT buffer. During this pre-incubation step and the following overnight incubation vials were standing upright. End-labeling was carried out overnight at RT in TdT buffer containing $0.5 \mathrm{mM}$ digoxygenin-dUTP and $150 \mathrm{U} / \mathrm{ml}$ terminal deoxynucleotidyl transferase (Invitrogene). Embryos were washed twice for 2 hours with PBS/EDTA at $65^{\circ} \mathrm{C}$ in a water bath. After washing embryos four times for 1 hour in PBS, it was exchanged with PBT and incubated for $20 \mathrm{~min}$. Embryos were blocked for 1 hour by incubation in PBT containing 20\% heat-treated horse serum. Embryos were placed in the antibody solution and incubated overnight at $4^{\circ} \mathrm{C}$. To remove unbound antibody, embryos were washed 8 times in PBT and then washed overnight in PBT at $4{ }^{\circ} \mathrm{C}$. The chromogenic reaction was performed as described for WMISH.

TdT Buffer: 1X TdT (Invitrogene) in 1X PBS;

PBS/EDTA: 1 mM EDTA in 1X PBS;

PBT: $2 \mathrm{mg} / \mathrm{ml} \mathrm{BMB,} 0.1 \%$ Triton-X-100 in PBS;

Antibody solution: 20\% heat-treated horse serum, 1:2,000 dilution of antidigoxigenin alkaline phosphatase coupled antibody (Roche).

3.5.4 Vibratome sectioning (Hollemann et al., 1999)

Oocytes and embryos were embedded in gelatin-albumin, which was polymerised by mixing $2 \mathrm{ml}$ of it with $125 \mu \mathrm{l}$ of $25 \%$ glutaldehyde. $30 \mu \mathrm{m}$ vibratome sections were made using a Leica VT1000S Vibratome. Sectioned tissue samples were mounted on glass slides using mowiol.

Gelatin/albumin: $4.88 \mathrm{mg} / \mathrm{ml}$ gelatin, $0.3 \mathrm{~g} / \mathrm{ml}$ bovines serum albumin, $0.2 \mathrm{mg} / \mathrm{ml}$ sucrose in PBS. The gelatin was dissolved by heating the solution to $60^{\circ} \mathrm{C}$. Albumin and sucrose was added, filtered with a $0.45 \mu \mathrm{m}$ filter (Satorius) and stored at $-20^{\circ} \mathrm{C}$;

Mowiol: $5 \mathrm{~g}$ Mowiol was stirred overnight in $20 \mathrm{ml}$ PBS. After addition of $10 \mathrm{ml}$ glycerol, the solution was stirred again overnight. Not dissolved Mowiol was collected by 
centrifugation for $30 \mathrm{~min}$ at $20,000 \mathrm{~g}$. The supernatant was $\mathrm{pH}$ adjusted to $\mathrm{pH} 7.0$ (using $\mathrm{pH}$ strips) and stored at $-20^{\circ} \mathrm{C}$.

3.5.5 Immunohistochemistry (modified from Hollemann et al., 1999; Collombat et al., 2003)

Paraffin embedded sectioned samples were dewaxed in xylene, rehydrated through a decreasing series of ethanol, and, finally, in 1xPBS. Vibratome sections were collected in 1xPBS directly. Both types of samples were blocked in 10\% Ficoll/ 1x PBS for $45 \mathrm{~min}$ at RT, followed by the incubation with primary antibodies (appropriate antibody dilution in the blocking buffer) $\mathrm{ON}$ at $4^{\circ} \mathrm{C}$. Following primary antibodies were used:

sheep anti Xpat (1:300) (Machado et al., 2005);

mouse anti-myc 9E10 (1:1000, Sigma);

mouse anti-FLAG (1:2000, Sigma);

rabbit anti-XGRIP2.1 (1:100; BioScienses).

On the next day, samples were washed trice with 1xPBS and incubated with the secondary antibody in the blocking buffer for $45 \mathrm{~min}$ at RT (for fluorescently labelled secondary antibodies this step was performed in dark). Following secondary antibodies were used:

FITC-conjugated anti-sheep (1:1000; Sigma);

Cy3-conjugated anti-mouse (1:500; Dianova);

Alexa conjugated anti-rabbit (1:1000, Sigma).

Alkaline- phosphatase conjugated anti-mouse (1:2000, Sigma).

Staining reaction with alkaline-phosphatase was done as described for the WMISH (APB washings and NBT/ BCIP colour development). Fluorescent immunostainings were washed trice again with 1xPBS and documented with a LSM 510 confocal microscope (Zeiss) or AxioPlan 2 fluorescence stereomicroscope (Zeiss).

\subsubsection{Time-lapse analysis of PGC migration in vivo}

Embryos injected with mRNAs encoding different GFP versions (see Materials) were cultured till stage 26 to 42 , followed by selection of ones with the brightest GFP expression in PGCs. These embryos were subjected for the time-lapsing using LumarV.12 fluorescence stereomicroscope (GFP_A filter), AxioCam camera and AxioPlan software (Zeiss). For time- 
lapsing embryos were placed in a $30 \mathrm{~mm}$ Petri-dish, anesthetised and immobilised by a piece of a glass coverslit having wax "stems" to prevent smashing. Time-lapse movies were acquired at RT for 4-8 hours with 1 frame per 15-20 min image collection.

\subsubsection{Cultivation of isolated PGC}

Embryos were injected vegetally into both blastomeres at 2-cell stage with $0.4 \mathrm{ng}$ of the synthetic mRNA encoding for enhanced GFP (EGFP) ORF fused to the XDead end LE, grown until stage 31-33 and sorted for the presence of PGC-specific GFP expression. Tailbud stage embryos with PGC-specific GFP expression were placed in a $60 \mathrm{~mm}$ Petri-dish coated with $0.7 \%$ agarose and then dissolved in the $\mathrm{Ca} / \mathrm{Mg}$-free medium or in the accutase solution (Sigma). GFPexpressing PGCs were manually sorted out from the endodermal cells mass and whether left in accutase or transferred into another culturing medium. Overall behaviour and movement of single PGCs in different culturing conditions was observed by time-lapsing using LumarV.12 fluorescence stereomicroscope (GFPA filter), AxioCam camera and AxioPlan software (Zeiss). Time-lapse movies were acquired at RT for $5 \mathrm{~min}$ with 1 frame per $10 \mathrm{sec}$ image collection.

PGC behaviour and migration was observed in the following buffer conditions:

1. $1 \mathrm{xMBSH}$ on an $0.7 \%$ agarose;

2. $1 \mathrm{xMBSH}$ on a fibronectin coated dish;

3. Accutase solution (Sigma) on an $0.7 \%$ agarose;

4. $\mathrm{Ca} / \mathrm{Mg}$ free medium on $0.7 \%$ agarose;

5. DFA-medium on a fibronectin coated dish;

Ca/Mg free medium: $10 \mathrm{mM}$ HEPES pH 7.4, $88 \mathrm{mM} \mathrm{NaCl}, 1 \mathrm{mM} \mathrm{KCl}, 2.4 \mathrm{mM}$ $\mathrm{NaHCO}_{3}, 0.66 \mathrm{mM} \mathrm{KNO}_{3}$;

DFA (Danilchik's for Amy) - medium: $53 \mathrm{mM} \mathrm{NaCl}, 5 \mathrm{mM} \mathrm{Na} \mathrm{CO}_{3}, 4.5 \mathrm{mM}$ potassium gluconate, $32 \mathrm{mM}$ sodium gluconate, $1 \mathrm{mM} \mathrm{MgSO}_{4}, 1 \mathrm{mM} \mathrm{CaCl}, 0.1 \%$ (w/v) BSA, $\mathrm{pH} 8.3$ with $1 \mathrm{M}$ bicine, filtered and stored at $-20^{\circ} \mathrm{C}$. 


\section{Results}

\subsection{Functional characterization of XGRIP2.1}

\subsubsection{Isolation of the XGRIP2.1 full length cDNA}

Initially, the $1617 \mathrm{bp}$ 3'UTR and part of the ORF sequence of XGRIP2.1 (termed first velo59) cDNA were identified by a microarray-based screen of a cDNA library enriched in vegetally localizing mRNAs (Horvay et al., 2006). 5'RACE extension of this fragment was performed. The resulting $2.5 \mathrm{~kb}$ product contained $125 \mathrm{bp}$ of the XGRIP2.1 5'UTR and the missing part of the ORF. The full length 4994 bp XGRIP2.1 cDNA (GenBank accession no. EF139240, Fig. 4.1) was amplified from total oocyte stage V-IV cDNA.

\footnotetext{
1 GCGCTACTGG ACCGCGGCGA ATCTTATGAC CGCGCTTAGT GTATGCGGCA ATCTCTGTCC

61 CTGTCTGAAA AGTCAACGTG AGAAGAGGGG TATTGATCCC CCCCAGCCAA TGAAGAACCT

121 CTAAATGCAT TTTTTCCAGA CCATTCTTAG GTGGAAGACT GCAAAAGGCC AGAAGTCCGT $\begin{array}{llllllllllllllllll}- & M & H & F & F & Q & T & I & L & R & W & K & T & A & K & G & Q & K\end{array}$

181 AACCTTCAAA AAgGATGATG GCCCCTACTC CAAAgGAAAC AAAgATCCAg CCGgAAATGA $\begin{array}{lllllllllllllllllllll}V & \mathrm{~T} & \mathrm{~F} & \mathrm{~K} & \mathrm{~K} & \mathrm{D} & \mathrm{D} & \mathrm{G} & \mathrm{P} & \mathrm{Y} & \mathrm{S} & \mathrm{K} & \mathrm{G} & \mathrm{N} & \mathrm{K} & \mathrm{D} & \mathrm{P} & \mathrm{A} & \mathrm{G} & \mathrm{N}\end{array}$

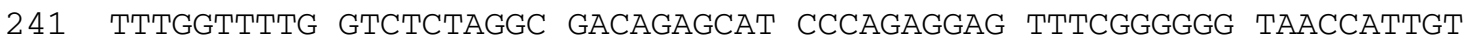
$\begin{array}{lllllllllllllllllllll}D & \mathrm{~L} & \mathrm{~V} & \mathrm{~L} & \mathrm{~V} & \mathrm{~S} & \mathrm{R} & \mathrm{R} & \mathrm{Q} & \mathrm{S} & \mathrm{I} & \mathrm{P} & \mathrm{E} & \mathrm{E} & \mathrm{F} & \mathrm{R} & \mathrm{G} & \mathrm{V} & \mathrm{T} & \mathrm{I}\end{array}$

301 GgAgCtgAtT AgGAAAgAAg GAAgtACGTt GgGgCtGACC ATCTCCGgtg GtACAgACAA $\begin{array}{llllllllllllllllllll}V & E & L & I & R & K & E & G & S & T & L & G & L & T & I & S & G & G & T & D\end{array}$

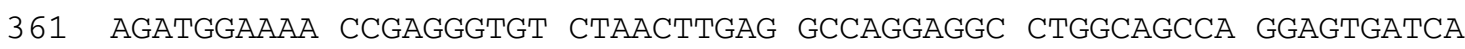
$\begin{array}{llllllllllllllllllll}K & \mathrm{D} & \mathrm{G} & \mathrm{K} & \mathrm{P} & \mathrm{R} & \mathrm{V} & \mathrm{S} & \mathrm{N} & \mathrm{L} & \mathrm{R} & \mathrm{P} & \mathrm{G} & \mathrm{G} & \mathrm{L} & \mathrm{A} & \mathrm{A} & \mathrm{R} & \mathrm{S} & \mathrm{D}\end{array}$

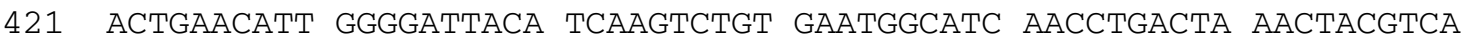
$\begin{array}{llllllllllllllllllll}\mathrm{Q} & \mathrm{L} & \mathrm{N} & \mathrm{I} & \mathrm{G} & \mathrm{D} & \mathrm{Y} & \mathrm{I} & \mathrm{K} & \mathrm{S} & \mathrm{V} & \mathrm{N} & \mathrm{G} & \mathrm{I} & \mathrm{N} & \mathrm{L} & \mathrm{T} & \mathrm{K} & \mathrm{L} & \mathrm{R}\end{array}$

481 TgAagAgAtC ATCAgCCTGC TGAAAAACGT GggCGAgCGA GTgGtCCTAg AAgtggagtA $\begin{array}{lllllllllllllllllllll}\mathrm{H} & \mathrm{E} & \mathrm{E} & \mathrm{I} & \mathrm{I} & \mathrm{S} & \mathrm{L} & \mathrm{L} & \mathrm{K} & \mathrm{N} & \mathrm{V} & \mathrm{G} & \mathrm{E} & \mathrm{R} & \mathrm{V} & \mathrm{V} & \mathrm{L} & \mathrm{E} & \mathrm{V} & \mathrm{E}\end{array}$

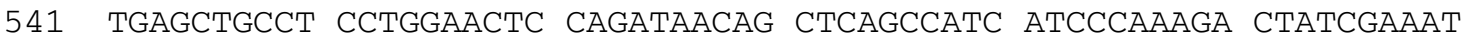
$\begin{array}{lllllllllllllllllllll}\mathrm{Y} & \mathrm{E} & \mathrm{L} & \mathrm{P} & \mathrm{P} & \mathrm{G} & \mathrm{T} & \mathrm{P} & \mathrm{D} & \mathrm{N} & \mathrm{S} & \mathrm{S} & \mathrm{A} & \mathrm{I} & \mathrm{I} & \mathrm{P} & \mathrm{K} & \mathrm{T} & \mathrm{I} & \mathrm{E}\end{array}$

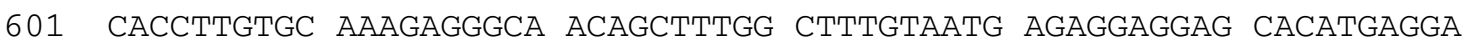
$\begin{array}{llllllllllllllllllllllll}I & T & \mathrm{~L} & \mathrm{C} & \mathrm{K} & \mathrm{E} & \mathrm{G} & \mathrm{N} & \mathrm{S} & \mathrm{F} & \mathrm{G} & \mathrm{F} & \mathrm{V} & \mathrm{M} & \mathrm{R} & \mathrm{G} & \mathrm{G} & \mathrm{A} & \mathrm{H} & \mathrm{E}\end{array}$

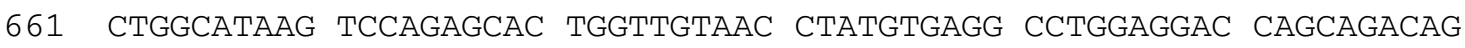
$\begin{array}{lllllllllllllllllllllll}\mathrm{D} & \mathrm{W} & \mathrm{H} & \mathrm{K} & \mathrm{S} & \mathrm{R} & \mathrm{A} & \mathrm{L} & \mathrm{V} & \mathrm{V} & \mathrm{T} & \mathrm{Y} & \mathrm{V} & \mathrm{R} & \mathrm{P} & \mathrm{G} & \mathrm{G} & \mathrm{P} & \mathrm{A} & \mathrm{D}\end{array}$

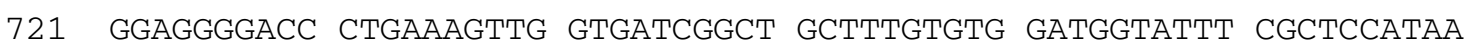
$\begin{array}{lllllllllllllllllllll}R & E & G & T & L & K & V & G & D & R & \text { L } & \text { L } & C & \text { V } & \text { D } & \text { G } & \text { I } & \text { S } & \text { L } & \text { H }\end{array}$

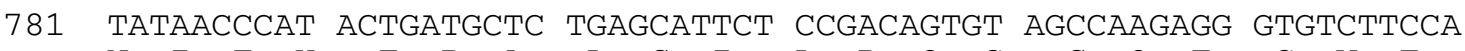
$\begin{array}{llllllllllllllllllll}N & I & T & H & \text { T } & \text { D } & A & \text { L } & \text { S } & \text { I } & \text { L } & R & Q & C & S & Q & E & G & V & F\end{array}$

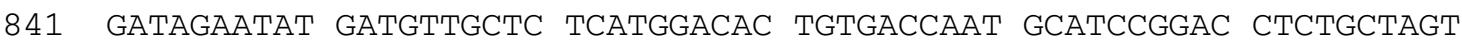


$\begin{array}{llllllllllllllllllll}Q & I & E & Y & D & V & A & L & M & D & T & V & T & N & A & S & G & P & L & L\end{array}$

901 GGAAATCGCC AAGACCCCAG GATCTACTCT GGGAATTTCT CTGAGCACAG GAACTCACCG $\begin{array}{llllllllllllllllllll}V & E & I & A & K & T & P & G & S & T & L & G & I & S & L & S & T & G & T & H\end{array}$

961 AAACAAGCAG GTCATTGTTA TAgACAAGgT GAAACCTGCC AGTGTGGTGg ACAgGTGCGg $\begin{array}{llllllllllllllllllll}R & N & K & Q & V & I & V & I & D & K & V & K & P & A & S & V & V & D & R & C\end{array}$

1021 AgCTCTGCAT CCAGGgGATC ACATTCTGTC CATCGATGGC ACTAGCACAg AgCACTGCAC $\begin{array}{llllllllllllllllllllll}G & A & L & H & P & G & D & H & I & L & S & I & D & G & T & S & T & E & H & C\end{array}$

1081 TCAAATGGAA GCCACGCAGC TCTTGGCCAg CATCATAGAg AATGTAAAAC TGgAAATTCT

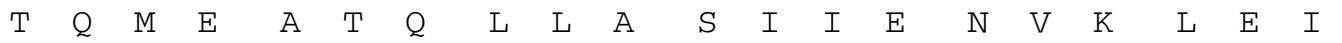

1141 CCCAGCCCAT CACAACAgAC tCCCTCTGAg ACCCCCAGAA ACGgTTAAgG tTCAGAAGAG $\begin{array}{llllllllllllllllllll}\mathrm{L} & \mathrm{P} & \mathrm{A} & \mathrm{H} & \mathrm{H} & \mathrm{N} & \mathrm{R} & \mathrm{L} & \mathrm{P} & \mathrm{L} & \mathrm{R} & \mathrm{P} & \mathrm{P} & \mathrm{E} & \mathrm{T} & \mathrm{V} & \mathrm{K} & \mathrm{V} & \mathrm{Q} & \mathrm{K}\end{array}$

1201 CGATCATCAT CACTGTTGg ACCCCTGTgt TAACTACTGC CATACACCCC ATCCTGGgCA $\begin{array}{llllllllllllllllllll}\mathrm{S} & \mathrm{D} & \mathrm{H} & \mathrm{H} & \mathrm{H} & \mathrm{C} & \mathrm{W} & \mathrm{D} & \mathrm{P} & \mathrm{C} & \mathrm{V} & \mathrm{N} & \mathrm{Y} & \mathrm{C} & \mathrm{H} & \mathrm{T} & \mathrm{P} & \mathrm{H} & \mathrm{P} & \mathrm{G}\end{array}$

1261 CTGCAAGACT CCAACATGgA ACCCTACGTC TAACCAAGAC TATTGCAAGT CGTTGGTTGC $\begin{array}{lllllllllllllllllllll}\mathrm{H} & \mathrm{C} & \mathrm{K} & \mathrm{T} & \mathrm{P} & \mathrm{T} & \mathrm{W} & \mathrm{N} & \mathrm{P} & \mathrm{T} & \mathrm{S} & \mathrm{N} & \mathrm{Q} & \mathrm{D} & \mathrm{Y} & \mathrm{C} & \mathrm{K} & \mathrm{S} & \mathrm{L} & \mathrm{V}\end{array}$

1321 TGCCAATTTC TCTTCCTCCT CTGtAGCCGg AACACCGgGA TTtAgCAgCC AgAATTCCAA $\begin{array}{llllllllllllllllllll}A & A & N & F & S & S & S & S & V & A & G & T & P & G & F & S & S & Q & N & S\end{array}$

1381 TACCCTTCCA CGCACAgTGC ACCCAATGAg CCCAAGAACC ACTATGAACA GgAgGCGACA $\begin{array}{llllllllllllllllllll}\mathrm{N} & \mathrm{T} & \mathrm{L} & \mathrm{P} & \mathrm{R} & \mathrm{T} & \mathrm{V} & \mathrm{H} & \mathrm{P} & \mathrm{M} & \mathrm{S} & \mathrm{P} & \mathrm{R} & \mathrm{T} & \mathrm{T} & \mathrm{M} & \mathrm{N} & \mathrm{R} & \mathrm{R} & \mathrm{R}\end{array}$

1441 GAAAAGGAAG GACCATAAAA ACTCCTTGTC CTTGGCTTCC AGTACTGTGG GGCCTGGTGG $\begin{array}{llllllllllllllllllll}\mathrm{Q} & \mathrm{K} & \mathrm{R} & \mathrm{K} & \mathrm{D} & \mathrm{H} & \mathrm{K} & \mathrm{N} & \mathrm{S} & \mathrm{L} & \mathrm{S} & \mathrm{L} & \mathrm{A} & \mathrm{S} & \mathrm{S} & \mathrm{T} & \mathrm{V} & \mathrm{G} & \mathrm{P} & \mathrm{G}\end{array}$

1501 GCAgAtAATA CACACGgAgA GCACAgAgAt CATTCTACGT GgAgATCCAT tAAATGgTTT $\begin{array}{llllllllllllllllllll}G & Q & I & I & H & T & E & S & T & E & I & I & L & R & G & D & P & L & N & G\end{array}$

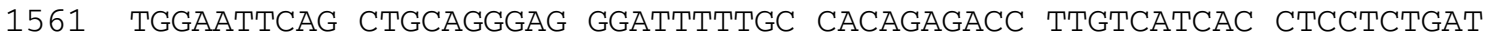
$\begin{array}{lllllllllllllllllllll}F & G & I & Q & L & Q & G & G & I & F & A & T & E & T & L & S & S & P & P & L\end{array}$

1621 AAgGTTTATT GAgCCAGACA GTCCCGCTGA GAgGTGTGgG CTCCTACAgG TTGGgGACAG $\begin{array}{llllllllllllllllllll}I & R & F & I & E & P & D & S & P & A & E & R & C & G & L & L & Q & V & G & D\end{array}$

1681 ACTACTTTCG ATTAATGgGA TCCTGACTgA AgATgGgACG CTAGAAgAAg CCAACCAGCT $\begin{array}{lllllllllllllllllllll}R & \mathrm{~L} & \mathrm{~L} & \mathrm{~S} & \mathrm{I} & \mathrm{N} & \mathrm{G} & \mathrm{I} & \mathrm{L} & \mathrm{T} & \mathrm{E} & \mathrm{D} & \mathrm{G} & \mathrm{T} & \mathrm{L} & \mathrm{E} & \mathrm{E} & \mathrm{A} & \mathrm{N} & \mathrm{Q}\end{array}$

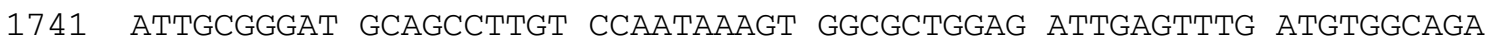
$\begin{array}{lllllllllllllllllllllllllll}\mathrm{L} & \mathrm{L} & \mathrm{R} & \mathrm{D} & \mathrm{A} & \mathrm{A} & \mathrm{L} & \mathrm{S} & \mathrm{N} & \mathrm{K} & \mathrm{V} & \mathrm{A} & \mathrm{L} & \mathrm{E} & \mathrm{I} & \mathrm{E} & \mathrm{F} & \mathrm{D} & \mathrm{V} & \mathrm{A}\end{array}$

1801 GTCTGTGgTt CCCAGCAgtg GTACGTTCCA CGTCAAACTG CCGAAAAGGA AAgGAgtgGA $\begin{array}{lllllllllllllllllllll}\mathrm{E} & \mathrm{S} & \mathrm{V} & \mathrm{V} & \mathrm{P} & \mathrm{S} & \mathrm{S} & \mathrm{G} & \mathrm{T} & \mathrm{F} & \mathrm{H} & \mathrm{V} & \mathrm{K} & \mathrm{L} & \mathrm{P} & \mathrm{K} & \mathrm{R} & \mathrm{K} & \mathrm{G} & \mathrm{V}\end{array}$

1861 GTTGgGgATC ACCATCAgCt CCAgCAgAAA ACCAGGgGAg CCGTTAATtA tATCCGACAT $\begin{array}{llllllllllllllllllll} & \mathrm{L} & \mathrm{G} & \mathrm{I} & \mathrm{T} & \mathrm{I} & \mathrm{S} & \mathrm{S} & \mathrm{S} & \mathrm{R} & \mathrm{K} & \mathrm{P} & \mathrm{G} & \mathrm{E} & \mathrm{P} & \mathrm{L} & \mathrm{I} & \mathrm{I} & \mathrm{S} & \mathrm{D}\end{array}$

1921 CAAGAAgGgC AgCGTGgCAC ACAgAACCGg CACCTTAgAg CCTGgAgAtA AACTgtTgGC $\begin{array}{lllllllllllllllllllllll}I & K & K & G & S & V & A & H & R & T & G & T & L & E & P & G & D & K & L & L\end{array}$

1981 CATTGACAAC ATCCGACTGg ACAATTGCTC TATGgAgGAT GCTGTGCAgA TACTGCGCCA $\begin{array}{llllllllllllllllllll}A & I & D & N & I & R & L & D & N & C & S & M & E & D & A & V & Q & I & L & R\end{array}$

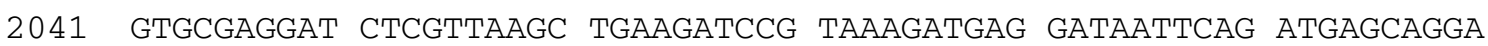
$\begin{array}{llllllllllllllllllll}\mathrm{Q} & \mathrm{C} & \mathrm{E} & \mathrm{D} & \mathrm{L} & \mathrm{V} & \mathrm{K} & \mathrm{L} & \mathrm{K} & \mathrm{I} & \mathrm{R} & \mathrm{K} & \mathrm{D} & \mathrm{E} & \mathrm{D} & \mathrm{N} & \mathrm{S} & \mathrm{D} & \mathrm{E} & \mathrm{Q}\end{array}$

2101 GACTTCTGGT GCCATTATAT ACACCGTTGA GCTCAAGAGA TGCGgTGgGC CACTGGGGAT $\begin{array}{llllllllllllllllllll}E & T & S & G & A & I & I & Y & T & V & E & L & K & R & C & G & G & P & L & G\end{array}$

2161 CACAATATCA GgGACTGAgG AgCCATTTGA TCCAATTGTT ATCTCTGgGC TTACAAAAAg $\begin{array}{llllllllllllllllllll}I & T & I & S & G & T & E & E & P & F & D & P & I & V & I & S & G & L & T & K\end{array}$

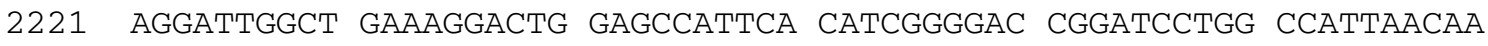
$\begin{array}{llllllllllllllllllll}R & G & L & A & E & R & T & G & A & I & H & I & G & D & R & I & L & A & I & N\end{array}$ 
2281 CATTAGCCTG AAAGGAAAAC CACTAAGTGA AGCCATCCAC CTTCTTCAAA TGGCAGGAGA $\begin{array}{lllllllllllllllllllllllllll}N & I & S & L & K & G & K & P & L & S & E & A & I & H & L & L & Q & M & A & G\end{array}$

2341 AACTGTGACC CTCAAGATAA AgAAACAgAC AgAgCGAATA TTCCCCCAAA GgCTTTCAGA $\begin{array}{llllllllllllllllllll}\mathrm{E} & \mathrm{T} & \mathrm{V} & \mathrm{T} & \mathrm{L} & \mathrm{K} & \mathrm{I} & \mathrm{K} & \mathrm{K} & \mathrm{Q} & \mathrm{T} & \mathrm{E} & \mathrm{R} & \mathrm{I} & \mathrm{F} & \mathrm{P} & \mathrm{Q} & \mathrm{R} & \mathrm{L} & \mathrm{S}\end{array}$

2401 CAGTATGAAT GAAGGGAGTG ACCCTGAgGA TGACCTGACA GACTCTCAAA AAACAAGTAA $\begin{array}{lllllllllllllllllllllllllll}D & S & M & N & E & G & S & D & P & E & D & D & L & T & D & S & Q & K & T & S\end{array}$

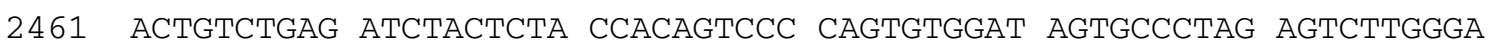
$\begin{array}{llllllllllllllllllll}K & L & S & E & I & Y & S & T & T & V & P & S & V & D & S & A & L & E & S & W\end{array}$

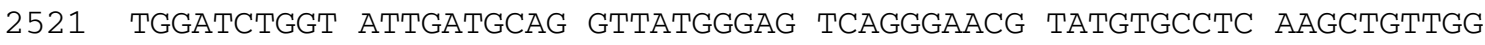
$\begin{array}{lllllllllllllllllllllllllllllllll}D & G & S & G & I & D & A & G & Y & G & S & Q & G & T & Y & V & P & Q & A & V\end{array}$

2581 TATCTCCCTC CACCCTCATG AgtgGagAAC AAGCCGACAg AAgAgCAACA CACCTCCTGT $\begin{array}{llllllllllllllllllll}\mathrm{G} & \mathrm{I} & \mathrm{S} & \mathrm{L} & \mathrm{H} & \mathrm{P} & \mathrm{H} & \mathrm{E} & \mathrm{W} & \mathrm{R} & \mathrm{T} & \mathrm{S} & \mathrm{R} & \mathrm{Q} & \mathrm{K} & \mathrm{S} & \mathrm{N} & \mathrm{T} & \mathrm{P} & \mathrm{P}\end{array}$

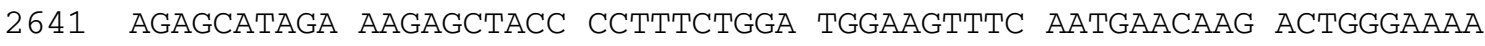
$\begin{array}{lllllllllllllllllllll}V & E & H & R & K & S & Y & P & F & L & D & G & S & F & N & E & Q & D & W & E\end{array}$

2701 GCCAACACGA TACCCCAGCC AGCCAAATGG CCTGGAAACT GACCATGACG ATAGCTTTTG $\begin{array}{llllllllllllllllllll}K & P & T & R & Y & P & S & Q & P & N & G & L & E & T & D & H & D & D & S & F\end{array}$

2761 GCGTGTTTTC GGAGAAGCCC TTGAAGACCT TGAAACATGT GGACAGTCAg AACTTTTGAG $\begin{array}{llllllllllllllllllll}W & R & V & F & G & E & A & L & E & D & L & E & T & C & G & Q & S & E & L & L\end{array}$

2821 AgAAATAGAg GCCTCCATTA TGACTGGTAg CGTGCAAGAT TTGGGTCTAG ACAGCAGCCA $\begin{array}{lllllllllllllllllll}R & E & I & E & A & S & I & M & T & G & S & V & Q & D & L & G & L & D & S\end{array}$

2881 AATACTTCTg GAAAATTCCA GCCAAGgAgg GCATGTACTG TTCAgGAgGg GAAGCCATCA $\begin{array}{llllllllllllllllllll}Q & I & L & L & E & N & S & S & Q & G & G & H & V & L & F & R & R & G & S & H\end{array}$

2941 CATCAGCAGC AACAGCCCCA AgAAGgAgAA CAAATTAAGC CAGGATGCTA GAAGCAAAAA $\begin{array}{llllllllllllllllllll}\mathrm{H} & \mathrm{I} & \mathrm{S} & \mathrm{S} & \mathrm{N} & \mathrm{S} & \mathrm{P} & \mathrm{K} & \mathrm{K} & \mathrm{E} & \mathrm{N} & \mathrm{K} & \mathrm{L} & \mathrm{S} & \mathrm{Q} & \mathrm{D} & \mathrm{A} & \mathrm{R} & \mathrm{S} & \mathrm{K}\end{array}$

3001 GgAAgAgGtg CACAATGCAC AgtCCtTAAC CACAgAgtTA CTAAAgGtAA CTGTACAgAA $\begin{array}{llllllllllllllllllll}K & E & E & V & H & N & A & Q & S & L & T & T & E & L & L & K & V & T & V & Q\end{array}$

3061 AgATATGgAt ACTGATGACT TTGgATTCAg CGTGTCAGAT GgTCTCCTGg AgAAAgGTGT $\begin{array}{lllllllllllllllllllll}K & D & M & D & T & D & D & F & G & F & S & V & S & D & G & L & L & E & K & G\end{array}$

3121 CTATGTAAAT ATGATTCGAC CTGgGgGtCC AgCAgACAgA AgTGgTCTGA AAACTTATGA $\begin{array}{llllllllllllllllllll}\mathrm{V} & \mathrm{Y} & \mathrm{V} & \mathrm{N} & \mathrm{M} & \mathrm{I} & \mathrm{R} & \mathrm{P} & \mathrm{G} & \mathrm{G} & \mathrm{P} & \mathrm{A} & \mathrm{D} & \mathrm{R} & \mathrm{S} & \mathrm{G} & \mathrm{L} & \mathrm{K} & \mathrm{T} & \mathrm{Y}\end{array}$

3181 TCAGATCTTG CAgGTGAACC ATGTGCGTAC CAGGGATTTT GACTGTTGCC TGACCGTGCC $\begin{array}{lllllllllllllllllllll}\mathrm{D} & \mathrm{Q} & \mathrm{I} & \mathrm{L} & \mathrm{Q} & \mathrm{V} & \mathrm{N} & \mathrm{H} & \mathrm{V} & \mathrm{R} & \mathrm{T} & \mathrm{R} & \mathrm{D} & \mathrm{F} & \mathrm{D} & \mathrm{C} & \mathrm{C} & \mathrm{L} & \mathrm{T} & \mathrm{V}\end{array}$

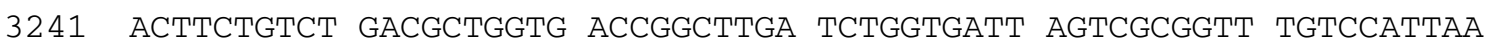

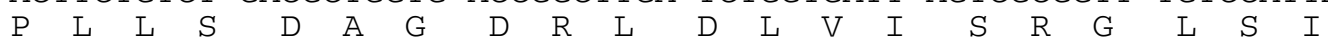

3301 AgCAgAggag Atgggggtag AgCAgAtAAA AggtcCAttg AgAatggagA cACAgAcAAg $\begin{array}{lllllllllllllllllllllllll}K & A & E & E & M & G & V & E & Q & I & K & G & P & L & R & M & E & T & Q & T\end{array}$

3361 CACAAAGACT CTCTGACCGC GGGATTGGAA TTCCACCCTA AATTAATCAT TTCAGGAGAT $S$ T $K$ T L

3421 TAATGTTTAA ACTGTTGAAA GCTGGGTGTT GCCCATTTAT TATTTTTAAT TAGCGAAGGG 3481 GATAAGATAC TTATTTTTTA ACGTGTGTTT ATGTATTGTC AGCACTTAGA TTATATTGTA

3541 CAAAGTGAAA CTGTGCAGAg GTCTGTTTCC AGTGGTGCAG GGGTCACCCT TCCCTGCCTC 3601 TTTTCACCCC ATCACAATTA AGTTATCACT TTCCTATTCC CTGAATCCCT GTATTGACGT 3661 TGGTTACAGA ACCCTGGTGG TTAAGGTTTA TCCTGTACTT ATGGTGCTAT TCCTTTATTA 3721 GCGTTCGATT ATAGCTTTTT CACCCCACGG AAACACACCC GCACTACACA ATTATTGAGG 3781 AAATGCACAA AGACTTGCTA GATCACAGGC ATTGGGGCCT TCCAAGGCTC CTCTGCCAAC 3841 CAGTGTTGGg CATTATAGTT CATTCATAGC ATCAGAGGCA GTTGTATCTC TTCTAAATGG 3901 ATAATAGCGT ACTCACCTCC CCCCCCCGTG TGATTTGTTC AACACTTGCA CTATAATTTG 3961 TTTCAGTTGA CTAGCGATGC TGAACAGTAT AACACTCATG CACTTTACAC CGTGTTTTCT 4021 CACTTTTTTC TTTGTTTGGG ATGTCTCTCA CCCATTGAGA ACTCCAACAC AACCTCTGCT 4081 CACTGCATCA TTAGGATGCT GTCTAGCAAT ATCCCTGTTC CACTCCCACA AGCCACCCTT 4141 CATATAGGAA TGCACAGCCA TCGTACCAGT CTACAGTATT TCAGGAGCAT CCCTTAATGC 4201 TTTTGCTTGG CACTTGTGAT ATCACACACA CTTCCAGAAA AAGAGCACAA CTCCTTTGTC 4261 ACTGCACCTT GACTCATTGT TTCACTGTAT CAGATTGTGT TTGTATTCTC TCCTCTGCAC

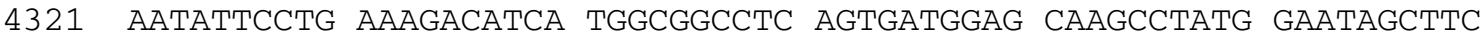


4381 AgACAATGTT CAATTGTATT CTTGTATCTC TCTGTCTGGA TTATGAAGTG TTTACTCCTT

4441 CTCCCTCTGG TTCTGGATGT TTATACTGGC ACAAGGGCCC ACAATCAGAT TTTTCTTTGC

4501 AAACATGGCA CCCACAGCAT ACTGTATGCA AACCATTTTA GAGGTATAAT CTGGATATCT

4561 TGTTGCTCAC CAAATTCCCA GTACAGGGTC TAATTGCTTG CTGTAGTAGT AATTCTTGAC

4621 CCCCTTTGAT GTCACCATCC CTCTTACAGT AATTATCATG GCTCCTATTC TCCACATACC

4681 AACGCTGAAG CCAGATAATT CACGAGAAGC CTTTGTGACT GGGGAGGGGA TGTTCTATGA

4741 CCACTTTAGG GCTTTGGAAC AGAGATCTCC CACCTGTGGC TGATACAGAG CCCTAGCATT

4801 GCCCAAGAAC CTTTGTAGGA GCTGTAGATA TGTTACATCT GAAGAGTCAC ATGTTGGGGA

4861 ACCCTTATCT TtAAgtTAAg GCACATAGCC CTTCTACTGT ATATAATTGT GACCACAAGA

4921 CTTGTCTCCA TGCCTAGgAA TCACTAGGCA TATATGATCC AAAAGCTGCT GGAGgCTGCG

4981 GCGAGCTGCC AATC

Fig. 4.1. Nucleotide and predicted amino acid sequence of the isolated full-length XGRIP2.1. The start-codon is labelled in bold, the upstream stop-codon is shown in italics, the ORF stop-codon is marked with the asterisk and the $210 \mathrm{bp}$ localization element in the 3'UTR is underlined (see Results 4.2)

The ORF encodes a predicted $130 \mathrm{kDa}$ protein containing seven PDZ (ㅍSD-95/Disclarge/ZZO-1) domains (Fig. 4.2A), which exhibits an overall amino acid identity of $80 \%$ in comparison to rat GRIP2 (Wyszynski et al., 1999) (GenBank accession no. Q9WTW1) and of 78\% in comparison to rat GRIP1 (Dong et al., 1997) (GenBank accession no. NP114458) (Fig. 2B). According to the highest degree of overall protein identity, the clone was termed XGRIP2.1 for Xenopus GRIP2. A closely related Xenopus laevis XGRIP2 sequences were recently published (Kaneshiro et al., 2007) (GenBank accession no. AB290863), (Kirilenko et al., 2007) (GenBank accession no. AM712310) and revealed to contain 5 amino acid changes (Fig. 4.2B). Another closely related Xenopus laevis sequence (accession no. LOC432193, RZPD ID no. BU920421), showing 82\% amino acid identity in comparison to XGRIP2, was found in the Xenopus database. This protein sequence is $90 \%$ identical to the mouse GRIP1 (GenBank accession no. AAH67328) and 91\% identical to the human GRIP1 (GenBank accession no. XP_001133925) (App. Fig 8.1). Taking into account sequence similarity and the expression pattern (App. Fig. 8.2), this clone was termed XGRIP1. 
A

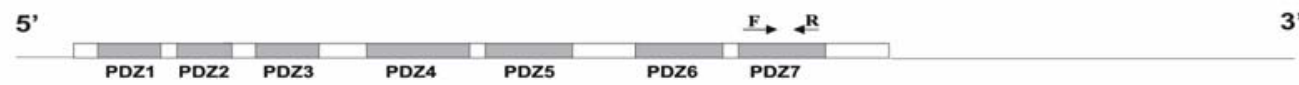

B

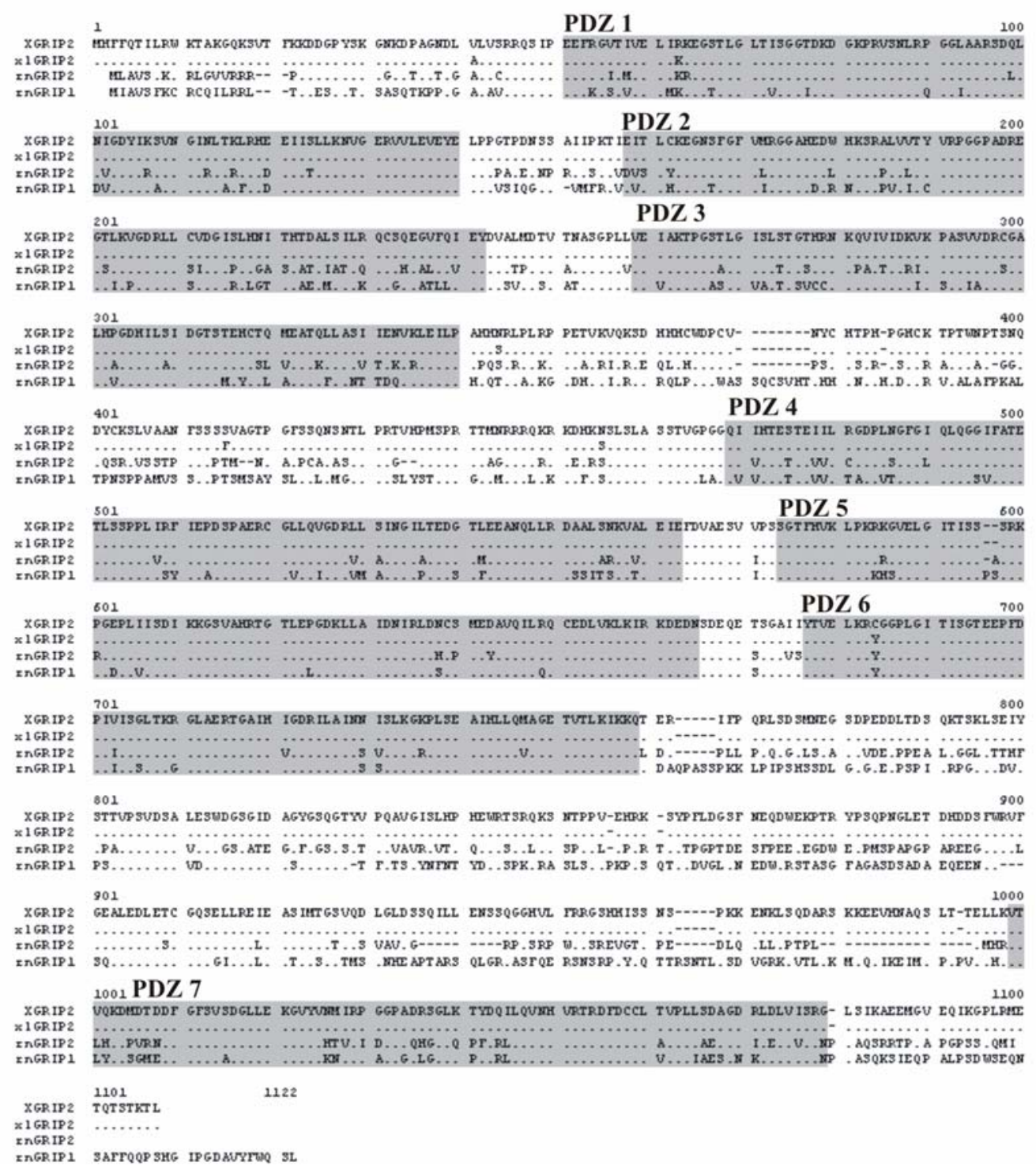

Fig. 4.2. Schematic illustration of the XGRIP2.1 cDNA structure and SWISS plot alignment of the predicted protein sequence. (A) Schematic illustration of the XGRIP2.1 cDNA structure. The seven PDZ domains in the ORF (boxed) are indicated. The positions of forward (F) and reverse (R) RT-PCR primers are marked with arrows. (B) SWISS-plot multiple alignment of our predicted Xenopus laevis XGRIP2.1 protein sequence (GenBank ID EF139240) with Rattus norvegicus GRIP1/ GRIP2 amino acid sequences and previously published Xenopus laevis XGRIP2 protein sequence (GenBank ID NP114458, Q9WTW1 and AB290863, correspondingly). PDZ domains of XGRIP2 are indicated as shaded boxes. 


\subsubsection{Spatiotemporal expression of XGRIP2.1}

The spatiotemporal expression of XGRIP2.1 mRNA during Xenopus development was analyzed by whole mount in situ hybridization (WMISH) and RT-PCR. Transcript levels of XGRIP2.1 are prominent in the egg and during early cleavage stages, slightly decreasing between neurula and late tailbud stage and elevated again at tadpole stages (Fig. 4.3G). In stage I-III oocytes, the XGRIP2.1 transcript is enriched in the mitochondrial cloud and subsequently at the tip of the vegetal cortex (Fig. 4.3A, A', B, B'). This RNA distribution during oogenesis characterizes $X G R I P 2.1$ as an early localizing mRNA.

During early cleavage stages, XGRIP2.1 mRNA is detected in the granular patches of the germ plasm (Fig. 4.3C, C'). At gastrula stage, the transcript is specifically localized in isolated cells within the involuting endoderm (Fig. 4.3D, D'). At neurula stage, no surface signal was detected by WMISH, but vibratome sections revealed XGRIP2.1 expression in single cells within the endoderm (data not shown). At tailbud stage, XGRIP2.1 was exclusively expressed in migrating primordial germ cells (PGCs), as revealed by its colocalization with the established PGC marker Xpat (Hudson and Woodland et al., 1998) (Fig. 4.3E, F). In adult frog tissues, XGRIP2.1 expression was detected in the brain, ovary, eye, muscle, spinal cord, and very weakly in adipocytes (Fig. 4.3H). Thus, XGRIP2.1 is an early localizing mRNA specifically expressed in the germ plasm and germ cells during the early phases of Xenopus development. 

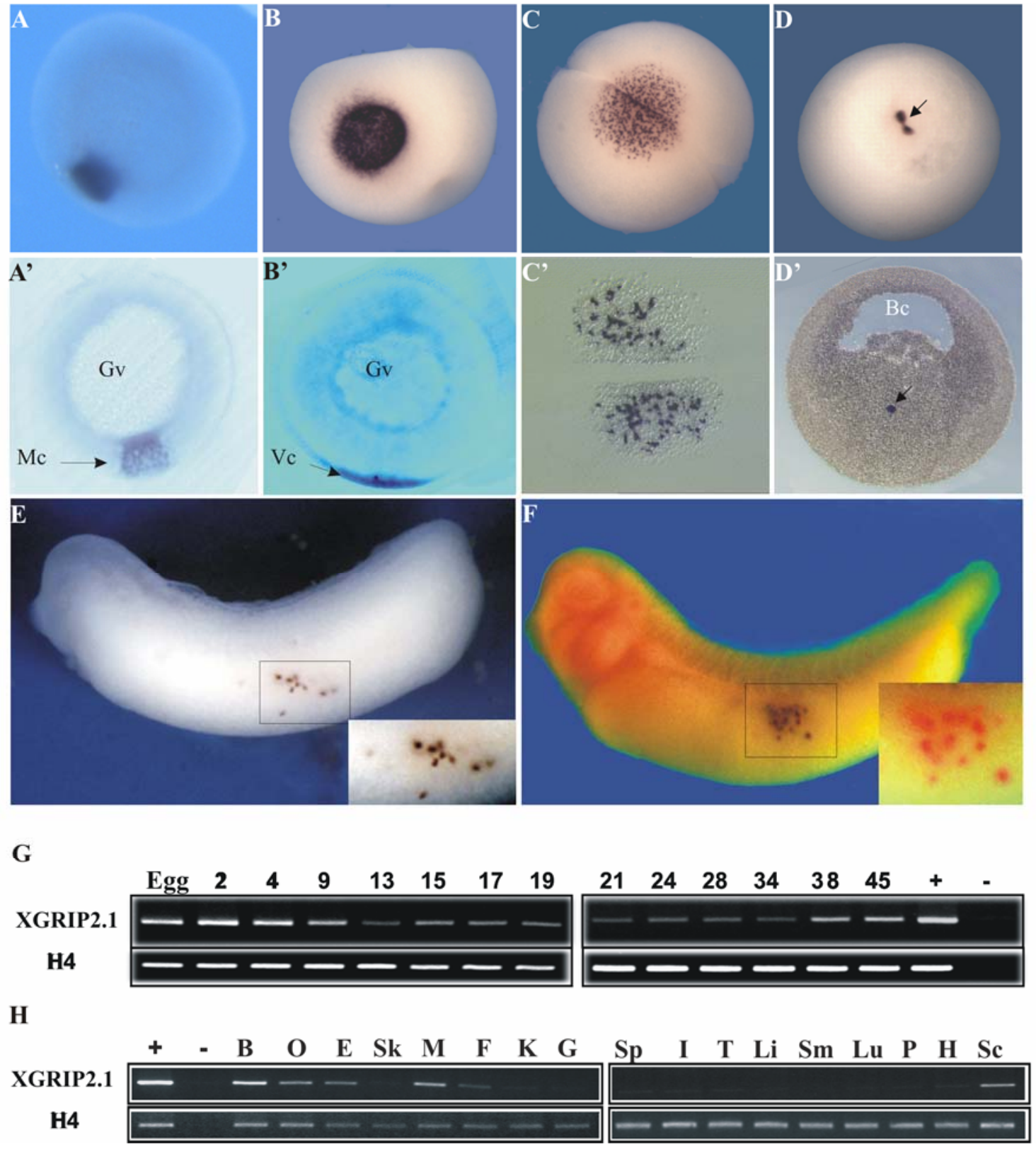

Fig. 4.3. Analysis of XGRIP2.1 expression by whole mount in situ hybridization and RTPCR. (A-F) The localization of XGRIP2.1 mRNA in Xenopus oocytes and embryos was analyzed by whole mount in situ hybridization, followed by vibratome sectioning (A'-D'). In stage I oocytes, XGRIP2.1 mRNA was detected in the mitochondrial cloud (A, A') and at early stage III at the tip of the vegetal cortex (B, B'). At the 2-cell stage of embryogenesis, XGRIP2.1 mRNA is enriched in granular patches of germ plasm at the vegetal pole (C, C', vegetal pole view). At gastrula stage, the transcript was detected in isolated cells within the endoderm (D, blastoporus view, arrow in D'). At tailbud stage, $X$ XRIP2.1 is specific to the migrating germ cells (E, lateral view of the embryo with the head to the left). XGRIP2.1 and Xpat RNAs colocalize in migrating PGCs at tailbud stage of embryogenesis. Embryos were sequentially stained for XGRIP2.1 (blue) and Xpat (red, magnified view in the inset, the first staining of the same embryo) (F, lateral view of the embryo with the head to the left).

RT-PCR analysis of the temporal expression during embryogenesis (G) and tissue- specific expression of XGRIP2.1 (H). Total RNA for RT-PCR was prepared from embryos or from adult tissues. Abbreviations: Gv - germinal vesicle, $\mathrm{Mc}$ - mitochondrial cloud, $\mathrm{Vc}$ - vegetal cortex, $\mathrm{Bc}$ - blastocoel, B - brain, O - ovary, E - eye, Sk - skin, M - muscle, F - fat, K - kidney, G - gall bladder, Sp - spleen, I intestine, T - testes, Li - liver, Sm - stomach, Lu - lung, P - pancreas, H - heart, Sc - spinal cord. 


\subsubsection{XGRIP2.1 protein expression and subcellular localization}

Protein expression of XGRIP2.1 was analysed by whole mount immunostaining on staged Xenopus laevis embryos. Unfortunately, the XGRIP2.1 antiserum (BioSciences, Göttingen, see Materials) has very low sensitivity and it only poorly detects the endogenous XGRIP2.1, also on Western-blots. Nevertheless, after several rounds of antibody purification, XGRIP2.1 was found to be expressed in PGCs at gastrula and tailbud stages (Fig. 4.4, A, B).

Weak sensitivity of the XGRIP2.1 antibody didn't allow to obtain any reliable results for the subcellular localization of the endogenous XGRIP2.1 protein. Therefore, recombinant FLAG- and mycGFP - tagged XGRIP2.1 ORF mRNAs were microinjected into in Xenopus embryos.

FLAG_XGRIP2.1 ORF injected embryos (1 ng of mRNA per embryo) were collected at stage 8 of embryogenesis and subjected to paraffin-sectioning. $5 \mu \mathrm{m}$ sections were stained for the FLAG-tag and the subcellular localization of XGRIP2.1 was analysed by confocal microscopy. The recombinant XGRIP2.1 was observed in the membrane and sub-membrane space with a tendency to localize asymmetrically at one side of the cell (Fig. 4.4, C, C').

mycGFP-tagged XGRIP2.1 ORF was fused to the XDead end 3'UTR localization element (Horvay et al., 2006) to enrich localization and expression of the transcript of interest to PGCs (Koebernick et al., unpublished). Embryos injected with $1 \mathrm{ng}$ of this mRNA were cultured till stage 32 and selected for the PGC-specific GFP expression. These sorted embryos were subjected to gelatine-albumin sectioning. One half of $30 \mu \mathrm{m}$ sections was stained for myc-tag and another half for XGRIP2.1. As far as gelatine-albumin has high background autofluorescence, secondary antibodies coupled to the alkaline-phosphatase were used. Both types of staining (anti-myc and anti-XGRIP2.1) revealed membrane and sub-membrane distribution of XGRIP2.1, confirming the results described above for anti-FLAG immunostainings. Enrichment of the protein at one edge of a cell was also reproduced. (Fig 4.4, D, D’). 

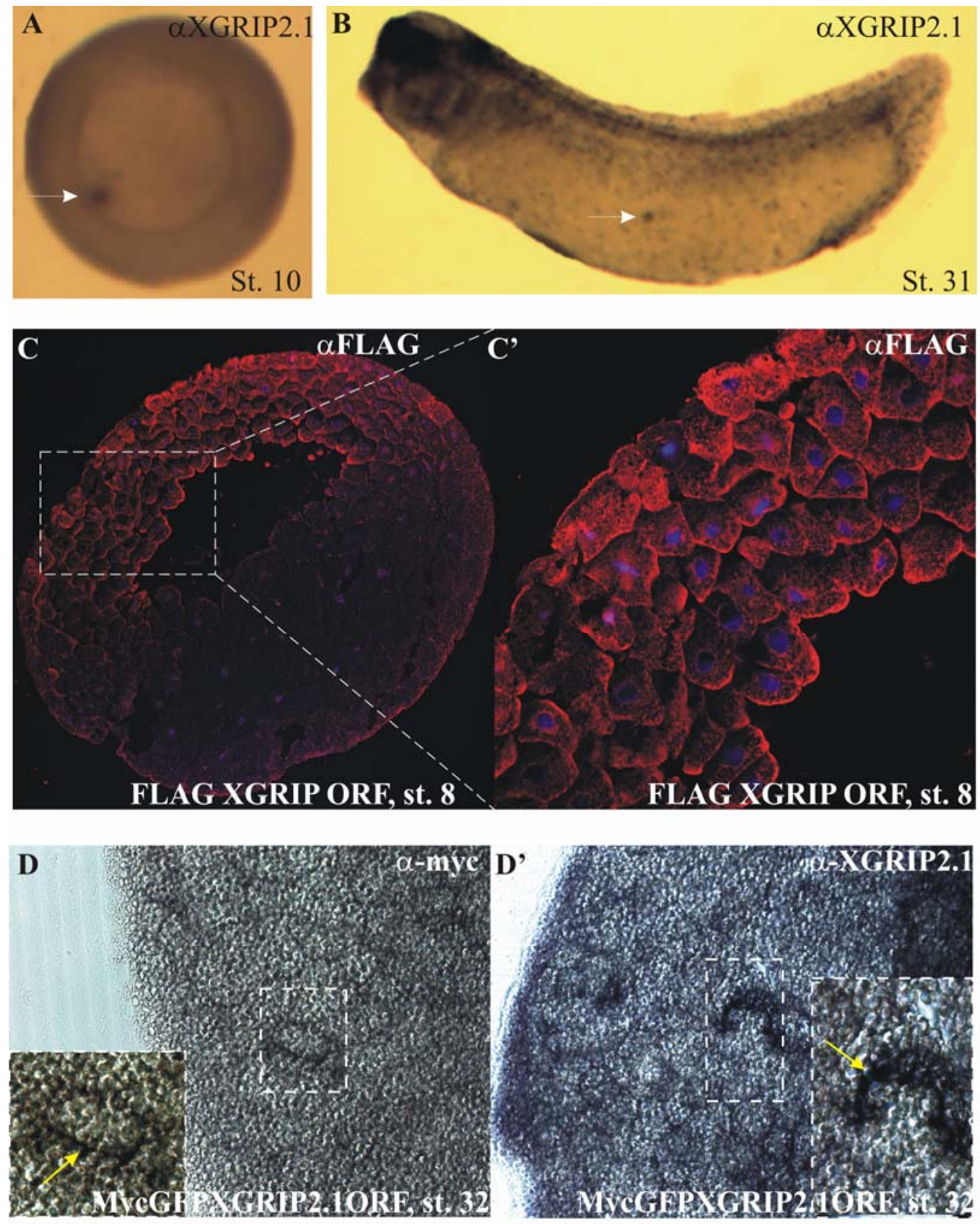

Fig. 4.4. Analysis of the XGRIP2.1 protein expression and subcellular localization. (A, B) Analysis of the XGRIP2.1 protein expression was performed by the whole mount immuostaining. XGRIP2.1 protein was found expressed in PGCs (arrows) at gastrula (A, blastoporus view) and at tailbud (B, lateral view) stages. Embryos were cleared with benzyl benzoate/ benzyl alcohol. (C-D) Embryos were injected vegetally into both blastomeres whether with FLAG- or mycGFP-tagged XGRIP2.1 ORF mRNAs. Analysis of the subcellular localization of the recombinant XGRIP2.1 protein was performed by immunoistichemistry on paraffin $\left(\mathrm{C}, \mathrm{C}^{\prime}\right.$, transverse sections) and gelantin-albumin (D, D', saggital sections) sections. 


\subsubsection{XGRIP2.1 gain-of-function results in a decrease of average PGC numbers}

For gain-of-function experiments, embryos were injected vegetally into both blastomeres at the 2-cell stage with the FLAG-tagged XGRIP2.1 ORF in pCS2+ vector. Uninjected embryos of the same batch of laid eggs were regarded as controls. For the estimation of the average PGC number, embryos fixed at stage 31-33 were stained by WMISH with Xpat (Hudson and Woodland, 1998). PGCs were scored on both sides of each embryo. The average PGC number was calculated for batches of thirty embryos. These numbers were then related to the corresponding control value for uninjected embryos, which was set to $100 \%$. The mean of the average PGC number (in \%) was calculated from results for three independent experiments.

Overexpression of $x$ GRIP2.1 in a low and moderate dosage (250 and $500 \mathrm{pg}$ of XGRIP2.1 ORF injected) led to the decrease in the average PGC number (Fig 4.5).

High dosage overexpression (1-2.5 ng of XGRIP2.1 ORF injected) resulted in neurulation defects, malformations and high lethality of injected embryos, which made it impossible to estimate specific effects on PGC development.

A
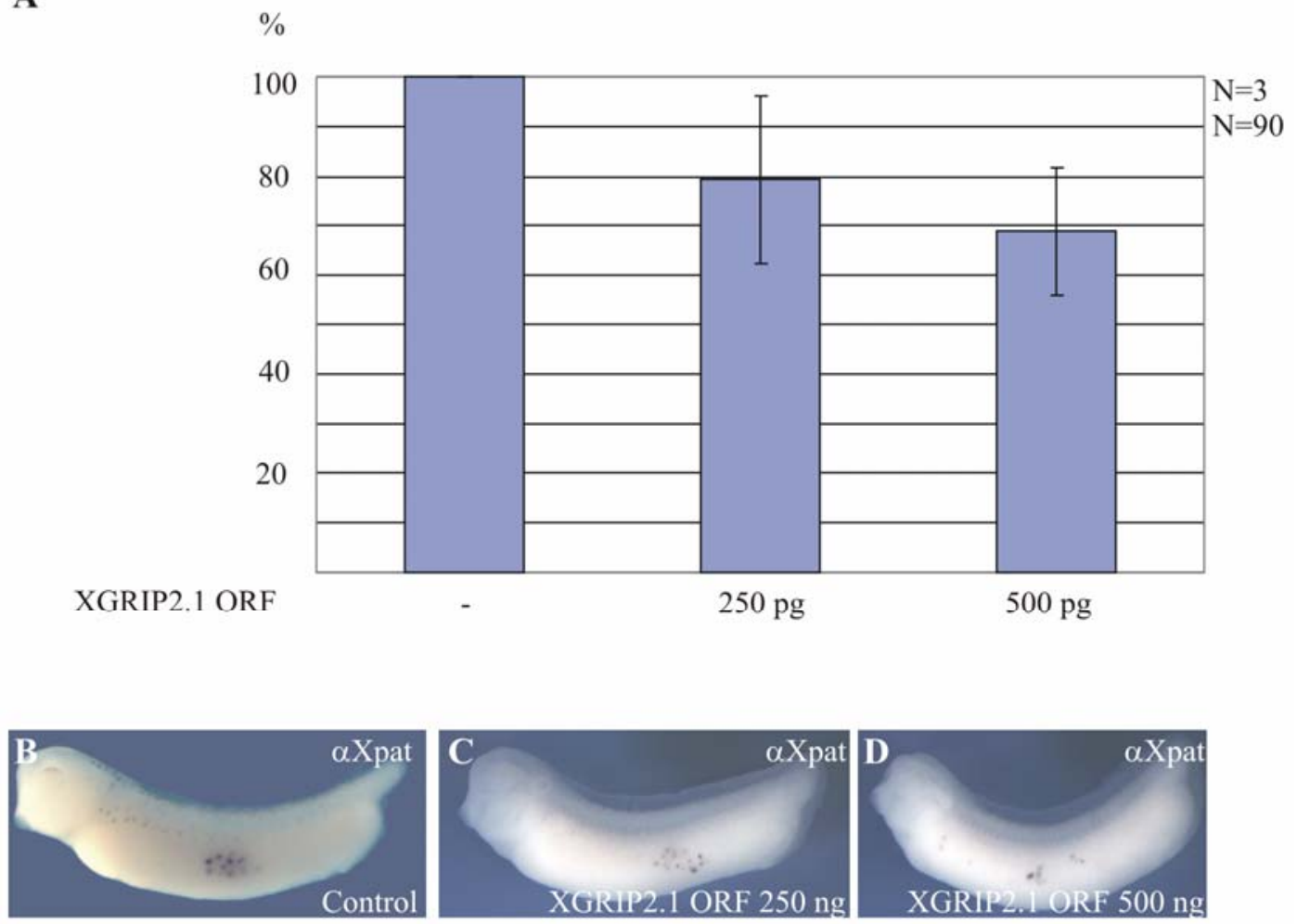

Fig. 4.5. Overexpression of XGRIP2.1 results in a very mild reduction in the average PGC number. (A-D) Embryos were injected vegetally into both blastomeres at the 2-cell stage. (A) Injection of XGRIP2.1 ORF results in a very mild decrease of the average PGC number. $\mathrm{N}$ number of independent experiments, $\mathrm{n}$ - number of analyzed embryos. (B-D) Representative examples of uninjected control embryos (B), embryos injected with $250 \mathrm{pg}$ (C) and $500 \mathrm{pg}$ (D) of the XGRIP2.1 ORF. 


\subsubsection{Morpholino-knockdown of XGRIP2.1}

\subsubsection{XGRIP2.1 morpholino oligonucleotides inhibit translation of XGRIP2.1 in} vitro and in vivo

To analyze the potential function of XGRIP2.1 in the context of PGC development, antisense morpholino oligonucleotide (MO) mediated knockdown experiments were carried out. For this purpose, two different XGRIP2.1-specific MOs were designed, targeting either the start codon region (MO1) or the 5'UTR region (MO2) (Fig. 4.6A). The specificity of both MOs was tested by in vitro translation (Fig. 4.6B) and in vivo, by Western blotting of total protein extracts from embryos microinjected with the synthetic XGRIP2.1 mRNA either alone or together with two different MOs (Fig. 4.6C). The overexpression approach was used, because the sensitivity of the XGRIP2.1 antibody that we have raised (see Materials) was too low to detect the endogenous protein. As additional in vivo specificity control, the reporter construct containing the XGRIP2.1 5'UTR fused to the mycGFP ORF was used (Fig. 4.6D-F). In all experiments, translation of the recombinant XGRIP2.1 or mycGFP protein was specifically inhibited.

Fig. 4.6. XGRIP2.1 morpholino oligonucleotides inhibit translation of XGRIP2.1 in vitro and in vivo. (A) Schematic illustration of morpholino oligonucleotide target sites. 5'UTR and ORF of XGRIP2.1 cDNA are marked as blue box and grey arrow, respectively. (B) Reduction or absence of XGRIP2.1 translation was observed in the coupled in vitro transcription/ translation reaction (Promega) upon addition of $1 \mathrm{nmol}$ or $0.1 \mathrm{nmol}$ of either MO1 or MO2, respectively. (C-F) Embryos were injected vegetally into both blastomeres at the 2-cell stage. (C) XGRIP2.1 MO1 and MO2 inhibit translation of XGRIP2.1 in vivo. Embryos were injected with XGRIP2.1 5'UTR_ORF RNA with or without coinjection of XGRIP2.1 specific MOs or the control morpholino and grown to the tailbud stage 32. Total protein extracts of injected embryos were subjected to Western blotting. XGRIP2.1 protein was no longer detected at high concentrations of either MO1 or MO2. (D-F) Embryos were injected with either 5'UTRXGRIP2.1 mycGFP or 5'UTRXGRIP2.1mycGFPmut (see Materials, Table 1) RNA together with XGRIP2.1 specific MOs and grown to tailbud stage (st. 30). (D) Total protein extracts of injected embryos were subjected to Western blotting. The recombinant mycGFP reporter protein was no longer detected at high concentrations of either MO1 or MO2. (E, F) mycGFP reporter protein expression analyzed by fluorescence microscopy. (a-c) normal light, (a'-c') UV-light. Two-cell stage embryos were coinjected with $0.2 \mathrm{ng}$ 5'UTRxGRIPmycGFPmutl RNA and 2 pmol MO1 (E, a, a'), $0.2 \mathrm{ng}$ 5'UTRXGRIP2.1mycGFP RNA and 0.2 pmol MO1 (E, b, b'), 0.2 ng 5'UTRXGRIP2.1mycGFP RNA and 2 pmol MO1 (E, c, c'), 0.2 ng 5'UTRXGRIP2.1mycGFPmut2 RNA and 2 pmol MO2 (F, a, a'), 0.2 ng 5'UTRXGRIP2.1mycGFP RNA and 0.2 pmol MO2 (F, b, b'), or 0.2 ng 5'UTRXGRIP2.1mycGFP RNA and 1 pmol MO2 (F, c, c'). 
A

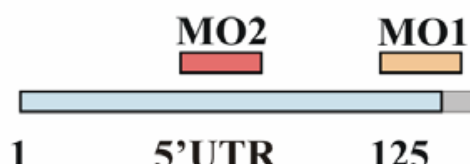

MO1

ORF

B

\begin{tabular}{|l|ccccc|}
\hline 5'UTR ORF & + & + & + & + & + \\
MO1, mM & - & 1 & & - & - \\
MO2, mM & & & & & \\
\hline & - & & & &
\end{tabular}

C

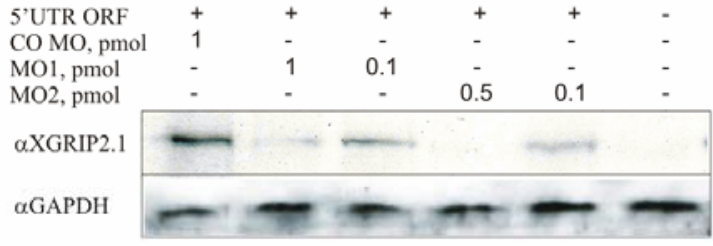

D

5'UTRXGRIP2.1 mycGFP $0.2 \mathrm{ng}$

5'UTRXGRIP2.1 mycGFPmut1 $0.2 \mathrm{ng}$

5'UTRXGRIP2.1 mycGFPmut2 $0.2 \mathrm{ng}$

$\mathrm{MO}, \mathrm{mM}$

$\mathrm{MO} 2, \mathrm{mM}$

\begin{tabular}{|ccccccc}
- & + & + & - & + & + & - \\
+ & - & - & - & - & - & - \\
- & - & - & + & - & - & - \\
1 & 1 & 0.1 & - & - & - & - \\
- & - & - & 1 & 0.5 & 0.1 & - \\
- & - & - & - & - \\
- & - & - & - & - & -
\end{tabular}

E
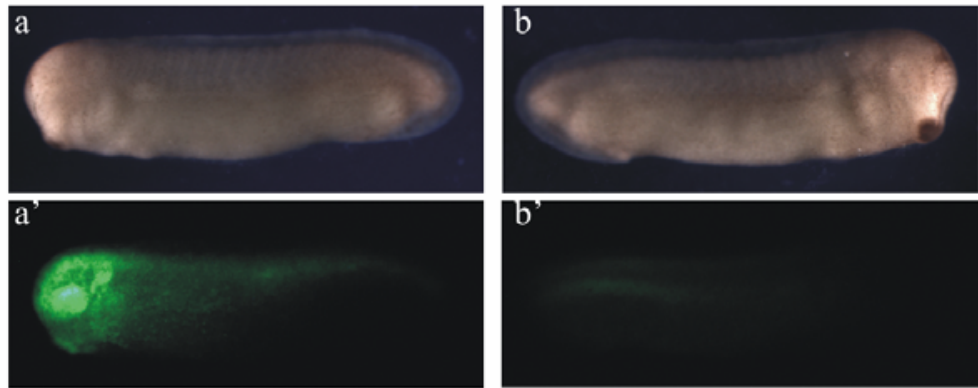

b'
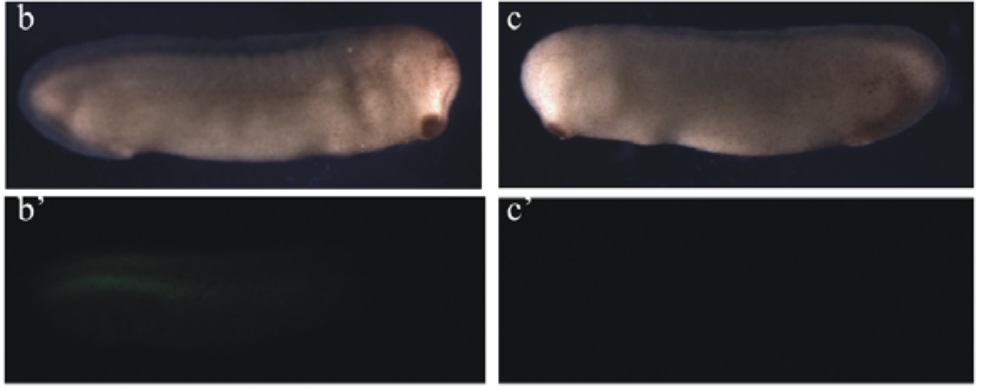

F
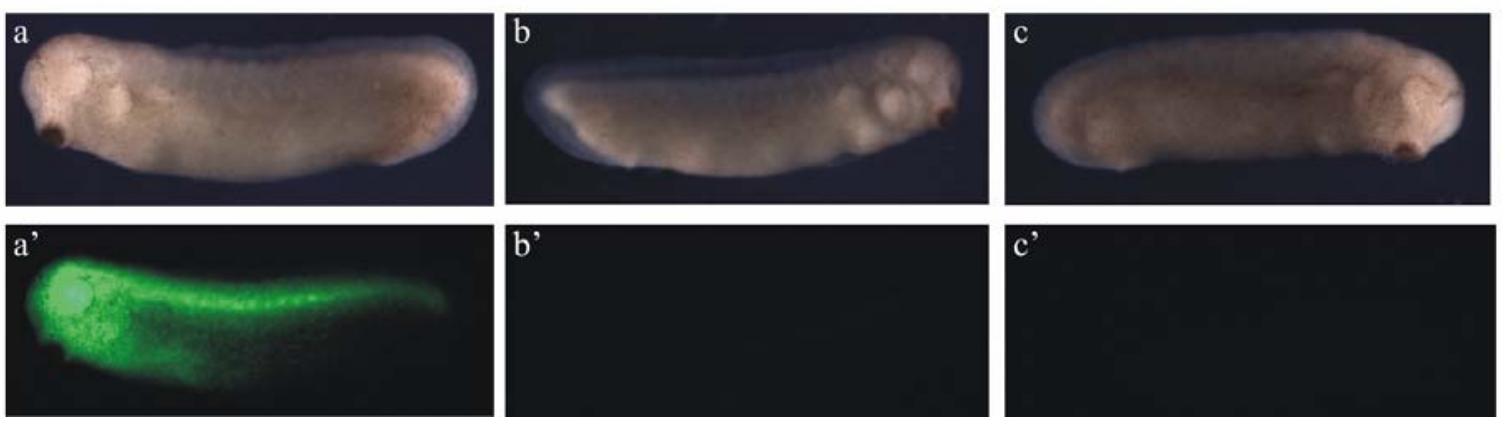
4.1.5.2 MO-mediated depletion of XGRIP2.1 reduces the average number of PGCs in tailbud stage Xenopus embryos

Vegetal injection of either MO into two-cell stage embryos resulted in a dose-dependent decrease of the average number of Xpat-positive cells scored in early tailbud stage embryos (Fig. 7A-E) when compared to embryos injected with control MO. Since the PGC number per embryo varies greatly between different batches (average number from 10 to 25 in control embryos); the average PGC number was calculated as percentage in relation to the values obtained for control embryos from the same batch in each experiment, which was set to $100 \%$. The threshold concentration of $\mathrm{MO}$ resulting in an approximately 50\% decrease of the average PGC number was between 0.5 and 1 pmol for MO1 and roughly 0.2 pmol for MO2 (Fig. 4.7A, B). Upon microinjection of the highest concentration of each MO compatible with embryonic viability, the number of PGCs detected at the surface of XGRIP2.1-depleted embryos was strongly reduced (Fig. 4.7D, E). To exclude the possibility that PGCs were still present inside of these embryos, they were cleared with benzyl benzoate/ benzyl alcohol (data not shown). No significant difference between the average PGC scores from transparent embryos when compared to those obtained by quantification of surface PGCs was observed. To verify that the decrease in PGC number is specific to PGCs in general and not only observed for Xpat-positive cells, XGRIP2.1 morphants were also stained for other PGC markers, i.e. Xdazl, DeadSouth and XGRIP2.1. For all these markers, the decrease in average PGC numbers did not differ significantly from the values obtained by scoring for Xpat expression (Fig. 4.7F-L). 
$\mathbf{A}$
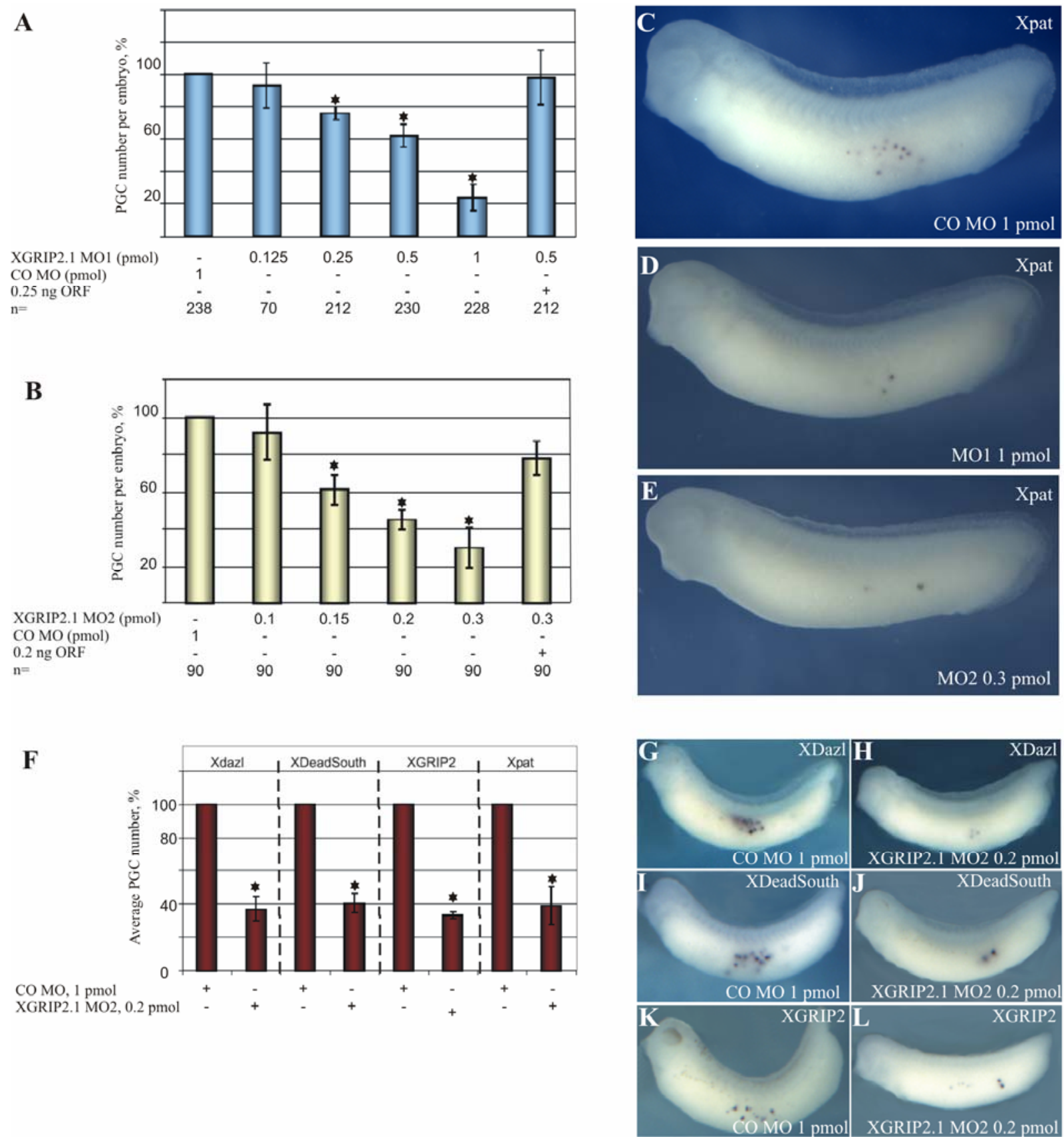

Fig. 4.7. XGRIP2.1 knockdown results in reduced average PGC numbers. (A-L) Embryos were injected vegetally into both blastomeres at the 2-cell stage. (A, B) Injection of either XGRIP2.1 MO results in a dose-dependent decrease of the average PGC number. The average PGC number was calculated from three independent experiments. The control score was in the range of 10 to 25 PGCs per embryo for the MO1 series (control in A) and 10 to 16 PGCs per embryo for the MO2 series (control in B), $n$ - number of analyzed embryos. (C-E) Representative examples of embryos injected with the control morpholino, XGRIP2.1 MO1 or with XGRIP2.1 MO2, respectively. (F-L) Reduced PGC number in MO2 injected embryos as evidenced by use of different PGC markers. Embryos were injected with 1 pmol of CO MO or 0.2 pmol of XGRIP2.1 MO2, cultivated to stage 31/32 and subjected to WMISH. (F) Average PGC number in control and MO2 injected embryos. The result was calculated as an average of three independent injection series, 60 embryos were analyzed for each treatment. (G-L) Representative examples of embryos injected with CO MO $(\mathrm{G}, \mathrm{I}, \mathrm{K})$ or XGRIP2.1 MO2 (H, J, L) and stained for Xdazl $(\mathrm{G}, \mathrm{H})$, XDeadSouth (I, J), XGRIP2.1 (K, L).

$$
*-\mathrm{p}(\mathrm{t})<0.05 \text {. }
$$




\subsubsection{Normal positioning of PGCs along the anteroposterior axis in Xenopus tailbud stage embryos}

To characterize the effect of the XGRIP2.1 MO-mediated knockdown in further details, we addressed the question if proper anteroposterior positioning of PGCs is affected in this situation. Since the dynamics of PGC positioning along the $\mathrm{A} / \mathrm{P}$ axis had so far not been documented in Xenopus embryos, a systematic analysis of the PGC migration profile between stage 24 and 32 was performed (Fig. 4.8). The anteroposterior position of the PGCs was mapped in relation to the array of somites visualized by $M y o D$ mRNA expression. The average PGC number per somite was determined in uninjected tailbud stage embryos (st. 24-32, $\mathrm{n}=90$ ) obtained from three different frogs (Fig. 4.8A-H).

The number of PGCs at individual somite positions was scored on both sides of 30 randomly chosen embryos. The average PGC number per somite was calculated in percentage of the total PGC number for any given group of embryos. The mean value of average numbers obtained was calculated from three independent experiments. The $p(t)$-values were determined via one-tailed paired Student's t-test.

The position of PGCs along the A/P axis from stage 24 to stage 29 is shown in relation to somite number 12 (Fig. 4.8A-F). With progressing tailbud stage, the position of the majority of the scored PGCs appears to shift anteriorly. More than 90\% of PGCs were located between somites 6 to 12 at stage 29 (Fig. 4.8F) and between somites 5 to 11 at stage 32 (Fig. 4.8G). This distribution of PGCs was regarded as "normal", while migration of PGCs beyond these limits was defined as "mislocalization".

Applying this system to XGRIP2.1 morphant embryos, 12\% of PGCs were scored as mislocalized in comparison to $2.7 \%$ calculated for uninjected controls at stage 32 (Fig. 4.8J). Therefore, XGRIP2.1 morphants exhibit both significantly reduced PGC numbers and a slight degree of PGC mislocalization, implying an important role for XGRIP2.1 in PGC maintenance and migration. 

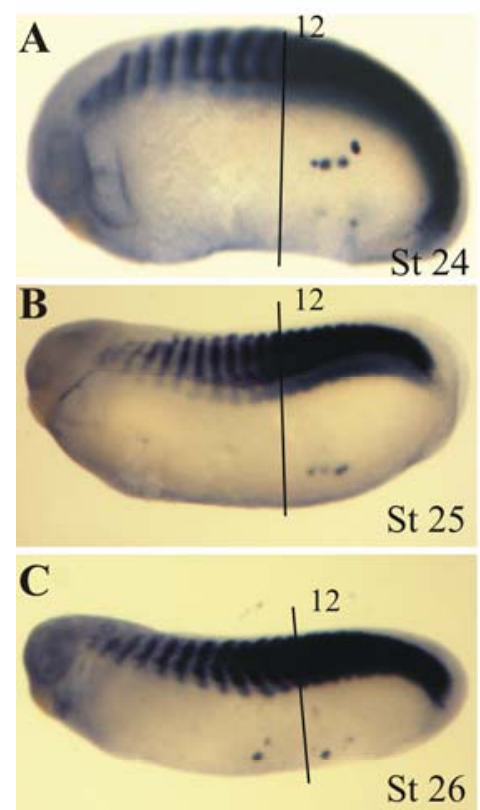

D
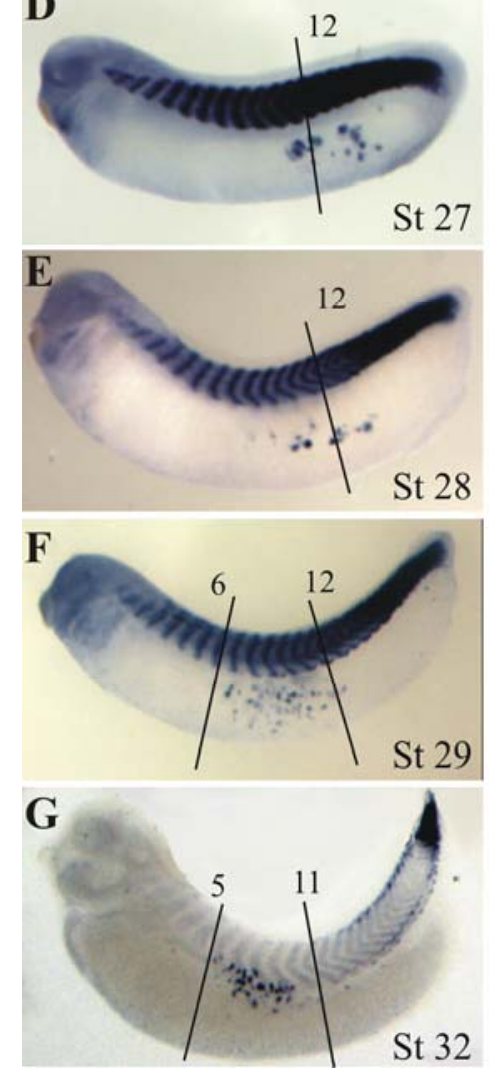

H

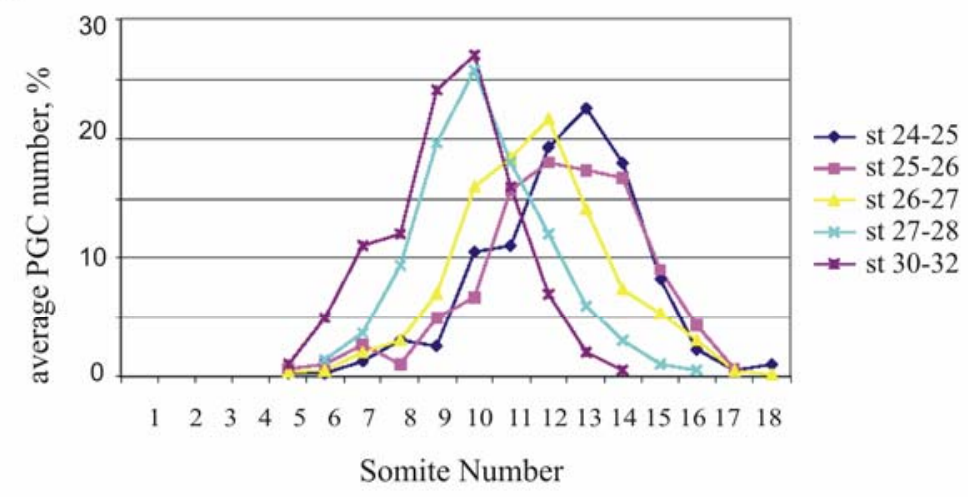

$\mathbf{J}$

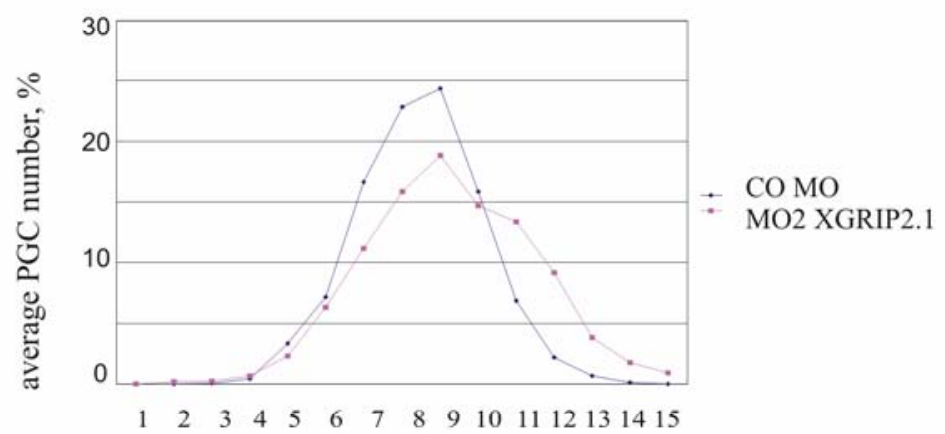

Somite Number

Fig 4.8. Positioning of PGCs along the $\mathrm{A} / \mathrm{P}$ axis in control and XGRIP2.1 morphant embryos. (A-H) Representative examples of uninjected control embryos exhibiting normal PGC positioning between stage 24 and stage 32. PGCs were stained for Xpat and somites for XMyoD by WMISH. (A-G) Embryos were cleared with benzyl benzoate/ benzyl alcohol. (H) PGC migration profile of uninjected control embryos (stage 24-33). (J) The PGC distribution profile of embryos at stage 32 injected vegetally into both blastomeres at the 2-cell stage with 0.2 pmol of MO2 XGRIP2.1 or CO MO. Average PGC numbers at each somite position were calculated from results of three independent experiments. A total of 60 embryos were analyzed for each stage of development or treatment. 
4.1.7 The XGRIP2.1 dominant-negative PDZ 23 interferes with the survival and anteroposterior migration of PGCs

\subsubsection{Design and identification of the most prominent XGRIP2.1 dominant-negative fragment}

As a second approach to interfere with the function of XGRIP2.1 during embryogenesis, a series of XGRIP2.1 fragments was generated, potentially acting as dominant-negative (DN) proteins, which were cloned as cassettes of two or three contiguous PDZ domains, spanning the entire length of the ORF (Fig. 4.9A). These fragments were fused to a 3'UTR fragment of the XDead end cDNA, restricting their expression to the germ cells (Koebernick and Pieler, unpublished data), thereby avoiding indirect effects resulting from overexpression of the putative DNs in the soma.

Vegetal injection of synthetic mRNAs encoding these putative DNs into both blastomeres of two-cell stage embryos at a dose of $2 \mathrm{fmol}$ was well compatible with embryonic survival up to stage 35, thus allowing for the analysis of their impact on PGC development. For several of these XGRIP2.1 fragments, a significant reduction in PGC number was observed (Fig. 4.9A). Among the constructs containing three PDZ domains, the strongest effect was observed for the PDZ 234 fragment (37\% decrease in the average PGC number). An even more pronounced effect was obtained upon injection of the two PDZ domains containing constructs PDZ 23 and PDZ 67, each resulting in a reduction of the average PGC number to about 50\%. This effect was rescued to an average PGC number of $93 \%$ for the XGRIP2.1 PDZ 23 construct by coinjecting $0.2 \mathrm{ng}$ of XGRIP2.1 ORF mRNA (Fig. 4.9A). Coinjection of XGRIP2.1 PDZ 67 together with the ORF did not have any rescuing effect (data not shown). Therefore, this effect appears to be unspecific.

Mislocalization of PGCs was observed in only 3-6\% of the control embryos, but was increased significantly upon misexpression of several of the putative DN constructs (Fig. 4.9A) with the most severe effect caused by the XGRIP2.1 fragment encoding PDZ domains 2 and 3. Microinjection of $2 \mathrm{fmol}$ of this mRNA resulted in mislocalization of $30 \%$ of the PGCs at stage 32 (Fig. 4.9A, B, D, E). A posterior shift in PGC positioning upon XGRIP2.1 knockdown persisted at least until stage 34-35 (not shown).

A comparative profile of PGC localization along the anteroposterior axis of uninjected control embryos and PDZ 23 mRNA-injected embryos stage 32 is represented in Fig. 4.9B. In control embryos, 97\% of the PGCs were located between somites 5 and 11 with the maximum detected at the level of somite 8. In contrast, in PDZ 23 mRNA-injected embryos, PGCs were 
spread in a much broader area between somites 3 and 17 and the peak of PGC distribution was shifted posteriorly. Coinjection of $0.2 \mathrm{ng}$ of XGRIP2.1 ORF mRNA together with 2 fmol PDZ 23 mRNA rescued the phenotypic effects (Fig. 4.9A, B).

A

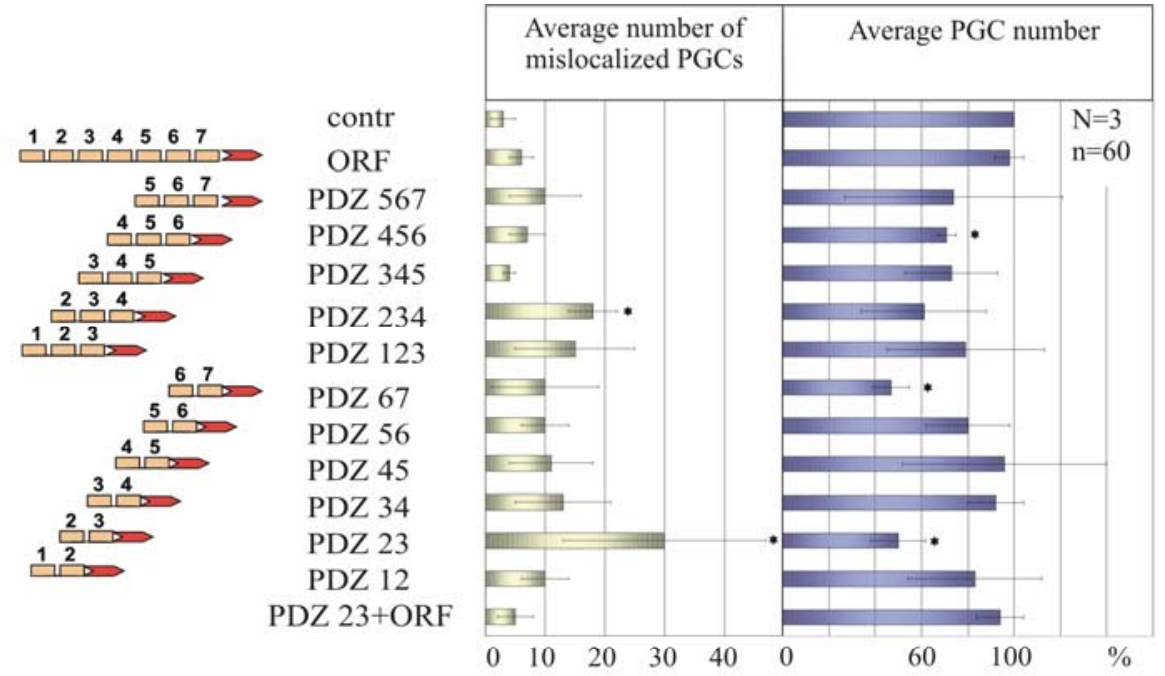

B
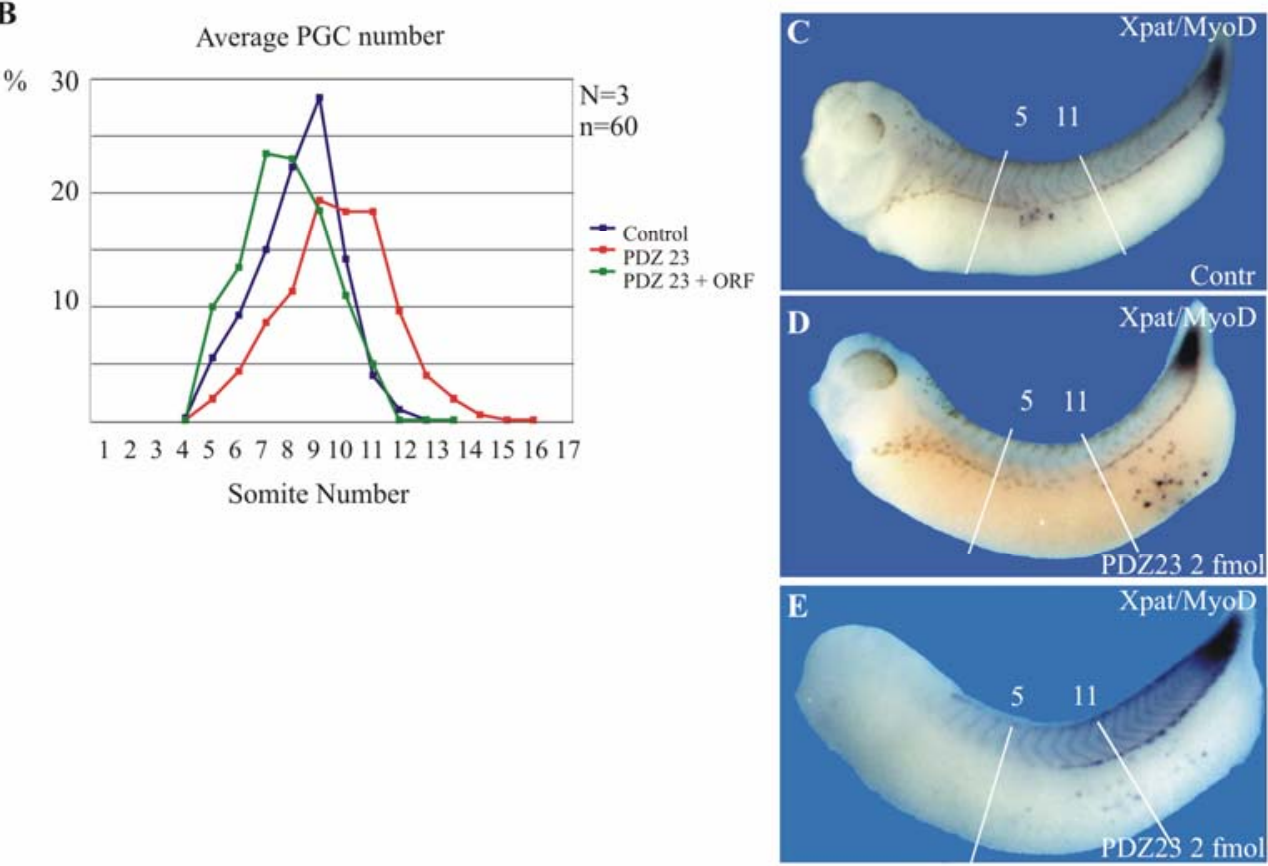

Fig. 4.9. Misexpression of the putative dominant negative XGRIP2.1 fragment PDZ 23 impairs normal PGC development and migration. (A, B, D) Embryos were injected vegetally into both blastomeres of the 2-cell stage. (A) Injection of synthetic mRNAs ( $2 \mathrm{fmol}$ each) encoding for a series of putative dominant negative protein fragments of XGRIP2.1 results in a reduced average PGC number and mislocalization of PGCs. * $-\mathrm{p}(\mathrm{t})<0.1$ for average numbers of mislocalized PGCs and $\mathrm{p}(\mathrm{t})<$ 0.05 for average PGC numbers. (B) The PGC migration profile of uninjected control embryos (stage 3233) (dark blue curve) and embryos injected with PDZ 23 RNA (2 fmol) alone (red curve) or together with XGRIP2.1 ORF RNA (0.2 ng) (green curve). (C) An uninjected control embryo (stage 33) illustrating the borders (somite numbers, white lines) of normal PGC positioning along the A/P axis. (D) An extreme example of an embryo injected with 2 fmol of PDZ 23 RNA exhibiting mislocalization of PGCs. (E) A representative example of an embryo injected with 2 fmol of PDZ 23 RNA exhibiting mislocalization of PGCs. $\mathrm{N}$ - number of independent injections, $\mathrm{n}$ - number of embryos analyzed in each experiment. 
To further test for the specificity of this effect, two mutant versions of PDZ 23 were designed to abolish the binding of putative interacting proteins by deleting a stretch of 36 amino acids from the PDZ domain 2 (PDZ 23 del) and by mutation of the FGF-motif in the putative binding cleft to SRS (PDZ 23 SRSmut) (Fig. 4.10A) (Im et al., 2003). Injection of mRNA encoding these mutant forms of the PDZ 23 construct did not result in a significant change of the PGC migration profile (Fig. 4.10B, C), indicating that proper folding of this part of the XGRIP2.1 protein is required for the interaction(s) with putative binding partner(s), resulting in the phenotype observed.

\subsubsection{Analysis of the functional significance of $P D Z$ domains 2 and 3 in the context of the full-length ORF of XGRIP2.1}

To further analyze for the importance of PDZ domains 2 and 3 in the context of fulllength XGRIP2.1, additional mutant forms of XGRIP2.1 were generated. In the first one (SRSmutORF), the FGF-cleft (Im et al., 2003) was mutated to SRS, as described above for PDZ 23. In addition to this, we generated three deletion mutants lacking either a single or both PDZ domains 2 and 3 ( $\triangle \mathrm{PDZ} 2 \mathrm{ORF}, \triangle \mathrm{PDZ} 3 \mathrm{ORF}$ and $\triangle \mathrm{PDZ} 23 \mathrm{ORF}$, correspondingly). These constructs were analyzed for their capacity to rescue the MO-mediated reduction of average PGC numbers. Coinjection of $\triangle \mathrm{PDZ} 2 \mathrm{ORF}$ or $\triangle \mathrm{PDZ} 3$ ORF deletion mutants together with the XGRIP2.1 MO2 was not lethal and did not result in a significant rescue of the MO effects (Fig. 4.11A). Similarly, coinjection of SRSmutORF did not lead to a significant rescue of the MO induced phenotype, for both, effects on average PGC number and PGC migration (Fig. 4.11A). Coinjection of the $\triangle \mathrm{PDZ} 23$ ORF mRNA together with the XGRIP2.1 MO2 was lethal even at a limit of $30 \mathrm{pgs}$, the mRNA dose equivalent to the threshold dose of the wtORF mRNA needed to achieve a statistically significant rescue of the MO effects. Overexpression of XGRIP2.1 ORF mutants alone didn't result in any significant difference neither in the average PGC number nor in their positioning (except for $\triangle \mathrm{PDZ} 23$, injections of which were still lethal). To prove that the mutant forms of XGRIP2.1 ORF were indeed overexpressed, 2-cell stage embryos were microinjected with mRNAs encoding each of the mutant XGRIP2.1 ORF variant. All the mutants were successfully detected by Western-blotting (Fig 4.11B). Taken together, these additional rescue experiments indicate that PDZ 2 and 3 are essential for the normal function of XGRIP2.1 in the context of PGC development. 
A

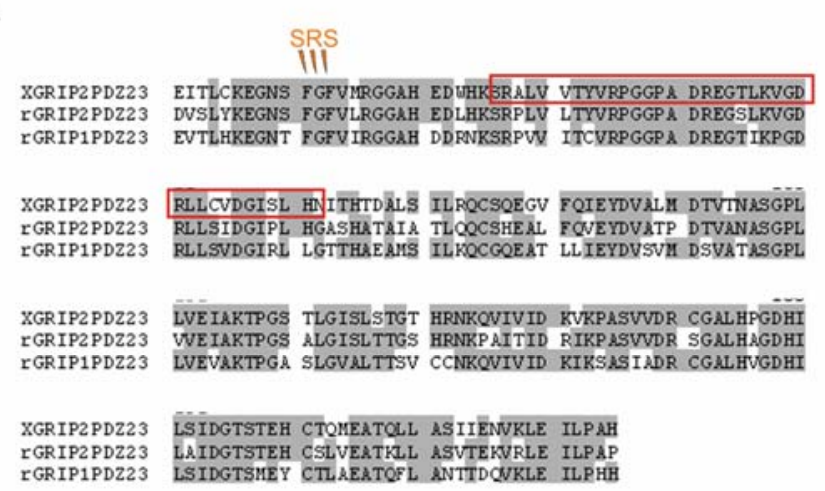

B

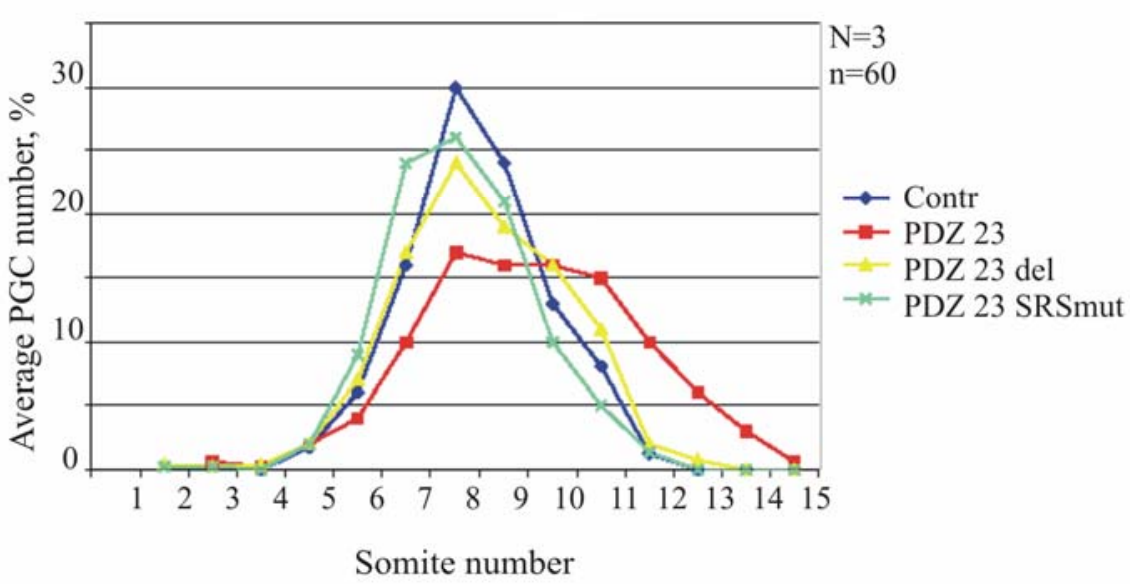

C

Average number of mislocalized PGCs

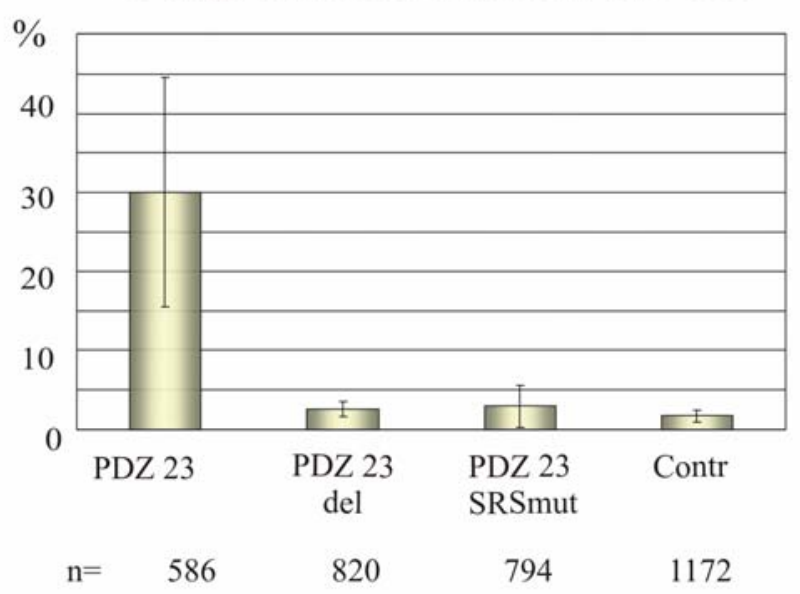

Fig. 4.10. Dominant negative activity of XGRIP2.1 PRZ 23 requires structural integrity of the predicted cargo binding domain. (A) Alignment of PDZ domains 2 and 3 of XGRIP2.1 with the corresponding domains of Rattus norvegicus GRIP1/ GRIP2. Identical amino acids are marked as shaded boxes. The red box depicts the internal deletion introduced into the XGRIP2.1 PDZ 23 del construct; three amino acid changes introduced into PDZ 23 SRSmut are shown in orange. (B) The PGC migration profile of uninjected control embryos (dark blue curve), embryos injected with 2 fmol of PDZ 23 (red curve), PDZ 23 del (yellow curve) or PDZ 23 SRSmut (light green curve) mRNA. n- number of embryos analyzed. (C) Injection of $2 \mathrm{fmol}$ of the PDZ 23 RNA increases the average number of mislocalized PGCs, calculated as percentage of the total PGC number from three independent experiments (see Materials and Methods). 60 embryos were analyzed in total for each kind of treatment. $\mathrm{n}$ - number of PGCs scored. (B-C) Embryos were injected vegetally into both blastomeres at the 2-cell stage. $\mathrm{n}-$ number of PGCs scored, $\mathrm{N}$ - number of independent injections. 
A

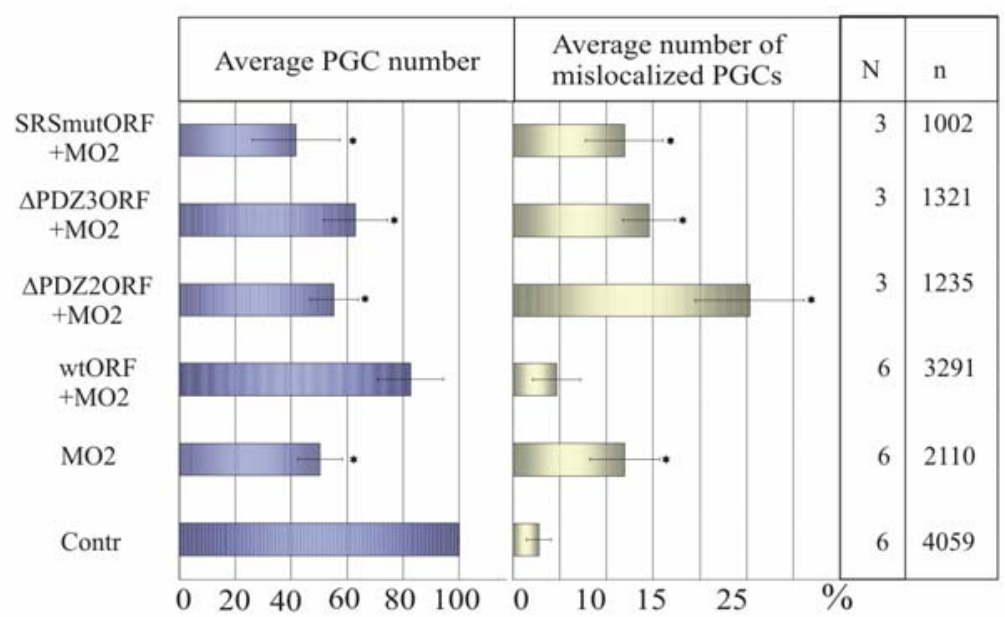

B

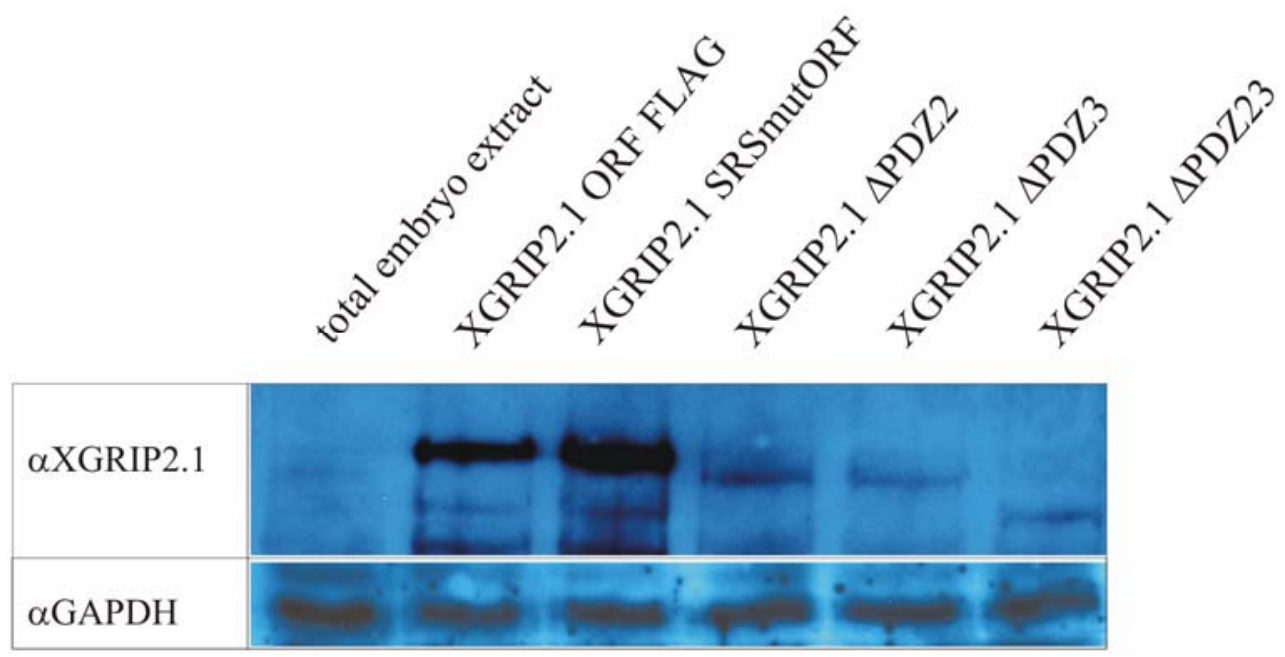

Fig. 4.11. PDZ domains 2 and 3 are necessary for the normal functioning of XGRIP.2.1 (A) Coinjection of wtORF XGRIP2.1 can rescue the average PGC number and anteroposterior positioning of PGCs induced by 0.2 pmol of MO2 XGRIP2.1. Mutations within PDZs 2 or 3 abolish the rescuing activity. Embryos were injected vegetally into both blastomeres at the 2-cell stage. $n$ - number of PGCs scored, $\mathrm{N}-$ number of independent injections. ${ }^{*}-\mathrm{p}(\mathrm{t})<0.05$. (B) Embryos were injected vegetally into both blastomeres at 2 -cell stage with XGRIP2.1 wtORF, SRSmut ORF, $\triangle$ PDZ2, $\triangle$ PDZ3, and $\triangle$ PDZ23 mRNAs and cultured till gastrula stage. Total protein extract were prepared from five embryos of each kind of treatment and subjected to western-blotting. All mutant forms and wtORF XGRIP2.1 were detected.

In summary, similar to the effects obtained in MO-mediated knockdown experiments, PGC-specific misexpression of a dominant-negative protein fragment encoding PDZ domains 2 and 3 of XGRIP2.1 leads to a reduction of the average PGC number, substantiating the idea that proper function of XGRIP2.1 is required for PGC maintenance. Furthermore, misexpression of the PDZ 23 construct and MO-mediated depletion of XGRIP2.1 interfere with the normal positioning of PGCs along the A/P axis, suggesting a function of XGRIP2.1 in the context of PGC migration. 


\subsubsection{Time-lapse analysis of PGC migration Xenopus embryos}

To further investigate the role of XGRIP2.1 in PGC migration and to analyse in more detail the XGRIP2.1 loss-of function- mediated posterior shift in PGC positioning along the A/P axis, time-lapse analysis was performed.

Several GFP versions were designed to test for their ability of stable PGC-specific expression, which allows efficient in vivo time-lapsing of migrating PGCs. So far, the best results were obtained upon injection of mRNAs coding for enhanced GFP (EGFP) and farnesylated short-living GFP (fpd2EGFP). Both GFP-variants were cloned into pCS2+ vector, containing the XDead end 3'UTR localization element (see Materials).

Embryos were injected vegetally into both blastomeres at the 2-cell stage, grown till tailbud stage and analysed for PGC-specific GFP expression. Titration series for both construct revealed the most efficient PGC labelling upon injection of 0.5-0.8 ng of mRNAs coding for GFP-variants described above.

To study anteroposterior PGC positioning, sorted for time-lapsing embryos were additionally co-injected anteriorly (the level of the first-second somites) at tailbud stage with $\mathrm{DiOC}_{6}(1 \mathrm{mg} / \mathrm{ml} \mathrm{DMSO})$. This lipophilic dye emits in the green channel as well as GFP, which allowed having a reference label to analyse possible anterior migration of PGCs.

After establishing the labelling system, migration of 10 PGCs was traced in 10 Xenopus laevis embryos during developmental stages 26 to 41 (Fig. 4.12A) (appr. 80 hours). Calculation of relative average velocities of migrating PGCs was performed for six time-windows, combining stages 26 to 31,31 to 33,33 to 25,25 to 37 and 37 to 41 . This analysis allowed to conclude that the average velocity of migrating PGC does not change significantly during stages 26 to $35(0.25 \mathrm{~mm} / \mathrm{h})$ and is decreasing afterwards till stage 41 (Fig. 4.12B).

As far as the majority of PGCs can be observed on the lateral surfaces of an embryo during tailbud stages 31-33, which also fits with the calculated maximal average velocity of germ cells migration, all time-lapse analyses described here after were done with embryos of these developmental stages. 
A

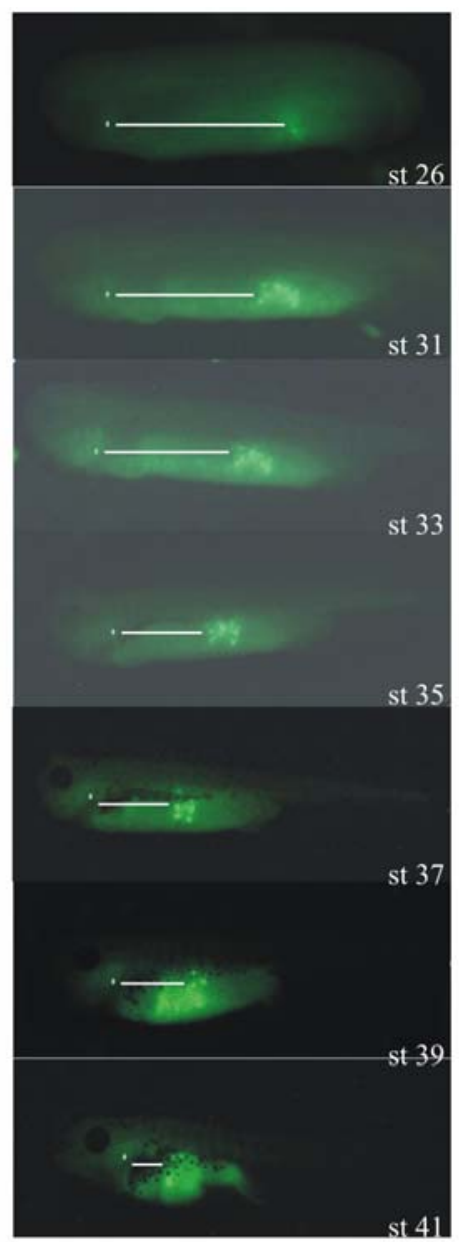

B

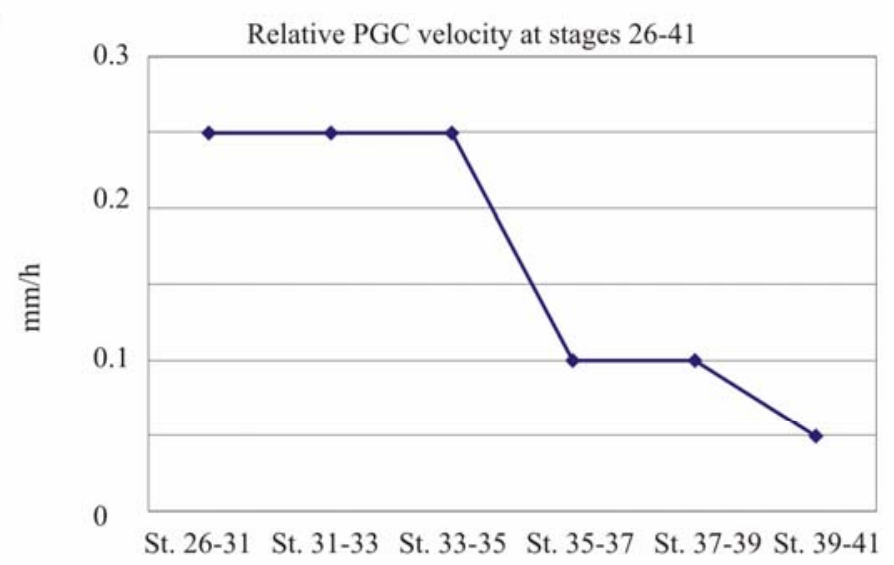

$\mathrm{C}$

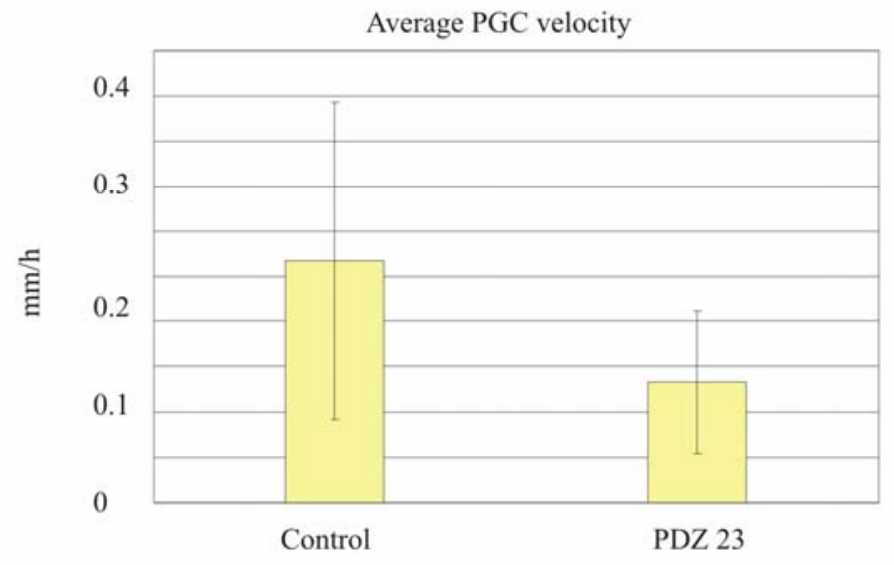

Fig. 4.12. Time-lapse analysis of PGC migration and average PGC velocities during embryionic stages 26-42. (A) Time-lapse analysis of PGC migration in Xenopus embryo during stages 26-42. (B) Average PGC velocities during embryionic stages 26-41. PGC velocities were calculated at each time window for 5 control embryos. (C) Embryos injected with XGRIP2.1 DN PDZ 23 exhibit reduced PGC velocities at stages 31-33. (A-C) Embryos were injected vegetally into both blastomeres at 2- cell stage whether with DELE-tagged EGFP ORF $(0.2 \mathrm{ng} / \mu \mathrm{l}) \mathrm{mRNA}$ alone or coinjected with XGRIP2.1 DN PDZ 23 mRNA (2 fmol).

To shed more light on the XGRIP2.1 loss-of function phenotype, we addressed the question whether the posterior shift in PGC positioning in these embryos is a result of PGC mismigration or loss of motility. The time-lapse analysis was performed with 10 embryos coinjected with $0.5 \mathrm{ng}$ of EGFP mRNA described above and 2 fmol XGRIP2.1 DN PDZ 23 mRNA. PGCs in these embryos were still motile, but the average velocity was significantly reduced $(0.13 \mathrm{~mm} / \mathrm{h})$ in comparison to the control embryos injected only with EGFP mRNA $(0.25 \mathrm{~mm} / \mathrm{h})($ Fig. 4.12C, 4.13A; Movies 1, 2). In extreme cases, more that $50 \%$ of germ cells in PDZ 23-injected embryos were not moving anteriorly at all, but just trembled at their initial positions for all the period of the time-lapse (Fig. 4.13B, Movie 3). In some cases, the most posteriorly positioned PGCs disappeared during time-lapsing without any attempts to migrate (Fig. 4.13B, yellow arrow) 


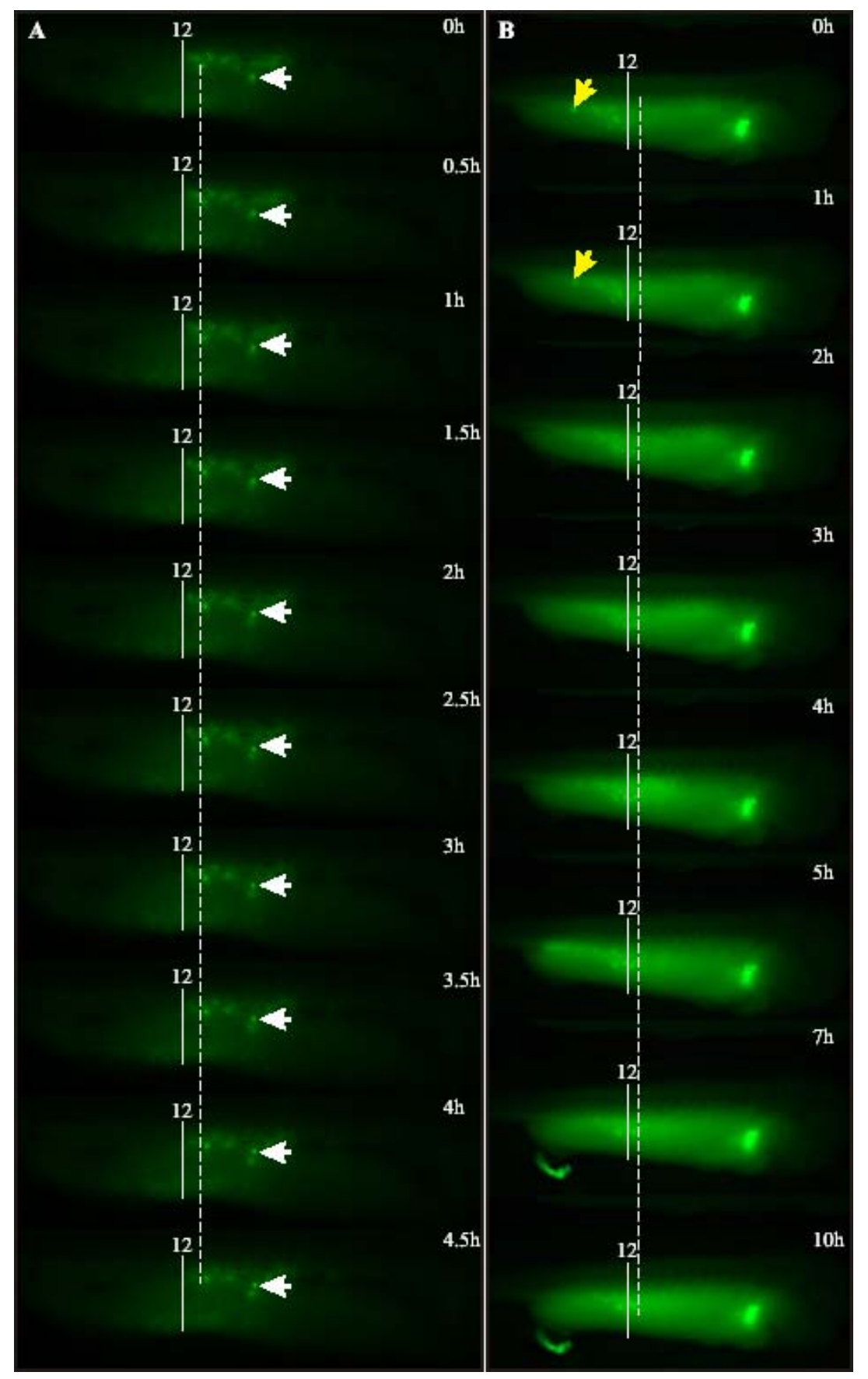

Fig. 4.13. Time-lapse analysis of PGC migration in control and PDZ 23 injected Xenopus embryos stage 32-33. Time-lapse analysis of PGC migration in Xenopus embryo stage 33 injected with $0.4 \mathrm{ng}$ of the DELE-tagged EGFP ORF mRNA alone (A) or together with 2 fmol of XGRIP2.1 DN PDZ 23 mRNA (B). Images were taken from the 10 hours movies acquired at $40 \mathrm{X}$ and $30 \mathrm{X}$ magnifications, respectively. The anterior migration of PGCs is shown in respect to the dashed line; dorsally/anteriorly migrating PGC of a control embryo is depicted with a white arrow. A mislocalized PGC in the XGRIP2.1 DN PDZ 23 injected embryo not visible after 1 hour of observation is marked with the yellow arrow.

In summary, studies performed so far allow to conclude that interfering with the normal XGRIP2.1 function does not result in severe mismigration of PGCs, but affects the average velocity of their movement. 


\subsection{Characterization of the XGRIP2.1 mRNA localization element necessary and sufficient for its vegetal localization during oogenesis}

\subsubsection{A 210 nucleotide element within the XGRIP2.1 3'UTR is necessary and sufficient for vegetal localization of this mRNA}

To identify the cis-acting localization element driving vegetal transport of XGRIP2.1 mRNA, we performed microinjection assays in cultured stage I-II oocytes using a series of deletion fragments derived from the full-length XGRIP2.1 cDNA, which were fused to the lacZ reporter RNA (Fig. 4.14F). A stretch of 210 nucleotides (nt 3875-4084) residing within the XGRIP2.1 3'UTR was found to be necessary and sufficient to mediate vegetal localization (Fig. 4.14D, E, E'). The XGRIP2.1 localization element (LE) also drives vegetal RNA transport at later stages of oogenesis (stage III), resulting in an RNA distribution pattern reminiscent of the late localization pathway (Fig. 4.14G, H). Thus, the XGRIP2.1 LE can use both the early and the late pathway machineries for vegetal localization.

To test for a possible correlation between the sequence of the XGRIP2.1 LE and for the presence of repeated VM1/E2 motifs, which were previously reported to cluster within LEs and thus proposed to function in vegetal RNA localization (Betley et al., 2002; Cote et al., 1999; Deshler et al., 1998; Lewis et al., 2004; Mowry, 1996), we mapped their positions in the XGRIP2.1 3'UTR. Only one E2 motif (UUCAC) and two VM1 motifs (YYUCU) were located within the XGRIP2 LE sequence, whereas two E2 and 15 VM1 motifs were found outside of the LE. Thus, the XGRIP2 LE does not contain a significant cluster of E2/VM1 motifs, arguing against their involvement in vegetal RNA transport of XGRIP2.1.

Fig. 4.14. The 3'UTR of XGRIP2.1 contains a $210 \mathrm{nt}$ localization element. Initially, Alexa-546-labeled XGRIP2.1 RNA fragments were injected into stage I-II oocytes and visualized in vivo by fluorescence microscopy (C, E'). For the most relevant fragments, injections were repeated with corresponding LacZ-tagged RNAs, which were detected by whole mount in situ hybridization (A, B, D, E, G, H). Vegetal localization was not observed in oocytes injected with 5'UTR and ORF RNA (A), but the 3'UTR fragment was localized (B). Further deletion mutagenesis of the XGRIP2.1 3'UTR defined the fragment containing nucleotides 3734-4169 as being capable to mediate vegetal RNA localization (C). The given fragment was further restricted to the minimal localization element containing nucleotides 3875-4084 (D), which was found to be sufficient and necessary for vegetal RNA localization, since the 3'UTR fragment lacking nucleotides 3874-4084 was not localized (E, E'). (F) A schematic illustration of the deletion constructs used for the mapping of the XGRIP2.1 LE. The ORF is marked by a blue rectangle; the localization element is depicted as a red box. Corresponding nucleotide positions of the XGRIP2.1 cDNA are indicated. The capability of each construct to drive vegetal 
localization is indicated in (+/-). The lacZ-tagged XGRIP2.1 3'UTR (G) and the fragment containing nucleotides $3875-4084(\mathrm{H})$ are also localized to the vegetal cortex upon injection into stage III oocytes.
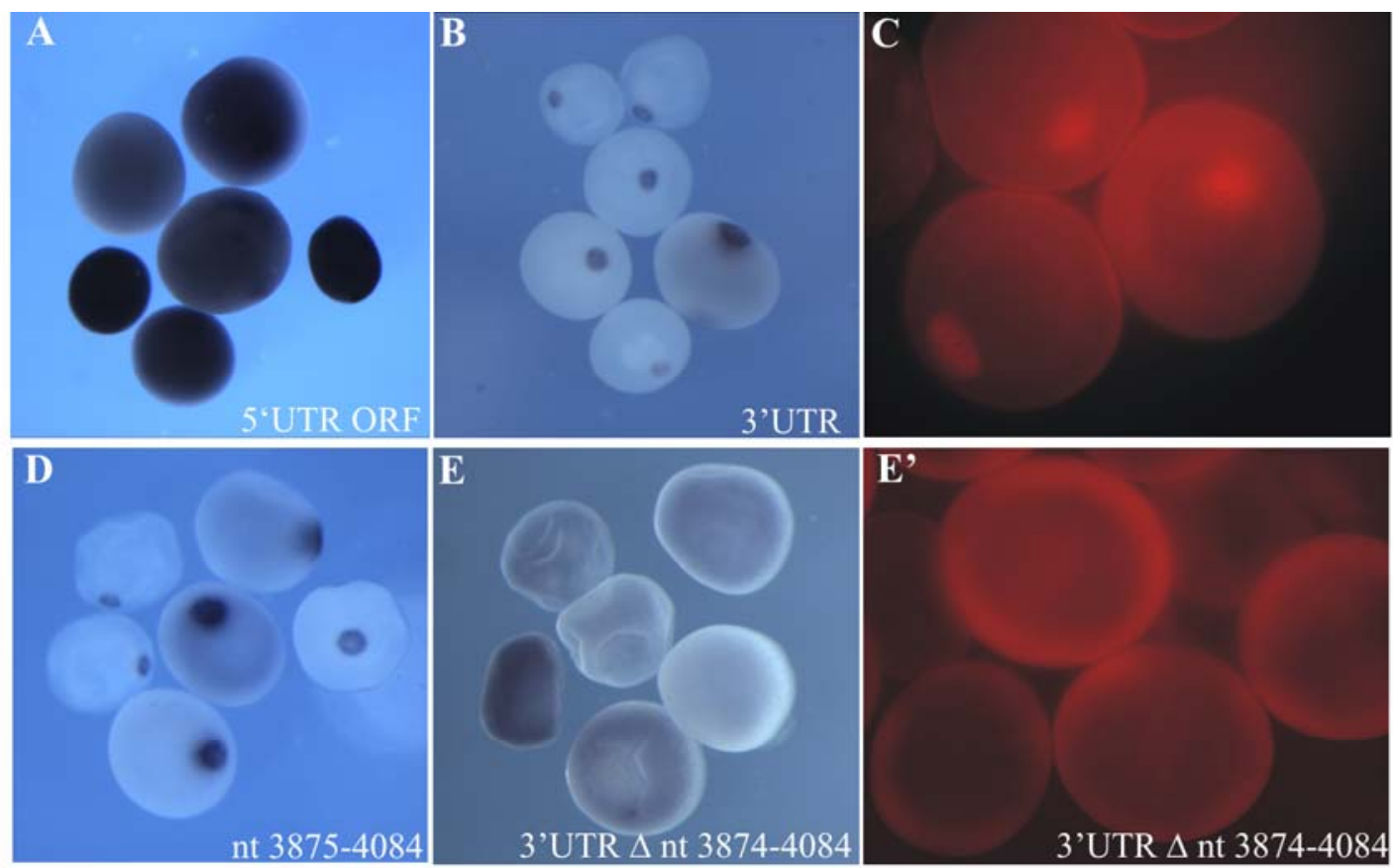

E'

F

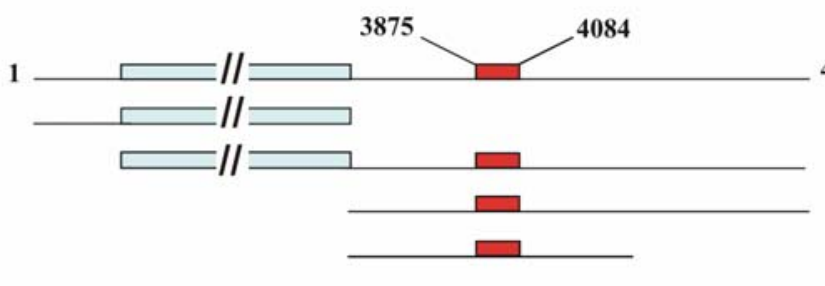
4994

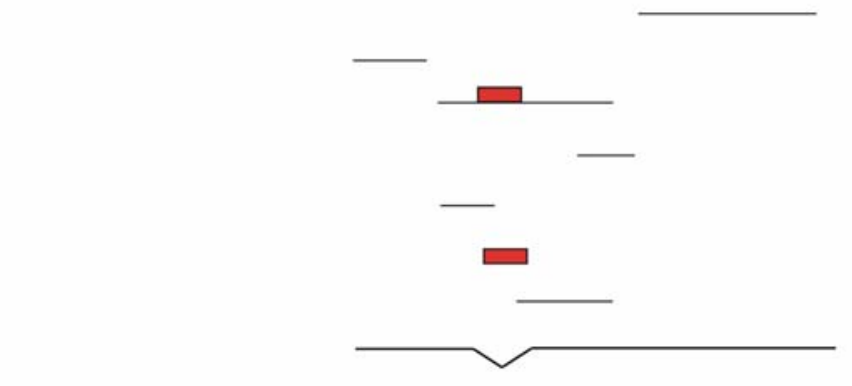

Veg Loc

3'UTR $\Delta$ nt 3874-4084

$$
\begin{array}{ll}
- & \text { 5'UTR ORF } \\
+ & \text { ORF 3·UTR } \\
+ & \text { 3'UTR } \\
+ & \text { nt } 3376-4376 \\
- & \text { nt } 4374-4992 \\
- & \text { nt } 3376-3840 \\
+ & \text { nt } 3734-4169 \\
- & \text { nt } 4033-4376 \\
- & \text { nt } 3730-3880 \\
+ & \text { nt 3875-4084 ( XGRIP2 LE) } \\
- & \text { nt } 4067-4164 \\
- & \text { 3'UTR } \triangle \text { nt } 3874-4084
\end{array}
$$
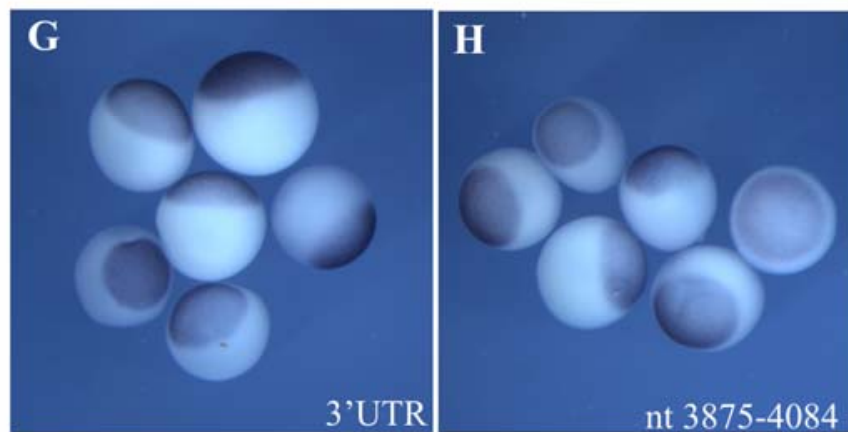


\subsubsection{Six LE-binding proteins are shared by XGRIP2.1 and two other germ cell specific mRNAs, XDead end and XDeadSouth}

To find out, which trans-acting factors might interact with the XGRIP2.1 LE and mediate vegetal transport of XGRIP2.1 mRNA, comparative UV-cross-linking experiments were performed. To discriminate between the properties of the early-localizing, PGC specific mRNA XGRIP2.1 and other vegetally localizing mRNAs, the protein binding pattern of the XGRIP2.1 LE was compared to corresponding patterns of the germ cell specific, but late localizing mRNA XDead end (Horvay et al., 2006), germ cell specific but also early localizing XDeadSouth (MacArthur et al., 2000) and of the early localizing, but not germ cell specific mRNA XNIF (Claussen et al., 2004).

Of the six proteins cross-linking with the XGRIP2.1, XDead end and XDeadSouth LEs, two migrate at 54/56 kDa and likely represent the highly abundant FRGY proteins (Fig. 4.15A, B, black arrowheads) (Cote et al., 1999). The 69 kDa protein (Fig. 4.15A, B, white arrowheads) was competed efficiently with LacZ competitor RNA and could therefore not be regarded as specific.

Three of the detected proteins, migrating at 42, 40, and $33 \mathrm{kDa}$, respectively, specifically interact with the XGRIP2.1 LE (Fig. 4.15A, B, black asterices), since their binding is eliminated upon competition with XDead end and XDeadSouth LEs, but not with LacZ RNA. Binding of these proteins to the XGRIP2.1 LE can also be cross-competed by addition of non-radioactively labelled Vg1 LE RNA, but not XNIF LE RNA. Correspondingly, binding of the 42, 40, and 33 $\mathrm{kDa}$ proteins to radioactively labelled XDead end and XDeadSouth LEs RNAs can be crosscompeted by non-radioactively labelled XGRIP2.1 LE RNA (Fig. 4.15A, B).

UV-crosslinking experiments above were done with standard S100 total protein extracts from stage V-VI oocytes. To further resolve the protein binding pattern, UV-crosslinks with the RNP-enriched protein fractions (RNP200) (P.K. Arthur, PhD-thesis, University Göttingen, in preparation) were performed. Binding of the six proteins described above was reproduced with much higher intensity of the signal, but no binding of other trans-acting factor(s) was detected (Fig. 4.16). 
A

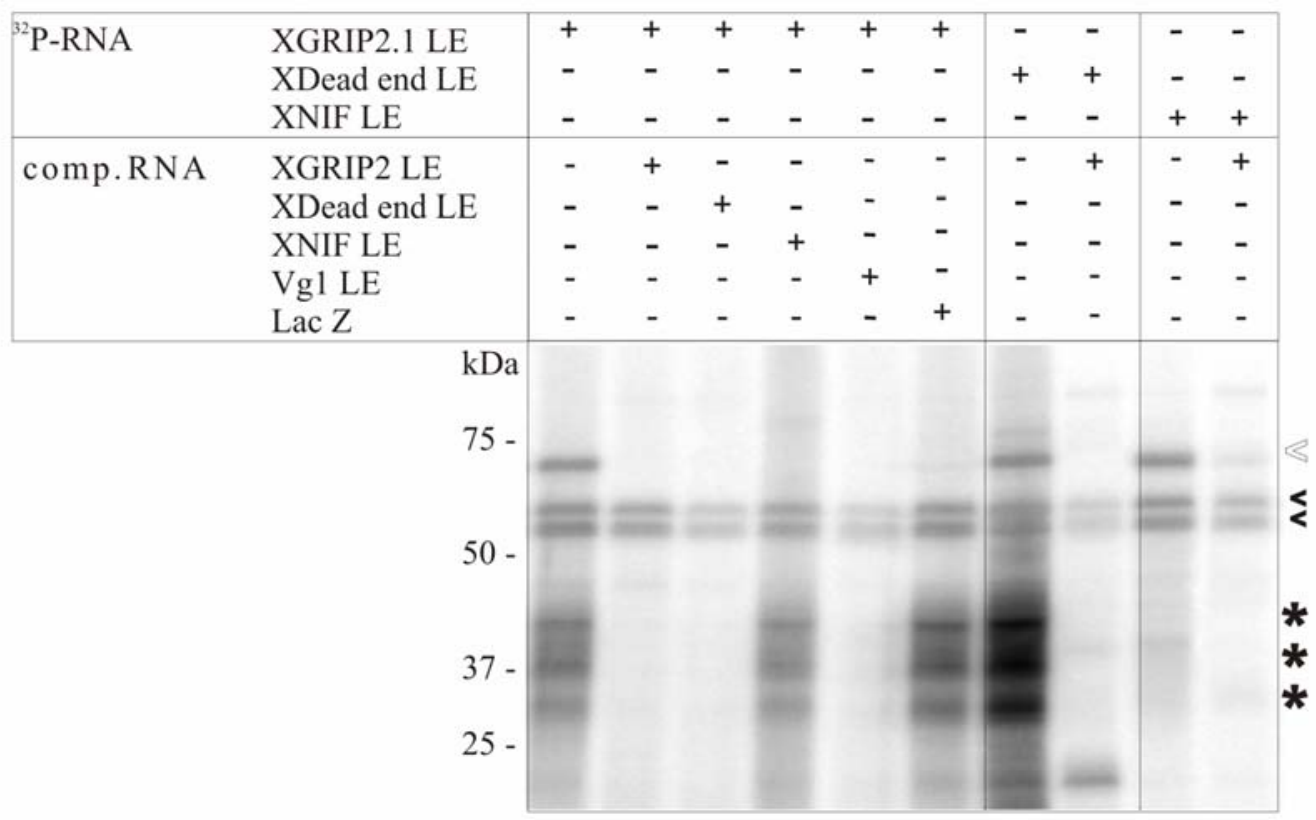

B

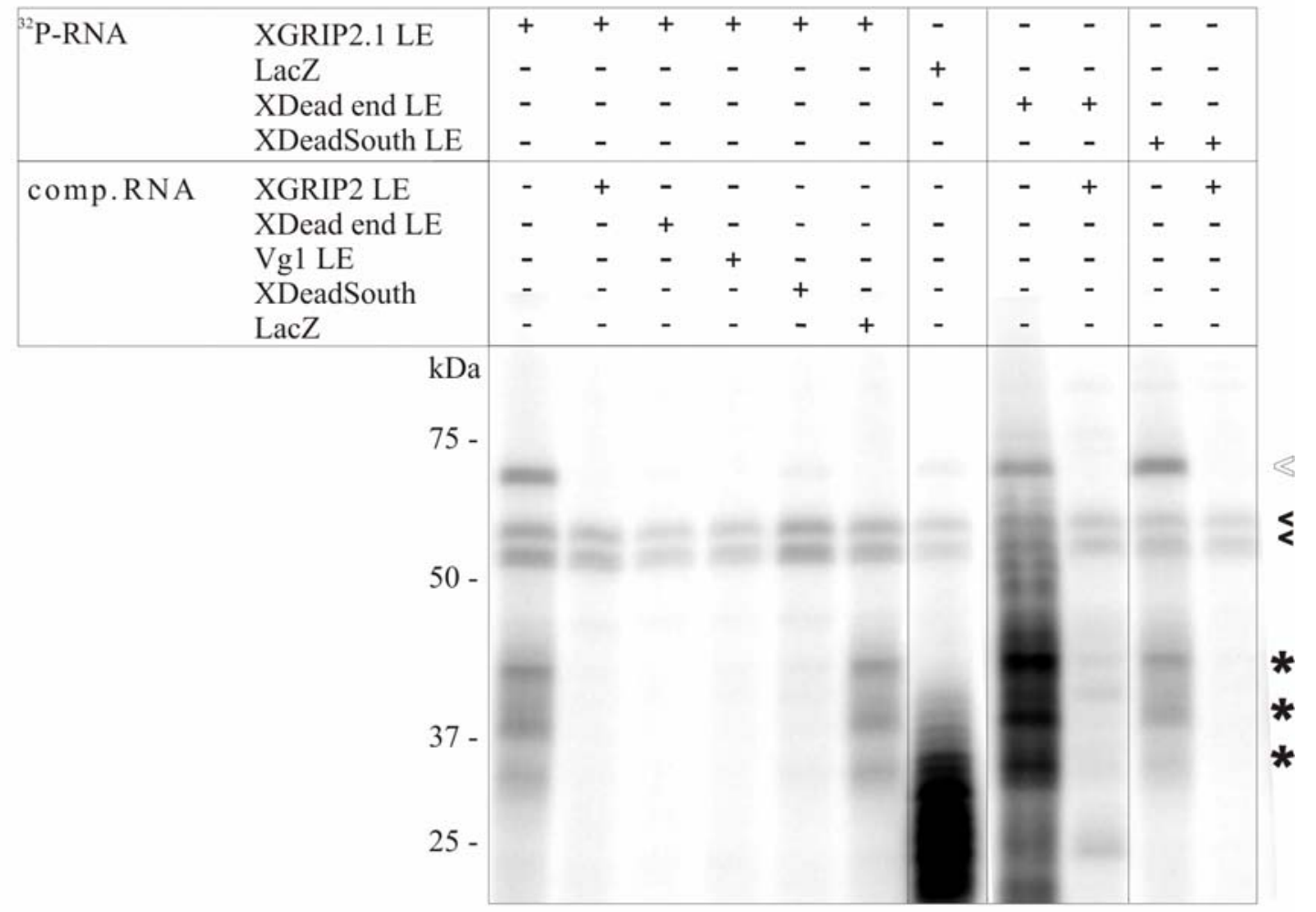

Fig. 4.15. UV-cross-linking analysis of XGRIP2.1 LE binding proteins with S100 oocyte extract. (A) RNA-binding reactions contained ${ }^{32} \mathrm{P}-$-labeled XGRIP2.1 LE (nt 3875-4084) (lanes 1-6) or XDead end LE (lanes 7,8) RNAs were incubated with S100 oocyte extract and tRNA alone (lane 1,7) or together with either a non-specific LacZ competitor RNA (lane 6) or specific competitor RNAs (lane 2-5, 8), respectively. (B) RNA-binding reactions contained ${ }^{32}$ P-labeled XGRIP2.1 LE (nt 3875-4084) (lanes 16), LacZ (lane 7), XDead end LE (lanes 8, 9) or XDeadSouth LE $(10,11)$ RNAs were incubated with S100 oocyte extract and tRNA alone (lane 1, 7, 8, 10) or together with either a non-specific LacZ competitor RNA (lane 6) or specific competitor RNAs (lane 2-5, 9, 11), respectively. Cross-linked proteins were resolved by $12 \%$ SDS-PAGE and detected by phosphoimaging. Proteins specifically crosslinking to XDead end and XGRIP2.1 LEs are labelled with black asterisks. The $69 \mathrm{kDa}$ protein unspecifically interacting with XGRIP2.1 and XDead end LEs is labelled with a white arrowhead, the $54 / 56 \mathrm{kDa}$ FRGY proteins are indicated by black arrowheads. 


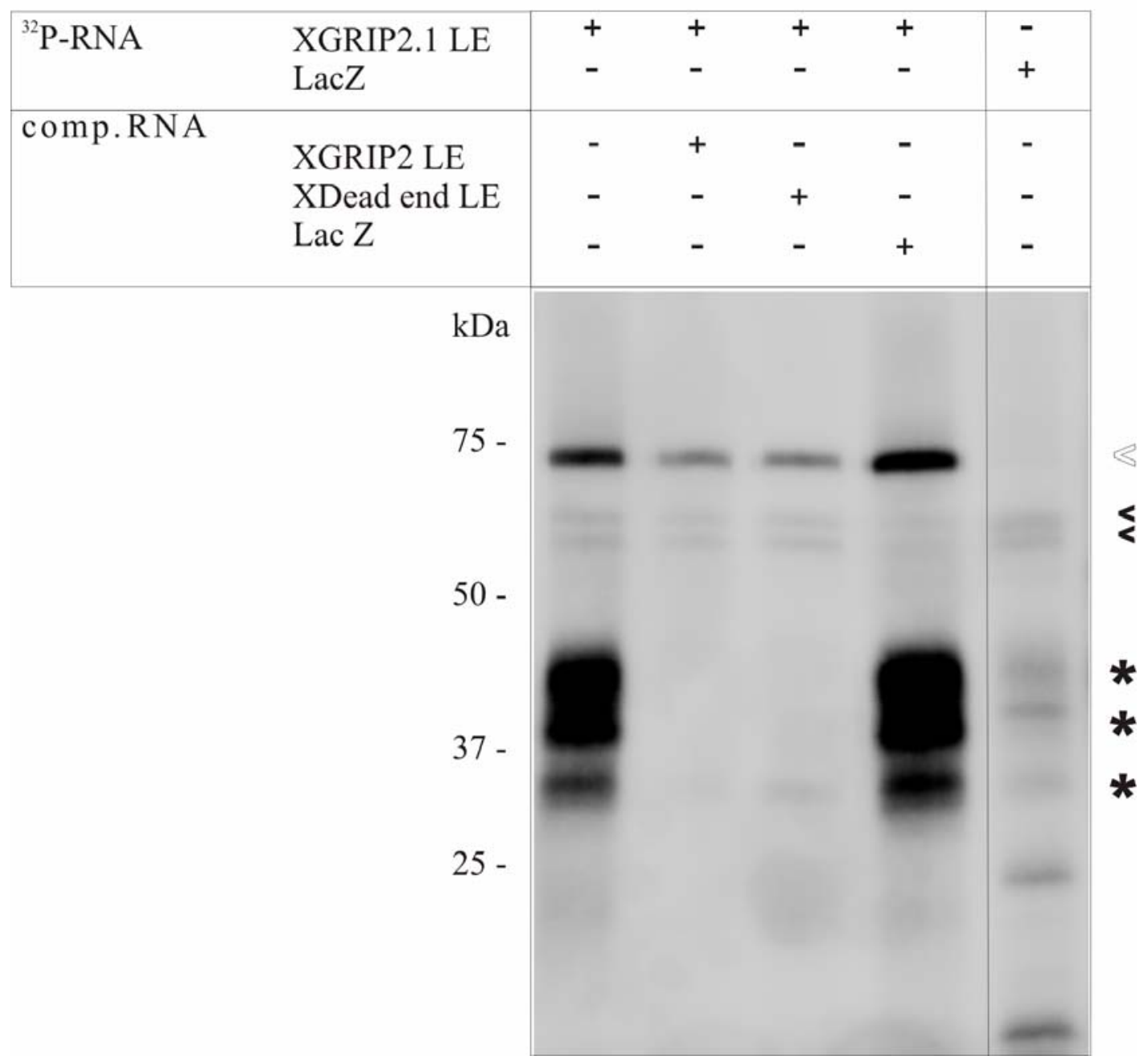

Fig. 4.16. UV-cross-linking analysis of XGRIP2.1 LE binding proteins with RNP-enriched protein fractions. RNA-binding reactions contained ${ }^{32} \mathrm{P}$-labeled XGRIP2.1 LE (nt 3875-4084) (lanes 1-4) or LacZ (lane 5) RNAs were incubated with RNP-enriched protein fractions and tRNA alone (lane 1, 5) or together with either a non-specific LacZ competitor RNA (lane 4) or specific competitor RNAs (lane 2, $3)$, respectively. Cross-linked proteins were resolved by $12 \%$ SDS-PAGE and detected by phosphoimaging. Proteins specifically cross-linking to XDead end and XGRIP2.1 LEs are labelled with black asterisks. The $69 \mathrm{kDa}$ protein unspecifically interacting with XGRIP2.1 and XDead end LEs is labelled with a white arrowhead, the 54/56 kDa FRGY proteins are indicated by black arrowheads.

To summarize, our cross-linking results reveal a strikingly similar protein binding pattern for LEs of three germ cell specific mRNAs: the early localizing XGRIP2.1 and XDeadSouth as well as of the late localizing XDead end. 


\subsubsection{Verification of Vg1RBP, ElrA, EIrB and FRGYs binding to the XGRIP2.1 LE by co-immunoprecipitation}

Identities of six proteins detected in UV-crosslinking experiments described in 4.2.2 were determined by P.K. Arthur in scopes of his $\mathrm{PhD}$ thesis (in preparation). He proved them to be Vg1RBP (Deshler et al., 1998) (69 kDa), FRGY (Cote et al., 1999) (54/56 kDa), ElrB (42/40 $\mathrm{kDa}$ ) and ElrA $33 \mathrm{kDa}$ (Colegrove-Otero et al., 2005). To further prove binding of these transacting factors to the XGRIP2.1 LE, co-immunoprecipitation of Alexa-UTP-labelled RNA with myc-tagged Vg1RBP, FRGY, ElrA, ElrB, Prrp (Kress et al., 2004) and Staufen (Yoon and Mowry, 2004) was performed (Fig. 4.17). Alexa-UTP-labelled XGRIP2.1 LE RNA was coimmunoprecipitated with Vg1RBP, FRGY, ElrA and ElrB proteins. No interaction with Prrp or Staufen was observed. Alexa-UTP-labelled XDead end LE RNA (taken here as appositive control) was co-immunoprecipitated with all proteins tested, but not with Staufen. Alexa-UTPlabelled LacZ RNA and the LE of another novel vegetally localized RNA Xvelo1 (Claussen and Pieler, 2004), were taken here as negative controls to verify the specificity of the assay. These RNAs co-immunoprecipitate only with Vg1RBP and FRGY (Fig. 4.17).

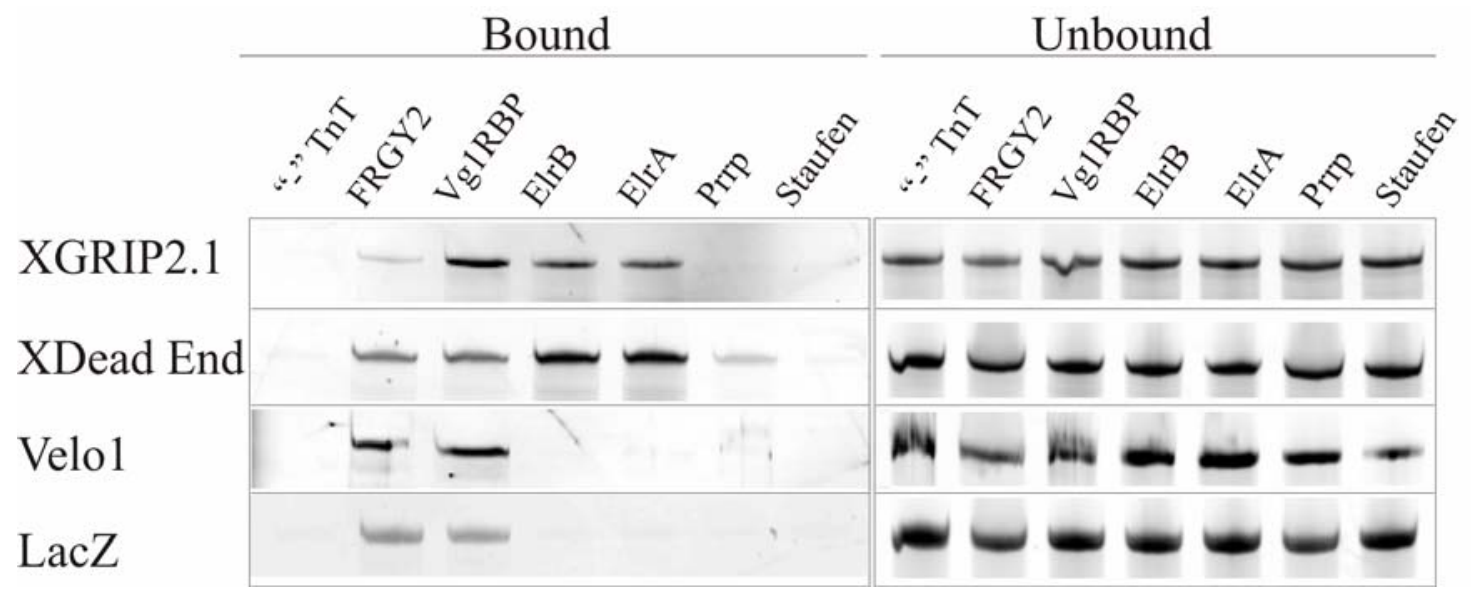

Fig. 4.17. Co-immunoprecipitations of Alexa-UTP-labelled XGRIP2.1 LE RNA with myctagged putative binding proteins. Alexa-UTP-labelled by in vitro transcription XGRIP2.1 LE, XDead end LE, Velo1 LE and LacZ RNAs were incubated with TnT-produced myc-tagged Vg1RBP, FRGY, ElrA, ElrB, Prrp and Staufen. “-“TnT represents coupled in vitro transcription/translation reaction without any plasmid added. Myc-tagged proteins with bound RNAs were precipitated on the myc-antibody (9E10, Sigma) coated beads. Alexa-labelled RNAs were phenol-extracted from the elution fraction ("Bound" RNAs) and from the supernatant before the first washing of beads with bound RNPs ("Unbound" RNAs regarded as loading control). Extracted RNAs were run on the 7\% Urea-PAGE and detected by Typhoon phosphoimager $(\lambda=584 \mathrm{~nm})$.

To summarise, Co-IPs confirmed interaction of the XGRIP2.1 LE with Vg1RBP, FRGY, ElrA and ElrB proteins in vitro, which is in agreement with results of UV-crosslinking experiments. 


\subsection{Functional characterization of xKIF13B}

\subsubsection{RACE-extension of the $x K I F 13 B$ cDNA}

$x K I F 13 B$ was identified in a microarray-based screen for novel vegetally localizing mRNAs in Xenopus oocytes (Horvay et al., 2006). The initial cDNA consisted of $800 \mathrm{bp}$ of the ORF. A single round of the 5'RACE- extension resulted in a $750 \mathrm{bp}$ product containing the remaining N-terminal part of the ORF and $96 \mathrm{bp}$ of the 5'UTR. Extensive 3'RACing allowed to obtain $3566 \mathrm{bp}$ of the ORF. The resulting $4506 \mathrm{bp}$ cDNA consists of $96 \mathrm{bp}$ 5'UTR and the partial ORF missing the C-terminal part (Fig. 4.18).

1 ccgccatggc cgcgggattt taatacgact cactataggg caagcagtgg tatcaacgca $\begin{array}{llllllllllllllllllllll}R & H & G & R & G & I & L & I & R & L & T & I & G & Q & A & V & V & S & T\end{array}$

61 gagtacgcgg ggaggttagg ggagctcgct gtgcaagatg agcgactcca atgtaaaggt

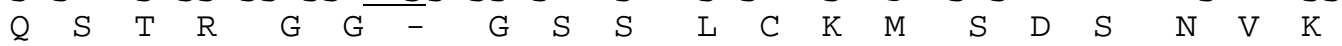

121 ggcggtgcgg atccgaccca tgaaccgaag agaacaggac cttcgcacaa aatgcgtagt $\begin{array}{lllllllllllllllllllll}\mathrm{V} & \mathrm{A} & \mathrm{V} & \mathrm{R} & \mathrm{I} & \mathrm{R} & \mathrm{P} & \mathrm{M} & \mathrm{N} & \mathrm{R} & \mathrm{R} & \mathrm{E} & \mathrm{Q} & \mathrm{D} & \mathrm{L} & \mathrm{R} & \mathrm{T} & \mathrm{K} & \mathrm{C} & \mathrm{V}\end{array}$

181 ggatgtagaa aacaatcaga tcgtcctgta cccatcaaat tccagtcttt ccaaggggga $\begin{array}{llllllllllllllllllll}V & D & V & E & N & N & Q & I & V & L & Y & P & S & N & S & S & L & S & K & G\end{array}$

241 tgccoggagc caaccaaagg tatttgccta cgatcactgc ttctggtcca tggatgagtc $\begin{array}{llllllllllllllllllllllllllllllllll}D & A & R & S & Q & P & K & V & F & A & Y & D & H & C & F & W & S & M & D & E\end{array}$

301 cgttaaggag aagtttgcag gacaagatgt agtctttcag tgccttggag agaacatact

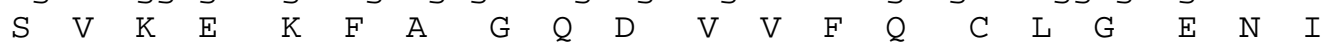

361 acagaatgcc tttgaaggct acaacgcatg catctttgcc tatgggcaga ctggatctgg $\begin{array}{llllllllllllllllllll}\mathrm{L} & \mathrm{Q} & \mathrm{N} & \mathrm{A} & \mathrm{F} & \mathrm{E} & \mathrm{G} & \mathrm{Y} & \mathrm{N} & \mathrm{A} & \mathrm{C} & \mathrm{I} & \mathrm{F} & \mathrm{A} & \mathrm{Y} & \mathrm{G} & \mathrm{Q} & \mathrm{T} & \mathrm{G} & \mathrm{S}\end{array}$

421 caagtcctac accatgatgg gcacggctga tcagccogga ctaatcccaa gactatgcag $\begin{array}{llllllllllllllllllllllll} & G & K & S & Y & T & M & M & G & T & A & D & Q & P & G & L & I & P & R & L & C\end{array}$

481 cactttattc gaaagaaccc agaaagcaga gaacgaagag ctgagcttta aagtagaagt $\begin{array}{llllllllllllllllllll}S & T & L & F & E & R & T & Q & K & A & E & N & E & E & L & S & F & K & V & E\end{array}$

541 ctcctttatg gaaatctaca atgaaaaagt ccgggatctc cttgacccaa aaggaagccg $\begin{array}{llllllllllllllllllll}V & S & F & M & E & I & Y & N & E & K & V & R & D & L & L & D & P & K & G & S\end{array}$

601 ccagtccctt aaagtcaggg agcacaaagt tttgggccca tacgtcgacg gcctatcaaa $\begin{array}{llllllllllllllllllll}R & Q & S & L & K & V & R & E & H & K & V & L & G & P & Y & V & D & G & L & S\end{array}$

661 gctagctgtc gccagttaca aggacattga gtcattgatg tcagaaggca acaaatctcg

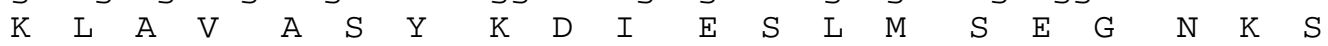

721 tacagtggcg gcaaccaaca tgaacgaaga gagtagccga tcccatgctg tcttcaacat $\begin{array}{lllllllllllllllllllllll}R & T & V & A & A & T & N & M & N & E & E & S & S & R & S & H & A & V & F & N\end{array}$

781 tatcctcacg cacactctga gcgacgtcaa atccgggacc tctggggaga aggtgagcaa

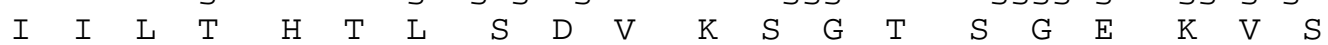


841 gctgagctta gtagatttgg ctgggagcga aagagccaca aagactggag cagccgggga $\begin{array}{llllllllllllllllllll}K & L & S & L & V & D & L & A & G & S & E & R & A & T & K & T & G & A & A & G\end{array}$

901 acgtttaaaa gaagggagca atatcaacaa gtctctcaca acccttggcc tggttatctc $\begin{array}{llllllllllllllllllllllllll} & \mathrm{R} & \mathrm{R} & \mathrm{L} & \mathrm{K} & \mathrm{E} & \mathrm{G} & \mathrm{S} & \mathrm{N} & \mathrm{I} & \mathrm{N} & \mathrm{K} & \mathrm{S} & \mathrm{L} & \mathrm{T} & \mathrm{T} & \mathrm{L} & \mathrm{G} & \mathrm{L} & \mathrm{V} & \mathrm{I}\end{array}$

961 agccctggca gaccaaggag ccgccaaaaa taagaacaaa tttgttccgt accgggactc

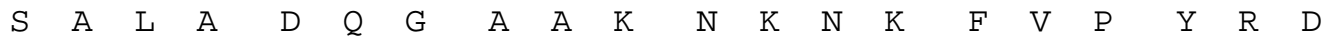

1021 tgtattaaca tggctgctga aagacagtct gggagggaac agtaaaacgg ctatggtagc $\begin{array}{lllllllllllllllllllll}S & V & L & T & W & L & L & K & D & S & L & G & G & N & S & K & T & A & M & V\end{array}$

1081 cacagttagc cccgctgctg ataactatga tgagacactc tccaccctaa ggtatgccga $\begin{array}{llllllllllllllllllll}A & T & V & S & P & A & A & D & N & Y & D & E & T & L & S & T & L & R & Y & A\end{array}$

1141 cagagccaag aacatagtca accatgctgt tgtcaatgag gaccccaacg ccagaataat

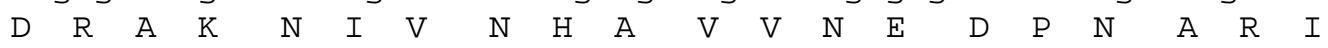

1201 ccgagaattg cgggaggaag tggagaaact gagggtgcag cttacccaag ctgagtctat $\begin{array}{llllllllllllllllllll}I & R & E & L & R & E & E & V & E & K & L & R & V & Q & L & T & Q & A & E & S\end{array}$

1261 gaaggcccca gagttaaaag aacgtctgca ggaatctgag aaactgatcc aagagatgac $\begin{array}{lllllllllllllllllllll}M & K & A & P & E & L & K & E & R & L & Q & E & S & E & K & L & I & Q & E & M\end{array}$

1321 tgtcacttgg gaagagaagc tcagaatgac agaggagatt gcccaggagc gccagaagca

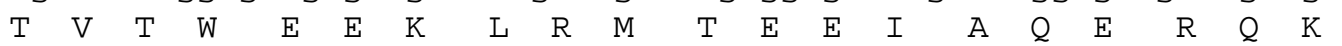

1381 acttgaaagc ctcgggattt cacttcagtc ttccgggatc aaagtgggag ataataagtg $\begin{array}{llllllllllllllllllll}Q & L & E & S & L & G & I & S & L & Q & S & S & G & I & K & V & G & D & N & K\end{array}$

1441 cttcttagtc aatttaaatg cagatccagc actcaacgag ctcctggtgt actaccttaa

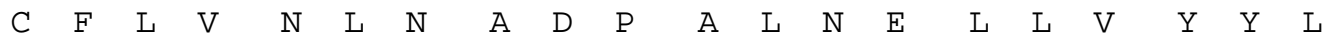

1501 ggatcacaca ttaatcgggt cccatgactc tcaggacatc cagctgtgtg gcttgggaat

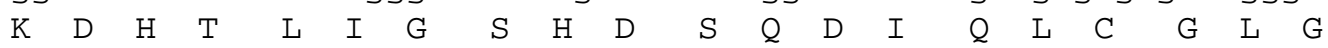

1561 tctcccogaa cactgcatca tagacatctc tccagaaggg caggttatac tgacgccaat $\begin{array}{lllllllllllllllllllll}I & L & P & E & H & C & I & I & D & I & S & P & E & G & Q & V & I & L & T & P\end{array}$

1621 gaaaaacacc aggacttatg tgaacggctc tgcagtctct aaagcaactc agctccagca

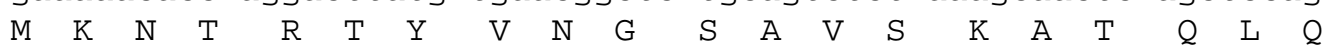

1681 cggagaccgc attctctggg ggaacaatca cttttcagg atcagcttac caaagaagaa $\begin{array}{llllllllllllllllllllllll}H & G & D & R & I & L & W & G & N & N & H & F & F & R & I & S & L & P & K & K\end{array}$

1741 aaaggccaaa caagaggatg aggaacaaga ctccatcctg aggaacagca gtagctttga $\begin{array}{llllllllllllllllllll}K & K & A & K & Q & E & D & E & E & Q & D & S & I & L & R & N & S & S & S & F\end{array}$

1801 acaactagac ttggatggag atagttccag tgaaggctcc agtgaggtca gcttcaacta $\begin{array}{lllllllllllllllllllll} & E & Q & L & D & L & D & G & D & S & S & S & E & G & S & S & E & V & S & F & N\end{array}$

1861 tgagtatgca cagatggaag tcatgatgaa agcccttgga aataatgacc caatgcagtc $\begin{array}{lllllllllllllllllllll} & \mathrm{E} & \mathrm{Y} & \mathrm{A} & \mathrm{Q} & \mathrm{M} & \mathrm{E} & \mathrm{V} & \mathrm{M} & \mathrm{M} & \mathrm{K} & \mathrm{A} & \mathrm{L} & \mathrm{G} & \mathrm{N} & \mathrm{N} & \mathrm{D} & \mathrm{P} & \mathrm{M} & \mathrm{Q}\end{array}$

1921 catcctacag agcctggagc aacagcatga ggaagagaag agatccgctc ttgagcgcca

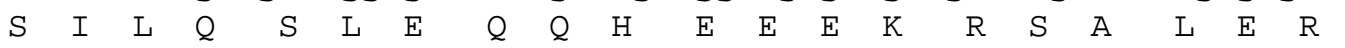

1981 gagactgatg tatgagcagg agttggacca gttgcgccgc agactttccc cagagaaaca

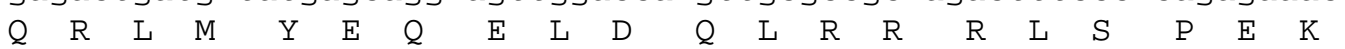

2041 gcattaccgt agcatggacc ggttctcctt tggatccccc aacgcgcagt accgaatcag $\begin{array}{llllllllllllllllllllllllll}Q & H & Y & R & S & M & D & R & F & S & F & G & S & P & N & A & Q & Y & R & I\end{array}$ 
2101 gcagtggaca gaagagaggg aggcaatgct gaaccagagc cttagaaagc tgcgtgagca $\begin{array}{llllllllllllllllllllllllllllll}R & Q & W & T & E & E & R & E & A & M & L & N & Q & S & L & R & K & L & R & E\end{array}$

2161 gatagccaaa gccaatctgc atgttcagga ggccaatttc atatcagagg agatggataa

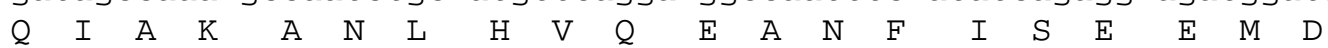

2221 gaggacagag tataaagtga cactgcagat tccagcctcc agtctcaatg ccaacaaaaa $\begin{array}{llllllllllllllllllll}K & R & T & E & Y & K & V & T & L & Q & I & P & A & S & S & L & N & A & N & K\end{array}$

2281 gcgaggagca gtgctgagcg agccagccat acaggtgcgc agaaaaggaa agggcaaaca $\begin{array}{llllllllllllllllllll}K & R & G & A & V & L & S & E & P & A & I & Q & V & R & R & K & G & K & G & K\end{array}$

2341 aatctggtcc ttggaaaagc tggaaaaccg tctggttgat atccgagacc tttatcagga $\begin{array}{llllllllllllllllllll}Q & I & W & S & L & E & K & L & E & N & R & L & V & D & I & R & D & L & Y & Q\end{array}$

2401 atggaaagaa tgtgatgaag acgaccctat gagccgctcc tatttccggc gagcagatcc

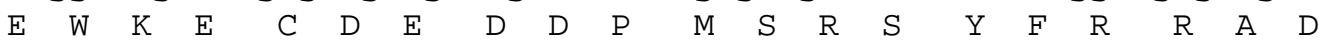

2461 tttctacgac gagcatgaga atcacagcct gatcggcgtg gccaacgtct tcttggagtc

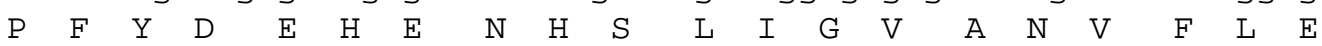

2521 tcttttccat gatgtgaagc ttcagtatgc ggttcctatc atcaaccaga aaggggaggt

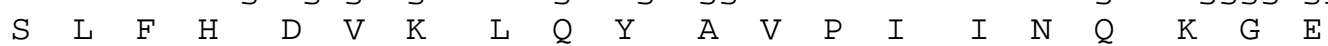

2581 tgcaggacgg ttacatatag aagtggtccg catcagtggt gacatcggag atcggatagc $\begin{array}{llllllllllllllllllll}V & A & G & R & L & H & I & E & V & V & R & I & S & G & D & I & G & D & R & I\end{array}$

2641 aggaggggaa gatggaacag atttctcttt tgagaaggag gttcaggaga acaagttagt $\begin{array}{llllllllllllllllllll}A & G & G & E & D & G & T & D & F & S & F & E & K & E & V & Q & E & N & K & L\end{array}$

2701 gtgcatgatt aaagtgctcc aggccacagg tttgccacag catctcacca actttgtctt $\begin{array}{llllllllllllllllllll}V & C & M & I & K & V & L & Q & A & T & G & L & P & Q & H & L & T & N & F & V\end{array}$

2761 ctgccattac gttttctggg atcagccaga acccactact gtggcacctg aagtggacac $\begin{array}{llllllllllllllllllllllllllll} & F & C & H & Y & V & F & W & D & Q & P & E & P & T & T & V & A & P & E & V & D\end{array}$

2821 agcgccccet gtcattaagg ggacagagtg catggtggtt tttgaccact gcaaagagtt

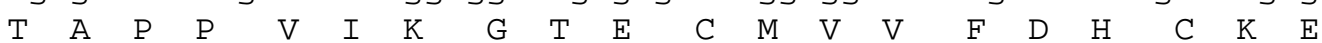

2881 tgctgtgaac attacagaag acttcttaga atatctttct gagggggccc tggccattga $F \quad A \quad V \quad N \quad I \quad T \quad E \quad D F F$

2941 ggtttatggt cacagacaga gcgaccctca caggaatcca gctctatggg atttaggaat

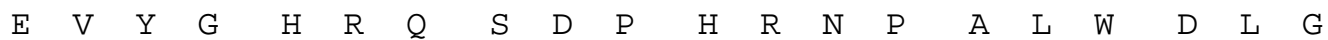

3001 aattcaagca aaaacacgca gcttgcgaga taggtggagt gaggttacca ggaaggtgga $\begin{array}{llllllllllllllllllll}I & I & Q & A & K & T & R & S & L & R & D & R & W & S & E & V & T & R & K & V\end{array}$

3061 actctgggtg cagattttag aactgaatga gaatggagag tactgcccag tggaagtgac $\begin{array}{llllllllllllllllllll} & E & L & W & V & Q & I & L & E & L & N & E & N & G & E & Y & C & P & V & E\end{array}$

3121 cccagccaaa gatgttcaga caggaggaat ctaccaactc aaacagggac agtcccggcg $\begin{array}{llllllllllllllllllll}T & P & A & K & D & V & Q & T & G & G & I & Y & Q & L & K & Q & G & Q & S & R\end{array}$

3181 ccttcatgta gaagtacgtt caatgcagga ttcaggaact ctgcccctta tagaagatgc $\begin{array}{llllllllllllllllllllllll}R & L & H & V & E & V & R & S & M & Q & D & S & G & T & L & P & L & I & E & D\end{array}$

3241 cattttatct gtctccattg gctgtgtaaa gatagtcaat gcaaaggcca ttaaagctca $\begin{array}{lllllllllllllllllllllllllllllllll}A & I & L & S & V & S & I & G & C & V & K & I & V & N & A & K & A & I & K & A\end{array}$

3301 agaccaccag gatgatcgag aagacgttga cagctaccag gaccgagatc tggagagact $\begin{array}{lllllllllllllllllllll}Q & D & H & Q & D & D & R & E & D & V & D & S & Y & Q & D & R & D & L & E & R\end{array}$ 
3361 gaggaggaaa tggctaaatg ctctcaccaa acgtcaggaa tacttagatc aacaactgca $\begin{array}{llllllllllllllllllll} & R & R & K & W & L & N & A & L & T & K & R & Q & E & Y & L & D & Q & Q & L\end{array}$

3421 aaaactggtc agcaaacaag ataaaacaga agacgatgca gatcgagagg cccagttgtt $\begin{array}{llllllllllllllllllll}Q & K & L & V & S & K & Q & D & K & T & E & D & D & A & D & R & E & A & Q & L\end{array}$

3481 agaaatgaga ctgacgctca ctgaagagag gaatgccgtt atggtgccgt ctgctggaag $\begin{array}{llllllllllllllllllll}L & E & M & R & L & T & L & T & E & E & R & N & A & V & M & V & P & S & A & G\end{array}$

3541 cggtattcct ggtgctcccg caaactggac tcccgtcttg ggaatggaga cccacattcc $\begin{array}{llllllllllllllllllll}S & G & I & P & G & A & P & A & N & W & T & P & V & L & G & M & E & T & H & I\end{array}$

3601 ggtcattttc ttagatctta atgtggacga cttcagctct caagatgact tggacgggtt $\begin{array}{llllllllllllllllllllll}P & V & I & F & L & D & L & N & V & D & D & F & S & S & Q & D & D & L & D & G\end{array}$

3661 ggaacctgca gggtgggact ccactctcac agcagaagat gagggcgagt tctttgacct

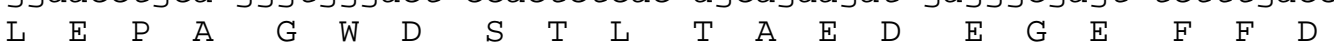

3721 gcagattgta aaacaccatg agagtgaggt aaaggcagaa gcctcctggg actgtaccat $\begin{array}{llllllllllllllllllll}L & Q & I & V & K & H & H & E & S & E & V & K & A & E & A & S & W & D & C & T\end{array}$

3781 ccataactgc ccccagctta gtaaaggttc tgcccctgag gagcgggtgt tcctgattgt $\begin{array}{llllllllllllllllllll}I & H & N & C & P & Q & L & S & K & G & S & A & P & E & E & R & V & F & L & I\end{array}$

3841 gagagtaact gtgcagctca gccacccagc agaaatgcag atcgttctgc gcaaacgcat $\begin{array}{llllllllllllllllllll}V & R & V & T & V & Q & L & S & H & P & A & E & M & Q & I & V & L & R & K & R\end{array}$

3901 ttgcgtcaat gtctacagcc gacaggggtt cgctcagagt ttcctaaggc gaatgtctca $\begin{array}{llllllllllllllllllll}I & C & V & N & V & Y & S & R & Q & G & F & A & Q & S & F & L & R & R & M & S\end{array}$

3961 ccgaagtaat atttccaact gtggagtcac tgtggaagtc gtctctaata tccoggagga

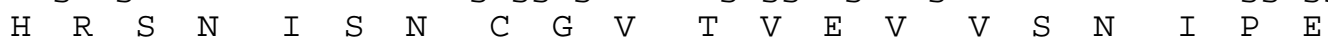

4021 ctcacagggg gcagaagatc gggaggctct tgccagaatg gcagcaaatg tggaggatgc

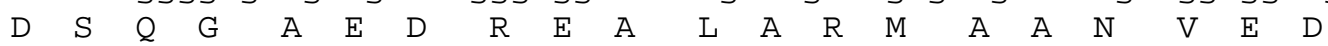

4081 cggatctgct gattcngagg catatattga gaagtacctg cgcagcgtgc tcgctgtaga

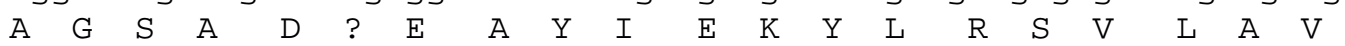

4141 gaacatcctt acattggacc gtctccgtca ggaagtggcg gtaaaaganc aattaaccgg

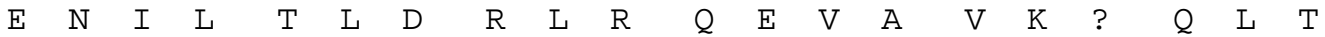

4201 gaaagggaaa ctgaacagaa agagcctcag ctcccctaat gttcacagac tgtntggaag

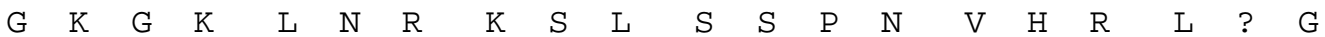

4261 ccgacaggac ctgggtgggc agccgagctt ggctagtaac aaggggcgtt gggaaagcca $\begin{array}{llllllllllllllllllllll}S & R & Q & D & L & G & G & Q & P & S & L & A & S & N & K & G & R & W & E & S\end{array}$

4321 acaggacgtg tcgcaaacct cccctgaccc cagacgggca gtngtttcag gccactcctn $\begin{array}{llllllllllllllllllll}Q & Q & D & V & S & Q & T & S & P & D & P & R & R & A & ? & V & S & G & H & S\end{array}$

4381 cctacccaaa atgttgccnc agtaccaaat gcaggattca ggtntggcaa acatggcaac $\begin{array}{lllllllllllllllllllllllll}\text { ? } & \mathrm{L} & \mathrm{P} & \mathrm{K} & \mathrm{M} & \mathrm{L} & \text { ? } & \mathrm{Q} & \mathrm{Y} & \mathrm{Q} & \mathrm{M} & \mathrm{Q} & \mathrm{D} & \mathrm{S} & \mathrm{G} & \text { ? } & \mathrm{A} & \mathrm{N} & \mathrm{M} & \mathrm{A}\end{array}$

4441 ctcatacctg agccccatta aaaccttagt gcctcagatg cccaagctgc ttaaatctct $\begin{array}{lllllllllllllllllllllllllll}T & S & Y & L & S & P & I & K & T & L & V & P & Q & M & P & K & L & L & K & S\end{array}$

4501 gtttcctcag cgggatgaga agagccgaca gtcctntccg ctcatccaac ag $\begin{array}{lllllllllllllllllll} & \mathrm{F} & \mathrm{P} & \mathrm{Q} & \mathrm{R} & \mathrm{D} & \mathrm{E} & \mathrm{K} & \mathrm{S} & \mathrm{R} & \mathrm{Q} & \mathrm{S} & \text { ? } & \mathrm{P} & \mathrm{L} & \mathrm{I} & \mathrm{Q} & \mathrm{Q}\end{array}$

Fig. 4.18. Nucleotide and amino acid sequence of xKIF13B. The start-codon is shown in bold, the upstream stop-codon is depicted in italics. 
A protein encoded by the amplified part of the ORF exhibits $81 \%$ of an overall amino acid identity to Drosophila KIF13B/GAKIN (Hanada et al., 2000) (GenBank accession no. AF279865) (Fig. 4.19). According to the highest degree of overall protein identity, the clone was termed xKIF13B for Xenopus kinesin 13B. MSDSTVKVAV RIRPMNRREV DLQTKCVVDV ENNQIVLYPS NASLSKGDAR MGDSKVKVAV RVRPMNRREI DLHTKCVVDV EANKVILNPV NTNLSKGDAR MGDSKVKVAV RVRPMNRREI DLHTKCVVDV EANKVILNPI NTNLSKGDAR MGDSKVKVAV RIRPMNRRET DLHTKCVVDV DANKVILNPV NTNLSKGDAR MGDSKVKVAV RIRPMNRRET DLHTKCVVDV DANKVILNPV NTNLSKGDAR

51

XKIF13B

SQPKVFAYDH CFWSMDESVK EKFAGQDVVF QCLGENILQN AFEGYNACIF

tKIF13B ...SVFAYDH CFWSMDESVK EKFAGQDVVF QCLGENILQN AFEGYNACIF mKIF13B GQPKIFAYDH CFWSMDESVR EKYAGOEDVF KCLGENILON AFDGYNACIF rKIF13B GQPKIFAYDH CFWSMDESVR EKYAGQDDVF KCLGENILQN AFDGYNACIF hKIF13B GQPKCFAYDH CFWSMDESVK EKYAGQDIVF KCLGENILQN AFDGYNACIF dKIF13B GQPKCFAYDH CFWSMDESVK EKYAGQDIVF KCLGENILQN AFDGYNACIF ZKIF13B LLTGFLSDLP LKTKILIVIQ SYFPGQDVVF QCLGESLLHN AFQGYNACIF

XKIF13B

AYGQTGSGKS YTMMGTADQP GLIPRLCSTL FERTQKAENE ELSFKVEVSF AYGQTGSGKS YTMMGTADQP GLIPRLCSTL FERTQKAENE ELSFKVEVSF AYGQTGSGKS YTMMGTADQP GLIPRLCSGL FERTQKEENE EQSFKVEVSY AYGQTGSGKS YTMMGTADQP GLIPRLCSGL FERTQKEENE EQSFKVEVSY AYGQTGSGKS YTMMGTADQP GLIPRLCSGL FERTQKEENE EQSFKVEVSY dKIF13B ZKIF13B AYGQTGSGKS YTMMGTADQP GLIPRLCSGL FERTQKEENE EQSFKVEVSY AYGQTGSGKS YTMMGSVDQP GLIPRLCSSL FERTVLHQRE EESFTVEVSY

151

200

XKIF13B

tKIF13B

mKIF13B

rKIF13B

hKIF13B

dKIF13B

ZKIF13B

MEIYNEKVRD LLDPKGSRQS LKVREHKVLG PYVDGLSKLA VASYKDIESL MEIYNEKVRD LLDPKG $\ldots \ldots \ldots \ldots \ldots \ldots \ldots \ldots$ MEIYNEKVRD LLDPKGSRQT LKVREHSVLG PYVDGLSKLA VTSYKDIESL MEIYNEKVRD LLDPKGSRQT LKVREHSVLG PYVDGLSKLA VTSYKDIESL MEIYNEKVRD LLDPKGSRQT LKVREHSVLG PYVDGLSKLA ATSYKDIESL MEIYNEKVRD LLDPKGSRQT LKVREHSVLG PYVDGLSKLA ATSYKDIESL MEIYNEKVRD LLDPKGSRQA LRVREHKVLG PYVDGLSRLA VESYKDIESL

XKIF13B ..... TSGEKVSKLS

rKIF13B hKIF13B dKIF13B zKIF13B MSEGNKSRTV AATNMNEESS RSHAVFKITL THTLYDVKSG TSGEKVGKLS MSEGNKSRTV AATNMNEESS RSHAVFKITL THTLYDVKSG TSGEKVGKLS MSEGNKSRTV AATNMNEESS RSHAVLKITL THTLYDAKSG TSGEKVGKLS MSEGNKSRTV AATNMNEESS RSHAVLKITL THTLYDAKSG TSGEKVGKLS MSEGNKSRTV AATNMNEESS RSHAVFNIIL THTLKDLQSG TSGEKVSKLS

TKA TKTGAGERL KEGSNINKSL TTLGLVISAL ADQGAAKNKN LVDLAGSERA TKTGAAGERL KEGSNINKSL TTLGLVISAL ADQGAGKNKN LVDLAGSERA TKTGAAGDRL KEGSNINKSL TTLGLVISAL ADQGAGKNKN LVDLAGSERA TKTGAAGDRL KEGSNINKSL TTLGLVISAL ADQGAGKNKN LVDLAGSERA TKTGAAGDRL KEGSNINESL TTLGLVISAL ADQSAGKNKN LVDLAGSERA TKTGAAGDRL KEGSNINESL TTLGLVISAL ADQSAGKNKN LVDLAGSERA AKTGAAGERL KEGSNINKSL TTLGLVISAL ADQGAGKNKN

XKIF13B 301

KFVPYRDSVL TWLLKDSLGG NSKTAMVATV SPAADNYDET ISTLRYADF RKIF13B KFVPYRDSVL TWLLKDSLGG NSKTAMVATV SPAADNYDET LSTLRYADRA hKIF13B KFVPYRDSVL TWLLKDSLGG NSKTAMVATV SPAADNYDET LSTLRYADRA dKIF13B KFVPYRDSVL TWLLKDSLGG NSKTAMVATV SPAADNYDET LSTLRYADRA ZKIF13B KFVPYRDSVL TWLLKDSLGG NSRTAMVATV SPAADNYDET LSTLRYADRA 
KNIVNHAVVN EDPNARIIRE LREEVEKLRV QLTQAESMKA PELKERLQES

tKIF13B KNIVNHAVVN EDPNARIIRE LREEVEKLRV QLTQAESMKA PELKERLQES mKIF13B KHIVNHAVVN EDPNARIIRD LREEVEKLRE QLTKAEAMKS PELKDRLEES rKIF13B KHIINHAVVN EDPNARIIRD LREEVEKLRE QLTKAEAMKS PELKDRLEES hKIF13B KHIVNNAVVN EDPNARIIRD LREEVEKLRE QLTKAEAMKS PELKDRLEES dKIF13B KHIVNNAVVN EDPNARIIRD LREEVEKLRE QLTKAEAMKS PELKDRLEES ZKIF13B KSIVNHAVVN EDPNARIIRE LREEVEKLRD QLTQAESMKA PELKERLEES

IAQERQKQLE SLGISLQSSG IKVGDNKCFL EKLIQEMTVT WEEKLRMTED IAQERQKQLE SLGISLQSSG IKVGDNKSFL EKLIQEMTVT WEEKLRKTEE IAQERQKQLE SLGISLQTSG IKVGDDKCFL EKLIQEMTVT WEEKLRKTEE IAQERQKQLE SLGISLQTSG IKVGDDKCFL EKLIQEMTVT WEEKLRKTEE IAQERQKQLE SLGISLQSSG IKVGDDKCFL EKLIQEMTVT WEEKLRKTEE IAQERQKQLE SLGISLQSSG IKVGDDKCFL EKLIQEMTVT WEEKLRKTEE IAQERQKQLE SLGISLQSSG IKVGEDKCFL

XKIF13B 451 500 tKIF13B mKIF13B rKIF13B hKIF13B dKIF13B ZKIF13B VNLNADPALN ELLVYYLKDH TLIGSHDSQD IQLCGLGILP EHCIIDISPE VNLNADPALN ELLVYYLKDH TLIGSHDSQD IQLCGLGILP EHCIIDISPE VNLNADPALN ELLVYYLKEH TLIGSANSOD IQLCGMGILP EHGIIDITPE VNLNADPALN ELLVYYLKEH TLIGSANSQD IQLCGMGILP EHGIIDIMPE VNLNADPALN ELLVYYLKEH TLIGSANSQD IQLCGMGILP EHCIIDITSE VNLNADPALN ELLVYYLKEH TLIGSANSOD IQLCGMGILP EHCIIDITSE VNLNADPALN ELLVYYLKEH TKVGSADSQD IQLCGMGIQA EHCVINITPE

GQVILTPMKN TRTYVNGSAV SKATQLQHGD RILWGNNHFF RISLPKKK.K

tKIF13B

mKIF13B

rKIF13B GOVILTPMKN TRTYVNGSAV TKATQLQHGD RILWGNNHFF RISLPKKK.K GQVVLTPQKN TRTFVNGSSV SSPIQLHHGD RILWGNNHFF RLNLPKKKKK GQVMLTPQKN TRTFVNGSSV SSPIQLHHGD RILWGNNHFF RLNLPKKKKK GQVMLTPQKN TRTFVNGSSV SSPIQLHHGD RILWGNNHFF RLNLPKKKKK dKIF13B GQVMLTPQKN TRTFVNGSSV SSPIQLHHGD RILWGNNHFF RLNLPKKKKK ZKIF13B GAVFINPYRN SRTCVNGSPV TSRQQLHHGD RILWGNNHFF RINLPKRRLR

551

600

XKIF13B

tKIF13B

mKIF13B

rKIF13B

hKIF13B

dKIF13B

ZKIF13B

XKIF13B

tKIF13B

mKIF13B

rKIF13B

hKIF13B

dKIF13B

ZKIF13B

tKIF13B

mKIF13B

rKIF13B

hKIF13B

dKIF13B

ZKIF13B

XKIF13B

tKIF13B

mKIF13B

rKIF13B

hKIF13B

dKIF13B

zKIF13B

XKIF13B

tKIF13B

mKIF13B

rKIF13B

hKIF13B

ILRNSSSFEO LDLDGDSSSE GSSEVSFNYE YAOMEVMMKA AKQEDEEQDS SLRNSSSFEQ LDLDGDSSSE GSSEVNFNYE YAQMEIMMKA AEREDEDREA SLKNDSSSEQ LDADGDSSSE VSSEINFNFE YAQMEVTMKA AEREDEEREA SLKNDSSSEQ LDADGDSSSE VSSEINFNFE YAQMEVTMKA AEREDEDQDP SMKNENSSEQ LDVDGDSSSE VSSEVNFNYE YAQMEVTMKA AEREDEDQDP SMKNENSSEQ LDVDGDSSSE VSSEVNFNYE YAQMEVTMKA GE. EEEGEGG NMKSSNSNEQ LDGEGDTASE VSSEVSFSYE FAQTEVMMKA

601 650

LGNNDPMQSI LQSLEQQHEE EKRSALERQR LMYEQELDQL RRRLSPEKQH LGNNDPMQSI LQSLEQQHEE EKRSALERQR LMYEHELDQL RRRLSPEKQH LGSNDPMOSI LSSLEOOHEE EKRSALEROR LMYEHELEOL RRRLSPERON LGSNDPMQSI LSSLEQQHEE EKRSALERQR LMYEHELEQL RRRLSPERQN LGSNDPMQSI LNSLEQQHEE EKRSALERQR LMYEHELEQL RRRLSPEKQN LGSNDPMQSI LNSLEQQHEE EKRSALERQR LMYEHELEQL RRRLSPEKQN LGSNDPMQAV LQSLERQHEE EKRTALERQR LMYEQELQQL RRQLTPDRQS

651

700 $\ldots \ldots$ YRSMDRFS $\ldots .$. FGSPNA QYRIRQWTEE REAMLNQSLR $\ldots \ldots$ YRSMDRFS $\ldots .$. FGSPNA QQRIRQWTEE REAMLNQSLR C........... RGVDRLS .... FHSPSA QQRLKQWAEE REATLNNSLM C...........RGVDRLS .... FHSPSA QQRLRQWAEE REATLNNSLM C.......... RSMDRFS ....FHSPSA QQRLRQWAEE REATLNNSLM C........... . RSMDRFS ....FHSPSA QQRLRQWAEE REATLNNSLM MQIPQSQPLQ PHYRSMERLS QGGMSSSSSA QHRLRQWSEE REVVLTRSLR

701

KLREOIAKAN LHVOEANFIS EEMDKRTEYK VTLOIPASSL NANKKRGAVL KLREQIAKAN LHVQEANFIA EEMDKRTEYK VTLQIPASSL NANKKRGAVL RLREQIVKAN LLVREASYIA EELDKRTEYK VTLQIPTSSL DANRKRGSLL RLREQIVKAN LLVREASYIA EELDKRTEYK VTLQIPASSL DANRKRGSLL RLREQIVKAN LLVREANYIA EELDKRTEYK VTLQIPASSL DANRKRGSLL RLREOIVKAN LLVREANYIA EELDKRTEYK VTLOIPASSL DANRKRGSLL KLREQIVRAN LLVQEASFIA EELDKRTEYR VTLQIPAANL NANRKRDAVL SEPAIQVRRK GKGKQIWSLE KLENRLLDMR DLYQEWKECE EDSPVSRSYF SEPAIQVRRK GKGKQIWSLE KLENRLLDMR DLYQEWKECE EDSPVSRSYF SEPAIQVRRK GKGKQIWSLE KLDNRLLDMR DLYQEWKECE EDNPVIRSYF 
dKIF13B ZKIF13B

XKIF13B

tKIF13B

mKIF13B

rKIF13B

hKIF13B

dKIF13B

zKIF13B

XKIF13B

tKIF13B

mKIF13B

rKIF13B

hKIF13B

dKIF13B

ZKIF13B

XKIF13B

tKIF13B

mKIF13B

rKIF13B

hKIF13B

dKIF13B

ZKIF13B

XKIF13B

tKIF13B

mKIF13B

rKIF13B

hKIF13B

dKIF13B

ZKIF13B

XKIF13B

tKIF13B

mKIF13B

rKIF13B

hKIF13B

dKIF13B

ZKIF13B

XKIF13B

tKIF13B

mKIF13B

rKIF13B

hKIF13B

dKIF13B

zKIF13B

XKIF13B

tKIF13B

mKIF13B

rKIF13B

hKIF13B

dKIF13B

ZKIF13B

XKIF13B

tKIF13B

mKIF13B

rKIF13B

hKIF13B

dKIF13B

ZKIF13B
SEPAIOVRRK GKGKOIWSLE KLDNRLLDMR DLYQEWKECE EDNPVIRSYF SEPAIQVRRK GKGKQIWALE KMENRLVDMR ELYQEWKDFD EDNSVMRSYF

801

850

RRADPFYDEH ENHSLIGVAN VFLESLFHDV KLQYAVPIIN QKGEVAGRLH RRADPFYDEH ENHSLIGVAN VFLESLFHDV KLQYAVPIIN QKGEVAGRLH KRADPFYDEQ ENHSLIGVAN VFLETLFYDV KLQYAVPIIN QKGEVAGRLH KRADPFYDEQ ENHSLIGVAN VFLETLFYDV KLQYAVPIIN QKGEVAGRLH KRADPFYDEQ ENLSLIGVAN VFLESLFYDV KLQYAVPIIN OKGEVAGRLH KRADPFYDEQ ENLSLIGVAN VFLESLFYDV KLQYAVPIIN QKGEVAGRLH KRADPFFDEQ VNHSLIGVAN VFLSCLFYDV KLQYAVPIIN QKGEVAGRLH

851

900

FVVRISGDI GDRIAGGEDG TDFSFEKEVQ ENKLVCMIKV LQATGLPQHL VEVVRISGDI EDRIAGGEDG ADFSFEKEAQ ENKLVCMIKV LQATGLPQHL VEVMRLSGAI GERIAGGDDP TEVSSEKEAQ ENRLVCMVKI LQATGLPQHL VEVMRLSGAI GERIAGGDDP TEVSSEKEVO ENRLVCMVKI LQATGLPOHL VEVMRLSGDV GERIAGGDEV AEVPFEKETQ ENKLVCMVKI LQATGLPQHL VEVMRLSGDV GERIAGGDEV AEVPFEKETQ ENKLVCMVKI LQATGLPQHL VEVMRMGGGF DDSVGGGEE. SDGSPDGDVQ ERKLVCMIKI LQATGLPQYL

901 950

TNFVFCHYVF WDQPEPTTVA PEVDTAP. .P VIKGTECMVV FDHCKEFAVN TNFVFCHYIF WDQPEPTTVA PEVDTAP. .P VIKGTECMVV FDHCKEFVVN CHFVFCKYDF WDOOEPVTVA PEVDTSSS.P TSKOPOCMVV FDHCSEFSVN CHFVFCKYDF WDQQEPVTVA PEVDTSSS.P TSKEPQCMVV FDHCSEFSVN SHFVFCKYSF WDQQEPVIVA PEVDTSSS.S VSKEPHCMVV FDHCNEFSVN SHFVFCKYSF WDQOEPVIVA PEVDTSSS.S VSKEPHCMVV FDHCNEFSVN SNFVFCQYSF WDQAEPIIVA PEVDPSASFS SSKDPHCMVV FDSLKEHAVN

951

1000

ITEDFLEYLS EGALAIEVYG HRQSDPHRNP ALWDLGIIQA KTRSLRDRWS ITEDFLEYLS EGALAIEVYG HROSDPHRNP ALWDLGIIQA KTRSLRDRWS ITEDFIEYLS EGALAIEVYG HKMNDPRKNP ALWDLGIIQA KTRSLRDRWS ITEDFIEYLS EGALAIEVYG HKMNDPRKNP ALWDLGIIQA KTRSLRDRWS ITEDFIEHLS EGALAIEVYG HKINDPRKNP ALWDLGIIQA KTRSLRDRWS ITEDFIEHLS EGALAIEVYG HKINDPRKNP ALWDLGIIQA KTRSLRDRWS VTEEFIEYLT EGAVGIEVYG HRQADPGRNP ALWDLSIIQA KTRTLRDRWS

1001

1050

SVTRKVELWV QILELNENGE YCPVEVTPAK DVQTGGIYQL KQGQSRRLHV EVTRKVELWV QILELNENGE YCPVEVTPAK DVQTGGIYQL KQ....... EVTRKLEFWV QILEQNENGD YCPVEVIAAK DVPTGGIFQL RQGQSRRVQV EVTRKLEFWV QILEQNENGE YCPVEVIAAK DVPTGGIFQL RQGQSRRVQV EVTRKLEFWV QILEQNENGE YCPVEVISAK DVPTGGIFQL RQGQSRRVQV EVTRKLEFWV OILEONENGE YCPVEVISAK DVPTGGIFOL ROGOSRRVQV EVTRKLEMWV QILELNENGE YMPVEVVPAR DVRTGGIFQL KQGQSRRVQV

1051 1100

EVRSMQDSGT LPLIEDAILS VSIGCVKIVN AKAIKAQDH. QDDREDVDSY $\ldots \ldots \ldots \ldots \ldots \ldots \ldots \ldots \ldots \ldots \ldots \ldots \ldots \ldots \ldots \ldots \ldots$ DAREDVDSY EVKSVQESGT LPLMEECILS VGIGCVKVRP LRSPKIHENV HEEEEDMDSY EVKSVQESGT LPLMEECILS VGIGCVKVRP LRSPKTHENI HEEEEDMDSY EVKSVQESGT LPLMEECILS VGIGCVKVRP LRAPRTHETF HEEEEDMDSY EVKSVQESGT LPLMEECILS VGIGCVKVRP LRAPRTHETF HEEEEDMDSY EVRSVQDSGT MPLISEIILG VSIGCVQIRQ V..PMTKNNE PQEGDEMDSY

1101

1150

QDRDLERLRR KWLNALTKRQ EYLDQQLQKL VSKQDKTEDD ADREAQLLEM QDRDLERLRR KWLNALTKRQ EYLDQQLQKL VSKQDKSEDD ADREAQLLEM QDRDLERLRR KWLNALTKRQ EYLDQQLQKL VSKHDKTEDD ADREAQLLEM QDRDLERLRR KWLNALTKRO EYLDQQLQKL VSKHDKTEDD ADREAQLLEM QDRDLERLRR KWLNALTKRQ EYLDQQLQKL VSKRDKTEDD ADREAQLLEM QDRDLERLRR KWLNALTKRQ EYLDQQLQKL VSKRDKTEDD ADREAQLLEM QERDLERLRH QWLTALTKRQ EYLDQHLQTL VSKSDKSEDD VEREAQLLEG

1151

RLTLTEERNA VMVPSAGSGI PGAPANWTPV LGMETHIPVI FLDLNVDDFS RLTLTEERNA VMVPSAGSGI PGAPANWTPV SGMETHIPVI FLDLNVDDFS RLTLTEERNA VMVPSAGSGI PGAPAEWTPV PGMETHIPVI FLDLNADDFS RLTLTEERNA VMVPSAGSGI PGAPAEWTPV PGMEAHIPVV FLDLNADDFS RLTLTEERNA VMVPSAGSGI PGAPAEWTPV PGMETHIPVI FLDLNADDFS RLTLTEERNA VMVPSAGSGI PGAPAEWTPV PGMETHIPVI FLDLNADDFS RLTLTEERNA VMVPSAGSGI PGAPAEWVPV PGMETHIPVL FLDLSADDFS 
XKIF13B

tKIF13B

mKIF13B

rKIF13B

hKIF13B

dKIF13B

zKIF13B

XKIF13B

tKIF13B

mKIF13B

rKIF13B

hKIF13B

dKIF13B

ZKIF13B

XKIF13B

tKIF13B

mKIF13B

rKIF13B

hKIF13B

dKIF13B

ZKIF13B

XKIF13B

tKIF13B

mKIF13B

rKIF13B

hKIF13B

dKIF13B

ZKIF13B

XKIF13B

tKIF13B

mKIF13B

rKIF13B

hKIF13B

dKIF13B

zKIF13B

XKIF13B

tKIF13B

mKIF13B

rKIF13B

hKIF13B

dKIF13B

ZKIF13B

XKIF13B

tKIF13B

mKIF13B

rKIF13B

hKIF13B

dKIF13B

ZKIF13B
1201

1250

SQDDLDGLEP AGWDSTLTAE DEGEFFDLQI VKHHESEVKA EASWDCTIHN

SQDDLDGLEP AGWDSTLTSE DEGEFFDLQI VKHHESEVKA EASWDCTVHN SQDNLDDPEA G.WDATLTGE EEEEFFELQI VKQHDGEVKA EASWDSAVHS SQDNLDDPEA G.WDATLTGE EEEEFFELQI VKHHDGEVKA EASWDSAVHN SQDNLDDPEA GGWDATLTGE EEEEFFELQI VKQHDGEVKA EASWDSAVHG SQDNLDDPEA GGWDATLTGE EEEEFFELQI VKQHDGEVKA EASWDSAVHG SQENLDVPEA GGWDATLSSE DEDEFFDLQI VKHYDGEVKA EASWDSTVHE

1251

1300

CPQLSKGSAP EERVFLIVRV TVQLSHPAEM QIVLRKRICV NVYSRQGFAQ CPQLSKGSAP EDRVFLIVRA TVQLSHPAEM QIVLRKRICV NVYSRQGFAQ CPQLSKGTPA DERVFLILRV TVQLSHPADM QLVLRKRICV HVHGRQGFAQ CPQLSKGTPA DERVFLILRV AVQLSHPADM QLVLRKRICV HVHGRQGFAQ CPQLSRGTPV DERLFLIVRV TVQLSHPADM QLVLRKRICV NVHGRQGFAQ CPQLSRGTPV DERLFLIVRV TVQLSHPADM QLVLRKRICV NVHGRQGFAQ CQQLSRGATA DQRVYLIVRT VVQLSHPAEM QLVLRKRICV NITGRQGFAQ

1301

1350

SFLRRMSHRS NISNCGVTVE VVSNIPE.DS OGAEDREALA RMAANVEDAG SFLRRMSHRS SISSCGVTVE VVSNIPE.DS QGAEDREALA RMAANVEDTG SLLKKMSHRS SIPGCGVTFE IVSNIPE.DA QGVEEREALA RMAANVENPA SLLKKMTHRS SIPGCGVTFE IVSNIPEVDA OGVEEREALA RMAANVENAA SLLKKMSHRS SIPGCGVTFE IVSNIPE.DA QGVEEREALA RMAANVENPA SLLKKMSHRS SIPGCGVTFE IVSNIPE.DA OGVEEREALA RMAANVENPA NFLRRMSTRS TIPGCGVTFE VVSNIPG.DS QSSEDREMLA RVAASAENPK

1351

1400

SAD.EAYIEK YLRSVLAVEN ILTLDRLRQE VAVK.QLTGK GKLNRKSLSS SADSEAYIEK YLRSVLAVEN ILTLDRLRQE VAVKEQLTGK GKLHRKSLSS SADSEAYIEK YLRSVLAVEN LLTLDRLRQE VAVKEQLTGK GKLSRRSISS SADSEACIEK YLRSVLAVEN LLTLDRLRQE VAVKEQLTGK GKLNRRSISS SADSEAYIEK YLRSVLAVEN LLTLDRLROE VAVKEQLTGK GKLSRRSISS SADSEAYIEK YLRSVLAVEN LLTLDRLRQE VAVKEQLTGK GKLSRRSISS SSDNEAAIEK YLRSVLAVEN ILTLDRLRQE VAVKEHLAGK GKGSRRSLSS

1401

1450

NVHRL.GSR ODLGGOPSLA SNKGRWESOO DVSOTSPDPR RAVSGH ..SL PNVHRLSGSR QDLGGQQSLA SNKGRWESQQ DVSQTSPVPS RAVVSGHSSL PSMNRLSGSR QELSPSHSLG SNKGRWESQQ DVSQTL.VSR G.IAPGPPAL

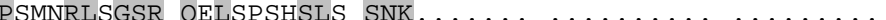
PNVNRLSGSR QDLIPSYSLG SNKGRWESQQ DVSQTT.VSR G.IAPAP.AL PNVNRLSGSR QDLIPSYSLG SNKGRWESQQ DVSQTT.VSR G.IAPAP.AL PSVHRLSGSR QDLSLNSVLD DNKNRWESQQ DIFATS.SGF SKTLPRPSRP

1451

1500

PKML.QYQMQ DSG.ANMATS YLSPIKTLVP QMPKLLKSLF PQRDEK. . SR PKMVPQYQLQ ESGLANMATS YLSPVKSLVP QMPKLLKSLF PQRDEK.GRQ SVSPQNNQSP DPGLGGVAAS YLNPVKSLVP QMPKLLKSLF PVRDDRRGRH SVSPONNHSP SVSPQNNHSP DPGLSNLAAS YLNPVKSFVP QMPKLLKSLF PVRDEKRGKR PTPPTQSQDP EQGFSGLAAS YISPVKALVP QMPKLLKSLF PVRDEKKDLR

1501

QSPLIQQ

SSPLSQQ

SSPLAHQ

PSPLÄ̈ं

PSPLAHQ

PSPHSQQ 
B

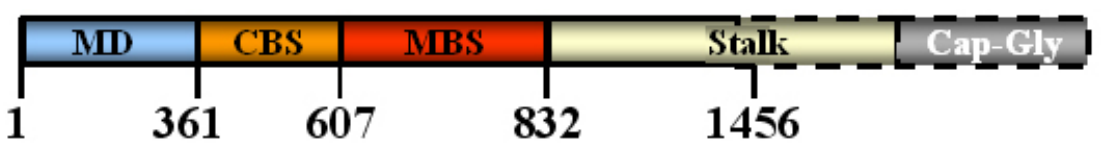

aa

Fig. 4.19. The schematic illustration of the xKIF13B protein structure and SWISS plot alignment with homologues from other organisms. (A) SWISS plot multiple alignment of our predicted Xenopus laevis KIF13B protein sequence with Xenopus tropicalis, Mus musculus, Rattus norvegicus, Drosophilae,Zebrafish and human homologues (GenBank ID sc428000019, NP001074646, NP998791, AF279865, XP691438 and BAA31614, correspondingly). (B) The schematic illustration of the xKIF13B protein structure. Abbreviations: MD -motor domain, CBS - centaurin binding site, MBS MAGUKs binding site. The missing C-terminus of the xKIF13B ORF (partially Stalk-domain and the Cap-Gly-domain) is boxed.

\subsubsection{The spatiotemporal expression of $x K I F 13 B$}

The spatiotemporal expression of $x K I F 13 B$ mRNA during Xenopus development was analyzed by whole mount in situ hybridization (WMISH) and RT-PCR. In stage I-III oocytes, the $x K I F 13 B$ transcript is enriched in the mitochondrial cloud and subsequently at the tip of the vegetal cortex (Fig. 4.20A, B). According to this RNA distribution during oogenesis $x$ KIF13B is an early localizing mRNA.

During embryogenesis the transcript was detected through all stages from the egg to the stage 42. Most prominent levels of $x$ KIF13B mRNA were observed in the egg and at stages 2, 8, 10 and 28 (Fig. $4.20 \mathrm{H}$ ).

During early cleavage stages, XGRIP2.1 mRNA is detected in the granular patches of the germ plasm (Fig. 4.20C). At gastrula stage, the transcript is specifically localized in single cells within the involuting endoderm (Fig. 4.20D). After gastrulation until late tailbud stage no internal or surface signal was detected by WMISH (Fig. 4.20E, F).

In adult frog tissues, $x K I F 13 B$ expression was detected in almost all samples tested with highest abundance in the skin, liver, heart, intestine, stomach, spinal cord, testes and ovary (Fig. 4.20G). Therefore, $x K I F 13 B$ is an early localizing mRNA specifically expressed in the germ plasm and germ cells during the early phases of Xenopus development. 

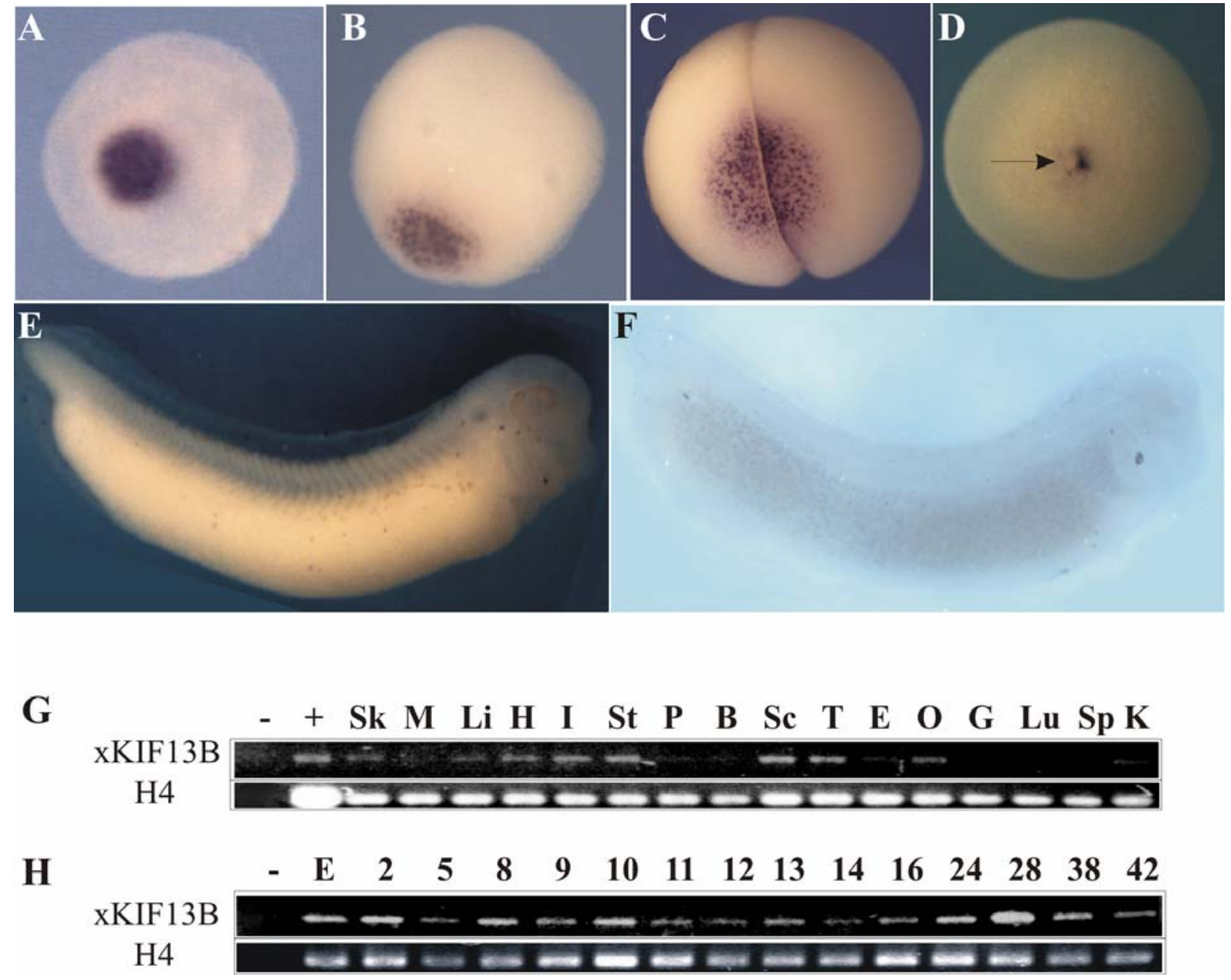

Fig. 4.20. Spaciotemporal analysis of $x K I F 13 B$ expression by whole mount in situ hybridization and RT-PCR.(A-F) The localization of $x$ KIF13B mRNA in Xenopus oocytes and embryos was analyzed by whole mount in situ hybridization, In stage II (A) and III (B) oocytes, $x K I F 13 B$ mRNA at the tip of the vegetal cortex. At the 2-cell stage of embryogenesis, $x K I F 13 B$ mRNA is enriched in granular germ plasm islands at the vegetal pole $(C$, vegetal pole view). At gastrula stage, the transcript was detected in isolated cells within the endoderm $(\mathrm{D}$, blastoporus view, arrow). At tailbud stage, no expression of $x K I F 13 B$ was observed (E, lateral view of the embryo with the head to the right; F, lateral view of the cleared with benzyl-benzoate/ benzyl alcohol embryos with the head to the right).

RT-PCR analysis of the temporal expression during embryogenesis (G) and tissue- specific expression of $m K I F 13 B(\mathrm{G})$. Total RNA for RT-PCR was prepared from embryos or from adult tissues. Abbreviations: Sk - skin, M - muscle, Li - liver, H - heart, I - intestine, St - stomach, P - pancreas, B brain, Sc - spinal cord, T - testes, E - eye, O - ovary, G - gall bladder, Lu - lung, Sp - spleen, K - kidney. 
4.3.3 Morpholino-mediated knockdown of xKIF13B reduces the average PGC numbers and results in the severe PGC mislocalization

\subsubsection{Both xKIF13B-specific morpholino oligonucleotides inhibit xKIF13B translation in vivo and in vitro}

To address the function of xKIF13B in the context of PGC development in Xenopus, two antisense morpholino oligonucleotides (MOs) were designed to perform knockdown experiments. $x K I F 13 B$-specific MOs were targeted to either the start codon region (MO1) or the 5'UTR region (MO2) (Fig. 4.21A). The specificity of MO1 was tested in the coupled in vitro transcription/translation reaction (Fig. 4.21B). To control the activity of both MOs in vivo, a reporter construct containing the $x K I F 13 B$ 5'UTR fused to the mycGFP ORF (Fig. 4.21C, D) was employed. In all experiments, translation of the reporter protein was strongly inhibited at all MO doses tested (Fig. 4.21C, D).

\subsubsection{2 xKIF13B morphants exhibit reduced PGC numbers and severe PGC} mislocalization

Loss-of-function experiments performed by vegetal injection of either MO into two-cell stage embryos resulted in a dose-dependent decrease of the average number of PGCs scored in early tailbud stage embryos (Fig. 4.22A, B, D, E) when compared to embryos injected with control MO (Fig. 4.22A-C). Average PGC numbers were calculated as described for the XGRIP2.1 knockdown. To exclude the possibility that PGCs were still present inside of these embryos, they were cleared with benzyl benzoate/ benzyl alcohol (data not shown). No significant difference between the average PGC scores from transparent embryos when compared to those obtained by quantification of surface PGCs was observed.

Except for the decrease in the average PGC numbers, xKIF13B MO-mediated knockdown lead to the severe PGC mislocalization (Fig. 4.22A, B, D, E. white arrows). Mismigrating germ cells were observed in the region of somites, head and at the very tip of a tail. Up to $14 \%$ PGCs were scored as "mislocalized" in morphant embryos in comparison to $2.5 \%$ calculated for uninjected controls at stage 32 (Fig. 4.22A, B). 
A

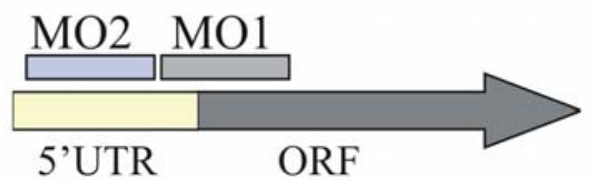

$\mathrm{B}$

\begin{tabular}{l|cccc|}
\hline xKIF13B MD_MBS, $0.5 \mathrm{ng}$ & + & + & + & + \\
xKIF13B MO1, mM & - & 1 & 0,5 & 0,1 \\
CO MO, mM & 1 & - & - & - \\
\hline & & & \\
\end{tabular}

$\mathrm{C}$

\begin{tabular}{|c|c|c|c|c|c|}
\hline xKIF13B 5'UTRmycGFP $0.2 \mathrm{ng}$ & + & + & + & + & + \\
\hline $\mathrm{CO} \mathrm{MO}, \mathrm{mM}$ & 1 & - & - & - & - \\
\hline xKIF13B MO1, mM & - & 1 & 0,1 & - & - \\
\hline XKIF13B MO2, mM & - & - & - & 1 & 0,1 \\
\hline$\alpha$ myc & $=$ & & & & \\
\hline$\alpha$ GAPDH & 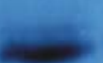 & - & 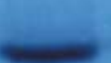 & 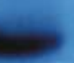 & - \\
\hline
\end{tabular}

$\mathrm{D}$
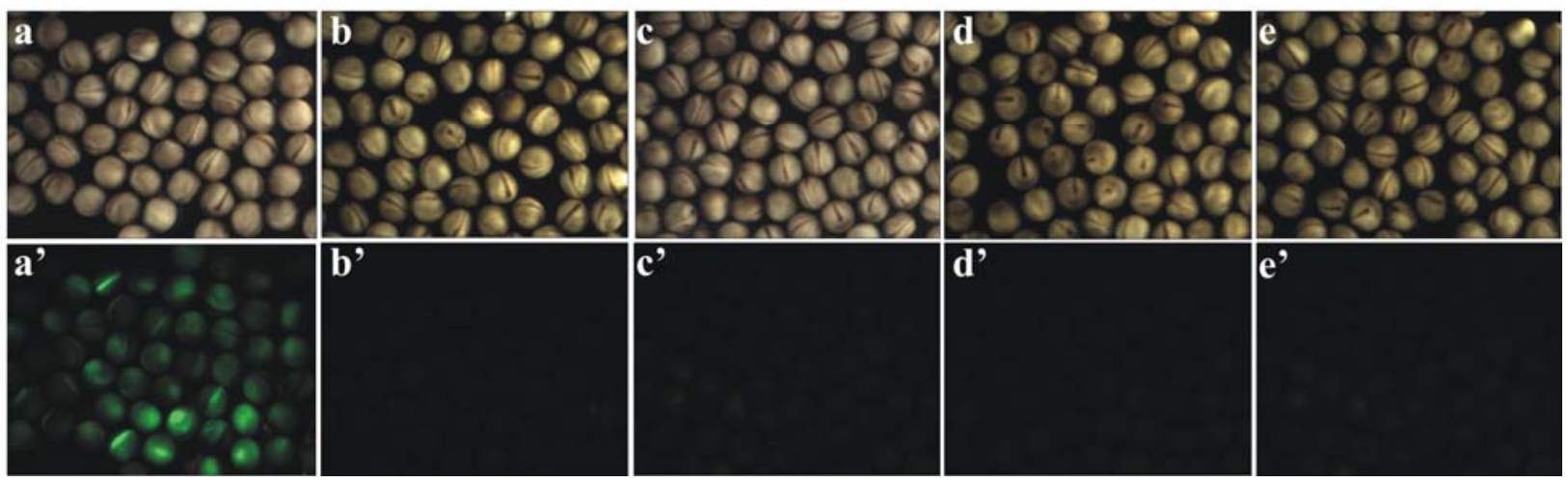

Fig. 4.21. XKIF13B MO1 and MO2 inhibit translation of XKIF13B in vitro and in vivo. (A) Schematic illustration of morpholino oligonucleotide target sites. 5'UTR and ORF of $x$ KIF13B cDNA are marked as yellow box and grey arrow, respectively. (B) Absence of xKIF13B translation was observed in the coupled in vitro transcription/ translation reaction (Promega) upon addition of $1 \mathrm{nmol}, 0.5 \mathrm{nmol}$ or 0.1 nmol of MO1. (C, D) Two-cell stage embryos were injected vegetally into both blastomeres with 5'UTRxKIF13BmycGFP (see Materials) RNA together with xKIF13B specific MOs and grown to stage 17. (C) Total protein extracts of injected embryos were subjected to Western blotting. The recombinant mycGFP reporter protein was no longer detected at any tested concentrations of either MO1 or MO2. (D) mycGFP reporter protein expression analyzed by fluorescence microscopy. (a-e) normal light, (a'-e') UVlight. Two-cell stage embryos were coinjected with 0.2 ng 5'UTRxKIF13BmycGFP RNA and 2 pmol CO MO (D, a, a'), 0.2 ng 5'UTRxKIF13BmycGFP RNA and 2 pmol MO1 (D, b, b'), 0.2 ng 5'UTRxKIF13BmycGFP RNA and 0.2 pmol MO1 (D, c, c'), 0.2 ng 5'UTRxKIF13BmycGFP RNA and 2 pmol MO2 (D, d, d'), or 0.2 ng 5'UTRxKIF13BmycGFP RNA and 0.2 pmol MO2 (D, e, e'). 
A

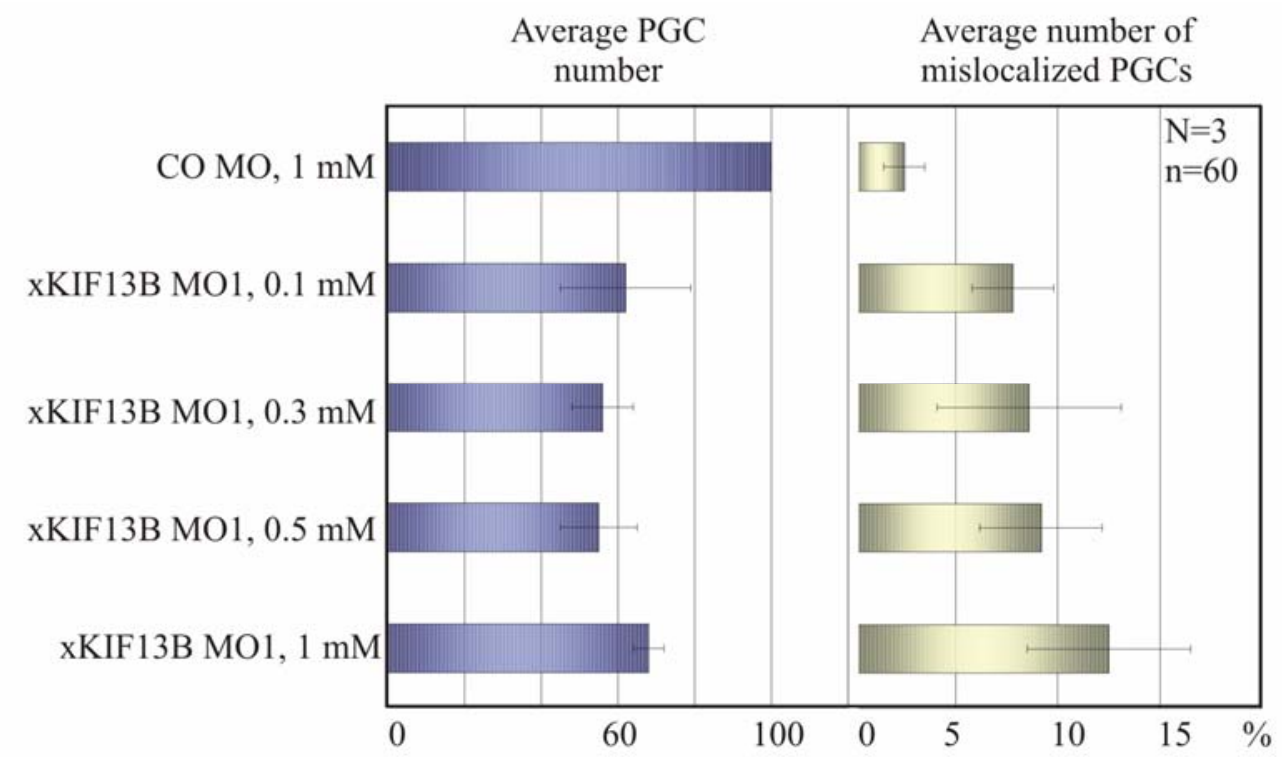

B
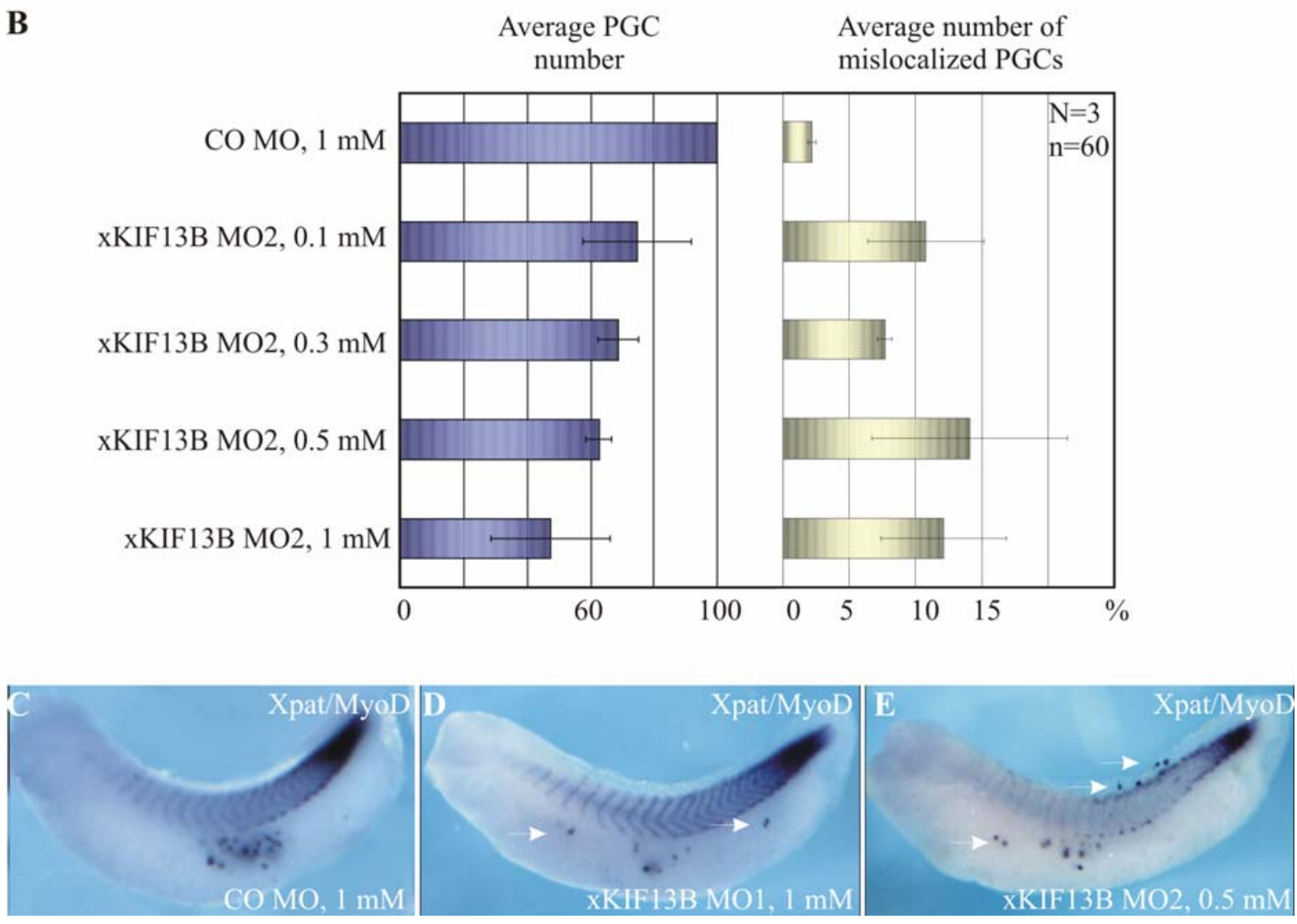

Fig. 4.22. xKIF13B knockdown results in reduced average PGC numbers and severe PGC mislocalization. (A-E) Embryos were injected vegetally into both blastomeres at the 2-cell stage. (A, B) Injection of either $x K I F 13 B$ MO results in a dose-dependent decrease of the average PGC number and severe PGC mislocalization. N- number of independent experiments, $\mathrm{n}$ - number of embryos analyzed in each experiment. (C-E) Representative examples of embryos injected with the control morpholino, $x K I F 13 B$ MO1 or with MO2, respectively. 
Taken together, xKIF13B morphants exhibit both significantly reduced PGC numbers and severe PGC mislocalization, revealing the importance of xKIF13B for normal development and migration of primordial germ cells.

\subsubsection{Overexpression of putative dominant negative fragments of xKIF13B reduces} average PGC numbers but has no significant effect on the PGC migration

The amplified part of the $x K I F 13 B$ ORF encodes for the N-terminal highly conserved motor domain (MD) (amino acids 1 to 361) and a stalk domain, within which centaurin (CBS) (Venkateshwarlu, 2005) - and MAGUKs (MBS) binding sites (Hanada et al., 2000) were mapped (amino acids 361 to 650 and 607 to 832, respectively) (Fig 4.19, B).

As reported by Venkateshwarlu et al. (2005), overexpression of the KIF13B domains responsible for the interaction with binding partners had a dominant negative effect because of the competition for the binding of a putative cargo (Venkateswarlu et al., 2005). Therefore, as a second approach to interfere with the function of xKIF13B during embryogenesis, seven xKIF13B ORF fragments were generated as shown on the Fig. 4.23 (A). They consist of the motor domain alone (MD), the motor domain with centaurin- and MAGUKs (membraneassociated guanylate kinease) binding sites (MD_MBS), centaurin- and MAGUKs binding sites alone (CBS_MBS), the part of the stalk domain available so far (CBS_Stalk), centaurin binding site (CBS) and MAGUKs binding site (MBS) alone. All putative dominant negatives (DNs) were fused to a 3'UTR fragment of the XDead end cDNA, restricting their expression to the germ cells (Koebernick and Pieler, unpublished data) to avoid indirect effects in the soma.

Vegetal injection of synthetic mRNAs encoding these putative DNs into both blastomeres of two-cell stage embryos at a dose of $1 \mathrm{pg}$ did not interfere with the survival of embryos, thus allowing to analyse their impact on PGC development and migration. The significant reduction of the average PGC number was observed in embryos with overexpressed MD, MBS_CBS and MBS fragments. None of DNs was able to phenocopy morphant embryos, no significant mislocalization of PGCs was revealed (Fig. 4.23). 
A
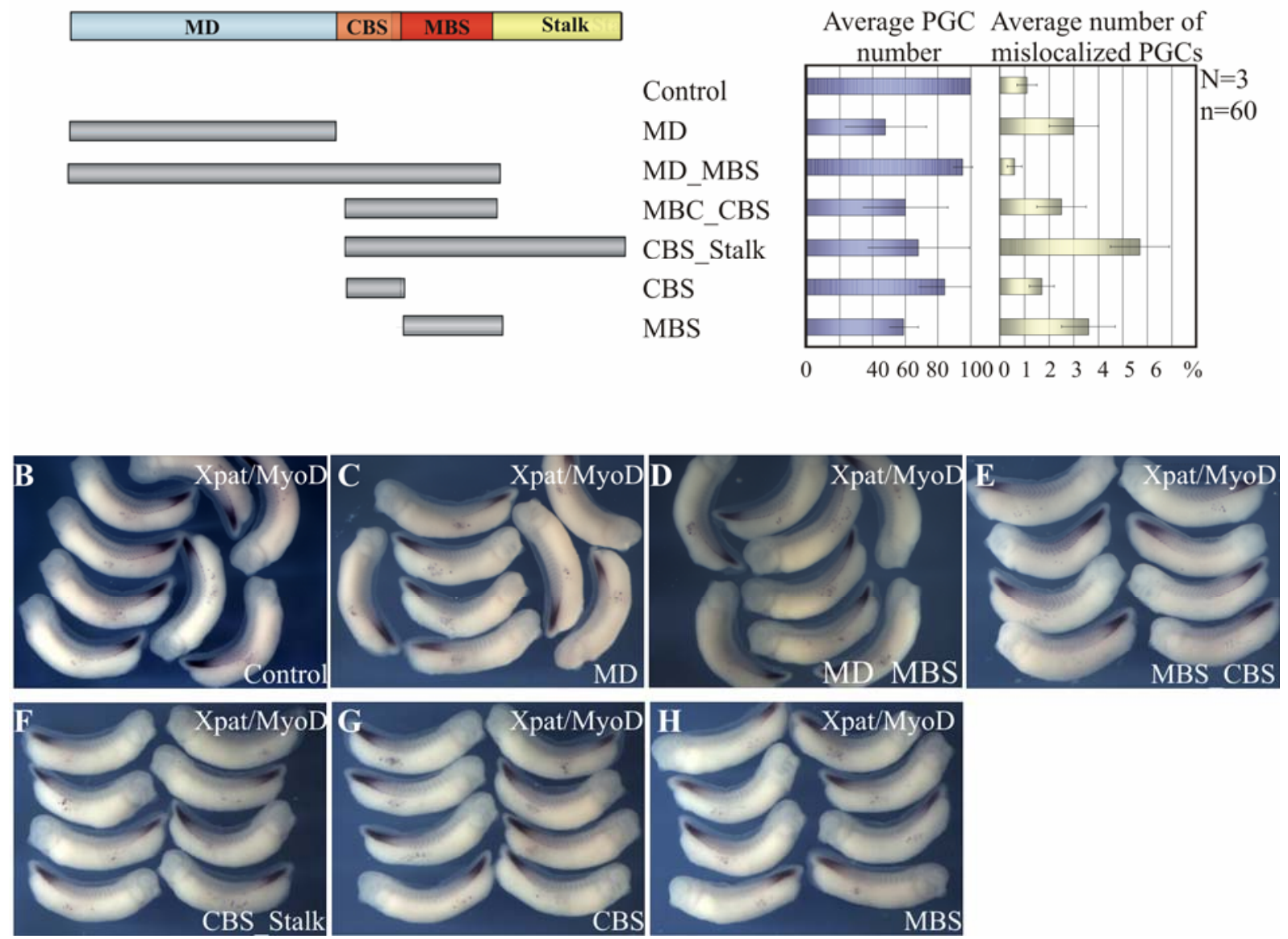

Fig. 4.23. Overexpression of putative dominant negative xKIF13B fragments leads to the moderate reduction of average PGC numbers. (A, D-I) Embryos were injected vegetally into both blastomeres of the 2-cell stage. (A) Injection of synthetic mRNAs encoding for a series of putative dominant negative protein fragments of xKIF13B results in a moderate reduction of the average PGC number, $\mathrm{p}(\mathrm{t})<0.1$. $\mathrm{N}$ - number of independent injections, $\mathrm{n}$ - number of embryos analyzed in each experiment. (B-H) Representative examples of control embryos (B) and embryos injected with $1 \mathrm{ng}$ of xKIF13B MD, MD_CBS, MD_MBS, CBS_Stalk, CBS, or MBS mRNAs (C-H, respectively).

\subsection{Comparative analysis of impacts of PIP3- and SDF1- signalling} pathways on the development and migration of Xenopus PGCs

4.4.1 Interference with the PIP3-signalling cascade results in a dramatic decrease of average PGC numbers and PGC mislocalization

PIP3-signalling was characterized in a variety of cell types as being crucial for the cell migration and establishing cell polarity. In addition, a direct link between this signalling cascade 
and KIF13B was shown by Venkateshwarlu et al. (2005) reported on the KIF13B-dependent trafficking of PIP3-coated vesicles to the growth corn of hippocampal neurons, which was proven important for the neuronal polarity and outgrowth (Venkateshwarlu et al., 2005).

To investigate the impact of PIP3-signalling cascade on PGC development and migration two types of experiments were performed. First, the synthesis of PIP3 was inhibited by blocking PI3K, the kinase responsible for the production of PIP3 at the leading edge of a migrating cell. Secondly, PIP3 pool was depleted within PGCs by overexpression of xPTEN, the phosphatase converting PIP3 to PIP2 at the rear of a cell.

\subsubsection{Inhibition of PI3K}

Normal functioning of PI3K was affected either by chemical inhibition with LY294002 (Sigma) or by overexpression of the mutant PI3K-variant acting as a dominant-negative.

The chemical inhibitor (LY294002, Sigma), blocking the PI3K phosphorylation site was employed. Embryos of 3 different stages $(25,29$ or 31) were incubated with four dilutions of LY294002 (Fig. 4.24A), fixed at stage 33 and analysed for the number and migration pattern of germ cells by WMISH. A significant reduction of the average PGC number was observed, when embryos were treated either with $100 \mu \mathrm{M}$ LY294002 at stage 25 for 30 or for $60 \mathrm{~min}$, or with 50 $\mu \mathrm{M}$ concentration of the inhibitor applied for $10 \mathrm{~min}$ at three different time-points (stages 25, 29 and 31). The most profound effect was observed by the treatment for 24 hours with $5 \mu \mathrm{M}$ LY294002 applied at stage 25. No significant PGC mislocalization was observed with any mode of LY294002 application tested (Fig. 4.24A). Higher dosages or longer treatments resulted in severe malformations of embryos.

As a second loss-of-function approach, the overexpression of the dominant-negative PI3K (Dumstrei et al., 2004) was performed. The dnPI3K ORF was fused to the XDead end LE to restrict the effect presumably to PGCs. Vegetal injections of this mRNA into both blastomeres at 2-cell stage resulted in a dramatic reduction of the average PGC numbers already at low dosages (Fig. 4.24B). Upon microinjection of $0.6 \mathrm{ng}$ of dnPI3K mRNA, only $20 \%$ of PGCs could be scored at stage 32 in comparison to the uninjected controls. In addition to the effect on PGC survival, severe mislocalization of PGCs and formation of germ cells aggregates was observed. For example, germ cells were detected in the most ventral parts of endoderm (Fig. 4.24E, arrow). 
A

\begin{tabular}{|c|c|c|}
\hline LY294002, $\mu \mathrm{M}$ & $\begin{array}{l}\text { Embryonic stage } \\
\text { of application }\end{array}$ & $\begin{array}{l}\text { Duration of } \\
\text { application }\end{array}$ \\
\hline
\end{tabular}

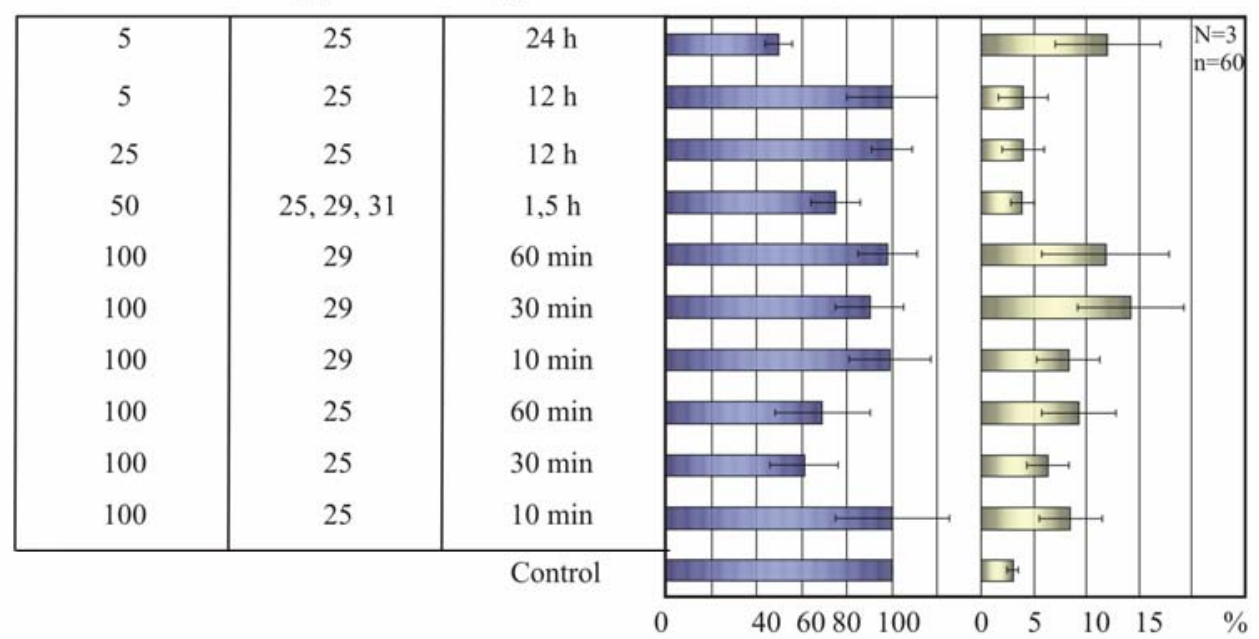

B

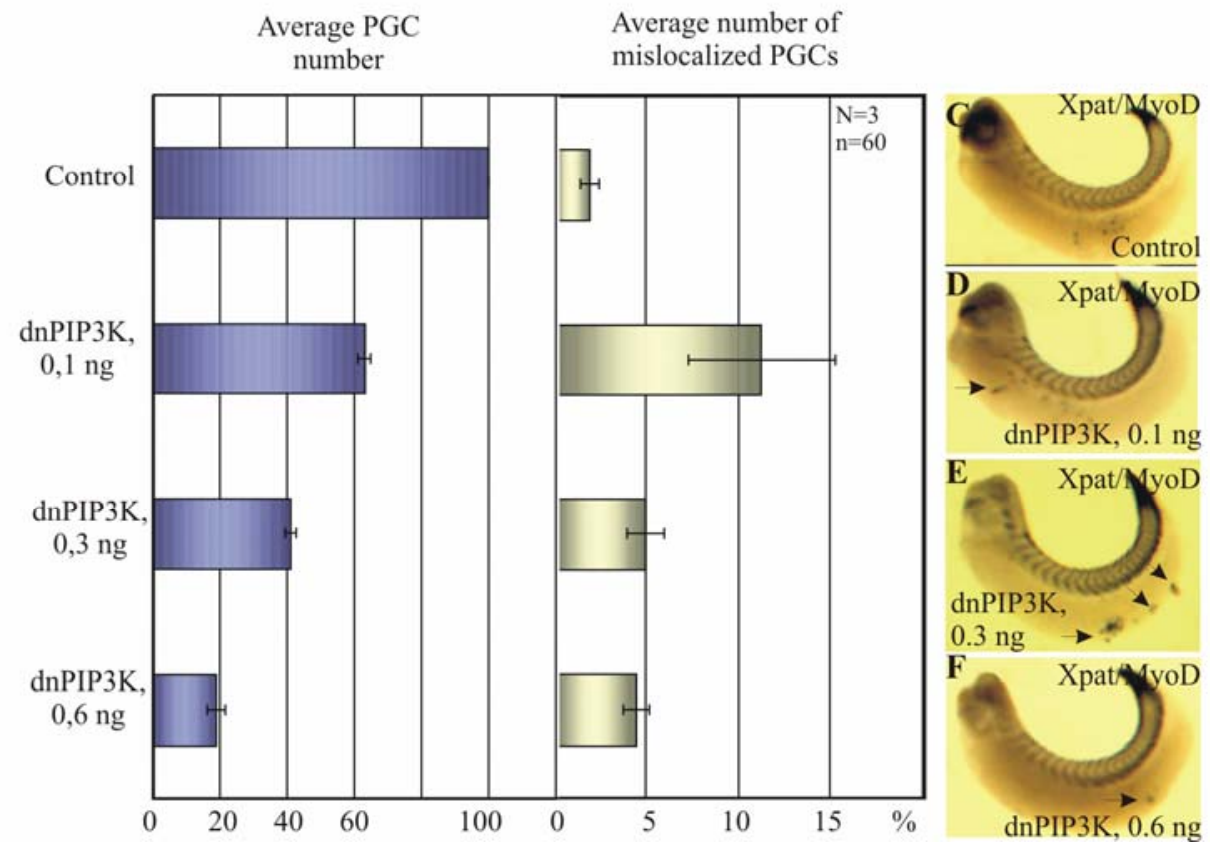

Fig. 4.24. Inhibition of PI3K impairs germ cell development and migration in Xenopus. (A) Implication of the chemical PI3K inhibitor LY294002 results in the moderate decrease in the average PGC number and PGC mislocalization. $\mathrm{p}(\mathrm{t})<0.1$. (B, D, F) Embryos were injected vegetally into both blastomeres of the 2-cell stage. (B) Overexpression of the dominant negative form of PI3K leads to the dramatic decrease in the average PGC number and severe PGC mislocalization. $\mathrm{p}(\mathrm{t})<0.05$. (C-F) Representative examples of control embryos (C) and embryos injected with $0.1,0.3$, or $0,6 \mathrm{ng}$ the $\mathrm{dnPI} 3 \mathrm{~K}$ mRNA (D-F, respectively). $\mathrm{N}$ - number of independent injections, $\mathrm{n}$ - number of embryos analyzed in each experiment.

\subsubsection{Overexpression of $x P T E N$}

Xenopus PTEN ORF (xPTEN) was amplified from the total egg cDNA and fused to XDead end LE to restrict the protein expression to PGCs and to avoid side-effects in somatic 
cells. In comparison to uninjected controls, vegetal injection of this mRNA into both blastomeres at the 2-cell stage caused five-fold decrease in the average PGC number even at lowest dosage tested (250 pg per embryo) (Fig. 4.25A). Reduction of the PGC quantity was accompanied with the dose-dependent mislocalization phenotype, similar to the one observed for xKIF13B morphants (Fig. 4.25A, C). The PGC mislocalization phenotype could be further separated to mismigration of single PGCs (Fig 4.25C, white arrows) and formation of large PGC aggregates, which in majority of cases were mispositioned as well (Fig. 4.25C, black arrows).

A
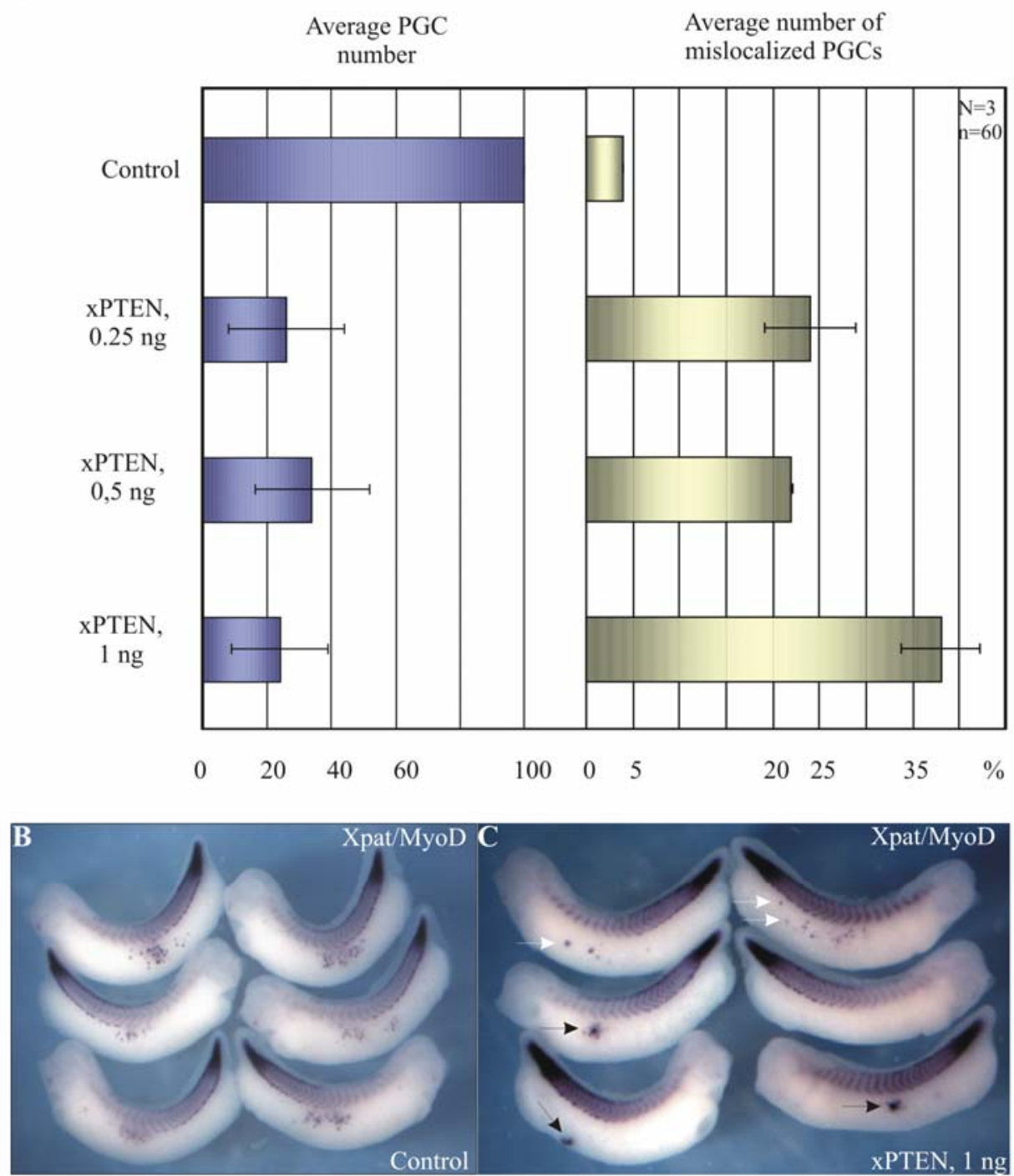

Fig. 4.25. Overexpression of XPTEN significantly impairs PGC development and migration in Xenopus. (A, C) Embryos were injected vegetally into both blastomeres of the 2-cell stage. (A) Overexpression of xPTEN dramatically decreases average PGC numbers and results in severe PGC mislocalization. $\mathrm{p}(\mathrm{t})<0.05$. (B, C) Representative examples of control embryos (B) and embryos injected $1 \mathrm{ng}$ the $\mathrm{xPTEN}$ mRNA (C). Mislocalized PGCs are depicted with white arrows, PGC forming aggregates are indicated with black arrows. $\mathrm{N}$ - number of independent injections, $\mathrm{n}$ - number of embryos analyzed in each experiment. 
To summarize, changing the normal PIP3 distribution within a migrating PGC by inhibition of the PI3K or by overexpression of the XPTEN affects both average PGC numbers and migration of primordial germ cells.

\subsubsection{Mis/overexpression of xSDF1 did not affect PGC migration in Xenopus until} tailbud stage 32

Stromal cell-derived factor-1 (SDF1) was found to guide migration of germ cells in mouse, chicken and zebrafish (Dumstrei et al., 2004; Stebler et al., 2004). To characterize the impact of the Xenopus stromal-derived factor 1 (xSDF1) (Braun et al., 2002) on the development and migration of primordial germ cells in Xenopus laevis, we started with the analysis of its expression pattern during embryogenesis by WMISH (App. Fig 8.2). The mRNA could be detected in the animal parts of embryos starting from the 2-cell stage, but the most intensive signal was observed from stage 23 on, presumably, in regions of neural crest, ectoderm and somites. No endodermal or PGC-specific staining was revealed.

Mis- and overexpression of $1 \mathrm{ng}$ of xSDF1 ORF mRNA (Moepps et al., 2000) resulted in the significant reduction of average PGC numbers upon vegetal or animal injections at 2-cell stage and microinjections into 2 dorsal cells animally at 4-cell stage (Fig. 4.26A). The moderate increase in the average number of mislocalized PGCs (12\%) was revealed only when the mRNA was injected into 2 dorsal cells animally at 4-cell stage (Fig. 4.26A, C, arrows). This mode of injections lead as well to overall malformations and poor survival rate of injected embryos in comparison to uninjected controls, which makes doubtful the specificity of the observed effects. 
A
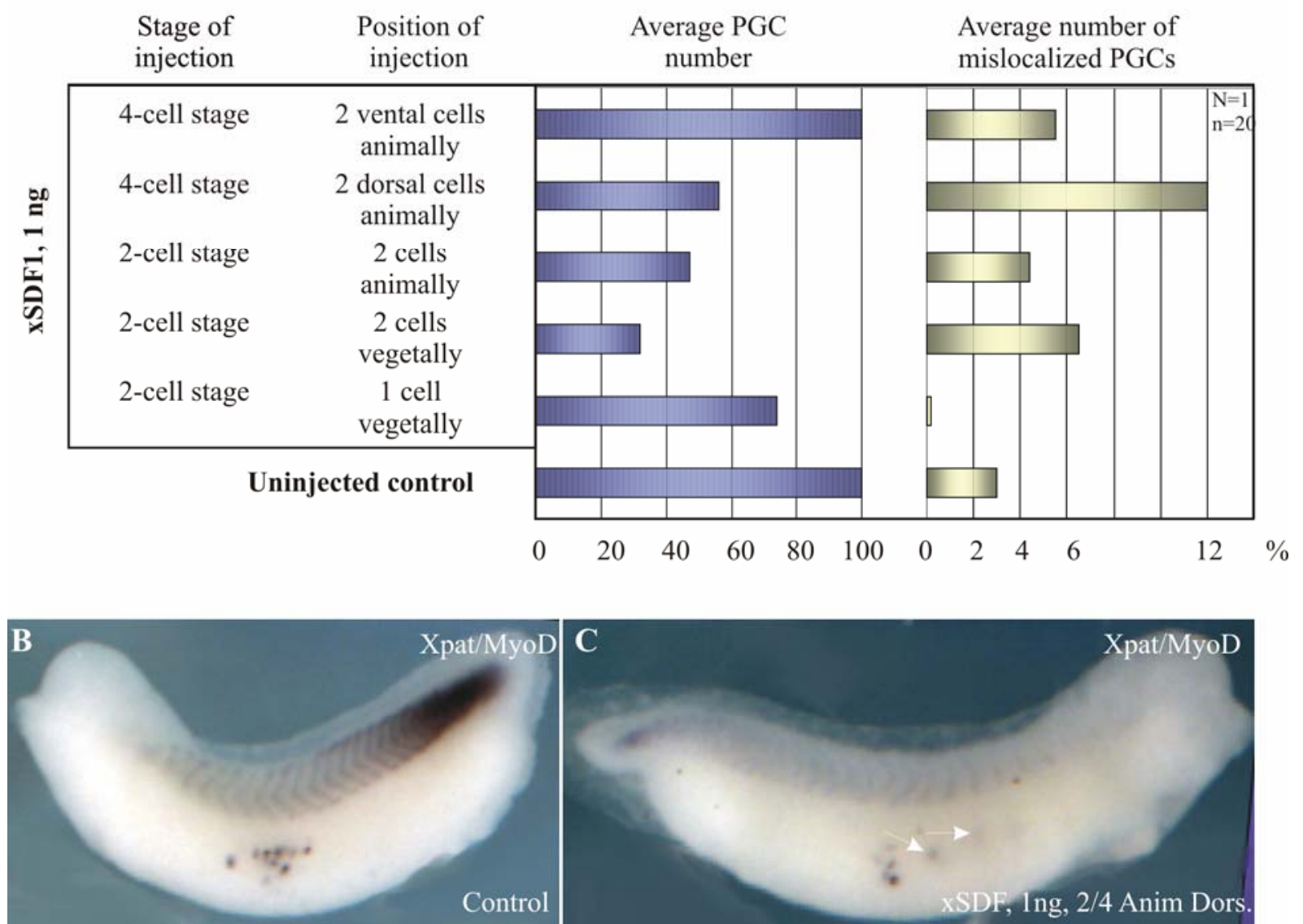

Fig. 4.26. Overexpression and misexpression of xSDF1 does not influence PGC migration in Xenopus. (A, C) Embryos were injected vegetally into both blastomeres of the 2-cell stage. (A) Overexpression of xSDF1 leads to the decreased average PGS numbers, but not to the PGC mislocalization. $\mathrm{N}$ - number of independent injections, $\mathrm{n}$ - number of embryos analyzed in each experiment. (B, C) Representative examples of a control embryo and an embryo injected with xSDF1 mRNA, respectively. PGCs forming aggregates are depicted with white arrows.

\subsubsection{PGC-specific overexpression of $\mathrm{xN}$-Wasp has no significant effect on average}

\section{PGC numbers and migration}

As far as N-Wasp is a well-known modulator of the actin-cytoskeleton involved in the formation of protrusions at the leading edge of migratory cells and taken into consideration that Xenopus N-Wasp (xN-Wasp) mRNA was found vegetally localized in oocytes (K. Horvay, PhDthesis, University Göttingen), we analysed its role in development and migration of Xenopus PGCs.

The spatiotemporal expression of $\mathrm{xN}$-Wasp mRNA during embryogenesis analysed by WMISH (App. Fig 8.2) did not reveal any endodermal or PGC-specific signal. The transcript was enriched animally from the 2-cell stage until neurulation. Starting from stage 15 the mRNA was detected in the midline and later in the head, somites and notochord regions. 
Vegetal injections of $1 \mathrm{ng}$ of the synthetic mRNA encoding for $\mathrm{xN}-\mathrm{Wasp}$ ORF fused to the XDead end LE into both blastomeres of the 2-cell stage resulted in $75 \%$ of the average PGC number and $6.3 \%$ of mislocalized PGCs. To compare, the corresponding values for uninjected controls were $100 \%$ and $2.5 \%$, respectively. According to the one-tailed paired t-Student test, the effects observed were regarded as insignificant.

In summary, the most profound effect on PGC development and migration was received by inhibition of the PIP3- signalling pathway. Mismigration of PGCs observed in this case phenocopied their behaviour in XKIF13B morphants, which argues for the possible involvement of XKIF13B in the establishment of the PIP3-gradient in germ cells as it was shown for neurons (Ventakeshwarlu et al., 2005).

\subsection{Time-lapse analysis of the migratory behaviour of isolated Xenopus PGCs in different culturing conditions}

The migratory behaviour of PGCs was observed for combinations of 3 different matrixes (agarose, fibronectin and Xenopus endodermal explants) and 4 types of mediums $(\mathrm{Ca} / \mathrm{Mg}$-free medium, accutase solution, 1xMBSH and DFA (see Methods)).

PGCs isolated in the $\mathrm{Ca} / \mathrm{Mg}$-free medium were not viable; therefore, all cell-dissociation experiments discussed later were done in accutase.

PGCs placed on $0.7 \%$ agarose in either of mediums employed did not adhere to the matrix and did not show any significant movement except for a slight tumbling (Movies 4 and 7).

PGCs isolated from stage 31-33 embryos placed on explanted endodermal Xenopus cells of the same stage attach to neighbouring cells and migrate into random directions up to several $\mathrm{mm}$ distance in 1xMBSH and DFA-medium. As an example, the migration of a single PGC in $1 \mathrm{xMBSH}$ is shown in the Movie 5.

Single PGCs placed on fibronectin adhere to the matrix and change their shapes rapidly by sending protrusions into al the directions, but do not migrate any significant distance both in 1xMBSH and DFA-medium (Movies 6, 8).

As far as the PGC motility decreases significantly from stages 31-33 to 42 (Fig. 4.12B), we tried to compare the behaviour of cultured PGCs isolated from embryos stage 31-33 and 42. At stage 42 PGCs were found clustered in the region of the future dorsal mesentery. This region 
was cut out in $1 \mathrm{xMBSH}$, and PGC motility was analysed by time-lapsing. No shape changes or migration of PGCs within the cluster was detected (Movie 9).

To summarize, no medium/matrix conditions tested so far allowed culturing Xenopus PGCs longer than for several hours. The best results for PGC attachment to the matrix and migration were observed in 1xMBSH on the endodermal explants and on the fibronectin in the DFA-medium. 


\section{Discussion}

In Xenopus, vegetal localization of mRNA is an important mechanism of creating oocyte polarity and further embryonic patterning. 55 novel vegetally localized transcripts were identified in the microarray-based screening performed in the lab (Horvay et al., 2006). Two of these novel mRNAs were further characterized in this work. XGRIP2.1 encoding for the Xenopus GRIP-family member, and xKIF13B (Xenopus kinesin 13B) are localized early during oogenesis and are expressed specifically in germ plasm/ germ cells later throughout embryogenesis. $X G R I P 2.1$ and $x K I F 13 B$ knockdowns reduce average PGC number, but the effect on PGC positioning at tailbud stages is different. Overexpression of the dominant negative XGRIP2.1 construct PDZ 23 resulted in a posterior shift in PGC positioning along the anteroposterior axis at stages 32-33, while morpholino-mediated knockdown of xKIF13B lead to the severe mismigration of PGCs all over the embryo. Similar phenotype was observed upon interference with PIP3-signalling pathway, which might provide a link between xKIF13B functioning and establishing of the PIP3-gradient in a germ cell important for PGC polarity and migration.

Mapping experiments performed for XGRIP2.1 resulted in identification of a $210 \mathrm{bp}$ fragment in the 3'UTR, which is necessary and sufficient for the vegetal localization of XGRIP2.1 mRNA. The protein binding pattern of this localization element revealed by UVcross-linking is similar to two other germ plasm/ germ cell specific mRNAs.

In order to simplify analysis of the PGC migratory behaviour by bringing cells into the culture, several matrix/medium combinations were tested. The most promising data were obtained in 1xMBSH and Danilchik-for-Amy medium on the fibronectin layer, where manually isolated germ cells could adhere and form protrusions.

Thus, both XGRIP2.1 and XKIF13B play an important role in development and migration of Xenopus germ cells. Further investigation of the xKIF13B function in PGCs migration as well as studying the migratory behaviour of germ cells in culture upon treatment with different signalling pathways inhibitors is the topic of the ongoing work. 


\subsection{XGRIP2.1 is encoded by a vegetally localizing, maternal mRNA and functions in germ cell development and anteroposterior positioning in Xenopus laevis}

XGRIP2.1 is a Xenopus member of the GRIP (glutamate receptor interacting protein) family of multi-PDZ domain proteins. The name stands for Xenopus GRIP2 because of the highest overall protein homology to the mammalian GRIP2. Mammalian GRIP proteins (GRIP1 and $\mathrm{ABP} / \mathrm{GRIP} 2$ ) were first identified as interaction partners of the AMPA receptor subunit GluR2 and proposed to be involved in its recycling and synaptic transport (Braithwaite et al., 2002; Dong et al., 1997; Osten et al., 2000; Setou et al., 2002; Srivastava et al., 1998; Wyszynski et al., 1999; Xia et al., 2000). Targeted inactivation of the rodent GRIP1 gene resulted in complex malformations similar to the human Fraser syndrome, suggesting its involvement in cell-matrix interactions during embryogenesis (Takamiya et al., 2004). The single Drosophila GRIP (DGrip) homologue was found to control directional migration of embryonic muscle cells and formation of glutamatergic synapses (Ataman et al., 2006; Swan et al., 2004).

According to the detected mRNA distribution of XGRIP2.1 during oogenesis and microinjection experiments in oocytes, XGRIP2.1 is localized via the early transport pathway. This is not in agreement with a recent publications reporting the identification of the Xenopus GRIP2 homologue, which is described as late localizing (Kaneshiro et al., 2007) or intermediate localizing (Kirilenko et al., 2007). Since this cDNA probably represents a pseudoallelic form of XGRIP2, sequence variations may account for the differing results.

The mechanism of directional mRNA localization exhibits a number of features conserved among species. According to the most general model, mRNA targeting to a certain cell region depends on the presence of RNA cis-acting elements or localization elements (LE), RNA-binding trans-acting factors, motor proteins and cytoskeletal components (St Johnston, 2005).

The minimal LE of the XGRIP2.1 mRNA was mapped to a stretch of 210 nucleotides within the 3'UTR, found to be sufficient and required for vegetal mRNA localization. So far, no common primary sequence or secondary mRNA structure for cis-elements with vegetal localization activity was described. According to one hypothesis, based on detailed analysis of Xenopus Vg1 mRNA, LEs are regarded as being defined by clusters of short redundant RNA sequence motifs, namely VM1 (YYUCU) and E2 (A/CYCAC), which were proposed to act as signals for RNA localization by the vegetal transport machinery (Betley et al., 2002; Bubunenko et al., 2002; Deshler et al., 1998; Kwon et al., 2002; Lewis et al., 2004). No clustering of these 
elements was observed within the XGRIP2.1 LE, although a number of them are present in the XGRIP2.1 3'UTR and ORF. Therefore, resembling results obtained for other vegetally localizing RNAs previously characterized in our lab (Claussen et al., 2004; Claussen and Pieler, 2004; Horvay et al., 2006), also for XGRIP2.1, no correlation between the presence of these motifs and vegetal mRNA localization was found.

To date, a number of trans-acting factors involved in the vegetal localization have been identified. While Vg1RBP/Vera (Deshler et al., 1998, Havin et al., 1998, Lewis et al., 2004) and VgRBP60 (Cote et al., 1999, Lewis et al., 2004) bind to LEs of Vg1 in the nucleus and initiate the localization process (Kress et al., 2004), Staufen accompanies the RNA in the cytoplasm and is involved in its directional transport (Yoon and Mowry, 2004), while Prrp has been implicated in anchoring of transcripts to the oocyte cortex (Kress et al., 2004).

According to UV cross-linking experiments, also confirmed by Co-IP, the XGRIP2.1 LE binds Vg1RBP/Vera, ElrA and ElrB. This protein binding pattern is similar to ones of the late localizing mRNA XDead end (Horvay et al., 2006) and of the early localizing mRNA XDEADSouth (MacArthur et. al., 2000). Intriguing, during embryogenesis, XGRIP2.1, XDead end and XDEADSouth are specifically enriched in the germ plasm and PGCs. However, during oogenesis, XDead end mRNA is localized late, while XGRIP2.1 and XDEADSouth follow the early localization pathway like the majority of germ line specific transcripts known in Xenopus, (Houston et al., 1998; Hudson and Woodland, 1998; MacArthur et al., 2000). Thus, the observed similarities in the protein binding patterns may be due to factors present in the germ plasm. Alternatively, since the LE of XGRIP2.1 and XDead end can also make use of the late transport pathway if injected late, these proteins might also represent factors common to both the early and late RNA localization machineries.

Since, Staufen was reported to be required for migration of germ cells in Zebrafish (Ramasamy et al., 2006), its binding to two germ plasm/ PGC specific mRNAs XGRIP2.1 and XDead end was tested. Interaction of Staufen with LEs of these transcripts would suggest enrichment of this protein in the germ plasm from early oogenesis, which could support its involvement in germ cell development and migration in Xenopus. No in vitro binding of Staufen was observed for both XGRIP2.1 and XDead end LEs, arguing against this hypothesis.

The germ line specific expression pattern of XGRIP2.1 strongly suggests its involvement in germ cell development in Xenopus. Indeed, specific antisense-mediated depletion of XGRIP2.1 using two different MOs results in a significant reduction of the PGC number as scored in early tailbud stage Xenopus embryos. Similar effects were obtained upon expression of the putative dominant-negative XGRIP2.1 fragments PDZ 23 and PDZ 67. Gain-of-function 
experiments performed by vegetal microinjection of XGRIP2.1 ORF also reduced average PGC numbers at low doses, albeit very mild. High doses caused neurulation defects and increased lethality of embryos. One possible explanation for that could be interference with the functioning of the recently identified XGRIP1. According the overall protein homology and mRNA expression pattern, Xenopus GRIP1 is an orthologue of the rodent GRIP1, shown to be important for the formation of glutamatergic synapses and neuronal guidance (Dong et al., 1997; Kim et al., 2005; Wyszynski et al., 1999). The exact function of XGRIP1 is yet to be identified. High amino acid identity level (82\%) between XGRIP1 and XGRIP2.1 might allow for XGRIP2.1, upon injection of more than $1 \mathrm{ng}$ of the mRNA, to overtake the function of XGRIP1 in the developing nervous system. This would create the XGRIP1 "gain-of-function" situation, which could result in neurulation defects observed.

Thus, gain- and loss-of-function experiments suggest that interfering with the function of XGRIP2.1 blocks normal PGC development up to stage 32, making the function of XGRIP2.1 protein essential for the maintenance of PGC identity, PGC proliferation or PGC survival. Loss of PGCs has also been observed upon depletion of Xdazl, XDead end and Xdsg, the causes of which remain unclear (Horvay et al., 2006; Houston and King, 2000b; Ikenishi et al., 2006). One possible explanation for the reduced PGC number could be apoptosis. However, TUNEL staining experiments did not reveal PGC specific signals in either uninjected or MO-injected Xenopus embryos (data not shown). It had previously been demonstrated that transplanted PGCs are capable to form part of a wide range of different tissues (Wylie et al., 1985). Thus, the loss of PGCs observed upon XGRIP2.1 knockdown may also result from their transdifferentiation. However, more complex experiments are needed to further elucidate the cause for PGC disappearance.

Loss-of-function experiments also revealed a second, unexpected role of the XGRIP2.1 protein in anteroposterior positioning of PGCs. Compared to the normal A/P distribution of PGCs, both MO-mediated knockdown and misexpression of putative dominant-negative XGRIP2.1 fragments resulted in mislocalization of PGCs to more posterior positions. The most pronounced posterior shift in PGC localization was obtained upon misexpression of the XGRIP2.1 fragment encoding PDZ domains 2 and 3. The phenotypes of decreased PGC numbers and PGC mislocalization thus seem to be coupled. However, upon injection of PDZ 67 reduced PGC numbers are observed in absence of significant effects on anteroposterior PGC positioning. This result indicates that reduced PGC numbers do not generally result in PGC mislocalization. The enhancement of the mislocalization phenotype obtained upon injection of the XGRIP2.1 DN construct PDZ 23 ( 2,5 fold compared to the MO) might reflect the existence of additional 
proteins, which are functionally redundant in respect to XGRIP2.1 and would also be inhibited by PDZ 23.

PDZ domains have been shown to selectively bind to the C-terminus or to a short internal segment of interacting proteins (Sheng and Sala, 2001). According to the crystal structure analysis of the GRIP1 PDZ6-cargo peptide complex (Im et al., 2003), the PDZ 23 mutant, carrying an internal deletion (PDZ 23 del), is predicted to partially lack a $\beta$-sheet structure involved in cargo interaction. Mutation of the putative hydrophobic carboxylate binding motif (as in XGRIP2.1 SRSmutPDZ23) is also predicted to block the function of the cargo binding pocket (Daniels et al., 1998). Since both these deleted and mutated forms of DN PDZ 23 did not inhibit proper A/P positioning of PGCs, the dominant-negative effect of PDZ 23 might rely on its interference with the specific binding of the endogenous XGRIP2.1 to a cargo protein. Further substantiating the importance of PDZ domains 2 and 3 for proper function of XGRIP2.1, mutation of the predicted cargo binding motif in PDZ 2 or internal deletion of PDZ domains 2 or 3 in the context of the fulllength protein results in a loss of XGRIP2.1 MO rescuing activity. Thus, PDZ domains 2 and 3 seem to be essential for the biological function of XGRIP2.1 in the context of survival and migration of PGCs.

Binding of the DGrip interaction partner Echinoid to either the two first PDZ domains or the C-terminal PDZ domain 7 was proposed to mediate activation or repression of Echinoid, respectively (Swan et al., 2006). Analogously, XGRIP2.1 DN PDZ 23 might have a similar function. GRIPs are known to form protein complexes with different binding partners even within one system. Different PDZ domains in DGrip were shown to interact with Echinoid, Frizzled2 and Kon-tiki (Ataman et al., 2006; Schnorrer et al., 2007; Swan et al., 2006). The design of our series of putative DNs as short overlapping fragments of 2 and 3 neighbouring PDZ domains covering the whole ORF allowed us to compete with binding of different potential interaction partners. To further understand the basis of the DN effect, identification of XGRIP2.1 binding proteins from PGCs will be crucial.

One possible hint for XGRIP2.1 interacting partners came, surprisingly, from the overexpression results with the constitutively active $\beta$-catenin. Co-injection of the ca- $\beta$-catenin together with the PDZ 23 leads to a 3-fold decrease of the average mislocalized PGC number, when compared to the value obtained for the ca- $\beta$-catenin injected alone. These results suggest involvement of XGRIP2.1 in Wnt- $\beta$-catenin-signalling in PGCs, which is in line with the data from Ataman et al. (2007), reporting on DGrip's necessity for the trafficking of the Frizzled-2 receptor. 
Apart from arguing for a role of XGRIP2.1 in PGC migration, these data also provide the first evidence for an anterior migration step of PGCs occurring during tailbud stages, prior to dorsal migration, which has not been previously documented in Xenopus embryos. The positioning of PGCs was described for tailbud stages 25-33. Stage 32-33 was selected for the further analysis of phenotypes, because of the maximal number of PGC, their most lateral location and clear development of somites. At that stage, the majority of PGCs was found between somites 5 and 11. These data were very recently also confirmed by Ikenichi et al. (2007), similarly reporting on anterior-posterior PGC positioning and mislocalizaiton (Ikenishi et al., 2007).

Posterior mispositioning of PGCs was evident at late tailbud stage (st.30-32) but not observed in early tailbud (st.26) stage embryos, just prior to the onset of active migration. At early tadpole stage (st.34), PDZ 23 injected embryos also exhibited retardation of dorsal PGC migration apart from persisting posterior PGC mislocalization (not shown). Therefore, the posterior mislocalization of PGCs may also be the result of a general delay in migration exhibited by PGCs expressing the DN form of XGRIP2.1. To address this, we are currently characterizing the anterior migration step in more detail using time-lapse microscopy. According to the imaging of PGCs in control embryos, the most active migration step with the calculated average PGC velocity of $0.26 \mathrm{~mm} / \mathrm{h}$ occurs during stages 26-33. PGCs of embryos injected with PDZ 23 do not migrate anteriorly at all or migrate two times slower in comparison to the controls (with the calculated average PGC velocity of $0.13 \mathrm{~mm} / \mathrm{h}$ ). Considering a PGC as a classical migratory cell, the decrease in the velocity of its movement could result either from the disruption of the cell polarity or from the interference with cell-to-cell/ cell-to-matrix interactions. GRIPs in a variety of organisms were shown to be important for both of these processes. As already described before, Drosophila DGrip interacts with the cell adhesion molecule Echinoid (Swan et al., 2006), mouse GRIP1 was found to bind Fras1 important for cell-to-matrix contacts (Takamiya et al., 2004), rodent GRIP1 and GRIP2/ABP are involved in the trafficking of AMPA receptors establishing the neuronal polarity (Dong et al., 1997; Wyszynski et al., 2002; Wyszynski et al., 1999). The membrane and sub-membrane enrichment of XGRIP2.1 suggests its involvement in the PGC polarization events, which could explain the decrease in average PGC velocities and posterior shift upon XGRIP2.1 knockdown. Albeit, further experiments to identify direct XGRIP2.1 binding partners are yet to be done.

In summary, the data obtained in this work imply a novel role for XGRIP2.1 in development and anteroposterior migration of primordial germ cell in Xenopus. 
5.2 xKIF13B is encoded by a novel vegetally localizing mRNA and plays an important role in primordial germ cells migration in Xenopus laevis

Xenopus kinesin 13B (xKIF13B) was identified as a novel early localizing mRNA in the microarray-based screening for vegetally localizing transcripts (Horvay et al., 2006).

Kinesin 13B or GAKIN (guanylate kinase associated kinesin) -proteins belong to the KIF13 subfamily of the KIF-N3 family also called N-kinesins, because of the N-terminal location of the motor domain. KIF13B and the other member of this subfamily, KIF13A, are non-conventional plus-end motor proteins responsible for the directional transport of synaptic and receptor-cargo vesicles to the cell membrane (Hirokawa and Takemura, 2005; Miki et al., 2001).

Structurally, KIF13B-proteins consist of a very conserved motor domain (MD), stalk domain with regulatory phosphorylation sites (so called fork-head domain) and the C-terminal Cap-Gly domain also referred to as the cytoskeleton-associated glycine-rich domain, involved in interactions with microtubules and intermediate filaments.

For KIF13B two main cargo molecules were identified so far: the membrane-associated guanylate kinase homologue (MAGUK) scaffolding protein $\mathrm{hDlg} / \mathrm{SAP} 97$ and centaurin- $\alpha 1$ or PIP3-binding protein, both being implicate in the establishment of cell polarity and adhesion (Asaba et al., 2003; Venkateswarlu et al., 2005).

hDlg/SAP97 (human lethal disc large tumour suppressor) is a member of MAGUKfamily of peripheral membrane proteins composed of one or three PDZ-domains, an SH3domain and a C-terminal guanylase kinase domain (GUK). Drosophila Dlg is a scaffolding protein involved in the formation of septate junctions of epithelial cells and neuromuscular junctions (Budnik, 1996; Woods and Bryant, 1991). Interaction of hDlg and KIF13B/GAKIN was shown to act as a switch between the inactive and the active conformational state of the motor protein (Yamada et al., 2007).

KIF13B/centaurine- $\alpha 1$-mediated trafficking of PIP3-coated vesicles to the distal parts of neurites was shown to regulate axon-dendrite polarity and neuronal outgrowth in the hippocampal neurons (Horiguchi et al., 2006; Venkateswarlu et al., 2005).

Extensive 5'/3' RACE-amplification of the xKIF13B allowed extending the initial $800 \mathrm{bp}$ to the 4506 bp cDNA fragment composed of a small 5'UTR and a partial ORF. The obtained xKIF13B ORF cDNA encodes for a conserved motor domain and the N-terminal part of a stalk, where the centaurine-binding site (CBS) and the MAGUK-binding site (MBS) are located. 
The RT-PCR analysis of $x K I F 13 B$ expression in adult tissues shows the presence of the transcript in almost all samples analysed, which is in line with previous findings for hKIf13B (Ishikawa et al., 1998). Albeit during embryogenesis $x$ KIF13B is specifically expressed in germ plasm and germ cells, suggesting its potential role in germ cells development. A part of the 5'UTR obtained by RACE-extensions was sufficient to design two $x K I F 13 B$-specific morpholino oligonucleotides for knockdown experiments. $x$ KIF13B morphants exhibit severe PGC mislocalization and reduction of average PGC numbers, confirming the importance on this motor-protein for PGC maintenance and migration.

For the mapping of the putative cargo-binding domain, as well as for a second type of the loss-of-function approach, a panel of putative dominant-negative ORF fragments of xKIF13B was designed. These proteins encode either MD, CSB, MBS and stalk alone or larger fragments covering MD, CBS and MBS (MD_MBS) or CBS with MBS (CBS_MBS). Vegetal injections of these mRNAs didn't phenocopy xKIF13B morphants, and none of these constructs could rescue MO-mediated PGC mislocalization upon co-injection with either of the MOs (data not shown). The most profound reduction in the average PGC number was obtained by overexpression of the MD alone. This effect could be explained by the microtubule-depolymerising activity of KIF13 motor domains, which is normally inhibited by the conformational changes upon cargo-binding (Moores and Milligan, 2006; Tan et al., 2006).

To summarize, xKIF13B appears to be important for the directional migration of PGCs in Xenopus, most probably, by the establishment of the PGC polarity, albeit the exact role of this protein is yet to be defined.

\subsection{Comparative analysis of the involvement of PIP3- and SDF1- signalling pathways in development and directional migration of Xenopus PGCs}

In attempt to identify a "target" signalling pathway for xKIF13B and XGRIP2.1 and in order to gain deeper insight into molecular mechanisms of PGC development and migration in Xenopus, a number of signalling pathways were analyzed for their impact on these processes. 


\subsubsection{Interference with PIP3-signalling cascade results in a dramatic decrease of average PGC numbers and PGC mislocalization}

PIP3-signalling pathway is known to be important for directional cell migration in a variety of cell types (Loovers et al., 2006; Venkateswarlu et al., 2005). Key players of this cascade are PIP3, PI3K, phospholipase C (PLC) and PTEN. PI3K is converting PIP2 into PIP3 when PLC was shown to degrade PIP2 into IP3 at the leading edge of a cell, at the same time PTEN is converting PIP3 into PIP2 at the rear. By this reciprocal distribution of PIP3 producing and degrading molecules, the gradient of PIP3 is created in a cell, triggering F-actin polymerization at the front and RhoA/myosin II- dependent rear contraction (Keizer-Gunnink et al., 2007; Van Keymeulen et al., 2006).

Inhibition of PI3K activity was shown to disrupt the PIP3-gradient formation described above and to abolish by this means migration of a Dictyostelium cell, the chemotropic outgrowth of Xenopus spinal neurons, and to slow down the migration of Zebrafish germ cells (Dumstrei et al., 2004; Loovers et al., 2006; Ming et al., 1999). For both, Dictyostelium and neuronal cell systems, the pharmacological inhibitor LY294002 was successfully employed. $60 \mu \mathrm{M}$ concentration of LY294002 was sufficient to completely block PI3 kinase activity (Ming et al., 1999; Loovers et al., 2006). To test the impact of LY294002-treatment on PGC migration and survival, $100,50,25$ or $5 \mu \mathrm{M}$ concentrations of the chemical were applied at stage 25 , when cells are starting to migrate actively, and at stages 29 or 31 , when the cells are in the middle of the migratory phase. Pharmacological PI3K inhibition resulted in the mild decrease in the average PGC numbers, but not in a significant degree of PGC mislocalization.

As a second approach, the PGC-specific knockdown of PI3K was performed by overexpression of dominant negative PI3K (dnPI3K, Dumstrei et al., 2004) fused to the XDead end localization element (Horvay et al., 2006). In this case, a dramatic reduction of the average PGC number accompanied by the formation of PGC-aggregates and PGC mislocalization was observed. Differences between these two types of PI3K inhibition could be explained by nonspecific effects for the LY294002-application as far as not only PGCs but the whole embryo were subjected to the treatment, while overexperession of the dnPI3K was supposedly PGCspecific.

Another way to interfere with the PIP3-signalling was to overexpress Xenopus PTEN in PGCs. This experiment resulted in the reduction of average PGC numbers and phenocopying PGC mislocalization reported for $x K I F 13 B$ morphants. In addition to the miclocalization of single germ cells, the formation of large PGC aggregates was observed. A similar phenotype was 
also previously described upon morpholino-mediated knockdown of XDead end (Horvay et al., 2006). Abnormal formation of the large PGC-aggregates can result from changes in the cell-tocell signalling or adhesive properties of PGCs, which are only poorly understood at present.

Inspired by the phenotypes observed for the inhibition of PIP3-signalling, we attempted to find the direct connection between this biochemical pathway and XKIF13B. Verkateshwarlu et al. (2005) reported on the KIF13B-dependent trafficking of PIP3-coated vesicles in hippocampal neurons. The linker molecule essential for this process was found to be centaurine- $\alpha 1$, also termed PIP3 binding protein (PIP3BP). Centaurines are small GTPase-activating proteins (GAPs), which inactivate ADP-ribosilation factors (ARFs) by triggering hydrolysis of bound GTP to GDP. By this means, centaurines are involved in the regulation of the intracellular vesicular trafficking (Kanamarlapudi, 2005). Therefore, expression patterns of two putative Xenopus homologues of centurine- $\alpha 1$, identified by BLASTing against Xenopus database, were analyzed. No PGC-specific or endodermal expression was observed.

In conclusion, PIP3-signalling appears to be essential for the maintenance and directional migration of Xenopus PGCs, albeit the triggering signal and the possible connection with xKIF13B activity remain to be defined.

\subsubsection{Misexpression of the xSDF1 does not significantly affect PGC migration in} Xenopus until late tailbud stages

Stromal cell-derived factor-1 (SDF1) was reported to serve as a guidance clue for CXCR4-receptor expressing germ cells in mouse, chicken and zebrafish (Dumstrei et al., 2004; Stebler et al., 2004). Two homologues of SDF1 were identified in Xenopus: 94 amino acids long xSDF1 (Braun et al., 2002) and, lacking 5 C-terminal amino acids, xSDF1 $\alpha$ (Fukui et al., 2007). Xenopus SDF1 (Braun et al., 2002) and CXCR4 (xCXCR4) (Moepps et al., 2000) were implicated in development of haematopoietic cells, in particular, in migration of cardiac neural crest cells to the heart primordium (Braun et al., 2002). xSDF1 $\alpha / \mathrm{CXCR} 4$-signalling was found to regulate migration of mesodermal cells during gastrulation (Fukui et al., 2007). In 2005, Nishuimi et al. reported detection of xCXCR4 protein in Xenopus primordial germ cells, suggesting a similar SDF1/CXCR4 guidance mechanism to control PGC migration in Xenopus as already described for mouse, chicken and zebrafish. 
If Xenopus PGC are as well guided by the SDF1-signalling, they should migrate to ectopic locations in response to ligand misexpression. To address this question, we overexpressed xSDF1 (Braun et al., 2002) in different germ layers of Xenopus embryos. No significant mispositioning of PGCs was observed for any kind of the ligand misexpression. Therefore, we can not confirm the hypothesis of Ikenishi et al. (2007), proposing the involvement of xSDF1-guidance for the anterior migration of PGCs during tailbud stages. On the other hand, findings by Stebler et al. (2004) suggest a requirement for SDF1-signalling during late but not early PGC migratory phases, when cells find their way through blood vessel endothelium in chick or through the gut epithelium in mice. We do not exclude the possibility of $\mathrm{xSDF} / \mathrm{xCXCR} 4$ regulation of germ cell migration at late tailbud-tadpole stages of frog development, which was not analysed so far.

\subsubsection{Interference with Xenopus N-Wasp does not significantly impair development} and migration of primordial germ cells

In the most simplified model for directional migration of a cell, four main steps can be highlighted: establishing cell polarity, formation of a protrusion at the leading edge, adhesion, and contraction of the rear. There are two main possibilities to form a protrusion. The first one is characteristic for the migratory germ cells in zebrafish and implies formation of a bled driven by myosin contraction and cytoplasmic flow (described in details by Blaser et al., 2006). The second way to extend the leading edge of a cell is to form lamellae- and filopodia by elevated actin polymerization, which is in turn regulated by the activity of Wasp/WAVE protein complex (Ridley et al., 2003).

Wiskott-Aldrich syndrome proteins (WASP) are well-studied scaffolding linkers between extracellular signalling and the intracellular burst of actin polymerization, which results in formation of cell protrusions and directional migration (Ridley et al., 2003; Takenawa and Suetsugu, 2007). Most interestingly, N-Wasp was reported to act downstream of PI3K during myogenic cell migration induced by hepatocyte growth factor. In these experiments, stimulation of cell migration by the overexpression of N-Wasp was abolished by PI3K inhibition with LY294002 (Kawamura et al., 2004). Taking the vegetal localization of N-Wasp mRNA in Xenopus oocytes into consideration (data of the microarray based screening, Horvay et al., 2006) and the intriguing link to PI3K signalling mentioned above, we focused on a possible connection between Xenopus N-Wasp (xN-Wasp) and the migratory activity of germ cells. To address this question we analysed the expression pattern of $\mathrm{xN}$-Wasp mRNA in Xenopus embryos, which 
was not described so far, and results of xN-Wasp overexpression in PGCs. $x N$-Wasp mRNA was neither detected in the endoderm region nor in germ cells until late tailbud stages. Overexpression of $\mathrm{xN}$-Wasp caused a slight decrease in the average PGC number, but no significant mispositioning of PGCs was observed. These data allow to rather exclude xN-Wasp from the list of key players required for Xenopus germ cell migration. To further investigate this issue, we plan to perform in vivo imaging of membrane/ cytoskeletal rearrangements in cultured germ cells.

\subsection{Investigation of the migratory behaviour of Xenopus PGCs in different culturing conditions}

Over at least thirty years scientists attempt to use cultured PGCs as a system to gain deeper insight into the molecular mechanisms of the migratory cell behaviour. The vast majority of data in this field comes from the mouse system, where PGC culturing experiments were most successful so far (De Felici, 2000; Molyneaux et al., 2001).

Attempts to maintain germ cells in culture are accompanied with significant difficulties from the very first steps of PGC isolation. There is only a limited number of these cells per embryo (around 30 at stage 32-33 for Xenopus); no PGC surface specific markers are known so far, which makes impossible specific cell sorting; embryos are not translucent, and cells are migrating internally through different tissues. Thus, isolation of migrating PGCs appears to be a nontrivial task.

In the mouse, this problem was solved in three ways: by mechanical disaggregation of the gonadal ridge tissue after EDTA treatment, by Percoll gradient and by Mini-MACS immunomagnetic cell sorting (De Felici, 2000). The last method is the most efficient one, albeit not applicable for Xenopus because of the lack of specific PGC-surface antibodies.

Even after successful isolation, germ cells do not survive in culture for longer than 2-3 days. Moreover, they hardy proliferate and do not undergo proper differentiation. Placing cells on the semi-native feeder layer (gonadal somatic tissue) and supplying the medium with leukaemia inhibitory factor (LIF), stem cell derived factor (SCF), retinoic acid and cAMP, significantly increased cell survival and partially solved proliferation problems, but the factors crucial for PGC differentiation are yet to be identified (De Felici, 2000).

In Xenopus, reports on PGC culturing coincide with the early studies on PGC development and migration per se, that holds back the early eighties of the last century (Brustis 
et al., 1984; Heasman et al., 1981; Heasman and Wylie, 1981). These investigations mainly address the question of the impact of different substrata on PGC migration. Fibronectin and collagen IV were found crucial for the migratory behaviour and specification of PGCs (Brustis et al., 1984; Heasman et al., 1981; Heasman and Wylie, 1981).

In this work we tried to combine the existing data for Xenopus PGC culturing with a number of successfully applied techniques from the mouse in attempt to establish Xenopus PGC culture system stable enough for the migratory observations.

As already mentioned above, we could not use the mini-MACS sorting system as applied for mice, because the specific PGC-surface markers are not available. The problem of cell labelling was solved by using enhanced or short-living GFP variants fused to the XDead end localization element for PGC specific expression (Koebernick et al., unpublished). Several rounds of FACS didn't give any reliable result. Instead of around 3000 PGCs we obtained 1000000 sorted cells from 100 selected embryos with PGC-specific GFP expression. This was due to the partial leakiness of the GFP-construct and very high sensitivity for fluorescence. Therefore, we switched to manual isolation of germ cells by dissecting tailbud stage embryos and dissociating cells in accutase.

For the PGC culturing, we aimed to find out the simplest medium/substrate conditions to be used in further experiments, and to apply in this system different putative guidance factors (chemokines, animal caps expressing Wnt- or FGF-ligands, etc), as well as to directly analyse their impact on PGC migration. We tried combinations of four buffer conditions and three matrices. The best adherence and PGC migration was documented for germ cells on the fibronectin or endodermal explant in gluconate-enriched DFA-medium. These data are in full agreement with reports on PGC culturing in mice (De Felici et al., 2000) and early findings in Xenopus (Heasman et al., 1981; Heasman and Wylie, 1981; Brustis et al., 1984). Endodermal explants were used in analogy to the mouse semi-native feeder layer, while fibronectin is known to be synthesized in large amounts by mesentery epithelial cells, making it a natural PGC adhesion substrate.

Interestingly, the average velocities of PGCs in culture were significantly higher in comparison to the results obtained from the in vivo imaging of PGC migration in a whole embryo. This phenomenon was as well described in mice for PGC migrating in cultured tissue slides (Molyneaux et al., 2001). These authors speculate that this could result from the loss of cell-to cell contacts. In other words, PGCs in culture do not need to find their way through the neighbouring tissues, which speeds up the migration. 
Another intriguing aspect to investigate in cultured PGCs is the possibility of PGC-toPGC signalling and contact. There are several adhesive molecules found to be expressed on mice PGCs (cadherins, integrins, oligosaccharides) (De Felici, 2000). No data on that topic exist in Xenopus until now, albeit changes in cell surface expression profile in response to an intracellular or environmental signal could result in abnormal cell-to-cell (PGC-to-PGC) contacts and formation of large PGC aggregates as observed, for example, for XDead end and PI3K lossof-function (Horvay et al., 2006).

To summarize, after more than thirty years of intensive investigation, some problems of survival and proliferation were solved at least for mouse cultured PGCs, but a number of difficulties remain to be overcome. For example, differentiation of PGCs in culture is still elusive, even though in Xenopus, vegetal germ plasm bearing cells transplanted into the endoderm of developing early tailbuds differentiated into PGCs (Ikenishi et al., 1984). As emphasized by De Felici and McLaren (1983) "PGCs do not at any time exist as an independent tissue", but are always surrounded by neighbouring cells, which could potentially supply all necessary nutrients and guidance clues (De Felici and McLaren, 1983). This cell-to cell/ cell-tomatrix environment is impossible to reproduce in culture. Therefore, studying cultured PGCs hardly would provide the complete understanding of the overall development of a germ cell, but could address and answer a number of questions about their migratory behaviour. 


\section{Conclusions}

The Xenopus germ cells are derived from a specialized region in the vegetal hemisphere of the oocyte, the germ plasm. Several maternal transcripts harboured in this region have been connected to the process of primordial germ cells specification. We identified and functionally characterized two novel vegetally localizing mRNAs. The first one encodes a glutamate receptor interacting protein (GRIP) family member in Xenopus, termed XGRIP2.1. The transcript is localized via early pathway during oogenesis. The $210 \mathrm{bp}$ localization element necessary and sufficient for this mRNA localization was mapped in the 3'UTR of XGRIP2.1. The protein binding pattern of this mRNA fragment is strikingly similar to at least two other germ plasm/ germ cell specific mRNAs XDead end and XDEADSouth. Throughout Xenopus embryogenesis, XGRIP2.1 is specifically associated with the germ plasm and PGCs. Morpholino-mediated knockdown and overexpression of a putative dominant negative XGRIP2.1 protein fragment PDZ 23 reduced average PGC numbers and interfered with the proper anteroposterior positioning of PGCs at tailbud stages. In vivo time-lapse analysis of PGC migration revealed significantly reduced velocities of these cells in embryos injected with PDZ 23 mRNA in comparison to controls. Thus, our results suggest that XGRIP2.1 is required for normal PGC development and migration in Xenopus.

The second novel transcript encodes the Xenopus kinesin 13B (xKIF13B). 5'RACE extensions allowed to amplify a partial cDNA containing the 5'UTR and the N-terminal part of the ORF. The $x K I F 13 B$ mRNA is vegetally localized via early pathway during oogenesis and specifically expressed in germ plasm and germ cells throughout embryogenesis. Morpholinomediated knockdown resulted in the reduction of the average PGC number and caused severe mislocalization of migrating PGCs at tailbud stages. Intriguingly, interference with PIP3signalling pathway in PGCs phenocopied xKIF13B morphants, suggesting possible involvement of this motor protein in the establishment of the PIP3 gradient in germ cells. KIF13B-mediated trafficking of the PIP3-coated vesicles is critical for the polarization and outgrowth of hippocampal neurons (Venkateshwarlu et al., 2005). Similar mechanism could facilitate germ cell polarity and directional migration of PGCs in Xenopus.

In addition, we attempted to find the most appropriate conditions to maintain Xenopus germ cells in culture, which would significantly facilitate investigation of the molecular mechanism of PGC migration in comparison to in vivo studies in the context of the whole embryo. The best results were obtained with manually isolated cells kept on fibronectin in the Danilchik-for-Amy medium, where PGCs are viable for several hours, can adhere and change 
the cell shape by sending protrusions. Ongoing work is concentrated on studying the migratory behaviour of germ cells isolated from XGRIP2.1 and $x K I F 13 B$ morphant embryos as well as under chemical inhibition of several signalling pathways. 


\section{Bibliography}

Allen, L., Kloc, M., and Etkin, L. D. (2003). Identification and characterization of the Xlsirt cis-acting RNA localization element. Differentiation 71, 311-21.

Anderson, R., Copeland, T. K., Scholer, H., Heasman, J., and Wylie, C. (2000). The onset of germ cell migration in the mouse embryo. Mech Dev 91, 61-8.

Anderson, R., Fassler, R., Georges-Labouesse, E., Hynes, R. O., Bader, B. L., Kreidberg, J. A., Schaible, K., Heasman, J., and Wylie, C. (1999). Mouse primordial germ cells lacking beta1 integrins enter the germline but fail to migrate normally to the gonads. Development 126, 1655-64.

Ara, T., Nakamura, Y., Egawa, T., Sugiyama, T., Abe, K., Kishimoto, T., Matsui, Y., and Nagasawa, T. (2003). Impaired colonization of the gonads by primordial germ cells in mice lacking a chemokine, stromal cell-derived factor-1 (SDF-1). Proc Natl Acad Sci U S A 100, 5319-23.

Asaba, N., Hanada, T., Takeuchi, A., and Chishti, A. H. (2003). Direct interaction with a kinesin-related motor mediates transport of mammalian discs large tumor suppressor homologue in epithelial cells. J Biol Chem 278, 8395-400.

Ataman, B., Ashley, J., Gorczyca, D., Gorczyca, M., Mathew, D., Wichmann, C., Sigrist, S. J., and Budnik, V. (2006). Nuclear trafficking of Drosophila Frizzled-2 during synapse development requires the PDZ protein dGRIP. Proc Natl Acad Sci U S A 103, 7841-6.

Bendel-Stenzel, M. R., Gomperts, M., Anderson, R., Heasman, J., and Wylie, C. (2000). The role of cadherins during primordial germ cell migration and early gonad formation in the mouse. Mech Dev 91, 143-52.

Berekelya, L. A., Mikryukov, A. A., Luchinskaya, N. N., Ponomarev, M. B., Woodland, H. R., and Belyavsky, A. V. (2007). The protein encoded by the germ plasm RNA Germes associates with dynein light chains and functions in Xenopus germline development. Differentiation 75, 546-58.

Berekelya, L. A., Ponomarev, M. B., Luchinskaya, N. N., and Belyavsky, A. V. (2003). Xenopus Germes encodes a novel germ plasm-associated transcript. Gene Expr Patterns 3, 521-4.

Berekelya, L. A., Ponomarev, M. B., Mikryukov, A. A., Luchinskaya, N. N., Belyavsky, A. V. (2005). Molecular mechanicmc of germ line cell determination in animals. Molecular Biol. 39, 664-677.

Betley, J. N., Frith, M. C., Graber, J. H., Choo, S., and Deshler, J. O. (2002). A ubiquitous and conserved signal for RNA localization in chordates. Curr Biol 12, 1756-61.

Betley, J. N., Heinrich, B., Vernos, I., Sardet, C., Prodon, F., and Deshler, J. O. (2004). Kinesin II mediates Vg1 mRNA transport in Xenopus oocytes. Curr Biol 14, 219-24.

Bilinski, S. M., Jaglarz, M. K., Szymanska, B., Etkin, L. D., and Kloc, M. (2004). Sm proteins, the constituents of the spliceosome, are components of nuage and mitochondrial cement in Xenopus oocytes. Exp Cell Res 299, 171-8.

Birsoy, B., Berg, L., Williams, P. H., Smith, J. C., Wylie, C. C., Christian, J. L., and Heasman, J. (2005). XPACE4 is a localized pro-protein convertase required for mesoderm induction and the cleavage of specific TGFbeta proteins in Xenopus development. Development 132, 591-602.

Blaser, H., Eisenbeiss, S., Neumann, M., Reichman-Fried, M., Thisse, B., Thisse, C., and Raz, E. (2005). Transition from non-motile behaviour to directed migration during early PGC development in zebrafish. J Cell Sci 118, 4027-38.

Blaser, H., Reichman-Fried, M., Castanon, I., Dumstrei, K., Marlow, F. L., Kawakami, K., SolnicaKrezel, L., Heisenberg, C. P., and Raz, E. (2006). Migration of zebrafish primordial germ cells: a role for myosin contraction and cytoplasmic flow. Dev Cell 11, 613-27.

Boldajipour, B., and Raz, E. (2007). What is left behind--quality control in germ cell migration. Sci STKE 2007, pe16.

Braat, A. K., Speksnijder, J. E., and Zivkovic, D. (1999a). Germ line development in fishes. Int J Dev Biol 43, 745-60.

Braat, A. K., Zandbergen, T., van de Water, S., Goos, H. J., and Zivkovic, D. (1999b). Characterization of zebrafish primordial germ cells: morphology and early distribution of vasa RNA. Dev Dyn 216, 153-67.

Bradford, M. M. (1976). A rapid and sensitive method for the quantitation of microgram quantities of protein utilizing the principle of protein-dye binding. Anal Biochem 72, 248-54. 
Braithwaite, S. P., Xia, H., and Malenka, R. C. (2002). Differential roles for NSF and GRIP/ABP in AMPA receptor cycling. Proc Natl Acad Sci U S A 99, 7096-101.

Braun, M., Wunderlin, M., Spieth, K., Knochel, W., Gierschik, P., and Moepps, B. (2002). Xenopus laevis Stromal cell-derived factor 1: conservation of structure and function during vertebrate development. J Immunol 168, 2340-7.

Brustis, J. J., Cathalot, B., Peyret, D., and Gipouloux, J. D. (1984). Evolution of Xenopus endodermal cells cultured on different extracellular matrix components. Identification of primordial germ cells. Anat Embryol (Berl) 170, 187-96.

Bubunenko, M., Kress, T. L., Vempati, U. D., Mowry, K. L., and King, M. L. (2002). A consensus RNA signal that directs germ layer determinants to the vegetal cortex of Xenopus oocytes. Dev Biol 248, 82-92.

Budnik, V. (1996). Synapse maturation and structural plasticity at Drosophila neuromuscular junctions. Curr Opin Neurobiol 6, 858-67.

Chan, A. P., Kloc, M., Bilinski, S., and Etkin, L. D. (2001). The vegetally localized mRNA fatvg is associated with the germ plasm in the early embryo and is later expressed in the fat body. Mech Dev 100, 137-40.

Chan, A. P., Kloc, M., and Etkin, L. D. (1999). fatvg encodes a new localized RNA that uses a 25nucleotide element (FVLE1) to localize to the vegetal cortex of Xenopus oocytes. Development 126, 4943-53.

Chang, P., Torres, J., Lewis, R. A., Mowry, K. L., Houliston, E., and King, M. L. (2004). Localization of RNAs to the mitochondrial cloud in Xenopus oocytes through entrapment and association with endoplasmic reticulum. Mol Biol Cell 15, 4669-81.

Clark, J. M., Joyce, C. M., and Beardsley, G. P. (1987). Novel blunt-end addition reactions catalyzed by DNA polymerase I of Escherichia coli. J Mol Biol 198, 123-7.

Claussen, M., Horvay, K., and Pieler, T. (2004). Evidence for overlapping, but not identical, protein machineries operating in vegetal RNA localization along early and late pathways in Xenopus oocytes. Development 131, 4263-73.

Claussen, M., and Pieler, T. (2004). Xvelo1 uses a novel 75-nucleotide signal sequence that drives vegetal localization along the late pathway in Xenopus oocytes. Dev Biol 266, 270-84.

Cohen, R. S. (2003). Halo: a guiding light for transport. Curr Biol 13, R869-70.

Colegrove-Otero, L. J., Devaux, A., and Standart, N. (2005). The Xenopus ELAV protein ElrB represses Vg1 mRNA translation during oogenesis. Mol Cell Biol 25, 9028-39.

Collombat, P., Mansouri, A., Hecksher-Sorensen, J., Serup, P., Krull, J., Gradwohl, G., and Gruss, P. (2003). Opposing actions of Arx and Pax4 in endocrine pancreas development. Genes Dev 17, 2591-603.

Condeelis, J., and Singer, R. H. (2005). How and why does beta-actin mRNA target? Biol Cell 97, 97110.

Cosma, M. P. (2004). Daughter-specific repression of Saccharomyces cerevisiae HO: Ash1 is the commander. EMBO Rep 5, 953-7.

Cote, C. A., Gautreau, D., Denegre, J. M., Kress, T. L., Terry, N. A., and Mowry, K. L. (1999). A Xenopus protein related to hnRNP I has a role in cytoplasmic RNA localization. Mol Cell 4, 4317.

Czaplinski, K., Kocher, T., Schelder, M., Segref, A., Wilm, M., and Mattaj, I. W. (2005). Identification of 40LoVe, a Xenopus hnRNP D family protein involved in localizing a TGF-beta-related mRNA during oogenesis. Dev Cell 8, 505-15.

Czaplinski, K., and Singer, R. H. (2006). Pathways for mRNA localization in the cytoplasm. Trends Biochem Sci 31, 687-93.

Daniels, D. L., Cohen, A. R., Anderson, J. M., and Brunger, A. T. (1998). Crystal structure of the hCASK PDZ domain reveals the structural basis of class II PDZ domain target recognition. Nat Struct Biol 5, 317-25.

De Felici, M. (2000). Regulation of primordial germ cell development in the mouse. Int J Dev Biol 44, 575-80.

De Felici, M., and McLaren, A. (1983). In vitro culture of mouse primordial germ cells. Exp Cell Res 144, 417-27. 
De, J., Lai, W. S., Thorn, J. M., Goldsworthy, S. M., Liu, X., Blackwell, T. K., and Blackshear, P. J. (1999). Identification of four CCCH zinc finger proteins in Xenopus, including a novel vertebrate protein with four zinc fingers and severely restricted expression. Gene 228, 133-45.

Deshler, J. O., Highett, M. I., Abramson, T., and Schnapp, B. J. (1998). A highly conserved RNA-binding protein for cytoplasmic mRNA localization in vertebrates. Curr Biol 8, 489-96.

Deshler, J. O., Highett, M. I., and Schnapp, B. J. (1997). Localization of Xenopus Vg1 mRNA by Vera protein and the endoplasmic reticulum. Science 276, 1128-31.

Doitsidou, M., Reichman-Fried, M., Stebler, J., Koprunner, M., Dorries, J., Meyer, D., Esguerra, C. V., Leung, T., and Raz, E. (2002). Guidance of primordial germ cell migration by the chemokine SDF-1. Cell 111, 647-59.

Dong, H., O'Brien, R. J., Fung, E. T., Lanahan, A. A., Worley, P. F., and Huganir, R. L. (1997). GRIP: a synaptic PDZ domain-containing protein that interacts with AMPA receptors. Nature 386, 27984.

Dower, W. J., Miller, J. F., and Ragsdale, C. W. (1988). High efficiency transformation of E. coli by high voltage electroporation. Nucleic Acids Res 16, 6127-45.

Du, T. G., Schmid, M., and Jansen, R. P. (2007). Why cells move messages: the biological functions of mRNA localization. Semin Cell Dev Biol 18, 171-7.

Dumstrei, K., Mennecke, R., and Raz, E. (2004). Signaling pathways controlling primordial germ cell migration in zebrafish. $J$ Cell Sci 117, 4787-95.

Ephrussi, A., Dickinson, L. K., and Lehmann, R. (1991). Oskar organizes the germ plasm and directs localization of the posterior determinant nanos. Cell 66, 37-50.

Ephrussi, A., and St Johnston, D. (2004). Seeing is believing: the bicoid morphogen gradient matures. Cell 116, 143-52.

Forristall, C., Pondel, M., Chen, L., and King, M. L. (1995). Patterns of localization and cytoskeletal association of two vegetally localized RNAs, Vg1 and Xcat-2. Development 121, 201-8.

Fukui, A., Goto, T., Kitamoto, J., Homma, M., and Asashima, M. (2007). SDF-1 alpha regulates mesendodermal cell migration during frog gastrulation. Biochem Biophys Res Commun 354, 4727.

Hamburger, V. a. H., H. L. (1951). A series of normal stages in development of the chick. J. Morphol. 88, 49-92.

Hanada, T., Lin, L., Tibaldi, E. V., Reinherz, E. L., and Chishti, A. H. (2000). GAKIN, a novel kinesinlike protein associates with the human homologue of the Drosophila discs large tumor suppressor in T lymphocytes. $J$ Biol Chem 275, $28774-84$.

Harland, R. M. (1991). In situ hybridization: an improved whole-mount method for Xenopus embryos. Methods Cell Biol 36, 685-95.

Havin, L., Git, A., Elisha, Z., Oberman, F., Yaniv, K., Schwartz, S. P., Standart, N., and Yisraeli, J. K. (1998). RNA-binding protein conserved in both microtubule- and microfilament- based RNA localization. Genes Dev 12, 1593-8.

Heasman, J., Hynes, R. O., Swan, A. P., Thomas, V., and Wylie, C. C. (1981). Primordial germ cells of Xenopus embryos: the role of fibronectin in their adhesion during migration. Cell 27, 437-47.

Heasman, J., Quarmby, J., and Wylie, C. C. (1984). The mitochondrial cloud of Xenopus oocytes: the source of germinal granule material. Dev Biol 105, 458-69.

Heasman, J., and Wylie, C. C. (1981). Contact relations and guidance of primordial germ cells on their migratory route in embryos of Xenopus laevis. Proc R Soc Lond B Biol Sci 213, 41-58.

Hensey, C., and Gautier, J. (1997). A developmental timer that regulates apoptosis at the onset of gastrulation. Mech Dev 69, 183-95.

Hirokawa, N., and Takemura, R. (2005). Molecular motors and mechanisms of directional transport in neurons. Nat Rev Neurosci 6, 201-14.

Hollemann, T., Panitz, F., and Pieler, T. (1999). In situ Hybridization Techniques with Xenopus Embryos. In "A Comparative Methods Approach to the Study of Oocytes and Embryos" (J. D. Richter, Ed.), pp. 279-290. Oxford University Press Inc., Oxford.

Holt, J. E., Jackson, A., Roman, S. D., Aitken, R. J., Koopman, P., and McLaughlin, E. A. (2006). CXCR4/SDF1 interaction inhibits the primordial to primary follicle transition in the neonatal mouse ovary. Dev Biol 293, 449-60.

Hopwood, N. D., Pluck, A., and Gurdon, J. B. (1989). MyoD expression in the forming somites is an early response to mesoderm induction in Xenopus embryos. Embo J 8, 3409-17. 
Horiguchi, K., Hanada, T., Fukui, Y., and Chishti, A. H. (2006). Transport of PIP3 by GAKIN, a kinesin3 family protein, regulates neuronal cell polarity. J Cell Biol 174, 425-36.

Horvay, K., Claussen, M., Katzer, M., Landgrebe, J., and Pieler, T. (2006). Xenopus Dead end mRNA is a localized maternal determinant that serves a conserved function in germ cell development. Dev Biol 291, 1-11.

Houston, D. W., and King, M. L. (2000a). A critical role for Xdazl, a germ plasm-localized RNA, in the differentiation of primordial germ cells in Xenopus. Development 127, 447-56.

Houston, D. W., and King, M. L. (2000b). Germ plasm and molecular determinants of germ cell fate. Curr Top Dev Biol 50, 155-81.

Houston, D. W., Zhang, J., Maines, J. Z., Wasserman, S. A., and King, M. L. (1998). A Xenopus DAZlike gene encodes an RNA component of germ plasm and is a functional homologue of Drosophila boule. Development 125, 171-80.

Hudson, C., and Woodland, H. R. (1998). Xpat, a gene expressed specifically in germ plasm and primordial germ cells of Xenopus laevis. Mech Dev 73, 159-68.

Hudson, J. W., Alarcon, V. B., and Elinson, R. P. (1996). Identification of new localized RNAs in the Xenopus oocyte by differential display PCR. Dev Genet 19, 190-8.

Ikenishi, K., Nishiumi, F., and Komiya, T. (2006). The Xdsg protein in presumptive primordial germ cells (pPGCs) is essential to their differentiation into PGCs in Xenopus. Dev Biol 297, 483-92.

Ikenishi, K., Ohno, T., and Komiya, T. (2007). Ectopic germline cells in embryos of Xenopus laevis. Dev Growth Differ 49, 561-70.

Ikenishi, K., Okuda, T., and Nakazato, S. (1984). Differentiation of presumptive primordial germ cell (pPGC)-like cells in explants into PGCs in experimental tadpoles. Dev Biol 103, 258-62.

Ikenishi, K., and Tanaka, T. S. (1997). Involvement of the protein of Xenopus vasa homolog (Xenopus vasa-like gene 1, XVLG1) in the differentiation of primordial germ cells. Dev Growth Differ 39, 625-33.

Im, Y. J., Park, S. H., Rho, S. H., Lee, J. H., Kang, G. B., Sheng, M., Kim, E., and Eom, S. H. (2003). Crystal structure of GRIP1 PDZ6-peptide complex reveals the structural basis for class II PDZ target recognition and PDZ domain-mediated multimerization. J Biol Chem 278, 8501-7.

Ishikawa, K., Nagase, T., Suyama, M., Miyajima, N., Tanaka, A., Kotani, H., Nomura, N., and Ohara, O. (1998). Prediction of the coding sequences of unidentified human genes. X. The complete sequences of 100 new cDNA clones from brain which can code for large proteins in vitro. DNA Res 5, 169-76.

Jaglarz, M. K., and Howard, K. R. (1994). Primordial germ cell migration in Drosophila melanogaster is controlled by somatic tissue. Development 120, 83-9.

Jenkins, A. B., McCaffery, J. M., and Van Doren, M. (2003). Drosophila E-cadherin is essential for proper germ cell-soma interaction during gonad morphogenesis. Development 130, 4417-26.

Jones, T. L., Karavanova, I., Chong, L., Zhou, R. P., and Daar, I. O. (1997). Identification of XLerk, an Eph family ligand regulated during mesoderm induction and neurogenesis in Xenopus laevis. Oncogene 14, 2159-66.

Jongens, T. A., Ackerman, L. D., Swedlow, J. R., Jan, L. Y., and Jan, Y. N. (1994). Germ cell-less encodes a cell type-specific nuclear pore-associated protein and functions early in the germ-cell specification pathway of Drosophila. Genes Dev 8, 2123-36.

Kanamarlapudi, V. (2005). Centaurin-alpha1 and KIF13B kinesin motor protein interaction in ARF6 signalling. Biochem Soc Trans 33, 1279-81.

Kaneshiro, K., Miyauchi, M., Tanigawa, Y., Ikenishi, K., and Komiya, T. (2007). The mRNA coding for Xenopus glutamate receptor interacting protein 2 (XGRIP2) is maternally transcribed, transported through the late pathway and localized to the germ plasm. Biochem Biophys Res Commun 355, 902-6.

Kawamura, K., Takano, K., Suetsugu, S., Kurisu, S., Yamazaki, D., Miki, H., Takenawa, T., and Endo, T. (2004). N-WASP and WAVE2 acting downstream of phosphatidylinositol 3-kinase are required for myogenic cell migration induced by hepatocyte growth factor. J Biol Chem 279, 54862-71.

Keizer-Gunnink, I., Kortholt, A., and Van Haastert, P. J. (2007). Chemoattractants and chemorepellents act by inducing opposite polarity in phospholipase C and PI3-kinase signaling. J Cell Biol 177, 579-85.

Kim, P. M., Aizawa, H., Kim, P. S., Huang, A. S., Wickramasinghe, S. R., Kashani, A. H., Barrow, R. K., Huganir, R. L., Ghosh, A., and Snyder, S. H. (2005). Serine racemase: activation by glutamate 
neurotransmission via glutamate receptor interacting protein and mediation of neuronal migration. Proc Natl Acad Sci U S A 102, 2105-10.

King, M. L. (1995). mRNA localization during frog oogenesis. In "'Localized RNAs"" (H. D. Lipshitz, Ed.), pp. 137-148. Landes Publishing, Austin, TX.

King, M. L., Messitt, T. J., and Mowry, K. L. (2005). Putting RNAs in the right place at the right time: RNA localization in the frog oocyte. Biol Cell 97, 19-33.

Kirilenko, P., Weierud, F. K., Zorn, A. M., and Woodland, H. R. (2007). The efficiency of Xenopus primordial germ cell migration depends on the germplasm mRNA encoding the PDZ domain protein Grip2. Differentiation.

Klisch, T. J., Souopgui, J., Juergens, K., Rust, B., Pieler, T., and Henningfeld, K. A. (2006). Mxi1 is essential for neurogenesis in Xenopus and acts by bridging the pan-neural and proneural genes. Dev Biol 292, 470-85.

Kloc, M., Bilinski, S., Dougherty, M. T., Brey, E. M., and Etkin, L. D. (2004a). Formation, architecture and polarity of female germline cyst in Xenopus. Dev Biol 266, 43-61.

Kloc, M., Bilinski, S., and Etkin, L. D. (2004b). The Balbiani body and germ cell determinants: 150 years later. Curr Top Dev Biol 59, 1-36.

Kloc, M., Bilinski, S., Pui-Yee Chan, A., and Etkin, L. D. (2000). The targeting of Xcat2 mRNA to the germinal granules depends on a cis- acting germinal granule localization element within the 3'UTR. Dev Biol 217, 221-9.

Kloc, M., Dougherty, M. T., Bilinski, S., Chan, A. P., Brey, E., King, M. L., Patrick, C. W., Jr., and Etkin, L. D. (2002a). Three-Dimensional Ultrastructural Analysis of RNA Distribution within Germinal Granules of Xenopus. Dev Biol 241, 79-93.

Kloc, M., and Etkin, L. D. (1994). Delocalization of Vg1 mRNA from the vegetal cortex in Xenopus oocytes after destruction of Xlsirt RNA. Science 265, 1101-3.

Kloc, M., and Etkin, L. D. (1995). Two distinct pathways for the localization of RNAs at the vegetal cortex in Xenopus oocytes. Development 121, 287-97.

Kloc, M., and Etkin, L. D. (1998). Apparent continuity between the messenger transport organizer and late RNA localization pathways during oogenesis in Xenopus. Mech Dev 73, 95-106.

Kloc, M., and Etkin, L. D. (2005). RNA localization mechanisms in oocytes. J Cell Sci 118, 269-82.

Kloc, M., Larabell, C., Chan, A. P., and Etkin, L. D. (1998). Contribution of METRO pathway localized molecules to the organization of the germ cell lineage. Mech Dev 75, 81-93.

Kloc, M., Larabell, C., and Etkin, L. D. (1996). Elaboration of the messenger transport organizer pathway for localization of RNA to the vegetal cortex of Xenopus oocytes. Dev Biol 180, 119-30.

Kloc, M., Spohr, G., and Etkin, L. D. (1993). Translocation of repetitive RNA sequences with the germ plasm in Xenopus oocytes. Science 262, 1712-4.

Kloc, M., Zearfoss, N. R., and Etkin, L. D. (2002b). Mechanisms of subcellular mRNA localization. Cell 108, 533-44.

Knaut, H., Werz, C., Geisler, R., and Nusslein-Volhard, C. (2003). A zebrafish homologue of the chemokine receptor Cxcr4 is a germ-cell guidance receptor. Nature 421, 279-82.

Knecht, H., Martius, F., Bachmann, E., Hoffman, T., Zimmermann, D. R., Rothenberger, S., Sandvej, K., Wegmann, W., Hurwitz, N., Odermatt, B. F., and et al. (1995). A deletion mutant of the LMP1 oncogene of Epstein-Barr virus is associated with evolution of angioimmunoblastic lymphadenopathy into B immunoblastic lymphoma. Leukemia 9, 458-65.

Komiya, T., Itoh, K., Ikenishi, K., and Furusawa, M. (1994). Isolation and characterization of a novel gene of the DEAD box protein family which is specifically expressed in germ cells of Xenopus laevis. Dev Biol 162, 354-63.

Kress, T. L., Yoon, Y. J., and Mowry, K. L. (2004). Nuclear RNP complex assembly initiates cytoplasmic RNA localization. J Cell Biol 165, 203-11.

Kroll, T. T., Zhao, W. M., Jiang, C., and Huber, P. W. (2002). A homolog of FBP2/KSRP binds to localized mRNAs in Xenopus oocytes. Development 129, 5609-19.

Ku, M., and Melton, D. A. (1993). Xwnt-11: a maternally expressed Xenopus wnt gene. Development 119, 1161-73.

Kwon, S., Abramson, T., Munro, T. P., John, C. M., Kohrmann, M., and Schnapp, B. J. (2002). UUCACand Vera-Dependent Localization of VegT RNA in Xenopus Oocytes. Curr Biol 12, 558-64.

Laemmli, U. K. (1970). Cleavage of structural proteins during the assembly of the head of bacteriophage T4. Nature 227, 680-5. 
Lawson, K. A., Dunn, N. R., Roelen, B. A., Zeinstra, L. M., Davis, A. M., Wright, C. V., Korving, J. P., and Hogan, B. L. (1999). Bmp4 is required for the generation of primordial germ cells in the mouse embryo. Genes Dev 13, 424-36.

Lawson, K. A., and Hage, W. J. (1994). Clonal analysis of the origin of primordial germ cells in the mouse. Ciba Found Symp 182, 68-84; discussion 84-91.

Lewis, R. A., Kress, T. L., Cote, C. A., Gautreau, D., Rokop, M. E., and Mowry, K. L. (2004). Conserved and clustered RNA recognition sequences are a critical feature of signals directing RNA localization in Xenopus oocytes. Mech Dev 121, 101-9.

Li, J., Xia, F., and Li, W. X. (2003). Coactivation of STAT and Ras is required for germ cell proliferation and invasive migration in Drosophila. Dev Cell 5, 787-98.

Loovers, H. M., Postma, M., Keizer-Gunnink, I., Huang, Y. E., Devreotes, P. N., and van Haastert, P. J. (2006). Distinct roles of PI(3,4,5)P3 during chemoattractant signaling in Dictyostelium: a quantitative in vivo analysis by inhibition of PI3-kinase. Mol Biol Cell 17, 1503-13.

Lustig, K. D., Kroll, K. L., Sun, E. E., and Kirschner, M. W. (1996). Expression cloning of a Xenopus Trelated gene (Xombi) involved in mesodermal patterning and blastopore lip formation. Development 122, 4001-12.

MacArthur, H., Houston, D. W., Bubunenko, M., Mosquera, L., and King, M. L. (2000). DEADSouth is a germ plasm specific DEAD-box RNA helicase in Xenopus related to eIF4A. Mech Dev 95, 2915.

Machado, R. J., Moore, W., Hames, R., Houliston, E., Chang, P., King, M. L., and Woodland, H. R. (2005). Xenopus Xpat protein is a major component of germ plasm and may function in its organisation and positioning. Dev Biol 287, 289-300.

Mahowald, A. P. (1968). Polar granules of Drosophila. II. Ultrastructural changes during early embryogenesis. J Exp Zool 167, 237-61.

Mahowald, T. A., Noltmann, E. A., and Kuby, S. A. (1962). Studies on adenosine triphosphate transphosphorylases. III. Inhibition reactions. J Biol Chem 237, 1535-48.

Mandel, M., and Higa, A. (1970). Calcium-dependent bacteriophage DNA infection. J Mol Biol 53, 15962.

Martinho, R. G., Kunwar, P. S., Casanova, J., and Lehmann, R. (2004). A noncoding RNA is required for the repression of RNApolII-dependent transcription in primordial germ cells. Curr Biol 14, 15965.

Megosh, H. B., Cox, D. N., Campbell, C., and Lin, H. (2006). The role of PIWI and the miRNA machinery in Drosophila germline determination. Curr Biol 16, 1884-94.

Melton, D. A. (1987). Translocation of a localized maternal mRNA to the vegetal pole of Xenopus oocytes. Nature 328, 80-2.

Miki, H., Setou, M., Kaneshiro, K., and Hirokawa, N. (2001). All kinesin superfamily protein, KIF, genes in mouse and human. Proc Natl Acad Sci U S A 98, 7004-11.

Ming, G., Song, H., Berninger, B., Inagaki, N., Tessier-Lavigne, M., and Poo, M. (1999). Phospholipase C-gamma and phosphoinositide 3-kinase mediate cytoplasmic signaling in nerve growth cone guidance. Neuron 23, 139-48.

Moepps, B., Braun, M., Knopfle, K., Dillinger, K., Knochel, W., and Gierschik, P. (2000). Characterization of a Xenopus laevis CXC chemokine receptor 4: implications for hematopoietic cell development in the vertebrate embryo. Eur J Immunol 30, 2924-34.

Molyneaux, K., and Wylie, C. (2004). Primordial germ cell migration. Int J Dev Biol 48, 537-44.

Molyneaux, K. A., Stallock, J., Schaible, K., and Wylie, C. (2001). Time-lapse analysis of living mouse germ cell migration. Dev Biol 240, 488-98.

Molyneaux, K. A., Wang, Y., Schaible, K., and Wylie, C. (2004). Transcriptional profiling identifies genes differentially expressed during and after migration in murine primordial germ cells. Gene Expr Patterns 4, 167-81.

Molyneaux, K. A., Zinszner, H., Kunwar, P. S., Schaible, K., Stebler, J., Sunshine, M. J., O'Brien, W., Raz, E., Littman, D., Wylie, C., and Lehmann, R. (2003). The chemokine SDF1/CXCL12 and its receptor CXCR4 regulate mouse germ cell migration and survival. Development 130, 4279-86.

Moores, C. A., and Milligan, R. A. (2006). Lucky 13-microtubule depolymerisation by kinesin-13 motors. J Cell Sci 119, 3905-13. 
Mosquera, L., Forristall, C., Zhou, Y., and King, M. L. (1993). A mRNA localized to the vegetal cortex of Xenopus oocytes encodes a protein with a nanos-like zinc finger domain. Development 117, 377-86.

Mowry, K. L. (1996). Complex formation between stage-specific oocyte factors and a Xenopus mRNA localization element. Proc Natl Acad Sci U S A 93, 14608-13.

Mowry, K. L., and Melton, D. A. (1992). Vegetal messenger RNA localization directed by a 340-nt RNA sequence element in Xenopus oocytes. Science 255, 991-4.

Mullis, K., Faloona, F., Scharf, S., Saiki, R., Horn, G., and Erlich, H. (1986). Specific enzymatic amplification of DNA in vitro: the polymerase chain reaction. Cold Spring Harb Symp Quant Biol 51 Pt 1, 263-73.

Nakamura, M., Kuwana, T., Miyayama, Y., and Fujimoto, T. (1988). Extragonadal distribution of primordial germ cells in the early chick embryo. Anat Rec 222, 90-4.

Nieuwkoop, P. D., and Sutasurya, L. A. (1976). Embryological evidence for a possible polyphyletic origin of the recent amphibians. J Embryol Exp Morphol 35, 159-67.

Oberman, F., Rand, K., Maizels, Y., Rubinstein, A. M., and Yisraeli, J. K. (2007). VICKZ proteins mediate cell migration via their RNA binding activity. Rna 13, 1558-69.

Osten, P., Khatri, L., Perez, J. L., Kohr, G., Giese, G., Daly, C., Schulz, T. W., Wensky, A., Lee, L. M., and Ziff, E. B. (2000). Mutagenesis reveals a role for ABP/GRIP binding to GluR2 in synaptic surface accumulation of the AMPA receptor. Neuron 27, 313-25.

Pannese, M., Cagliani, R., Pardini, C. L., and Boncinelli, E. (2000). Xotx1 maternal transcripts are vegetally localized in Xenopus laevis oocytes. Mech Dev 90, 111-4.

Petitte, J. N., Karagenc, L., and Ginsburg, M. (1997). The origin of the avian germ line and transgenesis in birds. Poult Sci 76, 1084-92.

Pfeiffer, D. C., and Gard, D. L. (1999). Microtubules in Xenopus oocytes are oriented with their minusends towards the cortex. Cell Motil Cytoskeleton 44, 34-43.

Ramasamy, S., Wang, H., Quach, H. N., and Sampath, K. (2006). Zebrafish Staufen1 and Staufen2 are required for the survival and migration of primordial germ cells. Dev Biol 292, 393-406.

Rebagliati, M. R., Weeks, D. L., Harvey, R. P., and Melton, D. A. (1985). Identification and cloning of localized maternal RNAs from Xenopus eggs. Cell 42, 769-77.

Reichman-Fried, M., Minina, S., and Raz, E. (2004). Autonomous modes of behaviour in primordial germ cell migration. Dev Cell 6, 589-96.

Renault, A. D., Sigal, Y. J., Morris, A. J., and Lehmann, R. (2004). Soma-germ line competition for lipid phosphate uptake regulates germ cell migration and survival. Science 305, 1963-6.

Richardson, J. C., Gatherer, D., and Woodland, H. R. (1995). Developmental effects of over-expression of normal and mutated forms of a Xenopus NF-kappa B homologue. Mech Dev 52, 165-77.

Ridley, A. J., Schwartz, M. A., Burridge, K., Firtel, R. A., Ginsberg, M. H., Borisy, G., Parsons, J. T., and Horwitz, A. R. (2003). Cell migration: integrating signals from front to back. Science 302, 17049.

Robb, D. L., Heasman, J., Raats, J., and Wylie, C. (1996). A kinesin-like protein is required for germ plasm aggregation in Xenopus. Cell 87, 823-31.

Rupp, R. A., Snider, L., and Weintraub, H. (1994). Xenopus embryos regulate the nuclear localization of XMyoD. Genes Dev 8, 1311-23.

Sambrook J., F. E. F., Maniatis T. (1989). Molecular cloning. A laboratory manual, $2^{\mathrm{d}}$ edition. Cold Spring Harbour. Cold Spring Harbour Laboratory Press.

Sanger, F., Nicklen, S., and Coulson, A. R. (1977). DNA sequencing with chain-terminating inhibitors. Proc Natl Acad Sci U S A 74, 5463-7.

Santos, A. C., and Lehmann, R. (2004). Germ cell specification and migration in Drosophila and beyond. Curr Biol 14, R578-89.

Schnorrer, F., Kalchhauser, I., and Dickson, B. J. (2007). The transmembrane protein Kon-tiki couples to Dgrip to mediate myotube targeting in Drosophila. Dev Cell 12, 751-66.

Setou, M., Seog, D. H., Tanaka, Y., Kanai, Y., Takei, Y., Kawagishi, M., and Hirokawa, N. (2002). Glutamate-receptor-interacting protein GRIP1 directly steers kinesin to dendrites. Nature 417, 83-7.

Sharp, P. A., Sugden, B., and Sambrook, J. (1973). Detection of two restriction endonuclease activities in Haemophilus parainfluenzae using analytical agarose--ethidium bromide electrophoresis. Biochemistry 12, 3055-63. 
Sheng, M., and Sala, C. (2001). PDZ domains and the organization of supramolecular complexes. Annu Rev Neurosci 24, 1-29.

Simmonds, A. J., dosSantos, G., Livne-Bar, I., and Krause, H. M. (2001). Apical localization of wingless transcripts is required for wingless signaling. Cell 105, 197-207.

Sottong, P., Harris, R., Graham, B., Rupp, B., Bell, C., Conlon, T., and Klecker, J. (1976). Purification of herpesvirus nucleocapsids by fluorocarbon extraction. Microbios 16, 105-10.

Srivastava, S., Osten, P., Vilim, F. S., Khatri, L., Inman, G., States, B., Daly, C., DeSouza, S., Abagyan, R., Valtschanoff, J. G., Weinberg, R. J., and Ziff, E. B. (1998). Novel anchorage of GluR2/3 to the postsynaptic density by the AMPA receptor-binding protein ABP. Neuron 21, 581-91.

St Johnston, D. (2005). Moving messages: the intracellular localization of mRNAs. Nat Rev Mol Cell Biol 6, 363-75.

St Johnston, D., Beuchle, D., and Nusslein-Volhard, C. (1991). Staufen, a gene required to localize maternal RNAs in the Drosophila egg. Cell 66, 51-63.

Stallock, J., Molyneaux, K., Schaible, K., Knudson, C. M., and Wylie, C. (2003). The pro-apoptotic gene $\mathrm{Bax}$ is required for the death of ectopic primordial germ cells during their migration in the mouse embryo. Development 130, 6589-97.

Starz-Gaiano, M., Cho, N. K., Forbes, A., and Lehmann, R. (2001). Spatially restricted activity of a Drosophila lipid phosphatase guides migrating germ cells. Development 128, 983-91.

Stebler, J., Spieler, D., Slanchev, K., Molyneaux, K. A., Richter, U., Cojocaru, V., Tarabykin, V., Wylie, C., Kessel, M., and Raz, E. (2004). Primordial germ cell migration in the chick and mouse embryo: the role of the chemokine SDF-1/CXCL12. Dev Biol 272, 351-61.

Stennard, F., Carnac, G., and Gurdon, J. B. (1996). The Xenopus T-box gene, Antipodean, encodes a vegetally localised maternal mRNA and can trigger mesoderm formation. Development 122, 4179-88.

Swan, L. E., Schmidt, M., Schwarz, T., Ponimaskin, E., Prange, U., Boeckers, T., Thomas, U., and Sigrist, S. J. (2006). Complex interaction of Drosophila GRIP PDZ domains and Echinoid during muscle morphogenesis. Embo J 25, 3640-51.

Swan, L. E., Wichmann, C., Prange, U., Schmid, A., Schmidt, M., Schwarz, T., Ponimaskin, E., Madeo, F., Vorbruggen, G., and Sigrist, S. J. (2004). A glutamate receptor-interacting protein homolog organizes muscle guidance in Drosophila. Genes Dev 18, 223-37.

Swift, C. H. (1914). Origin and early history of primordial germ cells in the chick. Am. J. Anat. 15, 483516.

Takamiya, K., Kostourou, V., Adams, S., Jadeja, S., Chalepakis, G., Scambler, P. J., Huganir, R. L., and Adams, R. H. (2004). A direct functional link between the multi-PDZ domain protein GRIP1 and the Fraser syndrome protein Fras1. Nat Genet 36, 172-7.

Takenawa, T., and Suetsugu, S. (2007). The WASP-WAVE protein network: connecting the membrane to the cytoskeleton. Nat Rev Mol Cell Biol 8, 37-48.

Takeuchi, Y., Molyneaux, K., Runyan, C., Schaible, K., and Wylie, C. (2005). The roles of FGF signaling in germ cell migration in the mouse. Development 132, 5399-409.

Tan, D., Asenjo, A. B., Mennella, V., Sharp, D. J., and Sosa, H. (2006). Kinesin-13s form rings around microtubules. J Cell Biol 175, 25-31.

Tarbashevich, K., Koebernick, K., and Pieler, T. (2007). XGRIP2.1 is encoded by a vegetally localizing, maternal mRNA and functions in germ cell development and anteroposterior PGC positioning in Xenopus laevis. Dev Biol.

Vagin, V. V., Sigova, A., Li, C., Seitz, H., Gvozdev, V., and Zamore, P. D. (2006). A distinct small RNA pathway silences selfish genetic elements in the germline. Science 313, 320-4.

Van Doren, M., Broihier, H. T., Moore, L. A., and Lehmann, R. (1998). HMG-CoA reductase guides migrating primordial germ cells. Nature 396, 466-9.

Van Doren, M., Mathews, W. R., Samuels, M., Moore, L. A., Broihier, H. T., and Lehmann, R. (2003). fear of intimacy encodes a novel transmembrane protein required for gonad morphogenesis in Drosophila. Development 130, 2355-64.

Van Keymeulen, A., Wong, K., Knight, Z. A., Govaerts, C., Hahn, K. M., Shokat, K. M., and Bourne, H. R. (2006). To stabilize neutrophil polarity, PIP3 and Cdc42 augment RhoA activity at the back as well as signals at the front. $J$ Cell Biol 174, 437-45.

Venkateswarlu, K., Hanada, T., and Chishti, A. H. (2005). Centaurin-alpha1 interacts directly with kinesin motor protein KIF13B. J Cell Sci 118, 2471-84. 
Wang, C., and Lehmann, R. (1991). Nanos is the localized posterior determinant in Drosophila. Cell 66, 637-47.

Weeks, D. L., and Melton, D. A. (1987). A maternal mRNA localized to the animal pole of Xenopus eggs encodes a subunit of mitochondrial ATPase. Proc Natl Acad Sci U S A 84, 2798-802.

Weidinger, G., Stebler, J., Slanchev, K., Dumstrei, K., Wise, C., Lovell-Badge, R., Thisse, C., Thisse, B., and Raz, E. (2003). dead end, a novel vertebrate germ plasm component, is required for zebrafish primordial germ cell migration and survival. Curr Biol 13, 1429-34.

Weidinger, G., Wolke, U., Koprunner, M., Klinger, M., and Raz, E. (1999). Identification of tissues and patterning events required for distinct steps in early migration of zebrafish primordial germ cells. Development 126, 5295-307.

Weidinger, G., Wolke, U., Koprunner, M., Thisse, C., Thisse, B., and Raz, E. (2002). Regulation of zebrafish primordial germ cell migration by attraction towards an intermediate target. Development 129, 25-36.

Wessely, O., and De Robertis, E. M. (2000). The Xenopus homologue of Bicaudal-C is a localized maternal mRNA that can induce endoderm formation. Development 127, 2053-62.

Whitington, P. M., and Dixon, K. E. (1975). Quantitative studies of germ plasm and germ cells during early embryogenesis of Xenopus laevis. J Embryol Exp Morphol 33, 57-74.

Williamson, A., and Lehmann, R. (1996). Germ cell development in Drosophila. Annu Rev Cell Dev Biol 12, 365-91.

Wilson, C., Cross, G. S., and Woodland, H. R. (1986). Tissue-specific expression of actin genes injected into Xenopus embryos. Cell 47, 589-99.

Woods, D. F., and Bryant, P. J. (1991). The discs-large tumor suppressor gene of Drosophila encodes a guanylate kinase homolog localized at septate junctions. Cell 66, 451-64.

Wylie, C. (2000). Germ cells. Curr Opin Genet Dev 10, 410-3.

Wylie, C. C., Holwill, S., O'Driscoll, M., Snape, A., and Heasman, J. (1985). Germ plasm and germ cell determination in Xenopus laevis as studied by cell transplantation analysis. Cold Spring Harb Symp Quant Biol 50, 37-43.

Wyszynski, M., Kim, E., Dunah, A. W., Passafaro, M., Valtschanoff, J. G., Serra-Pages, C., Streuli, M., Weinberg, R. J., and Sheng, M. (2002). Interaction between GRIP and liprin-alpha/SYD2 is required for AMPA receptor targeting. Neuron 34, 39-52.

Wyszynski, M., Valtschanoff, J. G., Naisbitt, S., Dunah, A. W., Kim, E., Standaert, D. G., Weinberg, R., and Sheng, M. (1999). Association of AMPA receptors with a subset of glutamate receptorinteracting protein in vivo. $J$ Neurosci 19, 6528-37.

Xia, J., Chung, H. J., Wihler, C., Huganir, R. L., and Linden, D. J. (2000). Cerebellar long-term depression requires PKC-regulated interactions between GluR2/3 and PDZ domain-containing proteins. Neuron 28, 499-510.

Xu, X., Li, W. E., Huang, G. Y., Meyer, R., Chen, T., Luo, Y., Thomas, M. P., Radice, G. L., and Lo, C. W. (2001). Modulation of mouse neural crest cell motility by N-cadherin and connexin 43 gap junctions. J Cell Biol 154, 217-30.

Yamada, K. H., Hanada, T., and Chishti, A. H. (2007). The effector domain of human Dlg tumor suppressor acts as a switch that relieves autoinhibition of kinesin-3 motor GAKIN/KIF13B. Biochemistry 46, 10039-45.

Yamakita, S., Mishima, Y., and Ikenishi, K. (2004). A novel gene, the protein product of which is mainly expressed in germline cells and in the dorsal structures of Xenopus. Dev Genes Evol 214, 89-95.

Ying, Y., Liu, X. M., Marble, A., Lawson, K. A., and Zhao, G. Q. (2000). Requirement of Bmp8b for the generation of primordial germ cells in the mouse. Mol Endocrinol 14, 1053-63.

Ying, Y., and Zhao, G. Q. (2001). Cooperation of endoderm-derived BMP2 and extraembryonic ectoderm-derived BMP4 in primordial germ cell generation in the mouse. Dev Biol 232, 484-92.

Yisraeli, J. K. (2005). VICKZ proteins: a multi-talented family of regulatory RNA-binding proteins. Biol Cell 97, 87-96.

Yoon, C., Kawakami, K., and Hopkins, N. (1997). Zebrafish vasa homologue RNA is localized to the cleavage planes of 2- and 4-cell-stage embryos and is expressed in the primordial germ cells. Development 124, 3157-65.

Yoon, Y. J., and Mowry, K. L. (2004). Xenopus Staufen is a component of a ribonucleoprotein complex containing Vg1 RNA and kinesin. Development 131, 3035-45. 
Zearfoss, N. R., Chan, A. P., Kloc, M., Allen, L. H., and Etkin, L. D. (2003). Identification of new Xlsirt family members in the Xenopus laevis oocyte. Mech Dev 120, 503-9.

Zearfoss, N. R., Chan, A. P., Wu, C. F., Kloc, M., and Etkin, L. D. (2004). Hermes is a localized factor regulating cleavage of vegetal blastomeres in Xenopus laevis. Dev Biol 267, 60-71.

Zhang, J., and King, M. L. (1996). Xenopus VegT RNA is localized to the vegetal cortex during oogenesis and encodes a novel T-box transcription factor involved in mesodermal patterning. Development 122, 4119-29.

Zhang, N., Zhang, J., Purcell, K. J., Cheng, Y., and Howard, K. (1997). The Drosophila protein Wunen repels migrating germ cells. Nature $\mathbf{3 8 5}, \mathbf{6 4 - 7}$.

Zhao, W. M., Jiang, C., Kroll, T. T., and Huber, P. W. (2001). A proline-rich protein binds to the localization element of Xenopus Vg1 mRNA and to ligands involved in actin polymerization. Embo J 20, 2315-25.

Zhou, Y., and King, M. L. (1996). Localization of Xcat-2 RNA, a putative germ plasm component, to the mitochondrial cloud in Xenopus stage I oocytes. Development 122, 2947-53.

Zhou, Y., Zhang, J., and King, M. L. (2003). Xenopus autosomal recessive hypercholesterolemia protein couples lipoprotein receptors with the AP-2 complex in oocytes and embryos and is required for vitellogenesis. J Biol Chem 278, 44584-92.

Zhou, Y., Zhang, J., and King, M. L. (2004). Polarized distribution of mRNAs encoding a putative LDL receptor adaptor protein, xARH (autosomal recessive hypercholesterolemia) in Xenopus oocytes. Mech Dev 121, 1249-58. 


\section{Appendix}

50

XGRIP1 ....MFINE YFQSLAARGF QGVDEGPYTK SSTPSKAPDG ALAVRRQSIT

rGRIP1 ..MIAVSFKC RCQILRRL.. . TKDESPYTK SASQTKPPDG ALAVRRQSIP

XGRIP2.1 MHFFQTILRW KTAKGQKSVT FKKDDGPYSK GNKDPAGNDL VLVSRRQSIP

rGRIP2 ..MLAVSLKW RLGVVRRR.. . .PKDDGPYSK GGKDTAGTDG ALVCRRQSIP

51

100

XGRIP1 EEFKGSTVVE LMKKEGTTLG LTVSGGIDKD GKPRVSNLRQ GGIAARSDQL rGRIP1 EEFKGSTVVE LMKKEGTTLG LTVSGGIDKD GKPRVSNLRQ GGIAARSDQL XGRIP2.1 EEFRGVTIVE LIRKEGSTLG LTISGGTDKD GKPRVSNLRP GGLAARSDQL rGRIP2 EEFRGITMVE LIKREGSTLG LTISGGTDKD GKPRVSNLRP GGLAARSDLL

101

150

XGRIP1 NVGDYIKAVN GINLTKFRHD EIISLLKNVG ERVVLEVEYE LPPVAIOGSG RGRIP1 DVGDYIKAVN GINLAKFRHD EIISLLKNVG ERVVLEVEYE LPPVSIQGSS

XGRIP2.1 NIGDYIKSVN GINLTKLRHE EIISLLKNVG ERVVLEVEYE LPPGTPDNSS RGRIP2 NVGDYIRSVN GIRLTRLRHD EIITLLKNVG ERVVLEVEYE LPPPAPENNP

151

200

XGRIP1 .VIFKTVEVT LHKEGNTFGF VIRGGAHEDR NKSRPIVITC IRPGGPADRE rGRIP1 . VMFRTVEVT LHKEGNTFGF VIRGGAHDDR NKSRPVVITC VRPGGPADRE XGRIP2.1 AIIPKTIEIT LCKEGNSFGF VMRGGAHEDW HKSRALVVTY VRPGGPADRE rGRIP2 RIISKTVDVS LYKEGNSFGF VLRGGAHEDL HKSRPLVLTY VRPGGPADRE

201

250

XGRIP1 GTIKPGDRLL SIDGIRLHGT THTEAMSILK QCGQEATLLI EYDVSVMDTV rGRIP1 GTIKPGDRLL SVDGIRLLGT THAEAMSILK OCGOEATLLI EYDVSVMDSV XGRIP2.1 GTLKVGDRLL CVDGISLHNI THTDALSILR QCSQEGVFQI EYDVALMDTV rGRIP2 GSLKVGDRLL SIDGIPLHGA SHATAIATLQ QCSHEALFQV EYDVATPDTV

251

300

XGRIP1 STASGPLLVE VAKTPGSNLG VALTTSMYYN KOVIVIDKIK SASIADRCGA rGRIP1 ATASGPLLVE VAKTPGASLG VALTTSVCCN KQVIVIDKIK SASIADRCGA XGRIP2.1 TNASGPLLVE IAKTPGSTLG ISLSTGTHRN KQVIVIDKVK PASVVDRCGA rGRIP2 ANASGPLVVE IAKTPGSALG ISLTTGSHRN KPAITIDRIK PASVVDRSGA

301

350

XGRIP1 LHIGDHILSV DGTSMEYCTL AESTQLLAST TEHVKLEILP YHQTRLALKG rGRIP1 LHVGDHILSI DGTSMEYCTL AEATQFLANT TDQVKLEILP HHQTRLALKG rGRIP2 LHAGDHILAI DGTSTEHCSL VEATKLLASV TEKVRLEILP APQSRRPLKP

351

400

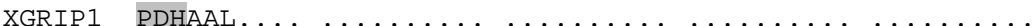

rGRIP1 PDHVKIQRSD RQLPWDPWAS SQCSVHTNHH HNPHHPDHCR VPALAFPKAL

XGRIP2.1 PETVKVQKSD HHHCWDPCV. .......NYC HTPH.PGHCK TPTWNPTSNQ

rGRIP2 PEAVRIQRSE QLHHWDPCV. .......PSC HSPR.PSHCR APTWAP.GGQ

401

450

XGRIP1 ......VVS SFSPTSMSAY SLSSLNTGTL PRSLYPTSPR GTLMRRRMKK

RGRIP1 TPNSPPAMVS SSSPTSMSAY SLSSLNMGTL PRSLYSTSPR GTMMRRRLKK

XGRIP2.1 DYCKSLVAAN FSSSSVAGTP GFSSQNSNTL PRTVHPMSPR TTMNRRRQKR

rGRIP2 DQSRSVSSTP FSSPTM. .NP AFPCANASTL PRG..PMSPR TTAGRRRQRR

451

500

XGRIP1 KDFKSSLSLA SSTVGLAGQI VHTESTEVVL TADPVVGFGI QLQGSVFATE rGRIP1 KDFKSSLSLA SSTVGLAGQV VHTETTEVVL TADPVTGFGI QLQGSVFATE XGRIP2.1 KDHKNSLSLA SSTVGPGGQI IHTESTEIIL RGDPLNGFGI QLQGGIFATE rGRIP2 KEHRSSLSLA SSTVGPGGQI VHTETTEVVL CGDPLSGFGL QLQGGIFATE

501

550

XGRIP1 TLSSPPLISY IDVDSPAERC GVLQVGDRVI AINGVQTEDS TFEEANQLLR rGRIP1 TLSSPPLISY IEADSPAERC GVLQIGDRVM AINGIPTEDS TFEEANQLLR XGRIP2.1 TLSSPPLIRF IEPDSPAERC GLLQVGDRLL SINGILTEDG TLEEANQLLR rGRIP2 TLSSPPLVRF IEPDSPAERC GLLQVGDRVL AINGIATEDG TMEEANQLLR

551

600

XGRIP1 DSTIAGKVTL EVEFDVAESV IPSSGTFHVK LPKKHNVELG ITISSPSTRK RGRIP1 DSSITSKVTL EIEFDVAESV IPSSGTFHVK LPKKHSVELG ITISSPSSRK XGRIP2.1 DAALSNKVAL EIEFDVAESV VPSSGTFHVK LPKRKGVELG ITISS..SRK RGRIP2 DAALARKVVL EIEFDVAESV IPSSGTFHVK LPKRRGVELG ITISS.ASRK

601

650

XGRIP1 NGDPLVISDI KKGSVAHRTG TLELGDKLLA IDNIRLDNCP MEDAVQILQQ 


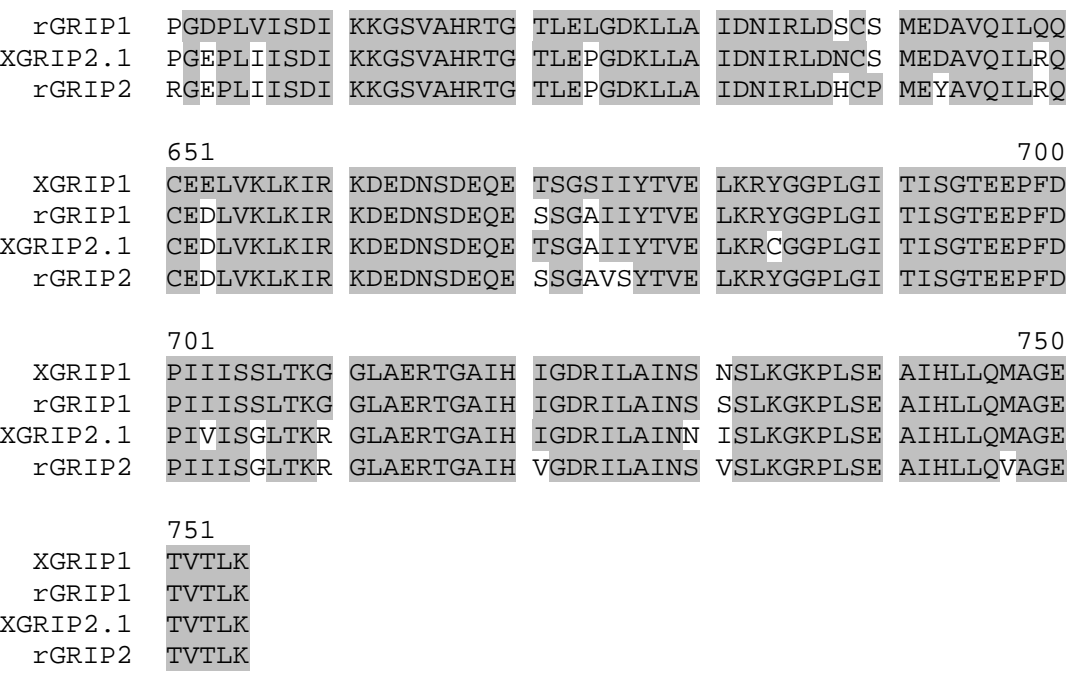

App. Fig. 8.1. SWISS plot multiple alignment of our predicted Xenopus laevis xGRIP1 protein sequence (GenBank ID LOC432193) with Rattus norvegicus GRIP1/ GRIP2 amino acid sequences and Xenopus laevis XGRIP2.1 protein sequence (GenBank ID NP114458, Q9WTW1 and EF139240, correspondingly).

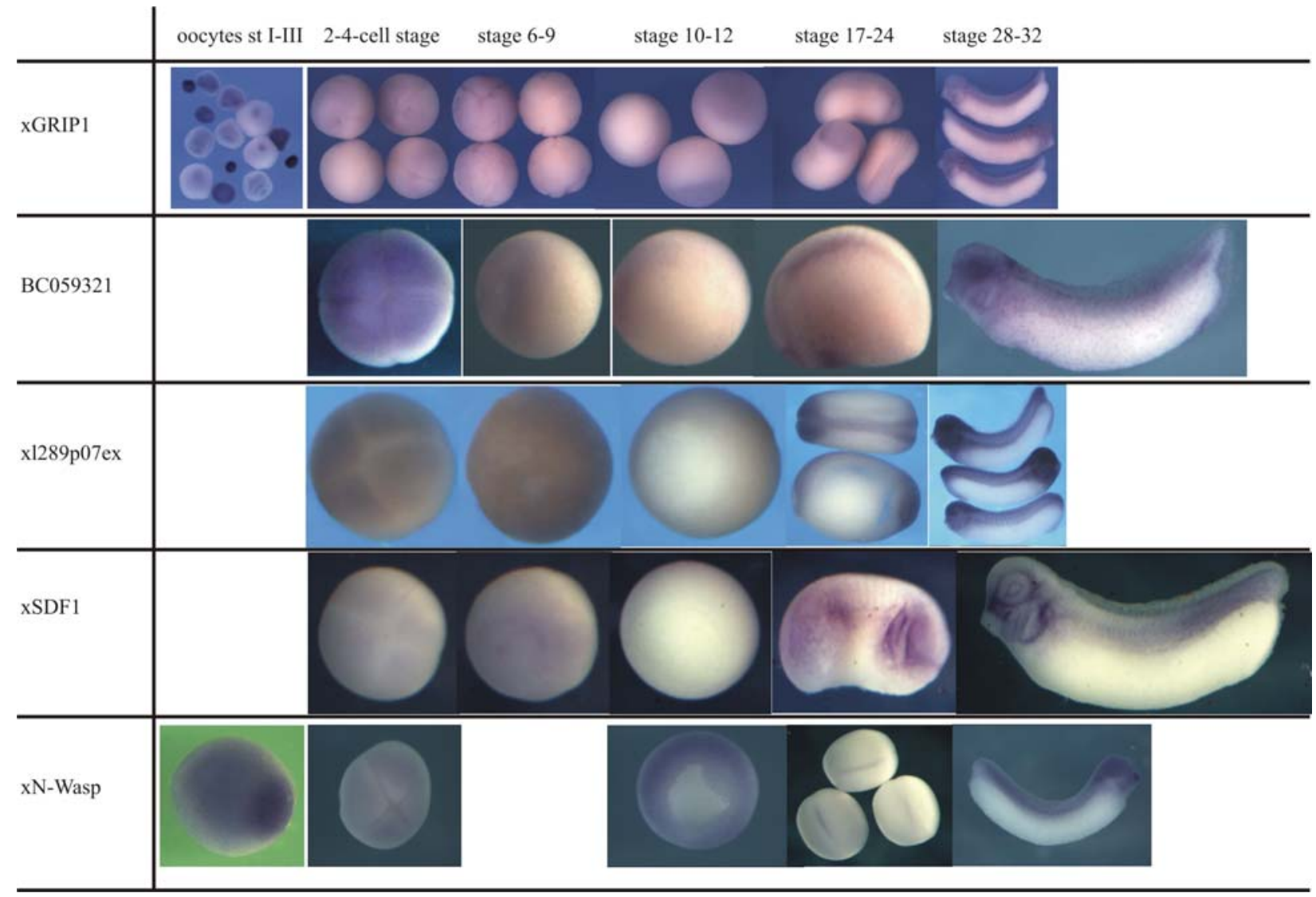

App. Fig. 8.2. Expression patterns of xGRIP1, BC059321, x1289p07ex, xSDF1, and xN-Wasp analysed by the whole-mount in situ hybridization. 


\section{Acknowledgements}

I want to express my deep gratitude to Prof. Tomas Pieler for the opportunity to do my $\mathrm{PhD}$ in his laboratory and for inspiring advices, support and encouragement throughout my work.

I am very grateful to Prof. Erez Raz and Prof. Ernst Wimmer, together with Prof. Tomas Pieler, as members of my $\mathrm{PhD}$ committee, for their time, helpful comments and critical evaluation of my work. In addition, I'd like to thank Prof. E. Raz and his group for sharing a lot of constructs and experimental details.

I'm very thankful to the entire Developmental Biochemistry team, especially to the “Transport" group (Jana, Patrick, Ines, Maike, Stefanie and Katja) and to all my friends for their friendship and help everyday.

I would like to thank the International $\mathrm{MSc} / \mathrm{PhD}$ program in Molecular Biology, in particular Dr. Steffen Burkhardt, for the excellent coordination and support for all these years.

I own my coming to Göttingen and, thus, this work to my parents. Therefore, my special thanks go to my family for their faith in me and for encouragement throughout my life. 


\section{Curriculum Vitae}

Name: Katsiaryna Tarbashevich (Ekaterina Torbashevich)

Nationality: Belarusian

Address: Im Hassel 6a, 37077 Goettingen, Germany

E-mail: ktarbas@gwdg.de

Date of birth: $21^{\text {th }}$ January 1981

Marital status: married

\section{Educational background}

1987-1988 Primary school, Volkovysk, Belarus

1988-1989 Primary school, Kediniaj, Lithuania

1989-1993 Primary and secondary schools, Panevezhis, Lithuania

1993-1998 Secondary school, Volkovysk, Belarus

1998-2003 International Sakharov Environmental University, Faculty of Radiobiology and Ecological Medicine, Minsk, Belarus

2003-2007 MSc/PhD Molecular biology program, University of Goettingen and International Max Plank Research School, Göttingen, Germany

2004-2007 PhD work in the department of Prof. Dr. T. Pieler, GZMB, Göttingen, Germany

\section{Experimental skills}

2001-2002 Changes of IgG glycosylation level in heart pathology (B.Sc. thesis work. Hons), Dept. of Ecological Medicine, International Sakharov Environmental University, Minsk, Belarus. Dr. A. Lapko.

2002-2003 Use of ARMAS-PCR and SSCP-analysis for revealing gene p53 mutations in samples of cancer tissues of patients with breast or bladder cancer (M. Sc. thesis. Diploma with Honor (Grade A)). Institute for hereditary diseases, Minsk, Belarus. Prof. Dr. Med. S. Feschenko

2004-2007 Molecular mechanisms of germ cell specification and migration in Xenopus laevis (PhD thesis). Dept. of Developmental Biochemistry, Center for biochemistry and molecular cell biology, Georg August University Goettingen, Prof. Dr. T Pieler.

\section{$\underline{\text { Scholarships }}$}

1. The President's scholarship for excellent knowledge (2002-2003);

2. The Sakharov's Prize for outstanding young scientist's project (2003);

3. Max Plank Research Institute/ DAAD Stipend (2003-2004)

4. Lichtenberg Stipend (2004-2007)

Göttingen, 20.12.2007 